\title{
Regional subepicardial mechanics under normoxic and ischemic circumstances : relation with hemodynamics, and regional electrical activation and oxygen uptake
}

Citation for published version (APA):

Delhaas, T. (1993). Regional subepicardial mechanics under normoxic and ischemic circumstances : relation with hemodynamics, and regional electrical activation and oxygen uptake. [Doctoral Thesis, Maastricht University]. Rijkuniversiteit Limburg. https://doi.org/10.26481/dis.19931217td

Document status and date:

Published: 01/01/1993

DOI:

$10.26481 /$ dis. 19931217 td

Document Version:

Publisher's PDF, also known as Version of record

Please check the document version of this publication:

- A submitted manuscript is the version of the article upon submission and before peer-review. There can be important differences between the submitted version and the official published version of record. People interested in the research are advised to contact the author for the final version of the publication, or visit the DOI to the publisher's website.

- The final author version and the galley proof are versions of the publication after peer review.

- The final published version features the final layout of the paper including the volume, issue and page numbers.

Link to publication

\footnotetext{
General rights rights.

- You may freely distribute the URL identifying the publication in the public portal. please follow below link for the End User Agreement:

www.umlib.nl/taverne-license

Take down policy

If you believe that this document breaches copyright please contact us at:

repository@maastrichtuniversity.nl

providing details and we will investigate your claim.
}

Copyright and moral rights for the publications made accessible in the public portal are retained by the authors and/or other copyright owners and it is a condition of accessing publications that users recognise and abide by the legal requirements associated with these

- Users may download and print one copy of any publication from the public portal for the purpose of private study or research.

- You may not further distribute the material or use it for any profit-making activity or commercial gain

If the publication is distributed under the terms of Article $25 \mathrm{fa}$ of the Dutch Copyright Act, indicated by the "Taverne" license above, 


\section{REGIONAL SUBEPICARDIAL MECHANICS UNDER NORMOXIC AND ISCHEMIC CIRCUMSTANCES}

relation with hemodynamics, and regional electrical activation and oxygen uptake 


\section{CIP DATA KONINKLIJKE BIBLIOTHEEK, DEN HAAG}

Delhaas, Tammo

Regional subepicardial mechanics under normoxic and ischemic circumstances : relation with hemodynamics, and regional electrical activation and oxygen uptake / Tammo Delhaas. - [S.I. : s.n.]. - Ill.

Thesis Maastricht. - With ref. - With summary in Dutch. ISBN 90-9006694-2

Subjects headings: biomechanics / electrical asynchrony / ischemia.

Front cover: Juan Heurter

Layout: Tammo Delhaas

Printing: Krips Repro, Meppel 


\section{REGIONAL SUBEPICARDIAL MECHANICS UNDER NORMOXIC AND ISCHEMIC CIRCUMSTANCES}

relation with hemodynamics, and regional electrical activation and oxygen uptake

\section{PROEFSCHRIFT}

ter verkrijging van de graad van doctor aan de Rijksuniversiteit Limburg te Maastricht, op gezag van de Rector Magnificus, Prof. dr H. Philipsen, volgens het besluit van het College van Dekanen, in het openbaar te verdedigen op vrijdag 17 december 1993 om 16.00 uur

door

Tammo Delhaas

geboren te Emmen in 1962 
Co-promotor:

Dr F.W. Prinzen

Beoordelingscommissie: Prof. dr J.F.M. Smits (voorzitter)

Prof. $d r$ ir J.D. Janssen (Technische Universiteit Eindhoven)

Prof. dr G.J. van der Vusse

Prof. dr H.J.J. Wellens

Prof. dr E.L. Yellin (Albert Einstein College, New York)

This thesis comprises studies carried out in the Departments of Physiology and Biophysics of the Cardiovascular Research Institute Maastricht, University of Limburg, Maastricht, The Netherlands. The studies described were supported by NWO grant 900-516-091. Financial support by the Netherlands Heart Foundation and Stichting Wetenschappelijk Durrer-Fonds for the publication of this thesis is gratefully acknowledged. Contributions to the printing costs were also made by Medtronic Incorporation.

I would like to express my gratitude to all colleagues, students, and friends who have made it possible to complete this thesis. 


\section{CONTENTS}

Chapter 1

Chapter 2

Chapter 3

Chapter 4

Chapter 5

Chapter 6

Chapter 7

Chapter 8

Samenvatting

Curriculum Vitae
General introduction

Relation between regional electrical activation time

and subepicardial fiber strain in the canine left ventricle

Subepicardial fiber strain and stress

as related to left ventricular pressure and volume

Regional fiber stress-fiber strain area as estimate

of regional oxygen demand in the canine heart

Regional blood flow and contractile work in the canine

left ventricular subepicardium during coronary artery occlusion

Contractile failure of regionally ischemic myocardium:

role of delayed electrical activation is minor

Asymmetrical changes in ventricular wall mass

by asynchronous electrical activation of the heart

General discussion and conclusions 
GENERAL INTRODUCTION 


\section{Introduction}

This thesis deals with the mechanical, electrophysiological, and metabolical properties of the canine left ventricle under a variety of experimental conditions. Although it is common physiology that global mechanical performance of the left ventricle is the resultant of cooperative action of muscle fibers, which start to contract after being depolarized, thereby consuming oxygen, the precise interaction between regional subepicardial mechanics and global hemodynamics, moment of regional electrical activation, and regional blood flow and oxygen uptake is not known. This lack of knowledge induced us to study these relationships at the anterior free wall of the left ventricle. Studies were performed in the normoxic synchronously or asynchronously activated left ventricle, as well as the ischemic left ventricle. In the first section of this chapter an overview of relevant anatomical and physiological properties of the left ventricle is given. The next section describes the methods and models used for the determination of global and regional mechanical pump function. In the third section, the aims of this study are formulated. The chapter is concluded with a description of the experimental approach used in this study.

\section{Basic anatomy and physiology of the heart}

This section is confined to a brief review of some anatomical and physiological aspects of the heart. The information presented is basic and is derived from textbooks $[7,11,17,18$, $20,46]$, unless specified otherwise.

\section{Basic anatomy}

The heart is a cavernous muscular organ that pumps blood through the vascular system, placed in series with it. The heart itself consists of two, anatomically parallel, functionally serial, pulsatile pumps. Each of the cardiac pumps consists of a low-pressure chamber, the atrium, and a high-pressure chamber, the ventricle (Fig. 1). The atria are chambers that receive blood from the veins and function as reservoirs between contractions of the heart. The ventricles are responsible for pumping the blood into the great arteries. The right atrium receives deoxygenated blood, returning from the various organs. It empties through the tricuspid valve into the right ventricle, which on its turn pumps the blood through the pulmonary valve into the pulmonary artery. The blood, after being oxygenated in the lungs, returns to the left atrium by the four pulmonary veins. From there it is passed through the mitral valve into the left ventricle, which pumps the blood, via the aorta, into the systemic circulation. The free edges of the leaflets of both the mitral and tricuspid valve are connected by chordae tendinae, fine fibrous bands, to papillary muscles, which originate from the wall of the respective ventricle (Fig. 1). During cardiac contraction, papillary muscles contract as well, thereby counteracting the tendency of the rise in intraventricular pres 


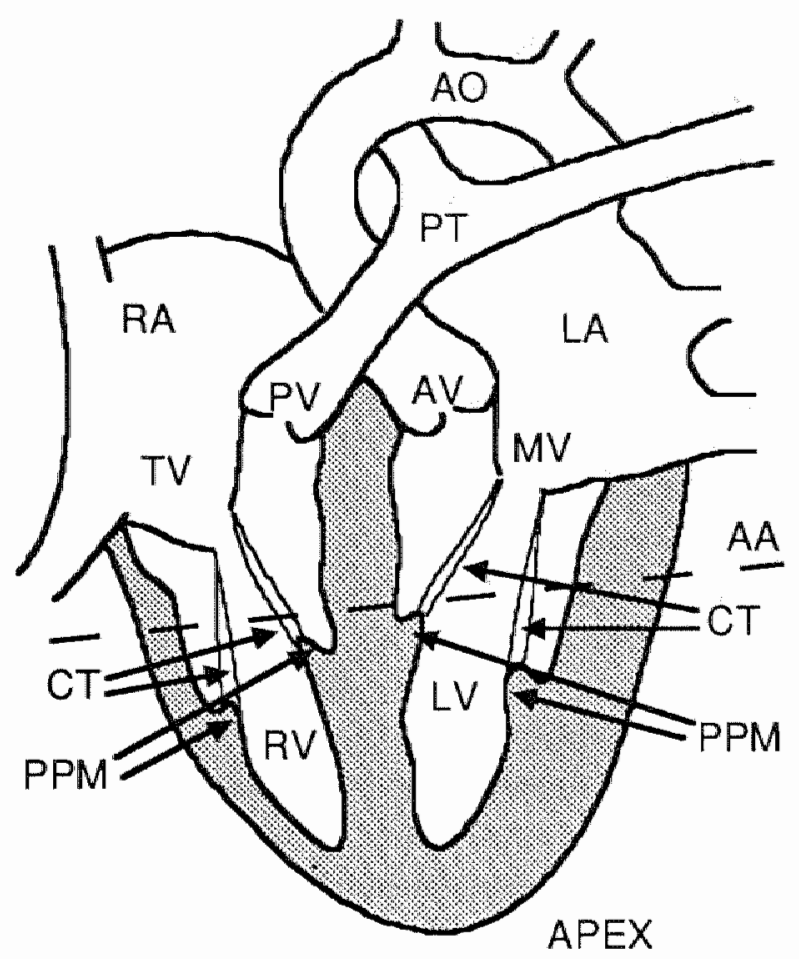

Fig.1. Schematic sagittal cross-section of the heart. $\mathrm{AA}=$ plane of minor axis cross-section shown in Fig. $3, \mathrm{AO}=$ aorta, $\mathrm{AV}=$ aortic valve, $\mathrm{CT}=$ chordae tendinae, $L A=$ left atrium, $L V=$ left ventricle, $\mathrm{MV}=$ mitral valve, $\mathrm{PPM}=$ papillary muscles, $\mathrm{PT}=$ pulmonary trunk, $\mathrm{PV}=$ pulmonary valve, $\mathrm{RA}=$ right atrium, $R V=$ right ventricle, $T V=$ tricuspid valve.

sure to turn the valve inside out and allow leakback into the atrium. The aortic and pulmonary valves have no strings attached. The closing and opening of all valves are operated by blood itself through hemodynamical forces. The four valve orifices are surrounded by rings of dense fibrous connective tissue, the annuli fibrosi. These rings are tightly connected, thus forming the base of the heart. The base serves as a tight skeleton for valve attachment and as an electrical isolator between atria and ventricles. The heart is connected to the surrounding tissue at the base by the large arteries and veins that enter and leave its chambers. The heart is also attached to other structures within the chest by the pericardium, a thin fibrous tissue bag, surrounding the heart. This bag is composed of two layers separated by a potential space called the pericardial cavity. The outer layer is termed the parietal pericardium. The inner layer is termed the visceral pericardium or epicardium and forms the outer layer of the heart. The pericardial cavity is filled with a thin layer of pericardial fluid which facilitates free motion of the heart within the pericardial bag.

The geometry of the left ventricle may be considered as a thick-walled truncated ellipsoid (Fig. 2) $[42,43,49,50]$. The minor axis projection of the left ventricle at the equator is virtually circular (Fig. 3). The inner surface of a ventricle, the endocardium is irregular, due to many invaginations, which protrude into the wall up to about $30 \%$ of its thickness. This portion of the wall is called the trabecular layer. The papillary muscles originate from the endocardial wall as well. The myocardium is the muscular tissue between the endo- and epicardium. The subendocardium and the subepicardium are the inner and outer layers of the myocardium, respectively. The free wall of the 


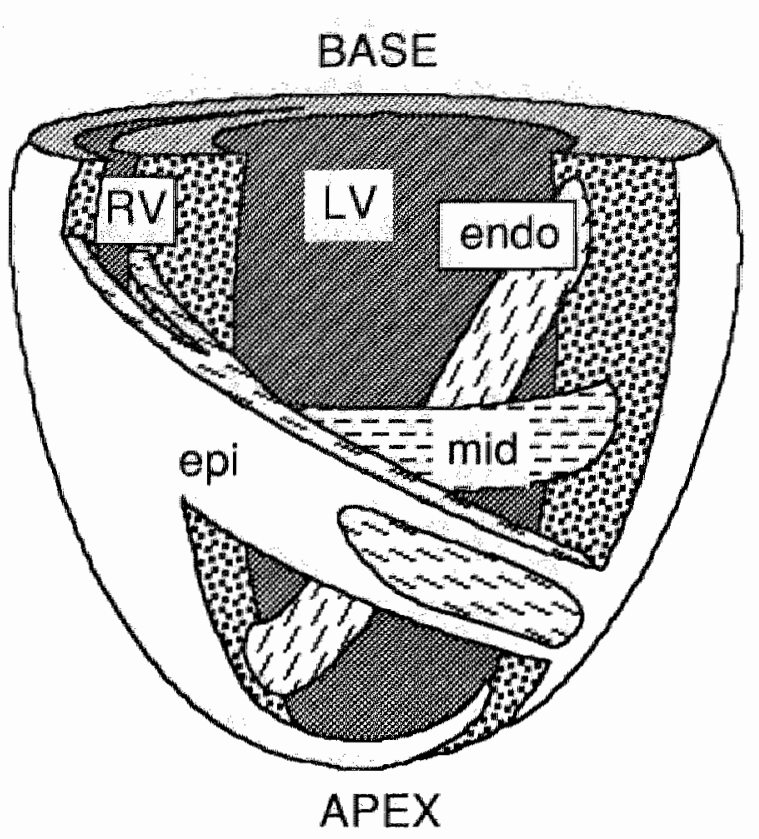

Fig. 2. Schematic illustration of the left and right ventricle ( $L V$ and $R V$, respectively). The geometry of the LV may be considered as a thick-walled truncated ellipsoid. The RV free wall is connected to the subepicardial layers of the LV and covers about half the surface of it. The wall consists of incompressible anisotropic material, simulated by muscle fibers embedded in soft incompressible material. The direction of the muscle fibers varies continuously across the wall. In the subepicardial layers (epi) the fibers follow the path of a left-handed helix around the cavity. In the mid-wall (mid), the fibers are directed circumferentially, and in the subendocardial layers (endo) the fibers follow a right-handed helical path.

right ventricle is significantly thinner than that of the left ventricle, because of a lower pressure in the right than in the left ventricle. The right ventricular free wall is connected to the subepi- cardial layers of the left ventricle and covers about half the surface of it. The ventricular septum is the common wall of the ventricles. Anatomically, as well as functionally, it belongs to the left ventricle.

The wall of the left ventricle is built up by muscle fibers embedded in a complex structure of cross-linked collagen $[9,29]$. The direction of the muscle fibers varies continuously across the wall (Fig. 2). In the subepicardial layers the fibers follow the path of a left-handed helix around the cavity. In the mid-wall, the fibers are directed circumferentially, and in the subendocardial layers the fibers follow a right-handed helical path $[27,44,51,58]$. Fibers do not terminate at the base or the apex. Near the basal plane and at the apex, the fibers cross-over from the endocardial wall to the epicardial wall.

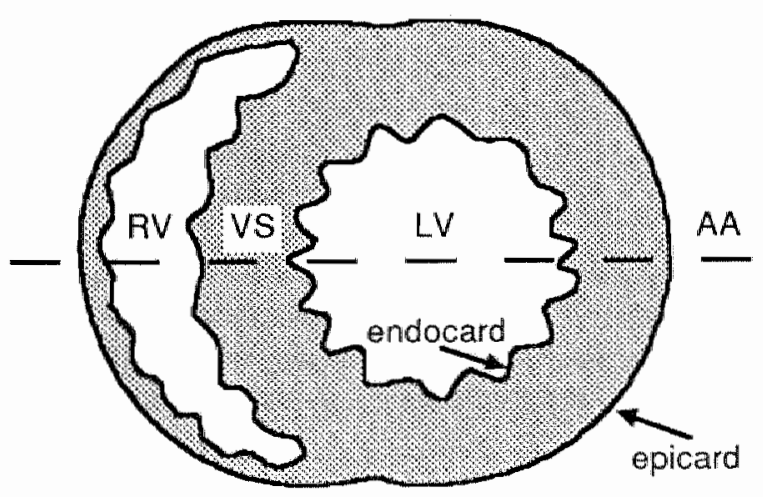

Fig. 3. Minor axis cross-section of the left and right ventricle ( $L V$ and $R V$, respectively) in a plane which is indicated as AA in Fig. 1. VS = ventricular septum. 


\section{Basic physiology}

Myocardial blood flow. The myocardium is almost entirely supplied with blood trough coronary arteries. Only the inner 75 to $100 \mu \mathrm{m}$ of the endocardial surface can obtain significant amounts of nutrition due to the diffusion of oxygen from the cavitary blood into the subendocardium [66]. The main coronary arteries originate at ostia which are situated in the aortic wall 0.7 to $1.0 \mathrm{~cm}$ distal to the roots of the semilunar cusps of the aortic valve so that they can not be occluded by the opening of the aortic valve during systole. The main coronary arteries lie on the surface of the heart and send of branches at approximately right angles into the myocardium. In dogs, the first main side branch of the left coronary artery is the septal branch which perfuses the anterior two-thirds of the interventricular septum and an important part of the conductive system. Just distal to the septal branch, the left coronary artery divides into two branches: the left anterior interventricular coronary artery (LAICA) and the left circumflex coronary artery (LCCA). The LAICA passes along the anterior interventricular groove toward the apex of the heart and perfuses the medial anterior left ventricular free wall and the apex of the right ventricle. The LCCA runs around the base of the left ventricle in the coronary sulcus and perfuses the basal parts of the anterior, lateral, and posterior parts of the left ventricular free wall. The right coronary artery runs around the base of the right ventricle in the coronary sulcus and continues in the posterior interven- tricular groove. It predominantly perfuses the right ventricular free wall (except for the apex), the posterior base of the left ventricle and onethird of the interventricular septum. Drainage of venous blood from the left and the right ventricular wall is distinctively different. Venous blood returning from the right ventricular wall flows through the anterior cardiac vein directly into the right atrium. Venous blood from the left ventricular wall is drained into the coronary sinus, which runs parallel to the LCCA, and empties into the right atrium on the posterior side of the heart. The subendocardial muscle layers of both right and left ventricle are drained directly into the ventricles by means of the Thebesian veins.

The electrical conduction system. Contraction of cardiac muscle fibers is induced by electrical activation. Rhythmical electrical impulses are generated in the sino-atrial ( $\mathrm{S}-\mathrm{A}$ ) node, a small mass of specialized myocardial tissue embedded in the right atrial wall near the entrance of the superior caval vein (Fig. 4). From the S-A node, the action potential spreads over the entire atrial muscle mass and eventually reaches the atrio-ventricular $(\mathrm{A}-\mathrm{V})$ node, located on the right side of the atrial septum, close to the entrance of the coronary sinus in the posterior septal wall of the right atrium. Once the electrical impulse has reached the A-V node, the transmission is delayed, allowing the atria to empty their contents into the ventricles before ventricular contraction begins. The $A-V$ node is the bulbous proximal ending of the bundle of 

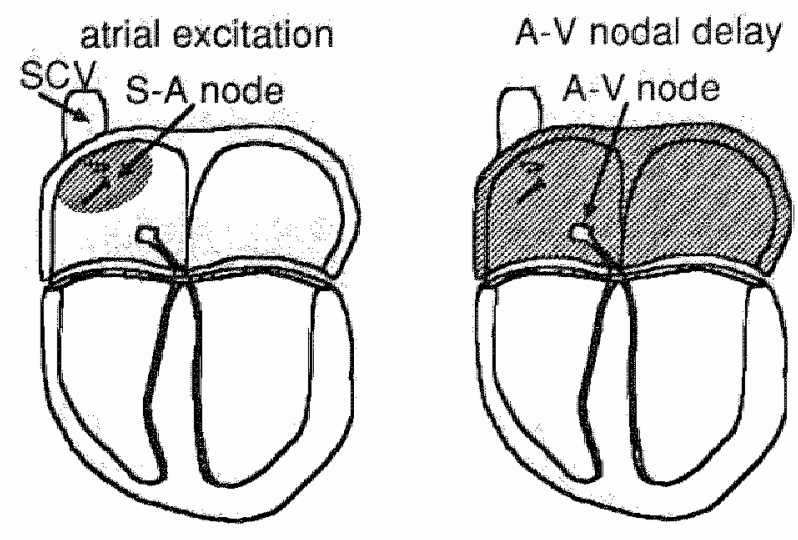

ventricular excitation start
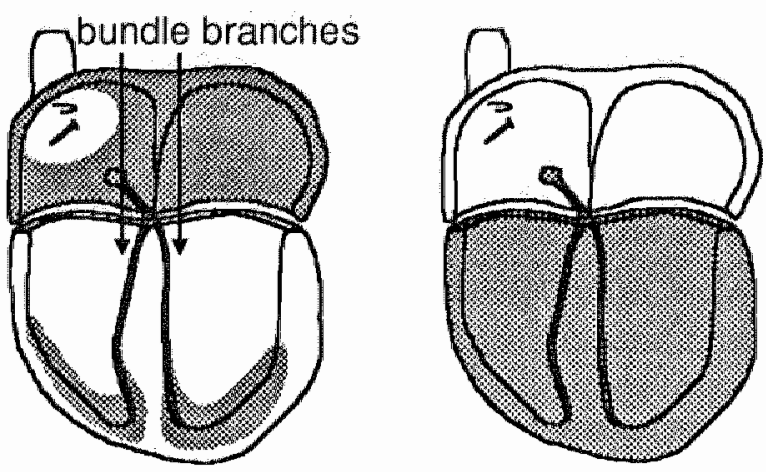

Fig. 4. Sequence of cardiac excitation. Excitation of the heart is normally initiated by an impulse which is generated by the sino-atrial (SA) node. From there, the action potential spreads through the entire atrial muscle mass. After a slight delay at the atrio-ventricular (AV) node, impulses are rapidly conducted by the bundle branches and the Purkinje fibers over both ventricles. Once the electrical impulse has reached the end of the Purkinje fibers, it is transmitted by the muscle fibers themselves. SVC = superior vena cava.
His. The latter one, a bundle of Purkinje fibers, passes through the atrioventricular fibrous barrier, and is the pathway for the electrical impulse to travel from the atria to the ventricles. The bundle of His passes downwards on the right side of the interventricular septum and then divides into the right and left bundle branches located in the endocardium at both sides of the septum. From these bundle branches, Purkinje fibers spread over both ventricles. The terminal fibers penetrate about one third of the muscle mass and then become continuous with the cardiac muscle fibers. The speed of electrical signal transmission in the Purkinje fibers is fast, ranging from 1 to $4 \mathrm{~m} \mathrm{~s}^{-1}$. Once the electrical impulse has reached the end of the Purkinje fibers, it is transmitted by the muscle fibers themselves at a rate of 0.3 to $0.5 \mathrm{~m} \mathrm{~s}^{-1}$. The total time for the transmission of the cardiac electrical impulse from the initial bundle branches to the last ventricular muscle fibers is approximately $60 \mathrm{~ms}$ [48]. This rapid spread of excitation through the ventricles produces more or less simultaneous contraction of the ventricular muscle fibers, which is essential for effective pressure generation in the ventricular chambers.

Myocardial metabolism. The heart uses chemical energy to provide the work for contraction. The heart is quite versatile in its use of substrates, and within certain limits the uptake of a particular substrate is directly proportional to its arterial concentration [33]. The utilization of a particular substrate is also influenced by the presence or absence of other substrates. During 
normoxia, the heart derives the major part of its energy from oxidation of fatty acids, and to a lesser extent of other nutrients, especially lactate and glucose. The contribution of pyruvate, ketone bodies, and amino acids appears to be of minor importance. During ischemia, however, coronary blood flow, and, hence, substrate and oxygen supply are restricted, causing suppression of fatty acid oxidation, leading to accumulation of fatty acids. The contribution of glucose as substrate becomes more significant, because it can be metabolized by anaerobic glycolysis. In stead of the 36 moles of ATP derived by oxidative phosphorylation of glucose, anaerobic glycolysis yields only 2 moles of ATP per mole of glucose. Then lactate is produced by the conversion of pyruvate, a breakdown product of the anaerobic glycolysis. Lactate accumulates due to a lack of washout and because it cannot be metabolized by the hypoxic heart. The decrease in intracellular $\mathrm{pH}$ which accompanies prolonged oxygen restriction inhibits glycolysis, fatty acid use, and protein synthesis, which results in impairment of membrane function, cellular damage, and eventually necrosis of myocardial cells (for detailed reviews see $[32,33$, $35,61]$ ).

The cardiac cycle. Myocardial contraction generates the energy for changes in atrial, ventricular, and arterial pressures and volumes. Blood flow within the cardiovascular system is directed by pressure differences and one-way valves. The concept of the hemodynamical events occurring during a cardiac cycle will be described for the left heart only (Fig. 5). In a cardiac cycle four phases can be distinguished.: the filling phase, the isovolumic contraction phase, the ejection phase, and the isovolumic relaxation phase. Diastole is defined as the nonactive period, i.e. the filling phase, whereas systole represents the remaining three phases. Left ventricular pressure rapidly decreases during deactivation. At the moment of crossover with left atrial pressure the filling phase starts with opening of the mitral valve. The small early atrio-ventricular pressure difference provides the force for the rapid acceleration of mitral flow to its peak. The pressure gradient soon becomes zero, and sometimes even reverses slightly. Flow then decelerates rapidly, but forward mitral flow continues for a while because of inertia. Atrial contraction reaccelerates mitral flow to a second peak, where after flow decelerates and left atrial pressure decreases. The deceleration of the mitral flow generates a pressure field, by which the mitral valve is closed [67]. This moment marks the beginning of the isovolumic contraction phase. The increasing active fiber stress is reflected by a rapid increase of ventricular pressure while the ventricular volume remains constant because both the mitral valve and the aortic valve are closed. When left ventricular pressure exceeds aortic pressure, the aortic valve opens, and blood is ejected into the aorta. The first part of the ejection phase is marked by a rapid increase in aortic flow. After the flow has reached its maximum, it declines relatively slowly. Although the pressure gradient reverses, forward aortic flow continues be 


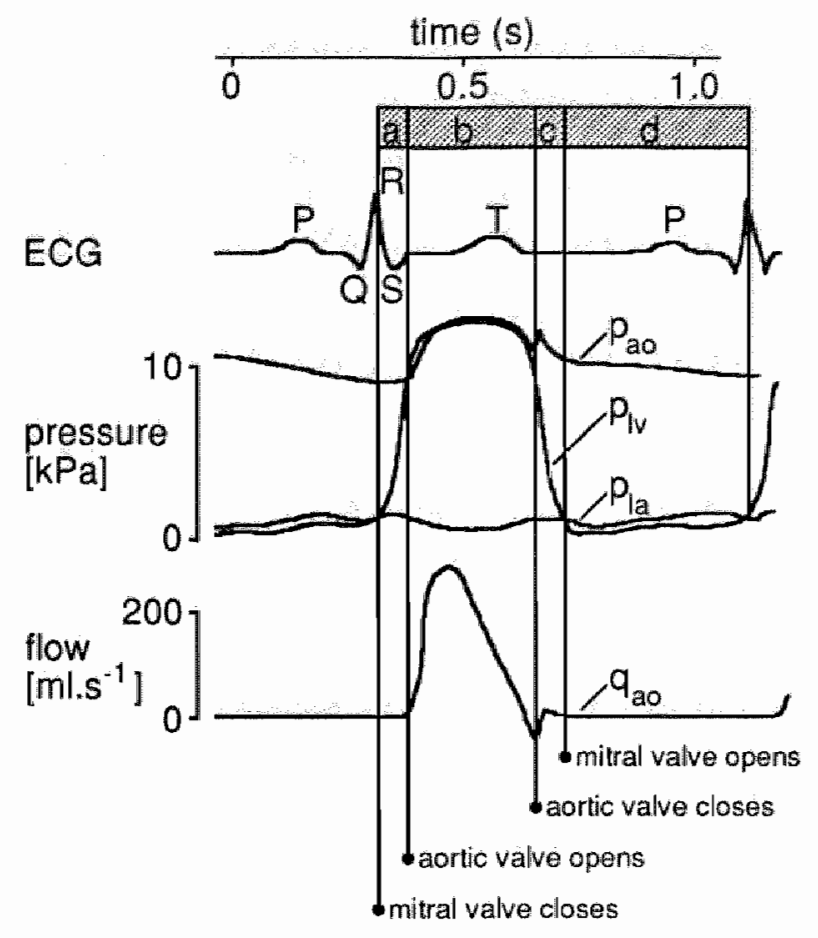

Fig. 5. Diagrammatic representation of the events on the left side of the heart during the candiac cycle. Traces from top to bottom: ECG, electrocardiogram; $p_{a o}$, aortic pressure; plv, left ventricular pressure; Pla, left atrial pressure; qao, aortic volume flow. The different phases of the cardiac cycle are indicated by letters in the hatched bar: $a=$ isovolumic contraction phase; $b=$ ejection phase; $c=$ isovolumic relaxation phase; $d=$ filling phase. In the ECG the ' $P$-wave' represents the contraction of the atria, the "QRS-complex" the depolarization of both ventricles, and the 'T-wave' the repolarization of the ventricles. cause of inertia. At the end of the ejection phase, the decelaration of aortic blood creates a pressure field to close the aortic valve [63]. Then the muscle relaxes causing a fall in left ventricular pressure, and because both the mitral valve and the aortic valve are closed again, ventricular volume remains constant. This is the isovolumic relaxation phase. As soon as ventricular pressure drops below atrial pressure, the filling or diastolic phase starts again.

\section{Global and regional mechanical pump function}

Global left ventricular pump function can be assessed with more or less standard techniques, available not only to the laboratory but also to the clinic. Measurements include the determination of left ventricular pressure, and aortic and mitral flow [60]. For a more precise analysis of global pump function, the more complicated measurement of left ventricular cavity volume is recommended [55]. For the latter measurement, several techniques with varying reliability, such as ultrasonic transducers, ultrasonic echocardiography, magnetic resonance imaging, or a conductance catheter have been proposed [ 5 , $42,49]$.

Assessment of regional myocardial mechanics requires measurement of regional deformation and stress. Regional deformation may be assessed with ultrasonic dimension gauges [26], inductive coils [3], video recording of markers attached to the epicardial surface [41], biplane cineradiography of implanted radio- 
paque markers $[15,25,65]$ or magnetic resonance imaging [68]. Measurement of fiber stress in vivo is difficult and probably not reliable because the local myocardial structure is easily damaged due to the insertion of the measuring device $[14,23]$. Therefore, a variety of mathematical models of cardiac mechanics, based on the laws of continuum mechanics, were designed to estimate fiber stress $[2,4,8$, $10,13,30]$. Mechanical stress in the left ventricular wall is born by muscle cells, blood vessels, and connective tissue. During the diastolic phase, collagen fibers form the main stress bearing structure in the wall. In the systolic phase, stresses generated by the contractile tissue overrule the passive stresses.

Using the principle of conservation of energy, global pump work equals the summed work of the regional fibers. To understand the mechanism of conversion of contractile work of myocardial tissue in the left ventricular wall to left ventricular pump work, information has to be obtained about the physical quantities related to fiber strain and stress in the wall on the one hand, and global left ventricular pump function on the other.

\section{Aims of the thesis}

It was the objective of this thesis to investigate regional subepicardial mechanics of the left ventricular anterior free wall and its relation with global hemodynamics, and regional electrical activation and perfusion under normoxic (chapter 2, 3, 4, and 7) and ischemic circumstances (chapter 5 and 6).

In case of normal electrical activation, the epicardium of the anterior free wall of the canine left ventricle is activated rather simultaneously $[6,48]$, resulting in a quite homogeneous distribution of subepicardial fiber strain [40]. In case of asynchronous electrical activation of the left ventricle, epicardial deformation and ventricular wall motion are disturbed $[6,12,16$, $19,22,31,40,47,64]$. When stimulating the ventricles directly $[6,40]$, regional subepicardial fiber strain during ejection was considerably less in early than in late activated regions. In chapter 2 it was investigated whether a proper time reference for electrical activation can be found, so that a unique relation can be described between the amount of fiber strain during the ejection phase and the thus defined electrical activation time.

Since measurement of fiber stress in vivo is difficult and probably not reliable, because the local myocardial structure is easily damaged due to the insertion of the measuring device [14, 23], a variety of mathematical models of cardiac mechanics, based on the laws of continuum mechanics, were designed to estimate fiber stress $[2,4,8,10,13,24,30]$. In a model by Arts and co-investigators [2] the assumption that fiber stress and fiber strain during systole might be uniformly distributed throughout the left ventricular wall was used to estimate these regional quantities from global quantities such as left ventricular pressure, cavity volume, and wall volume. The principle of conservation of 
energy was the only necessary assumption to derive the equation on fiber strain from the equation on fiber stress. In chapter 3 the proposed relations were evaluated experimentally. Calculated fiber strain was compared with our experimentally determined strain values, whereas calculated fiber stress was assessed with regard to experimental data obtained in isolated cardiac muscle as reported in literature $[37,56,62]$.

To be able to calculate regional fiber stress in the asynchronously activated or ischemic left ventricle, a modification of the model of Arts and co-investigators hitherto used $[2,4]$ was introduced (chapter 4). In addition, the relation between regional left ventricular contractile work, regional myocardial blood flow and oxygen uptake was assessed in the normoxic asynchronously activated left ventricle (chapter 4) and in the acutely ischemic left ventricle (chapter 5). In analogy to the use of the pressure-volume area (PVA) for the estimation of global oxygen demand [52-54], regionally the fiber stress-fiber strain area (SSA) was used to estimate regional oxygen demand. The more often used relation between the pressure-sarcomere length area (PSL) $[57,59]$ and regional oxygen demand was also assessed. Regional differences in mechanical work were generated by asynchronous electrical activation of the myocardial wall (chapter 4) or by occlusion of the distal part of the LAICA (chapter 5).

In chapter 6 it was investigated to what extent the mechanical dysfunction, as seen during ischemia, is caused by disturbances in electrical impulse propagation. Measurements were performed during normoxia, and after $15 \mathrm{~min}$ of total occlusion or $30,60,120$ and $180 \mathrm{~min}$ of partial occlusion of the LAICA.

Since mass and composition of cardiac muscle are known to adapt to altered external conditions $[34,36]$, in chapter 7 it was investigated to what extent the regional differences in contractile work, induced by chronic ventricular pacing, result in changes in the geometry of the left ventricular wall.

\section{Experimental approach}

The studies on the relation between regional subepicardial mechanics and global hemodynamics, the moment of regional electrical activation, and regional blood flow and oxygen uptake, as described in chapters 2 through 6 , were performed on hearts of open-thorax dogs anesthetized with pentobarbital. With this approach the following differences as compared to the awake closed-thorax dog were introduced. The chest was opened, causing an increase in intra-thoracic pressure from negative to atmospheric. There is no support for venous return by the thoraco-abdominal pump, resulting in a decrease in both end-diastolic left ventricular volume and contractility [45]. The opening of the pericardium affects both the shape and size of the heart. Due to the use of pentobarbital as anesthetic, inotropy is decreased [28]. Despite the disadvantages, we used this model because two-dimensional deformation could be measured at the epicardium of the left ventricular 
anterior free wall, using optical markers which were attached to the epicardial surface and recorded on video [41]. The exposed heart also enabled the measurement of regional electrical activation using a 192-electrode brush [1, 21]. Regional blood flow was measured with radioactively labeled microspheres [39], whereas regional oxygen uptake was estimated from regional myocardial blood flow values and arterio-venous differences in oxygen content. Arterio-venous differences in oxygen content were also used to calculate the oxygen extraction fraction.

Differences in global hemodynamical load were induced by volume loading, whereas differences in regional mechanical load were induced by pacing from different sites. Regional ischemia or impaired coronary perfusion was induced by narrowing the distal part of the LAICA by means of an inflatable cuff. The cuff was inflated guided by a preset value of the post-stenotic coronary artery pressure, so that a reproducible degree of ischemia could be obtained [38].

The influences of chronic asynchronous electrical activation on regional myocardial fiber growth (chapter 7) was investigated in the awake closed-thorax dog. The dog obtained DDD-pacing (dual chamber, dual sensing, dual pacing) with the atrial sense electrode attached to the right atrium and the ventricular pace electrode sutured to the epicardium of the left ventricular lateral free wall, $1 \mathrm{~cm}$ below the base. All dogs were permitted routine activity and were followed during 3 months after instrumen- tation. Two-dimensional echocardiography was used to assess left ventricular regional dimensions.

\section{References}

1. Allessie MA, Hoeks APG, Schmitz GML, Reneman RS (1986) On-line mapping system for the visualization of the electrical activation of the heart. Int J Cardiac Imag 2: 59-63

2. Arts T, Bovendeerd PHM, Prinzen FW, Reneman RS (1991) Relation between left ventricular cavity pressure and volume and systolic fiber stress and strain in the wall. Biophys J 59: 93-102

3. Arts $T$, Reneman RS (1980) Measurement of deformation of canine epicardium in vivo during cardiac cycle. Am J Physiol 239: H432-H437

4. Arts $T$, Veenstra PC, Reneman RS (1982) Epicardial deformation and left ventricular wall mechanics during ejection in the dog. Am J Physiol 243: H379-H390

5. Baan J, Aouw Jong TT, Kerkhof PLM, Moene RJ, van Dijk AD, van der Velde ET (1981) Continuous stroke volume and cardiac output from ventricular dimensions obtained with impedance catheter. Cardiovasc Res $\rrbracket 5: 328-334$

6. Badke FR, Boinay $P_{n}$ Covell JW (1980) Effect of ventricular pacing on regional left ventricular performance in the dog. Am J Physiol 238: H858H867

7. Berne RM (ed) (1979) Handbook of physiology, section 2, The cardiovascular system. American Physiological Society, Bethesda.

8. Beyar $R$, Sideman $S$ (1986) The dynamic twisting of the left ventricle: a computer study. Ann Biomed Eing 14: 547-562

9. Borg TK, Ranson WF, Moslehy FA, Caulfield JB (1981) Structural basis of ventricular stiffness. Lab Invest 44: $49-54$ 
10. Bovendeerd PHM, Arts T, Huyghe JM, van Campen DH, Reneman RS (1992) Dependence of local left ventricular wall mechanics on myocardial fiber orientation: a model study. J Biomech 25 : 1. 129.1140

11. Caro CG, Pedley TJ, Schroter RC, Seed WA (1978) The mechanics of the circulation. J.W. Arrowsmith Ltd, Bristol

12. Curtius JM, Knueppel S, Meschig R, Balkenhoff $K_{\text {. Arnold }} \mathrm{G}$, Loogen F (1986) Linksventrikulaerer Kontraktionsablauf beim Linksschenkelblock und seine haemodynamische Auswirkungen. Z Kardiol 75: $138-146$

13. Falsetti HL, Mates RE, Grant C, Greene DG, Bunnell IL (1970) Left ventricular wall stress calculated from one plane cineangiography - An approach to force-velocity analysis in man. Circ Res 26: $71-83$

14. Feigl EO, Simon GA, Fry DL (1967) Auxotonic and isometric cardiac force transducers. J Appl Physiol 23: 597-600

15. Fenton TR, Cherry JM, Klassen GA (1978) Transmural myocardiall deformation in the canine left ventricular wall. Am J Physiol 235: H523H530

16. Frais MA, Botvinick EH, Shosa DW, O'Connel WJ, Scheinman MM, Hattner RS, Morady F (1982) Phase image characterization of ventricular contraction in left and right bundle branch block. Am J Cardiol 50: 95-105

17. Fung YC (1984) Byodynamics: circulation. Springer, New York Berlin Heidelberg

18. Fung YC ( 1990$)$ Byomechanics: motion, flow, stress, and growth. Springer, New York Berlin Heidelberg

19. Grover M, Glantz SA (1983) Endocardial pacing site affects left ventricular end-diastolic volume and performance in the intact anesthetized dog. Circ Res. $53: 72-85$

20. Guyton AC (1991) Textbook of medical physiology. Saunders, Philladelphia
21. Hoeks APG, Schmitz GML, Allessie MA, Jas $H$, Hollen SJ, Reneman RS (1988) Multichannel storage and display system to record the electrical activity of the heart. Med \& Biol Eng \& Compul 26: $434-438$

22. Hotta S (1967) The sequence of mechanical activation of the ventricle. Jpn Circ J 31: 1568-1572

23. Huisman RM, Elzinga, Westerhof $N$, Sipkema $P$ (1980) Measurement of left ventricular wall stress. Cardiovasc Res 14: 142-153

24. Huyghe JM, Arts T, van Campen DH, Reneman RS (1992) Porous medium finite element model of the beating left ventricle. Am J Physiol 262: H1256-H1267

25. Ingels NB, Daughters GT, Stinson EB, Alderman EL (1980) Evaluation of methods for quantitating left ventricular segmental wall motion in man using myocardial markers as a standard. Circulation 61: $966-972$

26. LeWinter MM, Kent RS, Kroener JM, Carew TE, Covell JW (1975) Regional differences in myocardial performance in the left ventricle of the dog. Circ Res 37: 191-199

27. Lower $\mathbb{R}$ (1669) Tractatus de corde. London

28. Manders WT, Vatner SF (1976) Effects of sodium pentobarbital anesthesia on left ventricular function and distribution of cardiac output in dogs, with particular reference to the mechanism for tachycardia. Circ Res 39: 512-517

29. Medugorac I (1982) Characterization of intramuscular collagen in the mammalian left ventricle. Basic Res Cardiol 77: $589-598$

30. Mirsky I, Rankin JS (1979) The effects of geometry, elasticity and external pressures on the diastolic pressure-wolume and stiffness-stress relations; how important is the pericardium? Circ Res 44: 601.-611

31. Miyazawa K, Shirato $K$, Haneda $T$, Honna T, Arai ' $T$, Nakajima $T$ (1976) Effects of varying pacemaker sites on left ventricular performance. J Exp Med $120: 301-308$

32. Neely JR, Morgan HE (1974) Relationship be- 
tween carbohydrate and lipid metabolism and the energy balance of heart muscle. Ann Rev Physiol 36: $413-459$

33. Neely JR, Rovetto MJ, Oran JF (1972) Myocardial utilization of carbohydrate and lipids. Prog Cardiovasc Dis 15:289-329

34. Omens JH, Covell JW (1991) Transmural distribution of myocardial tissue growth induced by volume overload hypertrophy in the dog. Circulation 84: $1235-1245$

35. Opie LH (1969) Metabolism of the heart in health and disease. Am Heart J 77: 100-122

36. Pfeffer MA, Braunwald E (1990) Ventricular remodelling after myocardial infarction. Experimental observations and clinical implications. Circulation 81: 1161-1172

37. Pollack GH, Krueger JW (1976) Sarcomere dynamics in intact cardiac muscle. Eur J Cardiol 4 (suppl): 53-65

38. Prinzen FW, Alewijnse $\mathrm{R}$, van der Vusse GJ, Kruger RTI, van der Nagel T, Reneman RS (1987) Coronary artery stenosis controlled by distal perfusion pressure: description of the servo-system and time-dependent changes in regional myocardial blood flow. Basic Res Cardiol 82: 375-387

39. Prinzen FW, Arts $T$, van der Vusse GJ, Coumans WA, Reneman RS (1986) Gradients in fiber shortening and metabolism across ischemic left ventricular wall. Am J Physiol 250: $\mathrm{H} 255-\mathrm{H} 264$

40. Prinzen FW, Augustijn CH, Arts T, Allessie MA, Reneman RS (1990) Redistribution of myocardial fiber strain and blood flow by asynchronous electrical activation. Am J Physiol 259: H300-H308

41. Prinzen TT, Arts T, Prinzen FW, Reneman RS (1986) Mapping of epicardial deformation using a video processing technique. J Biomech 19:263-273

42. Rankin JS, McHale P, Arentzen CE, Ling D, Greenfield JC. Anderson RW (1976) The three-dimensional dynamic geometry of the left ventricle in the concious dog. Circ Res 39: 304-313

43. Regen DM, Graham TP, Wyse RKH, Deanfield J,
Franklin RCG (1988) Left ventricular cavity dimensions in children with normal and dillated hearts. Pediati Cardiol 9: 17-24

44. Ross J, Sonnenblick EH, Covell JW (1967) The architecture of the heart in systole and diastole: technigue of rapid fixation and analysis of left ventricular geometry. Circ Res 21: 409-421

45. Rushmer RF (1954) Shrinkage of the heart in anesthetized, thoracotomized dogs. Circ Res 2: 22-27

46. Rushmer RF (1976) Cardiovascular dynamics. Saunders, Philadelphia

47. Saito D, "Takeda K, Hyodo T, Abe Y, Tani H, Nagahana $H, T . U$, Haraoka S, Nagashima H (1984) Effect of pacemaker sites on contractile forees of the local myocardium and blood flow in the major branches of the left coronary artery in anesthetized open-chest dogs. Jpn Circ J 48: 331-335

48. Scher AM, Spach MS (1979) Cardiac depolarization and repolarization and the electrocardiogram. In: Berne RM (Ed) Handbook of physiology, section 2: The cardiovascular system. American Physiological Society, Bethesda, pp 357-392

49. Slinker BK, Glantz SA (1985) The accuracy of inferring left ventricular volume from dimension depends on the frequency of information needed to answer a given question. Circ Res 56: 161-1.74

50. Streeter DD, Hanna WT (1973) Engineering mechanics for successive states in canine left ventricular myocardium: I cavity and wall geometry. Circ Res 33: 639-655

51. Streeter DD, Spotnitz HM, Patel DP, Ross J, Sonnenblick EH (1969) Fiber orientation in the canine left ventricle during diastole and systole. Circ Res 24:339-347

52. Suga H (1979) Total mechanical energy of a ventricle model and cardiac oxygen consumption. Am J Physiol 236: H498-H505

53. Suga H, Hayashi T, Shirahata M (1981) Ventricular systolic pressure volume area als predictor of cardiac oxygen consumption. Am J Physiol 240: H39-H44 
54. Suga $H$, Hayashi $\mathrm{T}$, Shirahata $\mathrm{M}$, Suchiro $\mathrm{S}, \mathrm{Hi}$ sano R (1981) Regression of cardiac oxygen con sumption on ventricular pressure volume area in dog. Am $\mathbb{~ P h y s i o l ~ 2 4 0 : ~ H 3 2 0 - H 3 2 5 ~}$

55. Suga H, Yasumura $Y$, Nozawa T, Futaki $S$, Igardshi $Y$, Goto $Y$ (1987) Prospective prediction of $\mathrm{O} 2$ consumption from pressure-volume area in dog hearts: Am J Physiol 252: H1258-H1264

56. ter Keurs HEDJ, Bucx JJJ, de Tombe PP, Backx P, Iwazumi $\mathrm{T}$ (1988) The effects of sarcomere length and $\mathrm{Ca}++$ on force and velocity of shortening in cardiac muscle. In: Sugi $H$, Pollack GH (Eds) Molecular mechanism of muscle contraction. Plenum, New York, pp 581-593

57. Theroux $P$, Franklin D, Ross JJ, Kemper WS (1974) Regional myocardial function during acute coronary artery occlusion and its modification by pharmacologic agents in the dog. Circ Res 35: 896908

58. Torrent Guasp F (1973) The cardiac muscle. Juan March Foundation, Barcelona

59. Tyberg JV, Forrester JS, Wyatt HL, Goldner SJ, Parmley WW, Swan HJC (1974) An analysis of segmental dysfunction utilizing the pressure-length loop. Circulation 49: 748-754

60. wan den Horn GJ, Westerhof $N$, Elzinga $G$ (1985) Optimal power generation by the left ventricle. Circ Res 56:252-261

61. van der Vusse GJ, Glatz JFC, Stam HCG, Reneman RS (1992) Fatty acid homeostasis in the normoxic and ischemic heart. Physiological Reviews 72(4): $8811-940$

62. van Heuningen $\mathrm{R}$, Rijnsburger WH, ter Keurs HEDJ (1982) Sarcomere length control in striated muscle. Am J Physiol 242: H41 1-H420

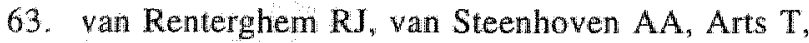
Reneman RS (1988) Deformation of the dog aortic valve ring during the cardiac cycle. Pfluegers Arch 412: $647-653$

64. Waldman LK, Covell JW (1987) Effects of ventricular pacing on finite deformation in canine left ventricles. Am J Physiol 252: H1023-H1030

65. Waldman LK, Nosan D, Covell JW (1988) Relation between transmural deformation and local myofiber direction in canine left ventricle. Circ Res 63: $550-562$

66. Wilensky RL, Tranum-Jensen J, Coronel R, Wilde AAM, Fiolet JWT, Janse MJ (1986) The subendocardial border zone during acute ischemia of the rabbit heart: an electrophysiologic, metabolic, and morphologic correlative study. Circulation 74 : $1137-1146$

67. Yellin EL, Nicolic S, Frater RWM (1990) Left ventricular filling dynamics and diastolic function. Prog Cardiovasc Dis 32: 247-271

68. Zerhouni EA, Parish DM, Rogers WJ, Yang A, Shapiro EP (1988) Human heart: tagging with MR imaging - a method for noninvasive assessment of myocardial motion. Radiology 169: 59-63 


\section{RELATION BETWEEN REGIONAL ELECTRICAL ACTIVATION TIME AND SUBEPICARDIAL FIBER STRAIN IN THE CANINE LEFT VENTRICLE}

Tammo Delhaas, Theo Arts*, Frits W. Prinzen and Robert S. Reneman

Departments of Physiology and Biophysics*,

Cardiovascular Research Institute Maastricht,

University of Limburg, P.O.Box 616,

NL-6200 MD Maastricht, The Netherlands.

Published in: Pflügers Arch (Eur J Physiol) (1993) 423: 78-87 
Abstract. To determine the relation between regional ellectrical activation time and fiber strain, epicardial electrical activation and deformation were measured in six open-thorax dogs at the left ventricular anterior free wall after 15 min of right atrial, left ventricular free wall, left ventricular apex, or right ventricular outflow tract pacing, when end-diastolic pressure was normal or elevated (volume-loading). Regional electrical activation was measured using a 192electrode brush. Regional subepicardial fiber strain ( $\left.e_{f}\right)$ was measured simultaneously in 16 regions, using optical markers which were attached to the epicardial surface and recorded on video. When relating regional $e_{f}$ during the ejection phase to regional activation time, the best correlation was found when a hemodynamic time reference rather than an electrophysiological one is used. Using the moment of the maximum rate of change of left ventricular pressure as the time reference for electrical activation, regional electrical activation time $\left(t_{e a}\right)$ and the degree of $e_{f}$ during the ejection phase could be fitted by a linear regression equation $e_{\mathrm{f}}=\mathrm{a} \mathrm{t}_{\mathrm{ea}}$ $+b$, in which $a=-3.46 \pm 0.73 \mathrm{~s}^{-1}$ and $\mathrm{b}=$ $-0.28 \pm 0.05$. For electrical activation times ranging from -40 to $-80 \mathrm{~ms}$, fiber strain was estimated with an accuracy of $\pm 0.026( \pm \mathrm{SE})$ with this relation. During right atrial pacing, $t_{\text {ea }}$ and $e_{f}$ were on the average $-48 \mathrm{~ms}$ and $-0.10 \mathrm{re}-$ spectively. On further investigation, the relation appeared to be influenced by end-diastolic pressure. For normal $(1.1 \mathrm{kPa})$ and elevated end-diastolic pressure $(1.8 \mathrm{kPa})$, the slope of the linear regression line was -3.96 and $-2.86 \mathrm{~s}^{-1}$, re- spectively. Three conclusions may be drawn. Firstly, the time interval between the moment of regional electrical activation and the moment of the maximum rate of change of left ventricular pressure is an index of regional fiber strain. Secondly, it can be concluded from the above equations that electrical asynchrony of more than 30 ms causes non-uniformities in the degree of $e_{f}$ of the order of mean $e_{f}$ during pacing from the right atrium. Finally, differences in fiber strain during asynchronous electrical activation are less pronounced at larger filling pressures.

\section{Introduction}

Normally, electrical activation of the left ventricular wall is quite synchronous $[6,26]$. Because contraction of muscle fibers follows electrical activation with a nearly fixed delay $[13,14,29]$, contraction occurs nearly simultaneously too [22]. For a given cardiac geometry, fiber stress in the wall is proportional to left ventricular pressure [3]. So, if pressure rises during the isovolumic phase, load is applied synchronously to all fibers. As a result, the distribution of subepicardial fiber strain during the ejection phase is also quite uniform [23].

When electrical activation is clearly asynchronous, the situation changes considerably $[6,23,28]$. If the ventricles are directly stimulated large differences in fiber strain may occur $[6,23]$. Early-activated muscle fibers contract early and with a high shortening velocity, thus stretching the serially connected, as yet non-ac- 
tivated fibers. This prestretch induces an increase in contractile force of these fibers [21]. When finally activated, these late-activated fibers shorten vigorously, counteracting further contraction of the early-activated fibers. A similar finding has been reported in an in vitro experiment with two asynchronously activated papillary muscles connected in series [28]. The moment of regional electrical activation is thus an important determinant of the regional contribution of the myocardium to total cardiac pumping.

The latter, qualitative finding has not been quantified to date. In the present study the question as to whether the moment of electrical activation can be used to predict the amount of fiber shortening during the ejection phase was investigated. The use of the moment of regional electrical activation to predict the amount of regional fiber shortening requires an accurate time reference. Comparing different beats and different hearts, it was investigated whether such a time reference could be found.

The first question requires experimental manipulation of asynchrony of electrical activation within the myocardium to be studied. This is achieved by direct epicardial electrical stimulation of the left ventricular free wall, the left ventricular apex and the right ventricular outflow tract. The second question requires a general method to determine a time reference to which the timing of electrical activation can be referred. Three different electrophysiological time references were investigated: the stimulus artifact, the onset of the QRS-complex, and the center of the QRS-complex. Furthermore, a hemodynamic time reference was assessed, i.e. the moment at which the rate of change of left ventricular pressure ( $\mathrm{dp}_{\mathrm{p} / \mathrm{d}} / \mathrm{dt}$ ) was maximal. The latter unconventional time reference was investigated because earlier studies have revealed a strong relation between the moment of regional electrical activation and regional mechanical performance $[5,22,23]$. Measurements were performed during normal as well as elevated enddiastolic pressure.

\section{Materials and methods}

\section{Experimental techniques}

Animal preparation and instrumentation. Six adult mongrel dogs of either sex, weighing $23-29 \mathrm{~kg}$, were premedicated by an intramuscular injection of Hypnorm ( $1 \mathrm{ml} \mathrm{kg}^{-1} ; 1 \mathrm{ml}$ Hypnorm contains $10 \mathrm{mg}$ fluanisone and 0.2 $\mathrm{mg}$ fentanyl base). Anesthesia was induced by an intravenous injection of pentobarbital sodium $\left(10 \mathrm{mg} \mathrm{kg}^{-1}\right)$ and maintained after endotracheal intubation with nitrous oxide $\left(33 \% \mathrm{O}_{2}, 67 \%\right.$ $\mathrm{N}_{2} \mathrm{O}$ ) and a continuous infusion of pentobarbital sodium ( $2 \mathrm{mg} \mathrm{kg}^{-1} \mathrm{~min}^{-1}$ ). Ventilation was kept constant with a positive pressure respirator (Pulmomat, Dräger). The animal was placed on its right side and body temperature was kept between 37.5 and $38.5^{\circ} \mathrm{C}$ by means of a thermostatically regulated heating pad. A standard limb lead electrocardiogram (ECG) was used. Arterial blood samples were taken periodically to determine $\mathrm{pO}_{2}, \mathrm{PCO}_{2}, \mathrm{pH}$, oxygen saturation 


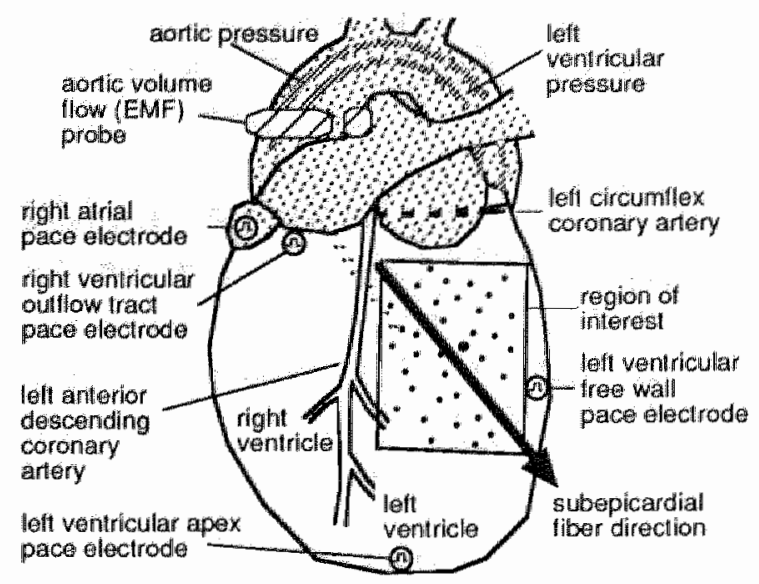

Fig. 1. Schematic representation of experimental setup.

and hemoglobin concentration (ABL 3, Radiometer). Sodium bicarbonate solution (4.2\%) was administered intravenously to adjust the acid-base balance when necessary.

The chest was opened through the left fifth intercostal space. After removal of the fifth rib, the pericardium was opened and the heart suspended in a pericardial cradle. Epicardial bipolar platinum pacing electrodes were sutured to the heart at the right atrium, left ventricular free wall, left ventricular apex and right ventricular outflow tract (Fig. 1).

Left ventricular cavity and ascending aortic pressure were measured with catheter-tip micromanometers (Millar PC -470 ), inserted via the right brachial and the right femoral artery, respectively. To enable pressure calibration during the experiment, the fluid-filled lumina of the catheter-tip micromanometers were connected via three-way cocks to an external pressure transducer (Electromedics MS20). The third opening of the three-way cock was connected to a reference pressure level, which was the right atrial level for all pressure measurements [4]. Ascending aortic volume flow was measured with an electromagnetic flow meter (Skalar Transflow 601). The diastolic aortic flow level was used as zero flow reference. ECG and pressure and flow signals were continuously displayed on an oscilloscope (Knott) and recorded on both a chart recorder (Schwarzer) and a multichannel tape recorder (Ampex PR2200).

Mapping of left ventricular epicardial electrical activation pattern. A 192-electrode brush (44 x $64 \mathrm{~mm}$ ) was used for simultaneous recording of epicardial surface electrograms from the left ventricular anterior wall. The grid spacing between the electrodes was approximately 3.5 $\mathrm{mm}$. After amplification and bandpass filtering $(3-400 \mathrm{~Hz})$, the analog signals were sampled and multiplexed with a frequency of $1 \mathrm{kHz}$ per electrode. The signals were converted to a single digital signal which was recorded on a video recorder (Sony SL-C9ES, Betamax) for off-line analysis [1, 12]. Left ventricular pressure, $\mathrm{ECG}$, right atrial and ventricular stimulus artifacts were recorded with the same system in parallel with the electrode signals.

Mapping of left ventricular epicardial deformation. Two-dimensional epicardial deformation 
was determined using a video technique as previously described in detail [24]. In brief, approximately 40 white markers were attached with tissue glue (Histoacryl) to the epicardial surface of the left ventricular anterior wall at mutual distances of approximately $6 \mathrm{~mm}$. The area covered with markers extended $3-4 \mathrm{~cm}$ in the circumferential and $4-5 \mathrm{~cm}$ in the base-toapex direction (Fig. 1). A video camera (Sony AVC $32500 \mathrm{CE}$ ) with a $200 \mathrm{~mm}$ tele-objective, positioned at a distance of $2.5 \mathrm{~m}$, and a mirror, mounted above the heart at an angle of $45^{\circ}$, were used to record the motion of the markers on a video recorder (Sony SL-C9ES, Betamax) at a speed of 50 frames $s^{-1}$. A video triggered xenon flashlight illumination (Chadwick-Helmuth) was employed. To enable synchronization of the hemodynamic data with the deformation data, a frequency-modulated left ventricular pressure signal was recorded on an audio channel of the video recorder.

Experimental protocol. The direction of the epicardial fibers and the long axis of the left ventricle as determined by visual inspection was indicated by a directed ruler and recorded on video (Fig. 1). For all sites of pacing, the minimum levels of current and pacing rate at which activation was regular were determined. Usually these values remained constant throughout an experiment. In two experiments, however, the stimulation frequency was increased, because the fraction of escape beats exceeded $5 \%$. Pacing was performed from the four different sites: right atrium, left ventricular free wall, left

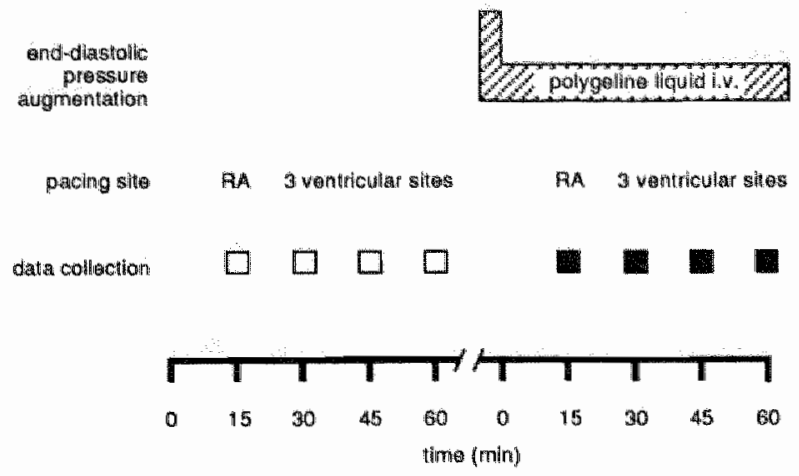

Fig. 2. Experimental protocol. Data were obtained during pacing from the right atrium (RA) and at random at three ventricular pacing sites (left ventricular free wall, left ventricular apex or right ventricular outflow tract). Squares indicate times at which data were recorded at normal $(1.1 \mathrm{kPa}$; open squares) and elevated (1.8 $\mathrm{kPa}$; closed squares) end-diastolic pressure.

ventricular apex and right ventricular outflow tract. During ventricular pacing the right atrium was stimulated $30 \mathrm{~ms}$ before the ventricle. After a stabilization period of $15 \mathrm{~min}$ during pacing from a particular site, hemodynamic variables and epicardial deformation were recorded simultaneously. Within 1 min thereafter hemodynamic variables and epicardial electrical activation were recorded simultaneously. After completion of the measurements for the four pacing sites, the heart was paced from the right atrium and end-diastolic pressure elevated to $1.8 \mathrm{kPa}$ by rapid intravenous infusion of a polygeline infusion liquid (Haemaccel ${ }^{\mathbb{B}}$, Behringwerke AG). After adjusting the infusion rate to maintain the 
$1.8 \mathrm{kPa}$ end-diastolic pressure level, the above measurements were repeated (Fig. 2).

\section{Data analysis}

Hemodynamics. After the experiment, the hemodynamic data as recorded on analog tape were sampled $(200 \mathrm{~Hz})$ and digitized using a 16-channel 12-bit A/D card (DASH 16G2) connected to an MS-DOS personal computer (Tulip AT Compact). Sampling and analysis were performed using a software package (ASYST 3.0, MacMillan Software) and software developed in our laboratory. In the cardiac cycle three events were determined (Fig. 3). The end of the diastolic phase was defined as the moment before ejection at which $\mathrm{dp}_{\mathrm{lv}} / \mathrm{dt}$ exceeded $10 \mathrm{kPa} \mathrm{s}^{-1}$ [15]. The beginning of the ejection phase was defined as the moment at which left ventricular pressure exceeded the level of end-diastolic aortic pressure. The duration of the ejection phase was determined from the aortic volume flow signal. The following hemodynamic variables were determined: heart rate, duration of isovolumic contraction phase, duration of ejection phase, end-diastolic left ventricular pressure, maximum left ventricular pressure, maximum $\mathrm{dp} l_{v} / \mathrm{dt}$, maximum instantaneous aortic volume flow and ejected volume (time integral of ascending aortic volume flow).

Left ventricular electrical activation. After the experiment, the recorded electrograms were transferred to a personal computer (Olivetti M380). The moment in each electrogram at

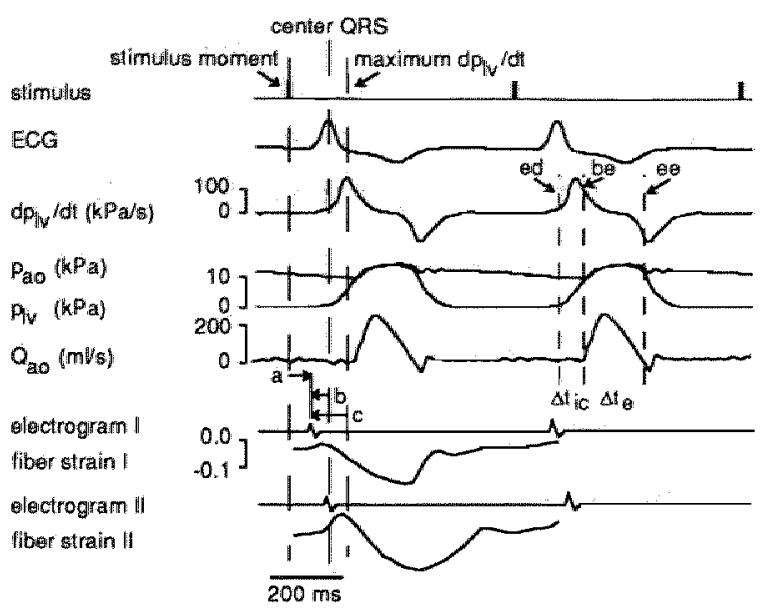

Fig. 3. Typical digital recordings of hemodynamic, electrophysiological and deformation data during pacing from the right ventricular outflow tract at normal end-diastolic pressure. Traces from top to bottom: stimulus artifact, electrocardiogram (ECG), first derivative of left ventricular pressure $(\mathrm{dp} / \mathrm{l} / \mathrm{dt})$, left ventricular pressure $(\mathrm{p} / \mathrm{v})$, instantaneous aortic volume flow $\left(Q_{a o}\right)$, regional epicardial electrogram and fiber strain in early-activated basal-medial region (electrogram I and fiber strain I) and in late-activated apical-lateral region (electrogram II and fiber strain II). Letters $a, b$, and $c$ indicate time intervals between the moment of regional electrical activation in region I and the stimulus artifact (a), the center of the QRS-complex (b), and the moment of maximum $\mathrm{dp}_{\mathrm{Iv}} / \mathrm{dt}(\mathrm{c})$. Note that $\mathrm{b}$ and $\mathrm{c}$ are less negative in late-activated regions. In the cardiac cycle three events are determined: end-diastole (ed), begin-ejection (be) and end-ejection (ee). $\Delta t_{i c}$ and $\Delta t_{e}$ indicate the duration of the isovolumic contraction phase and the ejection-phase respectively. 
which the negative deflection was steepest was automatically detected and labeled by a time mark, indicating the moment of regional activation of the tissue underneath the recording electrode. If necessary, the time marks could be removed or positioned manually [1, 12]. Regional electrical activation time ( $\left.\mathrm{t}_{\mathrm{ea}}\right)$ was calculated by determining the time interval between a reference time moment and the average moment of electrical activation of the electrodes within one region. The following reference moments were used: (1) for right atrial pacing the onset of the QRS-complex, (2) for ventricular pacing the moment at which the stimulus was given, (3) for all pacing modes both the center of the QRScomplex and the moment of maximum $\mathrm{dp}_{\mathrm{lv}} / \mathrm{dt}$ (Fig. 3).

Epicardial deformation. After the experiment, 64 consecutive video frames $(50 \mathrm{~Hz})$ were digitized and stored in a $2 \mathrm{MB}$ digital video memory which was coupled to a computer (PDP 11/73). Markers were detected and the traces of the position of their center of gravity determined. Incomplete traces were not analyzed further. Artifacts in motion due to differences between odd and even video frames were excluded by averaging the marker positions in successive video frames. The marker positions thus obtained were filtered using a singular value decomposition (SVD) filtering technique [19]. The area in which the deformation was analyzed was subdivided into $4 \times 4$ mutually overlapping regions. Epicardial deformation was estimated in each region and for each frame from the SVD- filtered marker positions by means of a leastsquares criterion [24]. Using begin-ejection as a reference for deformation, epicardial deformation during the ejection phase was expressed in terms of a natural strain in the direction of the subepicardial fibers $\left(e_{f}\right)$ by:

$$
e_{f}=\ln \frac{l_{f, e e}}{l_{f, b e}}
$$

in which $1_{f, \text { ee }}$ and $l_{f, \text { be }}$ represent epicardial segment length along the subepicardial fiber direction at the end and at the beginning of the ejection phase respectively.

\section{Synchronization of hemodynamic data with data} of deformation or electrical activation. Left ventricular pressure was recorded simultaneously on paper, on a multichannel tape recorder, on an audio channel of the video recorder used to record epicardial deformation and on a channel in the electrical mapping system. A time mark was given by adding an offset of $200 \mathrm{mV}$ for a period of $1 \mathrm{~s}$ to the left ventricular pressure signal before each measurement. After the experiment, left ventricular pressure signals were sampled and digitized. Using the time marks, corresponding heart beats registered by the different measuring equipment could be identified. Precise synchronization of hemodynamic data with deformation or electrical data was achieved by applying a correlation interpolation technique to the left ventricular pressure signals obtained from the different recording devices [9]. 
Spatial matching of electrophysiological and deformation data. During the experiment, reproducible positioning of the electrode brush was obtained by visual matching of the landmarks on the electrode brush with anatomical landmarks and video markers on the epicardial surface. To enable spatial matching of electrophysiological and deformation data, four white markers were attached to the upper surface of the multi-electrode brush. The position of each marker in relation to the electrodes was known. A video recording was made with the brush placed at the region of interest at the epicardium of the left ventricular anterior free wall. This video recording was used to reconstruct the position of each electrode in relation to the regions in which epicardial deformation was measured.

Relation between $t_{e a}$ and $e_{f}$ during the ejection phase. For each experiment and for each time reference, regional $e_{f}$ during the ejection phase was plotted as a function of regional $t_{\mathrm{ea}}$ for the various pace modes. In the analysis, measured regional $\mathrm{e}_{\mathrm{f}}$ in the corners of the area of interest were excluded because projection of the curved epicardial surface on the flat video sensor element causes distortion [24]. Therefore, only data obtained in the remaining 12 central regions were used. In each experiment, linear regression analysis was applied to this relation for both normal and elevated end-diastolic pressures. From the derived linear equations, $e_{f}$ during the ejection phase was estimated when the hearts were stimulated from the right atrium.
The accuracy of estimated $e_{f}$ for a given tea is given by the relation $\left[A^{2}+(\Delta t \cdot B)^{2}\right]^{1 / 2}$, where $A$ and $B$ are the standard errors for the constant and the slope of the linear equation respectively and $\Delta t$ the difference between the given $t_{e a}$ and the mean tea.

Statistical analysis. For the analysis of deformation and electrical activation data, only data from the 12 central regions were used. The Wilcoxon signed-rank test was used to test whether the differences in hemodynamic data were significant when pacing from the right atrium, the left ventricular free wall, the left ventricular apex or the right ventricular outflow tract. The Wilcoxon signed-rank test was also used to test whether $e_{f}$ during the ejection phase was changed significantly when end-diastolic pressure was elevated. The Sign test was applied to test whether the differences in hemodynamic data between normal and elevated end-diastolic pressure were significant. The estimated linear relations between regional $t_{\mathrm{ea}}$ and regional $\mathrm{e}_{\mathrm{f}}$ during the ejection phase were tested for similarity as follows: the offset of the linear equation at mean $t_{\text {ea }}$ during pacing from the right atrium was tested for similarity by means of the Wilcoxon signed-rank test; analysis of covariance was used to test the similarity of the slopes. The linear equations obtained during normal or elevated end-diastolic pressure were also tested for similarity between experiments. For each experiment the simillarity between the linear equations obtained during normal and elevated end-diastolic pressure was also tested. 
Estimated values of $\mathrm{e}_{\mathrm{f}}$ calculated from measured regional tea using the linear equations were compared with measured values of $e_{f}$ by means of the Wilcoxon signed-rank test. A value of $\mathrm{P}$ $<0.05$ was considered to be a significant difference (two-tailed probability).

\section{Results}

In one experiment epicardial electrical activation and deformation were analyzed only during normal end-diastolic pressure, because ventricular fibrillation occurred during the rapid intravenous fluid infusion to increase end-diastolic pressure.

Influence of pacing site and end-diastolic pressure on hemodynamic performance

For the various sites of electrical stimulation, the hemodynamic variables are shown while end-diastolic pressure was normal in Table 1 and when elevated in Table 2. Compared with atrial pacing, ventricular pacing resulted in a decrease of maximum left ventricular pressure, maximum $\mathrm{dp}_{\mathrm{lv}} / \mathrm{dt}$, maximum instantaneous aortic volume flow and stroke volume. This decrease in hemodynamic performance was most pronounced during right ventricular outflow tract pacing. Comparison of Tables 1 and 2 reveals that fluid infusion indeed led to an increased cardiac preload; left ventricular end-diastolic pressure increased significantly. During elevated end-diastolic pressure, ventricular pacing also resulted in a decrease of maximum left ventricular pressure, maximum $\mathrm{dp}_{\mathrm{v}} / \mathrm{dt}$, maximum instantaneous aortic volume flow and stroke volume.

Influence of pacing site and end-diastolic pressure on left ventricular electrical activation pattern

In Fig. 4 mean maps of regionall tea are shown for normal $(1.1 \mathrm{kPa}$, column $\mathrm{A})$ or elevated $(1.8$ $\mathrm{kPa}$, column B) end-diastolic pressure. The successive rows show the results obtained with pacing from the right atrium, the left ventricular free wall, the left ventricular apex or the right ventricular outflow tract. The moment of maximum $\mathrm{dplv} / \mathrm{dt}$ is used as time reference. Note that $t_{e a}$ is less negative in late- than in early-activated regions. During right atrial pacing, tea at the anterior free wall of the left ventricle was $-50 \pm 3$ ms (mean $\pm \mathrm{SD}$ ) when end-diastolic pressure was normal. Mean values of regional $t_{\mathrm{ea}}$ ranged between $-80 \mathrm{~ms}$ and $-40 \mathrm{~ms}$ during pacing from the three ventricular sites. The direction of the depolarization wave in the region of interest was highly dependent on the site of pacing. Stimulation at the right ventricular outflow tract caused a wave oppositely directed to that observed when the heart was stimulated at the apex. During stimulation at the left ventricular free wall the depolarization wave traveled more or less perpendicular to the two former directions. Elevated end-diastolic pressure barely influenced the direction of electrical activation, although it caused the region of interest to be activated slightly later during pacing from the 
Table 1. Hemodynamic variables during different pacing modes at normal left ventricular end-diastolic pressure.

\begin{tabular}{|c|c|c|c|c|}
\hline \multirow[b]{2}{*}{ Variable } & \multicolumn{4}{|l|}{ Pacing site } \\
\hline & $\mathrm{RA}$ & $\mathrm{I} \vee \mathrm{FW}$ & $L V A$ & RVOT \\
\hline$f_{h}\left(\right.$ beat.min $\left.{ }^{-1}\right)$ & $83 \pm 13$ & $93 \pm 17$ & \pm 17 & $91 \pm 17$ \\
\hline$\Delta \mathrm{t}_{\mathrm{ic}}(\mathrm{ms})$ & $58 \pm 9$ & $62 \pm 12$ & $63 \pm 10$ & $61 \pm 12$ \\
\hline$\Delta \mathrm{t}_{\mathrm{e}}(\mathrm{ms})$ & $178 \pm 9$ & $179 \pm 13$ & $181 \pm 17$ & \pm 19 \\
\hline Plved (kPa) & $1.1 \pm 0.2$ & $1.2 \pm \quad 0.2$ & $1.1 \pm 0.1$ & $1.1 \pm 0.3$ \\
\hline Plv, max $(k P a)$ & $13.2 \pm 2.0$ & $11.2 \pm 1.6 *$ & $11.6 \pm 1.5 *$ & $10.7 \pm 2.2 *$ \\
\hline $\mathrm{dp} \| \mathrm{v} / \mathrm{dt}_{\max }\left(\mathrm{kPa} \cdot \mathrm{s}^{-1}\right)$ & $188 \pm 32$ & $144 \pm 15 *$ & $161 \pm 35$ * & $128 \pm 26 *$ \\
\hline $\mathrm{Q}_{\mathrm{ao}, \max }\left(\mathrm{ml} . \mathrm{s}^{-1}\right)$ & $209 \pm 55$ & $173 \pm 37^{*}$ & $176 \pm 40^{*}$ & $180 \pm 60 *$ \\
\hline $\mathrm{V}_{\mathrm{e}}(\mathrm{ml})$ & $22.8 \pm 4.5$ & $18.9 \pm 3.2 *$ & $19.8 \pm 3.4 *$ & $19.3 \pm 5.4 *$ \\
\hline
\end{tabular}

Values are mean $\pm S D$. RA, Right atrium; RVOT, right ventricular outflow tract; LVA, left ventricular apex; LVFW, left ventricular free wall; $t_{h}$, heart rate; $\Delta t_{i c}$, duration of isovolumic contraction phase; $\Delta t_{\mathrm{e}}$, duration of ejection phase; PIv,ed, left ventricular pressure at end diastole; PIv, max maximum left ventricular pressure; $\mathrm{dp}_{\mathrm{f}} / \mathrm{dt}_{\mathrm{max}}$, maximum first derivative of left ventricular pressure; Qao,max, maximum instantaneous aortic volume flow; $V_{\mathrm{e}}$, ejected volume. * Statistically significantly different from results obtained with $\mathrm{RA}$ pacing $(\mathrm{P}<0.05$, Wilcoxon signed rank test).

Table 2. Hemodynamic variables during different pacing modes with elevated left ventricular end-diastolic pressure.

\begin{tabular}{|c|c|c|c|c|}
\hline \multirow[b]{2}{*}{ Variable } & \multicolumn{4}{|l|}{ Pacing Site } \\
\hline & RA & LVFW & LVA & RVOT \\
\hline$f_{h}\left(\right.$ beat.min $\left.{ }^{-1}\right)$ & $87 \pm 14$ & $102 \pm 13$ & $103 \pm 12$ & $101 \pm 12$ \\
\hline$\Delta \mathrm{t}_{\mathrm{ic}}(\mathrm{ms})$ & $64 \pm 9$ & $74 \pm 10$ & $74 \pm 9$ & $78 \pm 10$ \\
\hline$\Delta \mathrm{t}_{\mathrm{e}}(\mathrm{ms})$ & $211 \pm 24$ & $201 \pm 14 *$ & $203 \pm 14^{*}$ & $203 \pm 11 *$ \\
\hline$p_{\mid v, e d}(k P a)$ & $1.9 \pm 0.2 *$ & $1.7 \pm 0.3 *$ & $1.6 \pm 0.3 *$ & $1.8 \pm 0.2 *$ \\
\hline $\mathrm{Ply}, \max (\mathrm{kPa})$ & $16.7 \pm 2.6 *$ & $15.1 \pm 2.4 *$ & $15.4 \pm 2.8 *$ & $\mathbb{1 5 . 2 \pm 2 . 4 *}$ \\
\hline $\mathrm{d}_{\mathrm{p} \| \mathrm{v}} / \mathrm{dt}_{\max }\left(\mathrm{kPa} \cdot \mathrm{s}^{-1}\right)$ & $207 \pm 39 *$ & $184 \pm 27 *$ & $186 \pm 29 *$ & $174 \pm 28 *$ \\
\hline$Q_{n o, \max }\left(\operatorname{mil}, s^{-1}\right)$ & $253 \pm 47 *$ & $239 \pm 39 *$ & $238 \pm 41 *$ & $239 \pm 53 *$ \\
\hline $\mathrm{V}_{\mathrm{e}}(\mathrm{ml})$ & $33.9 \pm 4.4$ 非 & $29.8 \pm 3.5 *$ & $29.5 \pm 3.3^{*}$ & $31.1 \pm 6.1 *$ \\
\hline
\end{tabular}

Values are mean \pm SD. For explanation of symbols see Table 1. * Statistically significantly different from results obtained with normal end-diastolic pressure $(\mathrm{P}<0.05$, Sign test). 
Regional electrical activation and fiber strain

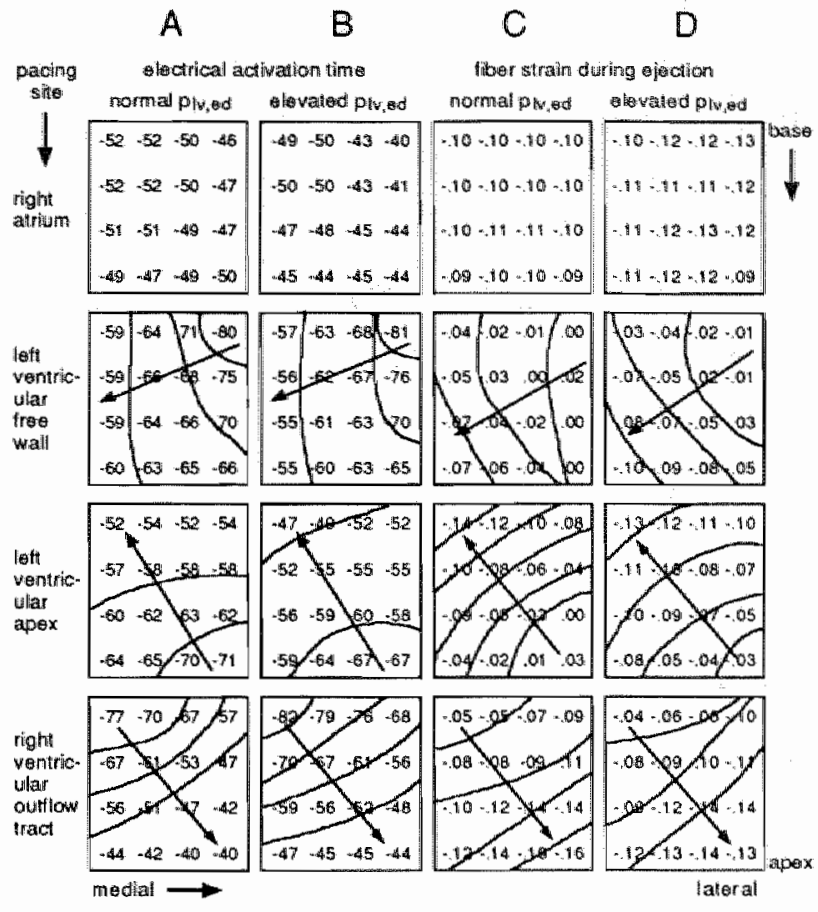

right atrium, the left ventricular free wall, and the left ventricular apex, and slightly earlier during pacing from the right ventricular outflow tract.

\section{Influence of pacing site and end-diastolic pres- sure on $e_{f}$}

Maps of mean regional ef during the ejection phase are shown in Fig. 4 for normal $(1.1 \mathrm{kPa}$, column $\mathrm{C}$ ) or elevated $(1.8 \mathrm{kPa}$, column $\mathrm{D})$ end-diastolic pressure. The successive rows show the results obtained with pacing from the right atrium, the left ventricular free wall, the left ventricular apex or the right ventricular out
Fig. 4. Maps of regional electrical activation time ( $t_{\text {ear }}$ columns $A$ and $B$ ) and regional subepicardial fiber strain during the ejection phase $\left(e_{i}\right.$ columns $C$ and D), as averaged over the experiments $(n=6)$ while end-diastolic pressure was normal $(1.1 \mathrm{kPa}$; columns $\mathrm{A}$ and $\mathrm{C})$ or elevated $(1.8 \mathrm{kPa}$; columns $\mathrm{B}$ and $D$ ). The successive rows show the results obtained with pacing from the right atrium, the left ventricular free wall, the left ventricular apex or the right ventricular outflow tract. The moment of maximum $\mathrm{dp}_{\mathrm{iv}} / \mathrm{dt}$ is used as time reference. Note that $\mathrm{t}_{\text {ea }} \mathrm{val}$ ues in late-activated regions are less negative than in early-activated regions. The arrows indicate maximum gradients in $t_{\mathrm{ea}}$ and $e_{\mathrm{f}}$. $\mathrm{A}, \mathrm{B}$ The detailed maps obtained with the 192-electrode brush were reduced to a $4 \times 4$ matrix. Isochrone lines are shown with time intervals of $10 \mathrm{~ms}$. $C, D$ e during the ejection phase measured in 16 regions. "Isostrain" lines are shown with strain intervals of 0.03 .

flow tract. At normal end-diastolic pressure ef was homogeneously distributed during pacing from the right atrium. During ventricular pacing, gradients in $e_{f}$ were found. The direction of this gradient was the same as the direction of the gradient of the related depolarization wave. The gradients in fiber shortening were most pronounced during pacing at the right ventricular outflow tract. Compared with normal end-diastolic pressure, during elevated end-diastolic pressure $e_{f}$ during the ejection phase was significantly higher when the heart was paced from the right atrium. After elevation of end-diastolic pressure, the gradients in fiber shortening during ventricular pacing were significantly de- 
creased. Although the differences were small, $\mathrm{e}_{\mathrm{f}}$ was higher in the early-activated regions and lower in the late-activated regions compared with normal end-diastolic pressure.

\section{Relation between $t_{e a}$ and $e_{f}$}

As an example (experiment 3 ), for normal enddiastolic pressure, $\mathrm{e}_{\mathrm{f}}$ during the ejection phase measured in the 12 central regions is plotted as a function of tea in Fig. 5A-C for the four pacing modes. In Fig. 5A the onset of the QRS-complex is used as the time reference during right atrial pacing, whereas for the three ventricular pacing sites the moment at which the stimulus was given is used. In Fig. 5B the center of the
QRS-complex is used as the time reference. In Fig. 5C the time reference is the moment of maximum $\mathrm{dp}_{\mathrm{l}} / \mathrm{dt}$. In general, using electrophysiological events to define the moment of electrical activation yielded distinct clusters of data points (Fig. 5A, B), for which linear regression analysis is not legitimate. Should a linear regression be nonetheless calculated, the relation was not reproducible from one experiment to the next. Using the moment of maximum $\mathrm{dp}_{\mathrm{IV}} / \mathrm{dt}$ as the time reference (Fig. 5C, D) generally resulted in merging of the clusters. The data points in these clusters fitted a linear regression line; the slope and offset were in a distinct range for all experiments (Tables 3,4 ). In the individual experiments, neither the slope

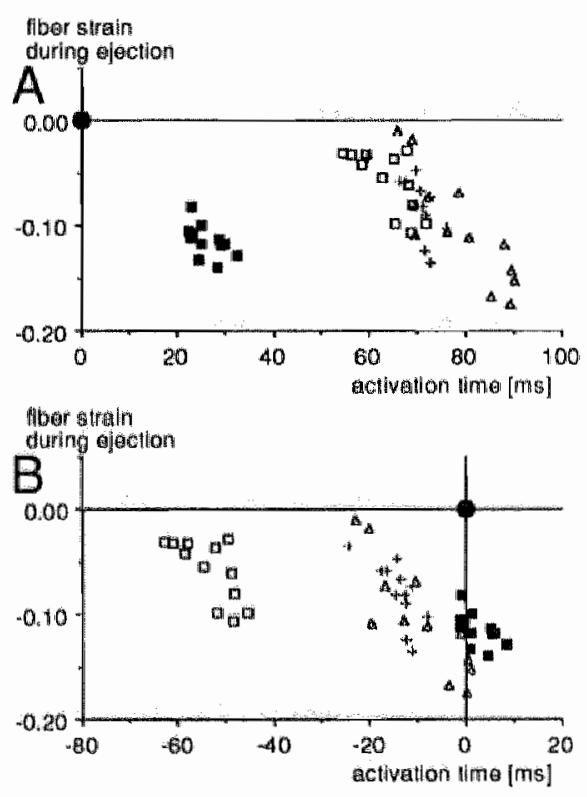

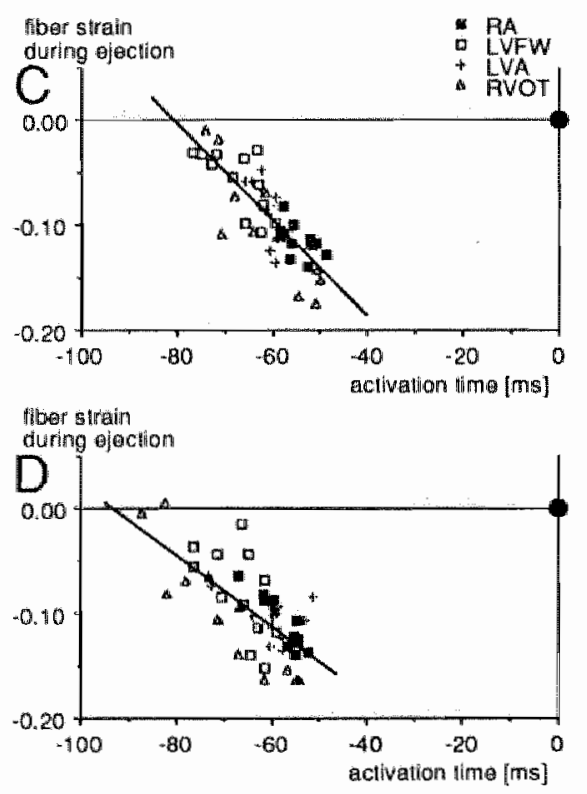

Fig. 5. Plots of regional subepicardial fiber strain during the ejection phase $\left(e_{f}\right)$ versus regional electrical activation time ( $t_{\text {ea }}, \mathrm{ms}$ ) obtained in experiment 3 with normal $(1.1 \mathrm{kPa}$; $A$, $\mathrm{B}$, and $\mathrm{C}$ ) or elevated (1.8 $\mathrm{kPa}$; D) end-diastolic pressure. A The onset of the QRS-complex or the stimulus moment is used as time reference for electrical activation. B The center of the QRS-complex is used as time reference. C, D The moment of maximum $\mathrm{dp}_{\mathrm{I}} / \mathrm{dt}$ is used as time reference. Using the latter time reference, the data points clusters merged, and the relation between tea and ef during the ejection phase could be fitted by linear regression. 
Regional electrical activation and fiber strain

Table 3. Equations of regression lines relating fiber strain during the ejection phase and electrical activation time with normal end-diastolic pressure.

\begin{tabular}{|c|c|c|c|c|c|c|c|c|c|}
\hline Expt. & Intercept & $\mathrm{SE}$ & Slope $\left(s^{-1}\right)$ & $\mathrm{SE}$ & r & $\begin{array}{l}\text { teat (ms) } \\
\text { (atrium) }\end{array}$ & $\begin{array}{l}\text { tea (ms) } \\
\text { (total) }\end{array}$ & $\begin{array}{l}\text { ef est } \pm S D \\
\text { (atrium) }\end{array}$ & $\begin{array}{l}\text { r, meas } \mathrm{SD} \\
\text { (atrium) }\end{array}$ \\
\hline 1 & -0.26 & 0.03 & -3.09 & 0.43 & 0.73 & -49.3 & -58.8 & $-0.105 \pm 0.026$ & $-0.091 \pm 0.015$ \\
\hline 2 & -0.32 & 0.03 & -4.31 & 0.51 & 0.88 & -52.0 & -57.7 & $-0.092 \pm 0.030$ & $-0.095 \pm 0.006$ \\
\hline 3 & -0.37 & 0.03 & -4.62 & 0.46 & 0.83 & -54.6 & -61.1 & $-0.119 \pm 0.029$ & $-0.115 \pm 0.016$ \\
\hline 4 & -0.27 & 0.03 & -3.92 & 0.59 & 0.70 & -48.6 & -54.5 & $-0.077 \pm 0.033$ & $-0.098 \pm 0.013$ \\
\hline 5 & -0.28 & 0.02 & -4.09 & 0.42 & 0.82 & -46.0 & -53.9 & $-0.092 \pm 0.024$ & $-0.092 \pm 0.012$ \\
\hline 6 & -0.30 & 0.03 & -3.71 & 0.44 & 0.78 & -47.9 & -56.9 & $-0.126 \pm 0.025$ & $-0.127 \pm 0.006$ \\
\hline MeantSD & $-0.30 \pm 0.04$ & & $-3.96 \pm 0.53$ & & & $-49.7 \pm 3.1$ & $-57.1 \pm 2.7$ & $-0.102 \pm 0.018$ & $-0,103+0.015$ \\
\hline
\end{tabular}

$r$, correlation coëfficient; $t_{\text {ea, }}$ electrical activation time; $e_{f, \text { est, }}$ estimated fiber strain during the ejection phase; ef,meas, measured fiber strain during the ejection phase. The moment of maximum dplv/dt was used as the time reference for ellectrical activation.

Table 4. Equations of regression lines relating fiber strain during the ejection phase and electrical activation time, while left ventricular end-diastolic pressure is elevated.

\begin{tabular}{llllllllll}
\hline Expt. & Intercept & $\mathrm{SE}$ & Slope $\left(\mathrm{s}^{-1}\right)$ & $\mathrm{SE}$ & $\mathrm{r}$ & $\begin{array}{l}\mathrm{t}_{\mathrm{ea}}(\mathrm{ms}) \\
(\mathrm{atrium})\end{array}$ & $\begin{array}{l}\mathrm{t}_{\mathrm{ea}}(\mathrm{ms}) \\
\text { (total) }\end{array}$ & $\begin{array}{l}\mathrm{e}_{\mathrm{f}, \mathrm{est}} \pm \mathrm{SD} \\
\text { (atrium) }\end{array}$ & $\begin{array}{l}\mathrm{e}_{\mathrm{f}, \mathrm{meas}} \pm \mathrm{SD} \\
\text { (atrium) }\end{array}$ \\
\hline 2 & -0.21 & 0.02 & $-2.45^{*}$ & 0.31 & 0.80 & -42.3 & -52.2 & $-0.106 \pm 0.017$ & $-0.112 \pm 0.010$ \\
3 & -0.31 & 0.03 & $-3.36^{*}$ & 0.50 & 0.71 & -57.7 & -63.4 & $-0.118 \pm 0.032$ & $-0.109 \pm 0.025$ \\
4 & -0.23 & 0.02 & $-2.68 *$ & 0.38 & 0.72 & -39.6 & -54.8 & $-0.124 \pm 0.022$ & $-0.106 \pm 0.009$ \\
5 & -0.26 & 0.03 & $-3.22^{*}$ & 0.52 & 0.68 & -43.0 & -53.9 & $-0.124 \pm 0.029$ & $-0.147 \pm 0.015$ \\
6 & -0.23 & 0.02 & $-2.56 *$ & 0.33 & 0.75 & -46.2 & -55.8 & $-0.107 \pm 0.019$ & $-0.108 \pm 0.011$ \\
Mean $\pm S D$ & $-0.25 \pm 0.04$ & & $-2.86 \pm 0.41$ & & & $-45.8 \pm 7.1$ & $-56.0 \pm 4.3$ & $-0.116 \pm 0.009$ & $-0.117 \pm 0.017$ \\
\hline
\end{tabular}

For explanation of symbols see Table $3 .{ }^{*}$ Statistically significant difference in slope of regression lines (analysis of covariance) compared with values at normal end-diastolic pressure, $\mathrm{P}<0.05$. The moment of maximum dplw/dt was used as the time reference for electrical activation.

nor the intercept could be estimated very accurately due to the limited number of measurements within an experiment. Therefore, the standard errors of the estimates are presented. However, because variances in the accurately measured $e_{f}$ or $t_{e a}$ had a biological origin, we preferred the use of standard deviations. When pooling the data on slopes and intercepts, the variance of these parameters might be of biological rather than analytical origin too. Therefore, 
the use of standard deviations is also to be preferred in this case. Pooling the derived linear equations for both normal and increased end-diastolic pressures yielded the following relation:

$$
e_{\mathrm{f}}=\mathrm{a} t_{\mathrm{ea}}+\mathrm{b}
$$

where $a=-3.46 \pm 0.73 \mathrm{~s}^{-1}$ and $b=-0.28 \pm$ 0.05 . Within a range of activation times of -40 to $-80 \mathrm{~ms}$, $\mathrm{e}_{\mathrm{f}}$ was estimated with an accuracy of $\pm 0.026( \pm \mathrm{SE})$ using this equation.

On further examination, this relation appeared to be influenced by end-diastolic pressure. In Table 3 the results of the linear regression analysis are summarized for normal enddiastolic pressures. In the individual experiments, the slopes of the linear equations were found not to be mutually different. Pooling all the derived linear equations yielded: $a=-3.96 \pm$ $0.53 \mathrm{~s}^{-1}$ and $\mathrm{b}=-0.30 \pm 0.04$. During pacing from the right atrium, tea in the region of interest was $-49.7 \mathrm{~ms}$ on the average. Using the relations presented in Table 3 , the corresponding estimate of $e_{f}$ was $-0.102 \pm 0.018$ (mean $\pm S D$ ). The estimated accuracy was \pm 0.028 ( $\pm \mathrm{SE}$ ). The estimated $e_{f}$ was not significantly different from mean measured $e_{f}$.

When end-diastolic pressure was elevated, the combination of the slightly later electrical activation (Fig. 4B), the increase in fiber shortening during atrial pacing, and the decrease in the gradient of fiber shortening during ventricular pacing (Fig. 4D) generally resulted in a decrease of the estimated slope of the linear equation. The degree of estimated $e_{f}$ during the ejec- tion phase, while the heart was paced from the right atrium, increased (Fig. 5D; Table 4). In Table 4 the results of the linear regression analysis for elevated end-diastolic pressure are summarized. The slopes of the linear equations were not different between the individual experiments. Pooling all the derived linear equations yielded: $a=-2.86 \pm 0.41 \mathrm{~s}^{-1}$ and $\mathrm{b}=-0.25 \pm$ 0.04 .

When end-diastolic pressure was elevated, $t_{e a}$ in the region of interest was $-45.8 \mathrm{~ms}$ on the average during pacing from the right atrium. Using the relations presented in Table 4 , the corresponding estimate of $\mathrm{e}_{\mathrm{f}}$ during the ejection phase was $-0.116 \pm 0.009$ (mean \pm SD). The estimated accuracy was \pm 0.024 ( \pm SE). Estimated $e_{f}$ was not significantly different from mean measured $e_{f}$.

\section{Discussion}

The major objective of the present study was to determine the relation between the moment of regional epicardial electrical activation and the degree of regional subepicardial fiber strain. To this end, electrical activation and fiber shortening were measured at various sites of the epicardium of the left ventricular free wall when the heart was paced from the right atrium, the left ventricular free wall, the left ventricular apex or the right ventricular outflow tract, while left ventricular end-diastolic pressure was normal $(1.1 \mathrm{kPa})$ or increased $(1.8 \mathrm{kPa})$ by means of volume-loading. Activation time has been defined as the time interval between a time refer- 
ence and the moment of regional electrical activation. Our results indicate that the choice of the time reference is important. When using electrophysiological events to define the moment of electrical activation, the correlation between the electrical activation time and the amount of fiber shortening during the ejection phase was poorer than when using the moment of maximum $\mathrm{dplv} / \mathrm{dt}$. Using the latter hemodynamically based time reference, linear regression analysis revealed that, within a range of activation times of -40 to $-80 \mathrm{~ms}$, fiber strain was estimated with an accuracy of $\pm 0.026( \pm S E)$. The slope of the mean linear equation between subepicardial fiber strain during the ejection phase and regional activation time was $-3.46 \pm 0.73 \mathrm{~s}^{-1}$, while the offset was $-0.28 \pm 0.05$. Moreover, the slope of the linear equation appeared to depend on end-diastolic pressure being $-3.96 \pm$ $0.53 \mathrm{~s}^{-1}$ and $-2.86 \pm 0.4 .1 \mathrm{~s}^{-1}$ for normal and elevated end-diastolic pressure respectively.

The slope of the relation under study reflects the increase in fiber strain during the ejection phase when the time difference between the moment of regional electrical activation and the moment of maximum $\mathrm{dp}_{\mathrm{I}} / \mathrm{dt}$ decreases. Because the range of regional activation times was the same for both normal and elevated enddiastolic pressures, the decreased slope during elevated end-diastolic pressure indicates that inhomogeneities in fiber shortening are less pronounced when myocardial contractile force is increased. The decreased slope when end-diastolic pressure is elevated is mainly caused by the decreased inhomogeneity in fiber shortening during ventricular pacing. When end-diastolic pressure was elevated, fiber shortening did not become more homogeneous during right atrial pacing, as can be noticed from the standard deviation of measured fiber strain shown in Tables 3 and 4.

A possible explanation for the more reproducible linear relationship between regional subepicardial fiber strain and regional electrical activation time, when using a hemodynamical time reference instead of an electrophysiological one, might be related to variations in the time interval between the very first activation of ventricular myocardium, completion of electrical activation and the moment of fast increase of left ventricular pressure. During a normal cardiac beat, electrical activation of the left ventricle is initiated from the atrium. Once the electrical impulse enters the bundle of His, which merges into the Purkinje fibers, transmission becomes very rapid, providing a relatively synchronous activation of the ventricular myocardium $[6$, 26]. This moment is indicated by the center of the QRS-complex. Ventricular pressure then rises quickly because the whole left ventricular cavity is surrounded by simultaneously activated myocardium. During ventricular stimulation, the ventricle depolarizes first by muscular conduction. After a few tens of milliseconds, fast depolarization of the Purkinje fibers occurs and the remaining part of the ventricle is activated within a short time $(25-35 \mathrm{~ms},[16])$. At this point the cavity is completely surrounded by mechanically cooperating activated tissue so that escape of volume in a soft, inactivated 
bulge is no longer possible and ventricular pressure rises [8]. The fast rise in ventricular pressure follows the initial electrical activation by various delays, depending on the mode of activation and the anatomy of the conduction system. At the moment of mechanical activation, the timing of loading of the myocardium is very critical. If loading is earlier than mechanical contraction, prestretch occurs whereas if loading is later, the muscle is free to contract before it is loaded. On a theoretical basis, the level of regional myocardial fiber stress is directly related to the level of left ventricular pressure [3]. When left ventricular pressure rises, regional wall stress increases synchronously, and load is applied synchronously to all fibers in the wall. The time interval between the moment of regional electrical activation and the moment at which left ventricular pressure increases rapidly may very well reflect the time between regional electrical activation and regional loading. In contrast, electrophysiological phenomena, like the moment at which the stimulus was given or the onset or the center of the QRS-complex, are moments in time which are not directly related to regional loading conditions. Apparently, the correlation between electrical activation time determined from electrophysiological time references and the degree of mechanical contraction is weak.

In the present study we did not manipulate cardiac afterload. An increase in afterload might be expected to cause a decrease of fiber shortening during the ejection phase, thus leading to a shift of the relation between electrical activation time and fiber shortening to smaller values of shortening. The relation between differences in regional activation time and differences in regional fiber shortening is also likely to be dependent on afterload. With increased afterload, muscle fibers shorten less for the same contracting force. This results in a decrease of the slope of the relation between the moment of regional electrical activation and regional fiber shortening. Therefore, variations in afterload - not controlled in the present study - might be responsible for the remaining variance in the relation between regional electrical activation time and regional fiber shortening (Tables 3,4 ).

The remaining variance in the relation between regional electrical activation time and regional fiber shortening may also be explained by the fact that electrical activation and mechanical measurements were not made simultaneously. Electrical activation was measured by a non-deformable electrode brush. Application of the brush to the epicardial surface deformed the heart slightly due to the force needed to guarantee electrical contact. Spatial matching of electrical and mechanical data can be achieved with high accuracy only when the position of the electrode brush on the epicardial surface is stable. During asynchronous electrical activation, early-activated regions already shorten while other areas covered by the electrode brush are not yet activated. This may hamper a stable positioning of the brush and, hence, exact matching of the regions in which the electrical and mechanical measurements were performed. Furthermore, in a number of experiments the 
time course of the left ventricular pressure development changed and, hence, the moment of maximum dplv/dt was shifted up to $5 \mathrm{~ms}$ compared with the mechanical measurements. The sampling frequency of deformation is $50 \mathrm{~Hz}$, which is the frame rate of the video system used. Contrary to intuition, a rate with time intervals of $20 \mathrm{~ms}$ enables a resolution of the order of $\pm 5 \mathrm{~ms}$ ( $\pm \mathrm{SD}$ ) [5]. Nevertheless, it is to be expected that inaccuracies in the estimation of the relation between regional fiber strain and regional electrical activation time are mainly due to the time inaccuracy of the deformation measurement, because the sampling interval of the electrophysiological measurements was $1 \mathrm{~ms}$. Inaccuracies in the estimation of subepicardial fiber strain due to the projection of the curved epicardial surface on the flat video sensor element is zero in the center of the image, and is \pm 0.03 ( $\pm \mathrm{SE}$ ) in the corners [24]. However, strain measurement in the direction of the subepicardial fibers will be affected minimally by this because of the relatively low curvature in this direction. Besides, the hearts used in our study were sufficiently large.

During right atrial pacing the distribution of fiber strain at the left ventricular anterior free wall during the ejection phase is quite uniform. During ventricular pacing, electrical activation is asynchronous, causing fiber strain to become non-uniform. Early-activated fibers contract early and with a high shortening velocity during the isovolumic phase, causing a prestretch in serially connected, as yet non-activated fibers (Fig. 3). The prestretch induces an increase in contractile force of these fibers [21]. When finally activated, the late-activated fibers shorten vigorously during the ejection phase, counteracting further contraction of the early-activated fibers, which are likely to be partly deactivated [27] due to the period of fast shortening during the isovolumic phase. As a result, fiber strain during the ejection phase is considerably less in early-activated than in late-activated regions. A similar finding has been reported in an in vitro experiment with two asynchronously activated papillary muscles connected in series [28]. These inhomogeneities in the degree of regional fiber strain during the ejection phase are quantified by the slope of the relation between regional electrical activation time and regional subepicardial fiber strain during the ejection phase.

Because $10-12 \%$ shortening is a normal value for fiber strain during the ejection phase while the heart is synchronously activated, variations in regional electrical activation time of $30-40 \mathrm{~ms}$ cause differences in regional fiber shortening of the order of fiber shortening itself. It can be expected that such differences in regional electrical activation time and the correlated inhomogeneities in regional fiber shortening result in the deterioration of global left ventricular hemodynamic performance as was also found in other studies $[2,6-8,13,16,18,20$, $30]$. The finding that the decrease in hemodynamic performance was most pronounced during pacing from the right ventricular outflow tract is in agreement with the suggestion of Wiggers [31] that the degree of electrical asyn- 
chrony is proportional to the contractile strength of the left ventricle.

In general, compared with other open-thorax studies $[6,10,11]$, left ventricular peak systolic pressure and maximum $\mathrm{dp}_{\mathrm{lv}} / \mathrm{dt}$ during both synchronous and asynchronous electrical activation were relatively low. This might be ascribed to the use of pentobarbital - known for its negative inotropic effect [17] - as anesthetic. Besides, compared with closed-thorax experiments $[6,10,11]$, in open-thorax experiments there is no support for venous return by the thoraco-abdominal pump, resulting in a decrease in both end-diastolic left ventricular volume and contractility [25].

The electrical activation patterns as depicted in Fig. $4 \mathrm{~A}$ and $\mathrm{B}$ are in agreement with those reported in a previous study from our laboratory [23]. In our experiments electrical impulse propagation in the vicinity of the ventricular stimulation electrode was slower than at greater distances. This finding is in agreement with a slow muscular conduction near the ventricular pacing site, followed by a fast conduction once the Purkinje system is reached. In general, the depolarization wave radiates from the ventricular pacing electrode, and the magnitude of the area with muscular conduction is proportional to the distance between the pacing electrode and the left ventricular apex. The latter finding can be explained by the distribution of the Purkinje fibers. In the left ventricular apical region these fibers extend further into the wall (endo to epicard), providing a better opportunity for the propagation wave to reach the Purkinje fibers.
Besides, the Purkinje system is designed to conduct the electrical impulses from the left ventricular apex to the rest of the left ventricular wall.

\section{References}

1. Allessie MA, Hoeks APG, Schmitz GML, Reneman RS (1986) On-line mapping system for the visualization of the electrical activation of the heart. Int J Cardiac Imag 2: 59-63

2. Aoyagi $T$, lizuka $M$, Takahashi $T$, Ohya $T$, Serizawa $T$, Momomura $S$, Sato $H$, Mochizuki $T$, Matsui H, Ikenouchi H, Shin I, Ma Y, Sugimoto $\mathrm{T}$ (1989) Wall motion asynchrony prolongs time constant of left ventricular relaxation. Am I Physiol 257: H883-H890

3. Arts T, Bovendeerd PHM, Prinzen FW, Reneman RS (1991) Relation between left ventricular cavity pressure and volume and systolic fiber stress and strain in the wall. Biophys J 59: 93-102

4. Arts T, Veenstra PC, Reneman RS (1982) Epicardial deformation and left ventricular wall mechanics during ejection in the dog. Am J Physiol 243: H379-H390

5. Augustijn $\mathrm{CH}$, Arts T, Prinzen FW, Reneman RS (1991) Mapping the sequence of contraction of the canine left ventricle. Pflügers Arch (Eur J Physiol) 419: 529-533

6. Badke FR, Boinay P, Covell JW (1980) Effect of ventricular pacing on regional left ventricular performance in the dog. Am J Physiol 238: H858H867

7. Baller D, Wolpres HG, Zipfel J, Brettschneider HJ, Hellige G (1988) Comparison of the effects of right atrial, right ventricular apex and atrioventricular sequential pacing on myocardial oxygen consumption and cardiac efficiency: a laboratory investigation. Pace 11: 394-403 
8. Burkhoff D, Oikawa RY, Sagawa K (1986) Influence of pacing site on canine left ventricular contraction. Am J Physiol 251: H428-H435

9. de Jong PGM, Arts T, Hoeks APG, Reneman RS (1990) Determination of tissue motion velocity by correlation interpolation of pulsed ultrasonic echo signals. Ultrasonic Imaging 12: 84-98

10. Grover M, Glantz SA (1983) Endocardial pacing site affects left ventricular end-diastolic volume and performance in the intact anesthetized dog. Circ Res 53: $72-85$

11. Heyndrickx GR, Vilaine JP, Knight DR, Vatner S (1985) Effects of altered site of electrical activation on myocardial performance during inotropic stimulation. Circulation 71: 1010-1016

12. Hoeks APG, Schmitz GML, Allessie MA, Jas H, Hollen SI, Reneman RS (1988) Multichannel storage and display system to record the electrical activity of the heart. Med \& Biol Eng \& Comput 26: 434-438

13. Hotta $S$ (1967) The sequence of mechanical activation of the ventricle. Jpn Circ J 31: 1568-1572

14. Kaufmann RL, Lab MJ, Hennekes R, Krause $H$ (1971) Feedback interaction of mechanical and electrical events in the isolated mammalian ventricular myocardium (cat papillary muscle). Pflügers Arch (Eur J Physiol) 324: 100-123

15. LeWinter MM, Kent RS, Kroener JM, Carew TE, Covell JW (1975) Regional differences in myocardial performance in the left ventricle of the dog. Circ Res 37: 191-199

16. Lister JW, Klotz DH, Jomain SL, Stuckey JH, Hoffman B (1964) Effect of pacemaker site on cardiac output and ventricular activation in dogs with complete heart block. Am J Cardiol 14: 494-503

17. Manders WT, Vatner SF (1976) Effects of sodium pentobarbital anesthesia on left ventricular function and distribution of cardiac output in dogs, with particular reference to the mechanism for tachycardia. Circ Res 39: 512-517

18. Miyazawa K, Shirato K, Haneda T, Honna T, Arai
$T$, Nakajima T(1976) Effects of varying pacemaker sites on left ventricular performance. I Exp Med $120: 301-308$

19. Muijtiens AMM, Roos JMA, Prinzen TT. Arts T (1990) Noise reduction in estimating epicardial deformation from marker tracks. Am J Physiol 258: H599-1605

20. Park RC, Little WC, ORourke RA (1985) Effect of alteration of left ventricular activation sequence on the left ventricular end-systolic pressure-volume relation in closed-chest dogs. Circ Res 57: 706-717

21. Pollack GH, Krueger JW (1976) Sarcomere dynamics in intact cardiac muscle. Eur J Cardiol 4 (suppl): 53-65

22. Prinzen FW, Augustijn CH, Allessie MA, Arts T, Delhaas T, Reneman RS (1992) The time sequence of electrical and mechanical activation during spontaneous beating and ectopic stimulation. Eur Heart J 13: 535-543

23. Prinzen FW, Augustijn CH, Arts T, Allessie MA, Reneman RS (1990) Redistribution of myocardial fiber strain and blood flow by asynchronous electrical activation. Am J Physiol 259: H300-H308

24. Prinzen TT, Arts T, Prinzen FW, Reneman RS (1986) Mapping of epicardial deformation using a video processing technique. J Biomech 19:263-273

25. Rushmer RF (1954) Shrinkage of the heart in anesthetized, thoracotomized dogs. Circ Res 2: 22-27

26. Scher AM, Spach MS (1979) Cardiac depolarization and repolarization and the electrocardiogram. In: Berne RM (Ed) Handbook of physiology, section 2: The cardiovascular system. American Physiological Society, Bethesda, pp 357-392

27. ter Keurs HEDJ, Rijnsburger WH, van Heuningen $R$, Nagelsmil MJ (1980) Tension development and sarcomere length in rat cardiac trabeculae; evidence of length-dependent activation. Circ Res 46: 703 714

28. Tyberg J, Parmley WW, Sonnenblick FH (1969) In-witro studies of myocardial asynchrony and regional hypoxia. Circ Res 25: 569-579 
29. van Heuningen $\mathrm{R}$, Rijnsburger WH, ter Keurs HEDJ (1982) Sarcomere length control in striated muscle. Am J Physiol 242: H411-H420

30. Waldman LK, Covell JW (1987) Effects of ventricular pacing on finite deformation in canine left ven- tricles. Am J Physiol 252: H1023-H1030

31. Wiggers CJ (1925) The muscular reactions of the mammalian ventricles to artificial surface stimuli. A.m If Physiol 73: 346-378 


\section{SUBEPICARDIAL FIBER STRAIN AND STRESS AS RELATED TO LEFT VENTRICULAR PRESSURE AND VOLUME}

Tammo Delhaas, Theo Arts*, Peter H.M. Bovendeerd*, Frits W. Prinzen and Robert S. Reneman

Departments of Physiology and Biophysics*,

Cardiovascular Research Institute Maastricht,

University of Limburg, P.O.Box 616,

NL-6200 MD Maastricht, The Netherlands.

Published in: Am J Physiol (1993) 264: H1548-H1559 
Abstract. In a mathematical model of the mechanics of the left ventricle (LV) by Arts and coinvestigators [1], assuming uniformity of fiber stress and fiber strain in the wall during the ejection phase, fiber stress $\left(\sigma_{f}\right)$ and fiber strain $\left(\Delta \mathrm{e}_{\mathrm{f}}\right)$ were related to $\mathrm{LV}$ cavity pressure ( $\mathrm{p}_{\mathrm{lv}}$ ), LV cavity volume $\left(\mathrm{V}_{\mathrm{IV}}\right)$ and wall volume $\left(\mathrm{V}_{\mathrm{W}}\right)$ by the following pair of equations: $\sigma_{\mathrm{f}}=\mathrm{p}_{\mathrm{lv}}$ $\left(1+3 V_{\mathrm{lv}} / \mathrm{V}_{\mathrm{w}}\right)$ and $\mathrm{e}_{\mathrm{f}}=1 / 3 \ln \left(1+3 \mathrm{~V}_{\mathrm{lv}} / \mathrm{V}_{\mathrm{w}}\right)$. The ratio $V_{l v} / V_{w}$ appeared to be the most important geometric parameter, while the actual LV shape was of minor importance. The relations on fiber strain and stress were evaluated experimentally in 6 anesthetized open-thorax dogs during normal and elevated (volumeloading) end-diastolic LV pressure. Subepicardial $e_{f}$ was measured simultaneously in 16 adjacent regions of the $\mathrm{LV}$ anterior wall, using optical markers which were attached to the epicardial surface and recorded on video. Changes in $V_{\| v}$ were measured using 4 inductive coils sutured to the LV in a tetrahedral configuration. $V_{W}$ was measured post-mortem. During control as well as hypervolemia the following results were found. At the anterior free wall of the left ventricle, the slope of the estimated linear relationship between measured and calculated fiber strain was $1.017 \pm 0.168$ (mean $\pm S D$ ), which is not significantly different from unity. Calculated fiber stress corresponded qualitatively and quantitatively with experimental results reported on isolated cardiac muscle. Calculated subepicardial contractile work per unit of tissue volume was not significantly different from global pump work as normalized to wall vol- ume. These findings support the assumption of homogeneity of muscle fiber strain and stress in the left ventricular wall during the ejection phase. Furthermore, average values of fiber stress and strain can be estimated on the basis of measured left ventricular pressure and volume.

\section{Introduction}

The left ventricle is a cavity, enclosed by a thick-walled structure, consisting of muscle fibers embedded in a complex structure of cross-linked collagen [15]. The direction of the muscle fibers varies continuously across the wall. In the subepicardial layers the fibers follow the path of a left-handed helix around the cavity. In the mid-wall, the fibers are directed circumferentially, and in the subendocardial layers the fibers follow a right-handed helical path $[25,27]$.

Global left ventricular pump work, as expressed in terms of cavity pressure and ejected volume, is generated by the myocardial fibers. Regional mechanical work is expressed in terms of fiber stress and strain. To understand the mechanism of conversion of contractile work of myocardial tissue in the left ventricular wall to left ventricular pump work clearly, the relation between regional myocardial mechanics on the one hand, and global left ventricular pump function on the other, has to be known.

Global left ventricular pump function can be assessed by measurement of left ventricular pressure and cavity volume, or aortic and mitral flow. Assessment of regional myocardial me- 
chanics requires measurement of regional deformation and stress. Regional deformation may be assessed with ultrasonic dimension gauges [14], inductive coils [2], video recording of markers attached to the epicardial surface [22], biplane cineradiography of implanted radiopaque beads $[10,32]$ or magnetic resonance imaging [34]. It was found that fiber shortening during the ejection phase was quite uniformly distributed in a region of approximately $4 \times 6$ $\mathrm{cm}$ at the anterior free wall of the left ventricle [21]. Also transmurally, fiber shortening during the ejection phase is likely to be uniformly distributed $[10,20,32,34]$.

Measurement of fiber stress in vivo is difficult and probably not reliable because the local myocardial structure is easily damaged in the direct environment of the measuring site due to the insertion of the measuring device $[9,12]$. Therefore, a variety of mathematical models of cardiac mechanics, based on the laws of continuum mechanics, were designed to estimate fiber stress $[1,3,4,6,8,16]$. In models in which myocardial tissue was considered to be isotropic, stress and shortening were predicted to be approximately twice as high in the endocardial as in the epicardial layers $[8,16]$. In models considering the anisotropic structure of the cardiac wall, transmural differences in fiber stress and shortening were significantly reduced $[1,3,4,6]$. When choosing an anatomically realistic transmural distribution of fiber direction in the wall, transmural differences in mechanical load could be made uniform with less than $\pm 10 \%$ deviation from the average stress and strain values [3]. Moreover, when using the hypothesis of homogeneous distribution of fiber stress as a modeling parameter for the transmural distribution of fiber direction in the left ventricular wall, a transmural distribution of fiber direction within the range of anatomical findings for this parameter [25] was found [5].

If fiber stress and strain are uniformly distributed in the left ventricular wall, as a consequence, regional contractile work per unit of tissue volume has to be uniformly distributed too. In the normal left ventricle, regional differences in mechanical load of myocardial fibers are likely to be small, as indicated by a number of physiological experiments. The transmural distribution of blood flow, oxygen consumption, enzyme activities and concentrations of substrates is generally found to be quite homogeneous $( \pm 10 \%)$, indicating that energy requirements are evenly distributed across the left ventricular wall. This supports the idea of a homogeneous distribution of mechanical load, and so of fiber stress and strain in the left ventricular wall (see [28] for review).

In a model by Arts and co-investigators [1] the finding that fiber stress and strain during systole might be uniformly distributed throughout the left ventricular wall was used to estimate these regional quantities from global quantities such as left ventricular pressure, cavity volume, and wall volume. The assumptions made are briefly recapitulated below:

- The thick-walled left ventricle is rotationally symmetric.

- The myocardium consists of muscle fibers em- 
bedded in soft incompressible material.

- Muscle fibers do not cross from the subendocardium to the subepicardium.

- Equilibrium of stresses and external forces is satisfied in the left ventricular wall.

- Fiber stress and fiber strain during systole are uniformly distributed throughout the left ventricular wall, and may therefore be expressed by single values valid for the whole wall.

- During systole, the myocardial fibers are activated and bear stress far above the passive stress levels associated with diastole. Therefore, stresses and mechanical work of the passive, soft material surrounding the muscle fibers, can be neglected.

In this model [1] the dimensionless ratio of left ventricular pressure $\left(\mathrm{p}_{\mathrm{v}}\right)$ and fiber stress $\left(\sigma_{f}\right)$ during the ejection phase was found to depend mainly on the dimensionless ratio of left ventricular cavity $\left(\mathrm{V}_{\mathrm{lv}}\right)$ to wall volume $\left(\mathrm{V}_{\mathrm{w}}\right)$ by:

$$
\frac{\sigma_{\mathrm{f}}}{\mathrm{p}_{\mathrm{Iv}}}=1+3 \frac{\mathrm{v}_{\mathrm{lv}}}{\mathrm{V}_{\mathrm{w}}}
$$

The geometry of the wall appeared to be of minor importance.

Assuming that the model by Arts et al. [1] accurately describes the kinetics of the left ventricle during systole, conservation of energy requires that incremental pump work is equal to total mechanical work of the wall:

$$
p_{I V} \Delta V_{l v}=\int_{V_{w}} \sigma_{f} \Delta e_{f} d V
$$

where $e_{f}$ represents fiber strain. Because fiber stress and fiber strain are assumed to be the same everywhere in the wall, Eq. (2) may be converted to:

$$
\frac{\Delta \mathrm{e}_{\mathrm{f}}}{\Delta \frac{\mathrm{V}_{\mathrm{lv}}}{\mathrm{V}_{\mathrm{w}}}}=\frac{\mathrm{p}_{\mathrm{lv}}}{\sigma_{\mathrm{f}}}
$$

Replacements of increments $(\Delta)$ by differentials, followed by integration of Eq. (3) with respect to $\mathrm{V}_{\mathrm{IV}}$ reveals that instantaneous fiber length during ejection depends solely on the instantaneous ratio of left ventricular cavity volume to wall volume by:

$$
\mathrm{e}_{\mathrm{f}}=\ln \frac{\mathrm{l}_{\mathrm{f}}}{\mathrm{l}_{\mathrm{f}, 0}}=\frac{1}{3} \ln \left[1+3 \mathrm{~V}_{\mathrm{lv}} / \mathrm{V}_{\mathrm{w}}\right]
$$

in which $\mathrm{l}_{\mathrm{f}}$ represents actual fiber length and $\mathrm{l}_{\mathrm{f}, 0}$ represents extrapolated fiber length at zero left ventricular cavity volume. Combining the equations for fiber length at the begin and at the end of the ejection phase, the following equation for fiber strain in the left ventricular wall during ejection $\left(e_{f, b e, e e}\right)$ was derived:

$$
\begin{aligned}
\mathrm{e}_{\mathrm{f}, \mathrm{be}, \mathrm{ee}} & =\ln \frac{1_{\mathrm{f}, \mathrm{ee}}}{\mathrm{l}_{\mathrm{f}, \mathrm{be}}} \\
& =\frac{1}{3} \ln \left[\frac{1+3 \mathrm{~V}_{1 \mathrm{v}, \mathrm{ee}} / \mathrm{V}_{\mathrm{w}}}{1+3 \mathrm{~V}_{\mathrm{lv}, \mathrm{be}} / \mathrm{V}_{\mathrm{w}}}\right]
\end{aligned}
$$


in which subscripts be and ee refer to begin and end of the ejection phase, respectively.

In the present study, the proposed relations by Arts and co-investigators [1] between left ventricular pressure, cavity volume and wall volume on the one hand, and regional fiber stress and strain in the wall on the other were evaluated experimentally. The applicability of the proposed model was first tested by comparing calculated fiber strain, using Eq. (5), with measured subepicardial fiber strain, using a video technique, since these two estimations of fiber strain are independent of each other. The principle of conservation of energy was the only necessary assumption to derive the equation on fiber strain from the equation on fiber stress. Therefore, non significant differences between calculated and measured fiber strain are interpreted as an indication of the applicability of the equations for fiber stress and strain. Fiber stress, as calculated according to Eq. (1), was assessed with regard to experimental findings reported in literature, both on the intact left ventricle and isolated cardiac muscle. Moreover, regional contractile work per unit of tissue volume, as calculated from the integral of calculated fiber stress with respect to measured fiber strain, was compared with global pump work as normalized to wall volume. Volume loading was used as an intervention to obtain different situations within each experiment with regard to left ventricular end-diastolic volume, and enddiastolic and maximum left ventricular pressure.

\section{Methods}

\section{Experimental techniques}

Animal preparation and instrumentation. Six adult mongrel dogs of either sex, ranging in weight from 23 to $37 \mathrm{~kg}$ were premedicated with an intramuscular injection of Hypnorm (1 ml. $\mathrm{kg}^{-1} ; 1 \mathrm{ml}$ Hypnorm contains $10 \mathrm{mg}$ fluanisone and $0.2 \mathrm{mg}$ fentanyl base). Anesthesia was induced with an intravenous injection of pentobarbital sodium (10 mg. $\mathrm{kg}^{-1}$ ) and was maintained, after endotracheal intubation, with nitrous oxide $\left(33 \% \mathrm{O}_{2}, 67 \% \mathrm{~N}_{2} \mathrm{O}\right)$ and a continuous infusion of pentobarbital sodium ( 2 $\left.\mathrm{mg} \cdot \mathrm{kg}^{-1} \cdot \mathrm{min}^{-1}\right)$. Ventilation was kept constant with a positive pressure respirator (Pulmomat, Dräger). The animal was placed on its right side, and body temperature was kept between 37.5 and $38.5^{\circ} \mathrm{C}$ by means of a thermostatically regulated heating pad. A standard limb lead electrocardiogram (ECG) was used. Arterial blood samples were taken periodically to determine $\mathrm{pO}_{2}, \mathrm{pCO}_{2}, \mathrm{pH}$, oxygen saturation and hemoglobin concentration (ABL 3, Radiometer). A sodium bicarbonate solution $(4.2 \%)$ was administered intravenously to adjust the acid-base balance when necessary.

The chest was opened through the left fifth intercostal space. After removal of the fifth rib, the pericardium was opened, and the heart was suspended in a pericardial cradle. Epicardial bipolar platinum pacing electrodes were sutured to the heart at the right atrium (Fig. 1). 
Left ventricular cavity and ascending aortic pressures were measured with catheter-tip micromanometers (Millar PC-470), inserted via the right brachial and femoral arteries, respectively. To enable pressure calibration during the experiment, the fluid-filled lumina of the catheter-tip micromanometers were connected via three-way cocks to an external pressure transducer (Electromedics MS20). The third opening of the three-way cock was connected to a reference pressure level, which was the right atrial level for all pressure measurements [3]. Ascending aortic volume flow was measured with an electromagnetic flow meter (Skalar Transflow 601).

To determine left ventricular cavity volume at end-diastole (Appendix A), four inductive coils were sutured to the epicardium of the left ventricle in a tetrahedral configuration, so that the length of each of the 6 edges was more or less equal.

ECG, pressure and ascending aorlic volume flow signals, as well as the 6 signals from the inductive coils were continuously visualized on an oscilloscope (Knott). These signals were also recorded on a paper recorder (Schwarzer) and a multichannel tape recorder (Ampex PR2200).

Mapping of left ventricular epicardial deformation. To determine two-dimensional epicardial deformation a video technique was used [22]. In brief, approximately 40 white markers were attached with tissue glue (Histoacryl) to the epicardial surface of the left ventricular anterior wall at mutual distances of approximately 6 $\mathrm{mm}$. The area covered with markers extended $3-4 \mathrm{~cm}$ in the circumferential and $4-5 \mathrm{~cm}$ in the base-to-apex direction (Fig. 1). A video camera (Sony AVC $32500 \mathrm{CE}$ ) with a $200 \mathrm{~mm}$ tele-objective, positioned at a distance of $2.5 \mathrm{~m}$, and a mirror which was mounted above the heart at an angle of $45^{\circ}$ were used to record the motion of the markers on a video recorder (Sony SL-C9ES, Betamax) at a speed of 50 frames per second. To avoid blurring of the image, a video-triggered xenon flashlight illumination (Chadwick-Helmuth) was applied. To enable synchronization of hemodynamic data with deformation data, after frequency-modulation the left ventricular pressure signal was recorded on an audio channel of the video recorder.

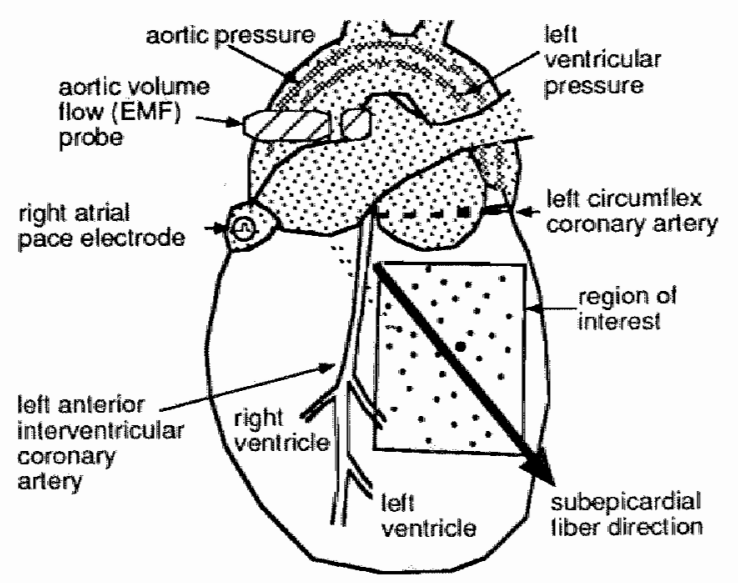

Fig. 1. Schematic representation of experimental setup. 
Experimental protocol. The direction of the subepicardial fibers and the long axis of the left ventricle were determined by visual inspection, and were indicated by a directed ruler, which was recorded on video (Fig. 1). Subsequently, two-dimensional echocardiographic imaging of the minor axis projection of the left ventricle at the equator was performed to obtain a reference left ventricular cavity volume at end-diastole (Appendix B). Minimum current and pace rate levels causing regular initiation of the electrical activation were determined. After $15 \mathrm{~min}$ of pacing, hemodynamic variables and epicardial deformation were recorded simultaneously. Subsequently hypervolemia was induced by rapid intravenous infusion of a polygeline infusion liquid (Haemaccel $^{(B)}$, Behringwerke AG). When end-diastolic pressure reached the level of $1.8 \mathrm{kPa}$ and was stable for more than $2 \mathrm{~min}$, infusion rate was decreased to a maintenance level. After $15 \mathrm{~min}$ the control measurements were repeated.

The experiment was terminated by administration of an overdose of pentobarbital sodium. Within 5 min thereafter, the heart was excised, the ventricles were removed from the atria, and were rinsed. To determine the volume of the left ventricular cavity at zero transmural pressure, the left ventricle was immersed in saline, keeping the base on top, just above the saline level. Subsequently, the content of the left ventricular cavity was withdrawn with a graded syringe. Thereafter the free wall of the right ventricle was dissected, and the weight of the left ventricle was determined.

\section{Data analysis}

Hemodynamics. After performing the experiment, the hemodynamic data as recorded on analog tape were sampled $(200 \mathrm{~Hz})$ and digitized using a 16-channel 12-bit A/D card (DASH 16G2), connected to a MS-DOS personal computer (Tulip AT Compact). Sampling and analysis were performed using a software package (ASYST 3.0, MacMillan Software Company) and software developed in our laboratory. In the cardiac cycle three events were determined. The end of the diastolic phase $\left(t_{e d}\right)$ was defined as the moment before ejection at which the rate of change of left ventricular pressure $\left(\mathrm{dp}_{\mathrm{lv}} / \mathrm{dt}\right)$ exceeded $10 \mathrm{kPa}^{-1} \mathrm{~s}^{-1}$ [14]. The beginning of the ejection phase (tbe) was determined by the moment at which left ventricular pressure exceeded end-diastolic aortic pressure. The duration of the isovolumic contraction phase $\left(\Delta t_{i c}\right)$ was calculated as the difference in time between $t_{e d}$ and $t_{b e}$. The duration of the ejection phase $\left(\Delta t_{e}\right)$ was determined from the aortic volume flow signal. From left ventricular pressure as a function of time $\left(\mathrm{plv}_{\mathrm{Iv}}(\mathrm{t})\right)$, end-diastolic left ventricular pressure $\left(\mathrm{p}_{\mathrm{v}, \mathrm{ed}}\right)$, maximum left ventricular pressure ( $p_{1 v, \max }$ ), and maximum first derivative of left ventricular pressure $\left(\mathrm{dplv}_{\mathrm{v}} / \mathrm{dt}_{\text {max }}\right.$ ) were determined. Besides, the following hemodynamic variables were determined: heart rate $\left(f_{h}\right)$, left ventricular cavity volume as a function of time $\left(\mathrm{V}_{\mathrm{lv}}(\mathrm{t})\right)$, maximum instantaneous ascending aortic flow (Qao,max), left ventricular cavity volume at begin-ejection $\left(V_{l v, b e}\right)$, wall volume $\left(V_{w}\right)$ and ejected volume 
$\left(\Delta V_{\mathrm{e}}\right)$. The latter variable was calculated as the time integral of ascending aortic volume flow (Qao).

Estimation of left ventricular cavity volume during systole was performed using the following techniques. A two-dimensional echocardiographic image of the minor axis projection at the equator of the left ventricle was used to calculate reference left ventricular cavity volume at enddiastole (Appendix B). During all following hemodynamic measurements, changes in enddiastolic volume, as compared to the reference situation, were determined by means of four inductive coils sutured to the left ventricle in a tetrahedral configuration (Appendix A). The instantaneous integral of ascending aortic volume flow was subtracted from measured end-diastolic volume to obtain left ventricular cavity volume at any moment during ejection. The diastolic aortic flow level was used as zero flow reference.

Measured instantaneous values of left ventricular pressure, cavity volume and wall volume were used to calculate average fiber stress and fiber strain according to Eq. (1) and (5), respectively.

Epicardial deformation. After the experiment 64 consecutive video frames $(50 \mathrm{~Hz}$ ) were digitized and stored in a 2 Mbyte digital video memory, coupled to a computer (PDP 1 1/73). Markers were detected, and the traces of the position of their center of gravity were determined. Incomplete traces were skipped from further analysis. Artifacts in motion due to differences between odd and even video frames were excluded by averaging the marker positions in successive video frames. The marker positions thus obtained were filtered using a singular value decomposition (SVD) filtering technique [17]. The area in which the deformation was analyzed was subdivided into $4 \times 4$ mutually overlapping regions. Epicardial deformation was estimated in each region and for each frame from the SVDfiltered marker positions by means of a leastsquares criterion [22]. Because we were interested in the relationship between regional fiber strain and the ratio of left ventricular cavity volume to wall volume during systole, mid-ejection was taken as a temporary reference for deformation. Epicardial deformation during the ejection phase was expressed in terms of a natural strain in the direction of the subepicardial fibers $\left(e_{f}\right)$ by:

$$
e_{\mathrm{f}}=\ln \frac{1_{\mathrm{f}}}{l_{\mathrm{f}, \mathrm{me}}}
$$

in which $I_{f}$ and $I_{f, m e}$ represent epicardial segment length along the subepicardial fiber direction in the actual situation and at mid-ejection, respectively. In the analysis, measured regional fiber strain in the corners of the area of interest was excluded, because projection of the curved epicardial surface on the flat video sensor element causes distortion. The related error is zero in the center of the image and most pronounced at the edges [22].

Regional subepicardial contractile work per 
unit of tissue volume $\left(\mathrm{E}_{\mathrm{reg}}\right)$ was estimated during ejection from the integral of calculated fiber stress with respect to measured regional fiber strain, as averaged over the 12 central regions $\left(\overrightarrow{e_{f}}\right)$ :

$$
E_{\text {reg }}=\int_{b e}^{e e} \sigma_{f} d \overrightarrow{e_{f}}
$$

be and ee indicate the begin and the end of the ejection phase, respectively.

Comparison of measured and predicted fiber strain. Regionally measured subepicardial fiber strain as well as predicted fiber strain during systole were plotted as a function of normalized cavity volume $\left(\mathrm{V}_{\mathrm{lv}} / \mathrm{V}_{\mathrm{w}}\right)$. After exclusion of the regions at the four corners, for the remaining 12 regions in which deformation was measured, it was tested whether the relation between measured subepicardial fiber strain during the ejection phase $\left(e_{f, e, m e a s}\right)$ and average fiber strain during the ejection phase calculated according to Eq. (5) $\left(e_{f, e, p r e d}\right)$ could be described by:

$$
e_{f, e, \text { meas }}=a+b e_{f, e, p r e d}
$$

The slopes of the thus obtained linear equations, which ideally should be 1 , will be referred to as $b_{i}$, with i referring to the region $(1 \leq i \leq 12)$. For the control as well as the hypervolemic state, the Wilcoxon signed-rank test was applied to test whether these slopes were statistically significantly different from 1 .
Comparison of calculated and measured stroke volume. To evaluate the reliability of Eq. (5), stroke volume $\left(\Delta V_{\text {calc }}\right)$ was calculated from measured subepicardial fiber strain as averaged over the 12 epicardial regions, wall volume and left ventricular cavity volume at the beginning of the ejection phase. Using Eq. (5) it holds:

$$
\Delta \mathrm{V}_{\text {calc }}=
$$

$$
\left(v_{l v, b e}+\frac{v_{w}}{3}\right)\left(1-\exp \left(3 \bar{e}_{f}\right)\right)
$$

This stroke volume was compared with stroke volume $\left(\Delta \mathrm{V}_{\mathrm{Qao}}\right)$ as calculated by time integration of instantaneous aortic volume flow.

Comparison of regional contractile work and normalized pump work. For the ejection phase subepicardial contractile work per unit of tissue volume was estimated from the integral of calculated fiber stress with respect to measured subepicardial fiber strain as averaged over the 12 epicardial regions. Global pump work during the ejection phase, as estimated from the time integral of left ventricular pressure and changes in left ventricular volume, was normalized by left ventricular wall volume. For the control as well as the hypervolemic situation in each experiment, a linear regression analysis was applied to mean subepicardial contractile work per unit of tissue volume and normalized global pump work. 
Statistical analysis. The effect of hypervolemia on hemodynamics and deformation was evaluated for statistical significance, using the values obtained during control in the same animal as a reference, by applying the Sign test $(n=5)$. Differences between deformation variables as predicted by the model and as measured were tested on significance applying, either the Wilcoxon matched-pairs signed-rank test in the control situation $(n=6)$ or the Sign test in the hypervolemic situation $(\mathrm{n}=5)$. A value of $\mathrm{P}<$ 0.05 was considered to be a significant difference. The data are presented as mean \pm SD.

\section{Results}

In one out of 6 experiments, hemodynamic and epicardial deformation data are only available for the control situation, because ventricular fibrillation occurred during the experiment.

\section{Hemodynamics}

Hemodynamic data are summarized in Table 1. Comparison of values obtained during control with those obtained during hypervolemia, reveals that all hemodynamic variables were affected significantly by the intravenous infusion of the polygeline infusion liquid, except for heart rate, the duration of the isovolumic contraction phase, and the maximum first derivative of left ventricular pressure. The intended increase of cardiac preload was successful, as is shown by the increase of end-diastolic pressure from $1.1 \pm 0.2$ to $1.9 \pm 0.2 \mathrm{kPa}$ (mean $\pm \mathrm{SD}$ ).
The duration of the ejection phase increased from $178 \pm 9$ to $211 \pm 24 \mathrm{~ms}$. Maximum left ventricular pressure and its first derivative with respect to time increased from $13.2 \pm 2.0$ and $188 \pm 32$ to $16.7 \pm 2.6 \mathrm{kPa}$ and $207 \pm 39$ $\mathrm{kPa} . \mathrm{s}^{-1}$, respectively, indicating an increase in contractile force. Maximum instantaneous aortic volume flow increased from $209 \pm 55$ to $253 \pm$ $47 \mathrm{ml} . \mathrm{s}^{-1}$ and stroke volume from $22.8 \pm 4.4$ to $34.5 \pm 4.4 \mathrm{ml}$. As a consequence of the induced hypervolemia, the hearts were dilated. The ratio of left ventricular cavity volume to left ventricular wall volume at begin-ejection increased from $0.37 \pm 0.09$ to $0.57 \pm 0.06$. Normalized cavity volume at zero transmural left ventricular pressure was $0.29 \pm 0.05$.

\section{Epicardial deformation}

For each experiment, regional subepicardial fiber strain was calculated for one single cardiac cycle for the control as well as the hypervolemic state. Typical recordings of subepicardial fiber strain as a function of time for the control situation are depicted in Fig. 2, which is a compilation of 16 plots. Fiber length at mid-ejection was used as a temporary reference length. The pattern of fiber strain in the various regions was almost uniform. Shortening of the fibers began during the isovolumic contraction phase, and was more pronounced during the ejection phase.

Values of subepicardial fiber strain during the isovolumic contraction and the ejection phase, as averaged over the 12 central regions 
Table 1. Hemodynamic variables in the control $(\mathrm{C})$ and the hypervolemic $(\mathrm{H})$ situation.

\begin{tabular}{|c|c|c|c|c|c|c|c|c|c|}
\hline \multirow{2}{*}{ Variable } & & \multicolumn{6}{|c|}{ Experiment } & \multirow[b]{2}{*}{ Mean } & \multirow[b]{2}{*}{ S D } \\
\hline & & 1 & 2 & 3 & 4. & 5 & 6 & & \\
\hline \multirow[t]{2}{*}{$\mathrm{f}_{\mathrm{h}}\left(\right.$ beat $\left.\min ^{-1}\right)$} & $\mathrm{C}$ & 67 & 99 & 85 & 90 & 92 & 66 & 83 & 12 \\
\hline & $\mathrm{H}$ & & 110 & 85 & 90 & 68 & 82 & 87 & 14 \\
\hline \multirow[t]{2}{*}{$\Delta \mathrm{t}_{\mathrm{ic}}(\mathrm{ms})$} & $\mathrm{C}$ & 40 & 62 & 63 & 70 & 55 & 57 & 58 & 9 \\
\hline & $\mathrm{H}$ & & 60 & 67 & 72 & 48 & 73 & 64 & 9 \\
\hline \multirow[t]{2}{*}{$\Delta t_{\mathrm{e}}(\mathrm{ms})$} & $\mathrm{C}$ & 195 & 170 & 170 & 172 & 183 & 177 & 178 & 9 \\
\hline & $\mathrm{H}$ & & 187 & 195 & 202 & 255 & 215 & $211 *$ & 24 \\
\hline \multirow[t]{2}{*}{ Plv,ed $(\mathrm{kPa})$} & C & 0.7 & 1.5 & 1.0 & 1.2 & 1.1 & 1.3 & 1.1 & 0.2 \\
\hline & $\mathrm{H}$ & & 2.1 & 1.4 & 2.0 & 1.8 & 2.0 & $1.9^{*}$ & 0.2 \\
\hline \multirow[t]{2}{*}{ Plv, max $(\mathrm{kPa})$} & $\mathrm{C}$ & 9.6 & 14.7 & 12.3 & 15.6 & 12.8 & 14.3 & 13.2 & 2.0 \\
\hline & $\mathrm{H}$ & & 16.6 & 14.5 & 21.4 & 14.0 & 17.0 & 16.7 将 & 2.6 \\
\hline \multirow[t]{2}{*}{$\mathrm{dplv} / \mathrm{dt}_{\max }\left(\mathrm{kPa}^{-1}\right)$} & $\mathrm{C}$ & 140 & 240 & 168 & 183 & 183 & 212 & 188 & 32 \\
\hline & $\mathrm{H}$ & & 267 & 169 & 231 & 163 & 207 & 207 & 39 \\
\hline \multirow[t]{2}{*}{$\mathrm{Q}_{\mathrm{ao}, \max }\left(\mathrm{ml} \cdot \mathrm{s}^{-1}\right)$} & $\mathrm{C}$ & 118 & 298 & 198 & 234 & 182 & 224 & 209 & 55 \\
\hline & $\mathbb{H}$ & & 330 & 207 & 286 & 217 & 226 & $253 *$ & 47 \\
\hline \multirow[t]{2}{*}{$V_{\mathrm{e}}(\mathrm{ml})$} & $\mathrm{C}$ & 15.6 & 29.0 & 21.0 & 23.6 & 20.4 & 27.0 & 22.8 & 4.4 \\
\hline & $\mathrm{H}$ & & 34.9 & 25.9 & 36.2 & 37.9 & 37.4 & 34.5 蟩 & 4.4 \\
\hline \multirow[t]{2}{*}{$\mathrm{V}_{\mathrm{I}, \text { be } / \mathrm{V}_{\mathrm{W}}}$} & $\mathrm{C}$ & 0.26 & 0.49 & 0.37 & 0.35 & 0.26 & 0.46 & 0.37 & 0.10 \\
\hline & $\mathrm{H}$ & & 0.53 & 0.48 & 0.60 & 0.58 & 0.67 & $0.57 *$ & 0.07 \\
\hline $\mathrm{V}_{0}, \mathrm{~V}_{\mathrm{W}}$ & & 0.38 & 0.28 & 0.28 & 0.30 & 0.23 & 0.26 & 0.29 & 0.05 \\
\hline $\mathrm{V}_{w}(\mathrm{ml})$ & & 109.5 & 135.2 & 122.9 & 158.1 & 147.6 & 118.1 & 131.9 & 16.9 \\
\hline Dog weight $(\mathrm{kg})$ & & 25 & 37 & 27 & 27 & 29 & 23 & 28 & 4 \\
\hline
\end{tabular}

Abbreviations: $f_{h}$, heart rate; $\Delta t_{i c}$, duration of isovolumic contraction phase; $\Delta t_{e}$, duration of ejection phase; plv,ed, left ventricular pressure at end diastole; $\mathrm{p}_{\mathrm{v}, \max }$, maximum left ventricular pressure; $\mathrm{dp} / \mathrm{w} / \mathrm{dt}_{\mathrm{max}}$, maximum first derivative of left ventricular pressure; $Q_{a 0, m a x}$, maximum instantaneous aortic volume flow; $V_{\mathrm{e}}$, ejected volume; $V_{\mid w, b e}$, cavity volume at beginning of the ejection phase $\mathrm{V}_{W}$, wall volume; $\mathrm{V}_{0}$, volume at zero transmural pressure; * $\mathbf{P}<0.05$ as compared with control (Sign test). 
Regional mechanics and global hemodynamics

Table 2. Relevant variables for epicardial deformation in the control (C) and the hypervolemic $(\mathrm{H})$ situation.

\begin{tabular}{|c|c|c|c|c|c|c|c|c|c|}
\hline \multirow[b]{2}{*}{ Variable } & & \multicolumn{6}{|l|}{ Experiment } & \multirow{2}{*}{\multicolumn{2}{|c|}{ Mean SD }} \\
\hline & & 1 & 2 & 3 & 4 & 5 & 6 & & \\
\hline \multirow[t]{2}{*}{$\mathrm{e}_{\mathrm{f}, \mathrm{ic}, \mathrm{meas}}$} & $\mathrm{C}$ & $.041 \pm .009$ & $.051 \pm .011$ & $-.023 \pm .005$ & $-.038 \pm .014$ & $.005 \pm .007$ & $-.049 \pm .010$ & $.0 .034^{\#}$ & .0117 \\
\hline & $\mathrm{H}$ & & $-.032 \pm .006$ & $-.008 \pm .009$ & $.010 \pm .006$ & $. .000 \pm .005$ & $-.003+.004$ & $-.011^{*}$ & .012 \\
\hline \multirow[t]{2}{*}{$e_{f, e, m e n t s}$} & $\mathrm{C}$ & $-.091 \pm .015$ & $.095 \pm .007$ & $-115 \pm .015$ & $.085 \pm .010$ & $.092 \pm .012$ & $-.112 \pm .006$ & -098 & .012 \\
\hline & $\mathrm{H}$ & & $-112 \pm 010$ & $-109 \pm 025$ & $-.097 \pm .008$ & $-147 \pm .016$ & $-.108 \pm .011$ &. .115 & .019 \\
\hline \multirow[t]{2}{*}{$e_{f,}$, pred } & 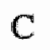 & -.091 & .101 & -093 & -083 & $\times .088$ & -.114 & -.095 & .011 \\
\hline & $\mathrm{H}$ & &. .119 & -.099 & -.094 & -.110 & -.126 &. $.110^{2 *}$ & .013 \\
\hline \multirow[t]{2}{*}{$\mathrm{V}_{\mathrm{lw}, \mathrm{be}} / \mathrm{V}_{\mathrm{w}}$} & $C$ & 0.2 .59 & 0.490 & 0.371 & 0.350 & 0.264 & 0.459 & 0.366 & 0.096 \\
\hline & $\mathrm{H}$ & & 0.529 & 0.484 & 0.604 & 0.579 & 0.674 & $0.574 *$ & 0.073 \\
\hline \multirow[t]{2}{*}{$\mathrm{V}_{\text {IV;ee }} / \mathrm{V}_{w}$} & $\mathrm{C}$ & 0.117 & 0.275 & 0.200 & 0.200 & 0.126 & 0.230 & 0.191 & 0.061 \\
\hline & $\mathrm{H}$ & & 0.271 & 0.274 & 0.374 & 0.322 & 0.376 & 0.323 & 0.051 \\
\hline \multirow[t]{2}{*}{$b_{i}$} & $\mathrm{C}$ & $0.929 \pm . \| 61$ & $0.920 \pm .075$ & $1.188 \pm .134$ & $1.006 \pm .103$ & $1.021 \pm .130$ & $0.968 \pm .044$ & 1.005 & 0.098 \\
\hline & $H$ & & $0.900 \pm .075$ & $1.072 \pm .220$ & $1.048 \pm .085$ & $1.267 \pm .155$ & $0.868 \pm .081$ & 1.031 & 0.159 \\
\hline \multirow[t]{2}{*}{$\mathrm{V}_{\text {short, max }}$} & $\mathrm{C}$ & $-0.989 \pm .167$ & $-1.034 \pm .100$ & $-0.986 \pm .102$ & $-0.847 \pm .125$ & $-0.783 \pm .1107$ & $-1.009 \pm .064$ & -0.941 & 0.101 \\
\hline & $\mathrm{H}$ & & $-1.037 \pm .1 .15$ & $-0.814 \pm .132$ & $-0.808 \pm .088$ & $-0.837 \pm .162$ & $-0.807 \pm .064$ & -0.861 & 0.099 \\
\hline \multirow[t]{2}{*}{$\sigma_{f, \max }(\mathrm{kPa})$} & $\mathrm{C}$ & 16.3 & 35.8 & 24.5 & 28.7 & 20.6 & 32.1 & 26.3 & 7.3 \\
\hline & $\mathrm{H}$ & & 39.2 & 31,6 . & 50.8 & 34.6 & 46.3 & $40.5 *$ & 8.0 \\
\hline
\end{tabular}

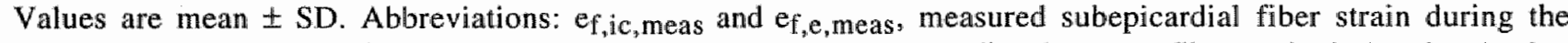
isovolumic contraction and the ejection phase, respectively; $\mathrm{e}_{\mathrm{f}, \mathrm{e}, \mathrm{pred}}$, predicted average fiber strain during the ejection phase; $V_{I v, b e} / V_{W}$ and $V_{I v, e d} / V_{W,}$, ratio of cavity volume to wall volume (normalized cavity volume) at begin- and endejection, respectively; $b_{\mathfrak{i}}$, slope of estimated linear relation between measured subepicardial fiber strain and $1 / 3 \ln (1+$ $3 \mathrm{~V}_{\mathrm{lv}} / \mathrm{V}_{\mathrm{w}}$ ); $\mathrm{v}_{\text {short, max }}$, maximum fiber strain rate; $\sigma_{\mathrm{f}, \max }$, maximum fiber stress. $* \mathrm{P}<0.05$ as compared with control (Sign test). $\mathrm{P}<0.05$ as compared with zero strain (Wilcoxon matched-pairs signed-rank test).

are presented in Table 2. For the control and the hypervolemic situation, fiber strain was nearly homogeneously distributed over the left ventricular anterior free wall during the ejection phase. This is indicated by the small standard deviation of measured regional fiber strain in the individual experiments (Table 2). During the isovolumic contraction phase in the control situation fiber shortening was significantly different from zero $(\mathbb{P}<0.05)$. The change in fiber length during the isovolumic contraction phase in the hypervolemic situation was not significantly different from zero. During the ejection phase fiber shortening was not significantly dif- 


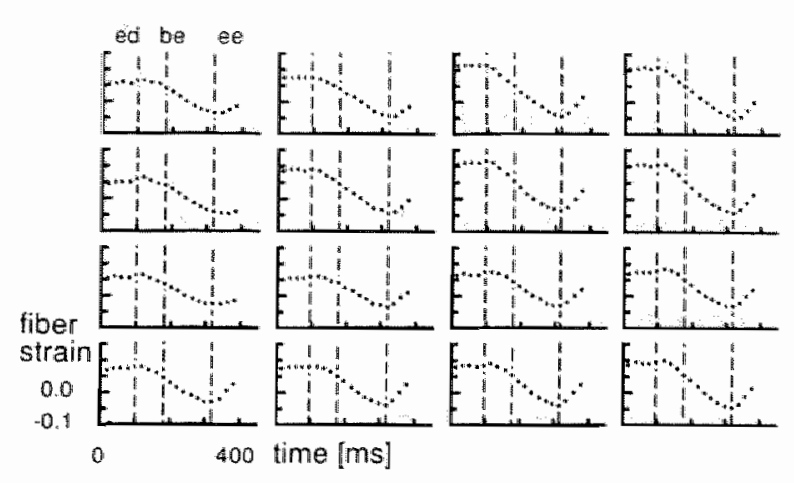

Fig. 2. Maps of measured subepicardial fiber strain ( $\left.\ln \left[1 / I_{m e}\right]\right)$ as a function of time as measured in 16 regions of the left ventricular anterior free wall in experiment 3 during right atrial pacing when enddiastolic pressure was normal. The top row of signals refers to regions near the base. The left column refers to regions near the left anterior descending coronary artery. ed, be and ee denote end-diastole, begin-ejection and end-ejection respectively.

ferent between the control and the hypervolemic situation.

In Fig. 3, for the control situation of the same experiment as shown in Fig. 2, subepicardial systolic fiber strain is plotted as a function of the ratio of left ventricular cavity volume to wall volume for 16 regions. The dots indicate subepicardial fiber strain as determined from measured epicardial deformation. The dashed lines indicate fiber strain as calculated from normalized cavity volume according to Eq. (5). Although the enclosed volume remains constant during the isovolumic contraction phase, muscle fibers appeared to shorten. During the ejection phase, muscle fiber length as well as cavity vol

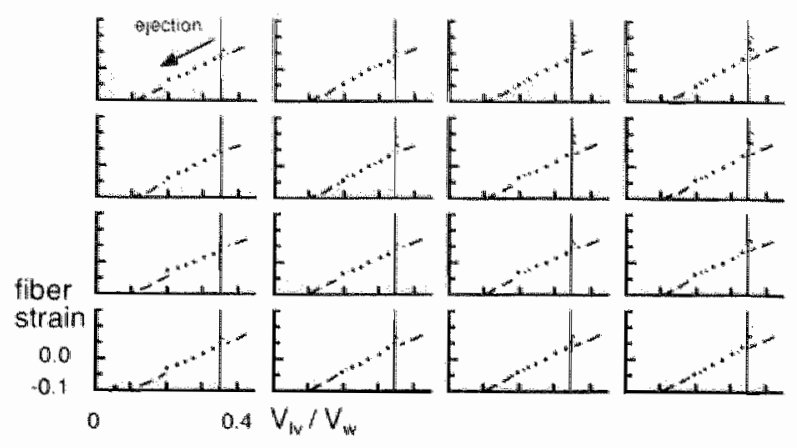

Fig. 3. Maps of measured (dots) and calculated (dashed lines) subepicardial fiber strain as a function of the ratio of left ventricular cavity volume ( $\left.V_{\text {IV }}\right)$ to wall volume $\left(V_{w}\right)$ during systole in the control situation of experiment 3 . The top row of signals refers to regions near the base. The left column refers to regions near the left anterior descending coronary artery

ume decreased. In this phase of the cardiac cycle, experimentally derived values for fiber strain closely followed the value as calculated with Eq. (5). In Fig. 4 the same data are shown as in Fig. 3, but now for the hypervolemic state of the same experiment. As compared to the control situation, similar changes in fiber length are related to greater changes in normalized left ventricular cavity volume. As a result the slope of the relation between fiber strain and normalized left ventricular cavity volume was less steep for the higher left ventricular cavity volumes. After exclusion of the regions at the four corners, measured subepicardial fiber strain was averaged over the remaining 12 re 


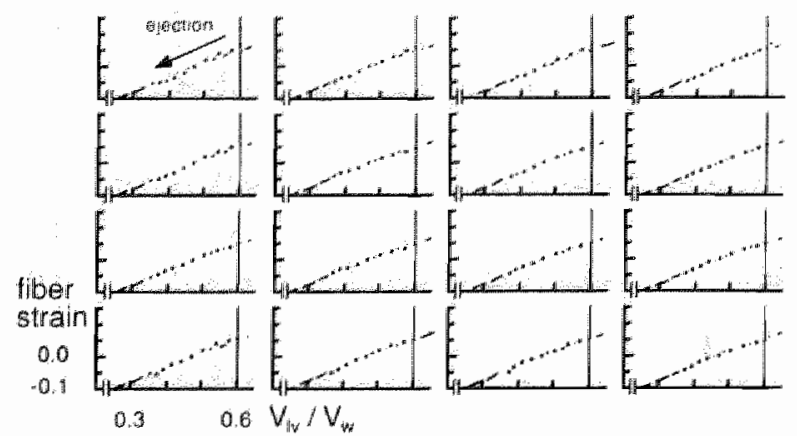

Fig. 4. Maps of measured (dots) and calculated (dashed lines) subepicardial fiber strain as a function of the ratio of left ventricular cavity volume $\left(\mathrm{V}_{\mathrm{IV}}\right)$ to wall volume $\left(V_{W}\right)$ during systole for experiment 3 when end-diastolic pressure was elevated by means of volume loading. The top row of signals refers to regions near the base. The left column refers to regions near the left anterior interventricular coronary artery gions. This averaged fiber strain during the ejection phase is compared with fiber strain as calculated according to Eq. (5). For the control situation as well as the hypervolemic situation (Table 2), both strain values were not significantly different. Hypervolemia did not affect subepicardial fiber strain during the ejection phase significantly $(\mathrm{P}>0.05)$.

In Fig. 5, for the ejection phases of 11 beats obtained from 6 experiments in the control situation (top row) or during hypervolemia (bottom row), subepicardial fiber strain during the ejection phase in the twelve central regions is plotted as a function of fiber strain as calculated with Eq. (5). The slope of the estimated linear relationships between both strains was $1.017 \pm 0.168$ (mean $\pm S D ; n=132$ ), which is not significantly different from unity.

$$
\exp 1 \quad \exp 2 \quad \exp 3
$$

$\exp 4$

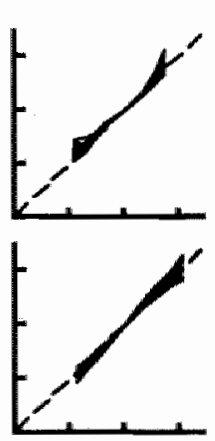

$\exp 5$

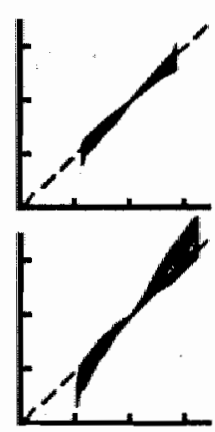

$\exp 6$

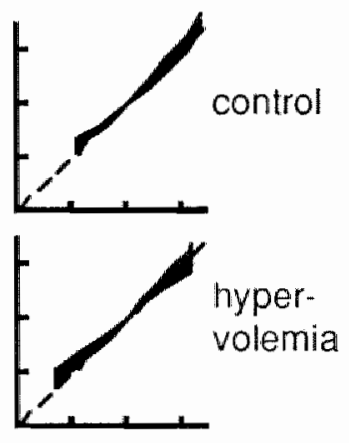

$\begin{array}{lll}-0.1 & 0.0 & \text { calculated fiber strain }\end{array}$

Fig. 5. Subepicardial fiber strain in the twelve regions plotted as a function of fiber strain as calculated with Eq. (5), for the ejection phases of 11 beats obtained from 6 experiments during control (top row) or hypervolemia (bottom row). 
Values for the slope of the estimated linear relation between measured subepicardial fiber strain during the ejection phase in the 12 central regions and average fiber strain during the ejection phase calculated according to Eq. (5) are summarized in Table 2 . The slopes of this relation were not significantly different from 1 , for both the control and the hypervolemic situation.

In Fig. 6 stroke volume calculated according to Eq. (9) is plotted as a function of stroke volume as found by integration of measured aortic volume flow. The slope of the relation, based on calculations from 11 beats in 6 experiments was $1.046 \pm 0.036$, which is not significantly different from unity.

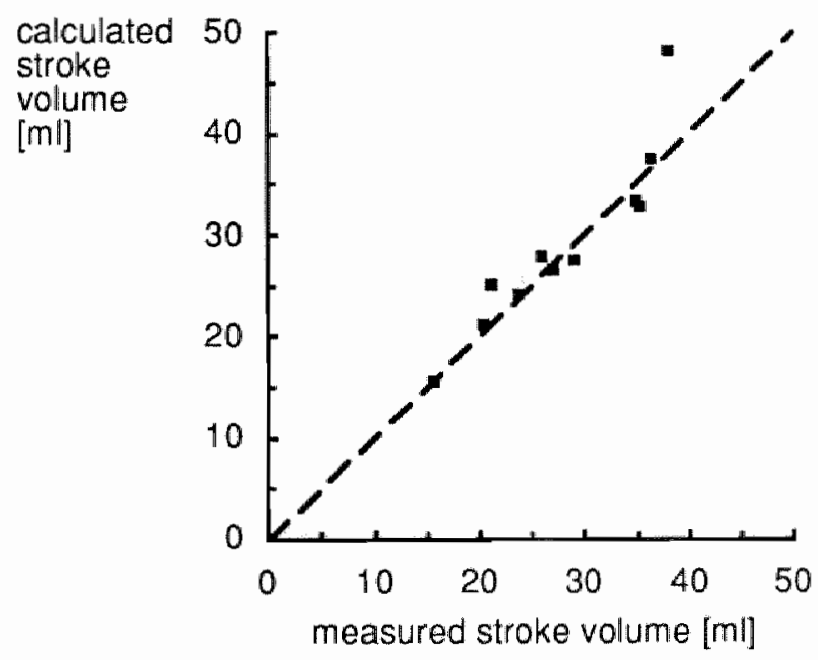

Fig. 6. Stroke volume calculated according to Eq. (9) plotted as a function of stroke volume as found by integration of measured aortic volume flow.
In Fig. 7A, for all beats anallyzed, measured subepicardial fiber strain during systole, as averaged over the 12 central regions, is plotted as a function of time. In Fig. 7B fiber stress during systole as calculated with the use of Eq. (1) is plotted as a function of time for the same beats. Calculated fiber stress rises during the isovolumic contraction phase, reaches a maximum soon after the beginning of the ejection phase, and declines steadily during the rest of the ejection phase. Maximum calculated fiber stress ranged from 16.3 to $35.8 \mathrm{kPa}$ in the control situation, and from 31.6 to $50.8 \mathrm{kPa}$ in the hypervolemic situation (Table 2). Volume loading resulted in an increase of maximum fiber stress by 30 to $80 \%$ in all experiments, except for experiment 2 . In this experiment, the control situation was not much different from the hypervolemic situation. In Fig. $7 \mathrm{C}$, for the systolic phase, calculated fiber stress is plotted as a function of mean measured fiber strain. During the isovolumic contraction phase fiber stress increases, while fiber strain decreases. During the ejection phase, fiber stress decreases approximately linearly with fiber strain. In Fig. 7D left ventricular pressure is plotted as a function of the ratio of left ventricular cavity volume to wall volume. In Fig. 7C and 7D the area enclosed by each curve and its base line represents the amount of contractile work per unit of tissue volume during systole. From these plots, it can be derived, that, although normalized global pump work during the isovolumic contraction phase is almost zero, the anterior free wall of the left ventricle generates 
A

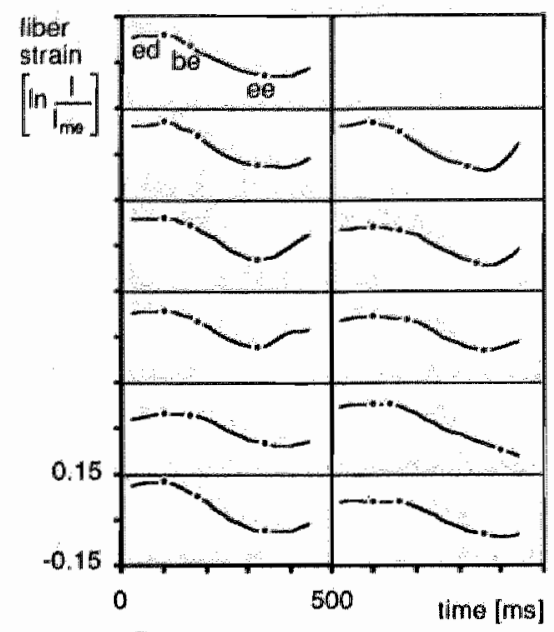

C

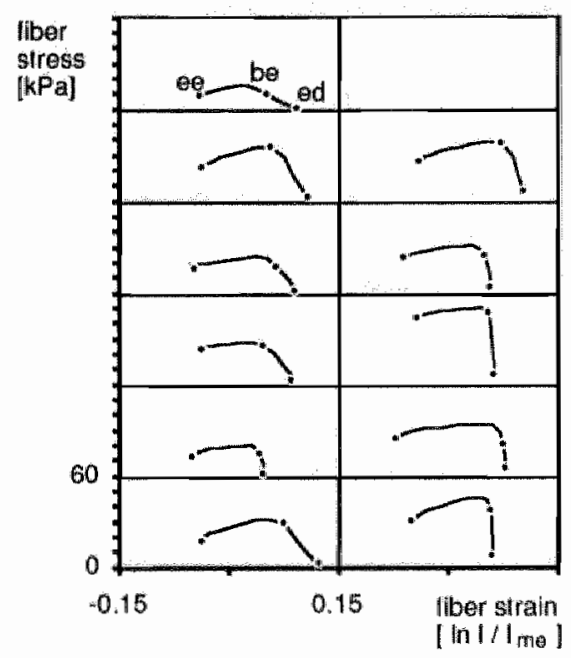

B

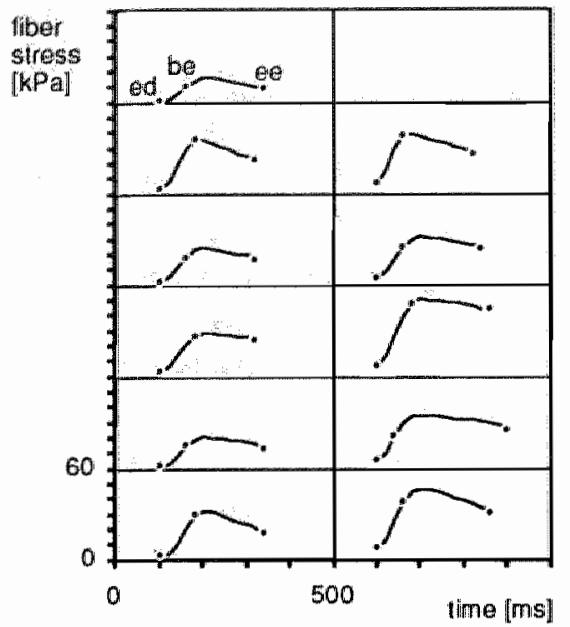

D

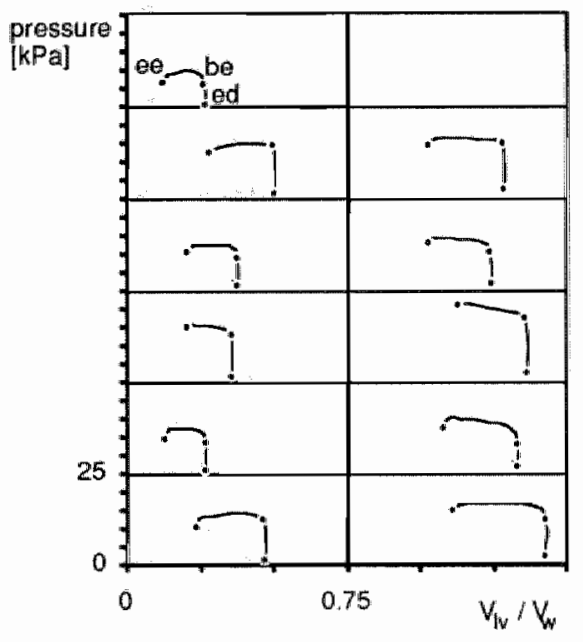

Fig. 7. For all 6 experiments (from top to bottom) the following variables are plotted for the control situation (left column of each panel) and the hyper* volemic state (right column). Panel A: measured subepicardial fiber strain as averaged over the 12 central regions is plotted as a function of time. Panel B: fiber stress, as calculated by means of Eq. (1) is plotted as a function of time for the same beats during systole. Panel C: calculated fiber stress is plotted as a function of mean measured fiber strain for the systolic phase. Panel D: left ventricular pressure is plotted as a function of the ratio of left ventricular cavity volume $\left(V_{\mid V}\right)$ to wall volume $\left(V_{w}\right)$. In Panel $C$ and $D$, the area enclosed by each curve and its base line represents the amount of contractile work per unit of tissue volume during systole. contractile work during the isovolumic contraction phase, especially in the control situation.

In Fig. 8 mean regional contractile work during the ejection phase is plotted as a function of normalized global pump work. The slope of the relation, based on calculations from 11 beats in 6 experiments was $1.00 \pm 0.05$, which is not significantly different from unity. 


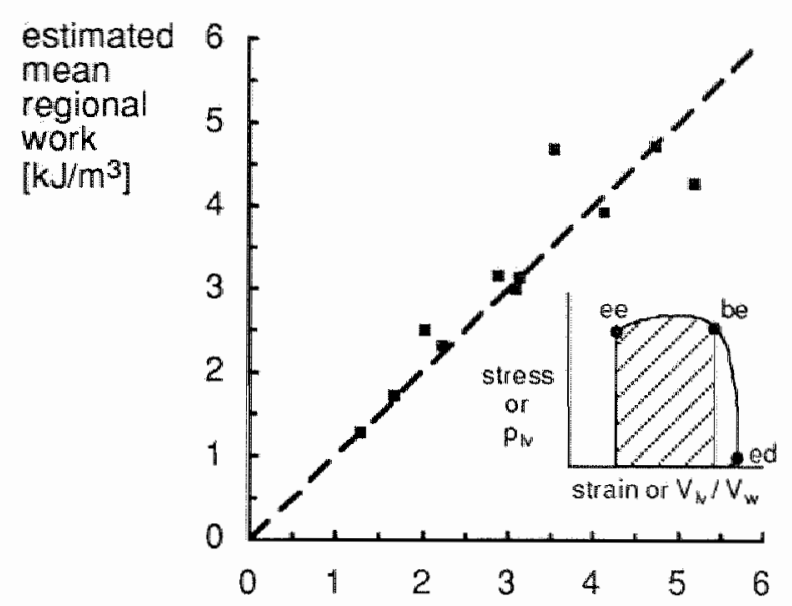

normalized global pump work $\left[\mathrm{kJ} / \mathrm{m}^{3}\right]$

Fig. 8. Mean regional contractile work during the ejection phase plotted as a function of normalized global pump work. The hatch-crossed area in the inserted figure is representative for external work during the ejection phase. $p_{I V}, V_{I V}$, and $V_{w}$ denote left ventricular pressure, cavity volume, and wall volume, respectively. ed, be, and ee indicate enddiastole, begin-ejection and end-ejection, respectively

\section{Discussion}

In the present study mathematically derived relationships by Arts and co-investigators [1] between muscle fiber stress and fiber strain in the left ventricular wall on the one hand, and left ventricular cavity pressure and the ratio of cavity volume to wall volume on the other, were assessed experimentally. In the model study, these relations have been reported to be practically independent of ventricular shape, preload and afterload [1]. In the experiments, volume loading was used as an intervention to obtain different situations within each experiment with regard to left ventricular end-diastolic volume, and end-diastolic and maximum left ventricular pressures. Due to this experimental setup, a fairly wide range of hemodynamic situations was covered. End-diastolic left ventricular pressure ranged from 0.7 to $2.1 \mathrm{kPa}$, maximum left ventricular pressure ranged from 9.6 to 21.4 $\mathrm{kPa}$, and, during systole, left ventricular cavity volume normalized to left ventricular wall volume ranged from 0.12 to 0.67 . The main findings were: 1) fiber strain during the ejection phase, as derived from Eq. (5), was not significantly different from subepicardial fiber strain as measured at the anterior free wall of the left ventricle; 2) regional contractile work per unit of tissue volume, calculated as the integral from estimated fiber stress with respect to measured fiber strain, was not significantly different from global pump work normalized to wall volume. These findings support the assumption of homogeneity of muscle fiber strain and stress in the left ventricular wall during the ejection phase and that average values of fiber stress and strain can be estimated on the basis of measured left ventricular pressure and volume according to the model by Arts and co-investigators [1].

In the control situation measured regional fiber strain during the isovolumic contraction phase was considerable $(-0.034 \pm 0.017)$, whereas during hypervolemia this strain was not significantly different from zero $(-0.011 \pm$ -0.012) (Table 2). However, according to the 
calculations based on Eq. (5) no change in fiber length was expected. This discrepancy between model and experiment for the control situation can likely be explained as follows. Firstly, during diastole in the left ventricle the balance between gravity forces and elastic wall forces, associated. with left ventricular pressure, is important. In the open-thorax preparation, the left ventricle has an elliptic shape at zero transmural pressure due to the action of gravity. As left ventricular pressure increases, elastic left ventricular wall forces become more important and the left ventricular geometry becomes more circular [23]. On the initially flattened anterior wall this change of shape will be observed as fiber shortening. Moreover, at low preload this transition from an elliptical to a circular crosssection will partly occur during the isovolumic contraction phase, contributing to the observed isovolumic fiber shortening, whereas during high preload, as induced by volume loading, this transition will be completed during diastole. Secondly, it can be expected that the relation between fiber strain and normalized cavity volume is not the same for diastole and systole. Experiments have shown that during the isovolumic contraction phase, changes in both global left ventricular geometry [18] and local myocardial strains [7] occur. These changes are related to the transition from more or less isotropic mechanical material properties in diastole, to strongly anisotropic mechanical material properties in systole. Since the increasing anisotropy is due to increasing fiber stiffness, it is likely that the observed global and local defor- mations correspond with a shortening of the muscle fibers. As a result, there will be a quick transmural redistribution of sarcomere length during the isovolumic contraction phase from diastolic inhomogeneity to early-systolic homogeneity. Thirdly, left ventricular cavity volume is determined from measured end-diastolic volume and the integral of aortic volume flow. Bulging of the mitral valves and eventual mitral regurgitation during the isovolumic phase [33], may cause a true decrease in left ventricular cavity volume.

As shown in detail in Figs. 3 and 4 for one experiment, and for all experiments in Fig. 5, measured regional subepicardial fiber strain during the ejection phase is in close agreement with predicted average fiber strain as calculated by means of the model of Arts et al. [1]. The close agreement between measured fiber strain in the observable regions at the epicardium of the left ventricle, and fiber strain as predicted for the average over the whole left ventricle, indicates that fiber strain is homogeneously distributed over a large part of the subepicardial fibers. This observation supports the idea that fiber shortening during the ejection phase is distributed uniformly over the whole left ventricular wall $[1,28]$, since there is no reason to believe that fiber shortening in the unseen epicardial parts of the left ventricle behaves differently.

At first sight, this uniformity in fiber shortening is in striking contrast with previously reported inhomogeneities in regional myocardial shortening throughout the left ventricular wall 
Regional mechanics and global hemodynamics

$[14,31]$. In a study using segmental ultrasonic distance transducers implanted in the canine left ventricular wall [14] lateral inhomogeneities in fiber shortening were reported. In these studies, systolic shortening in the apical region of the ventricle was more pronounced than in the midventricular or basilar regions. However, the reported inhomogeneities in fiber shortening are likely introduced by taking end-diastole as a reference situation, because the transmural redistribution of sarcomere length during the isovolumic contraction phase was not separated from the more uniform fiber shortening during the ejection phase. Moreover, determination of midwall fiber shortening is hampered by biological variations in fiber orientation as well as the presence of large local gradients in fiber orientation and deformation parameters. The required precise directioning of the transducer along the fibers is difficult because of absence of direct visual control. In a study using biplane cineradiography of implanted radiopaque markers arranged in closely spaced columns in the canine left ventricular free wall [31], transmural inhomogeneities of principal strains in planes parallel to the epicardium were reported. However, these differences in deformation are not necessarily associated with differences in fiber shortening. In a more recent study, using the same technique [32], fiber strain along the local fiber direction near the epicardium was $-0.09 \pm 0.04$, and in the inner half of the wall $-0.06 \pm 0.06$, implying that the difference between subepicardial and subendocardial fiber shortening was not significant. The larger standard deviation in measured fiber strain in the inner wall of the left ventricle can partly be explained by a greater uncertainty in the measured local fiber direction. Fiber direction was determined by taking the average of three measurements at a certain depth, thus averaging the possible biological variations. The thus derived fiber directions were available only at $0.5 \mathrm{~mm}$ intervals although large local gradients in fiber orientation exist in the mid-wall of the left ventricle. Other factors that may hamper accurate estimation of fiber strain in the inner wall of the left ventricle are the artifactual deformation arising from the histological procedures and the influence of the anterior papillary muscle. Despite these hampering factors, systolic fiber strain was much more homogeneous than reported or predicted earlier $[4,13,14]$. Homogeneity in fiber strain is also supported by a recent study by Rodriguez et al. [24]. They measured cyclic changes in myocardial sarcomere lengths at different depths in the left ventricular wall. Using values as presented by them (e.g., Fig. 5 in Ref. [24]), it can be derived that fiber strain during ejection is $-0.14,-0.14$, and -0.12 for the epicardial, the imiddle, and the deepest layer, respectively.

Stroke volume calculated according to Eq. (9) agreed fairly well with measured stroke volume. The sensitivity of Eq. (9) to a change of the ratio of left ventricular cavity volume at begin-ejection to wall volume is moderate. When changing this ratio from 0.6 to 0.5 , calculated stroke volume decreases by $11 \%$. An implication of this fairly good agreement between measured and calculated values of 
stroke volume or fiber strain is that, when three of the following four variables are known, i.e. mean fiber strain, wall volume, stroke volume, and left ventricular cavity volume at some moment during ejection, the remaining fourth can be estimated with reasonable accuracy.

It is desirable to compare calculated values of fiber stress with measured ones. Several methods for measuring left ventricular wall stress have been developed $[9,12]$. In these methods, a stiff force transducer was inserted into the wall of the left ventricle. However, changes in muscle length were found to disturb force measurements [12]. Furthermore, the relationship between measured wall stress and stress in the fibers depends on the orientation of the transducers with respect to the fiber orientation. This angle might be subject to experimental and biological variance. Therefore, measured stress is not reliable enough to be used as a standard for comparison with calculated fiber stress.

Calculated fiber stress in the left ventricular wall may be compared with fiber stress as measured in isolated contracting muscle. In rat papillary or trabecular muscle preparations, during isometric contraction active peak tension as a function of sarcomere length was found to be $100 \mathrm{kPa}$ at a sarcomere length of approximately $2.1 \mu \mathrm{m}[19,26,29]$. Under normal conditions, contractile work is maximal if contractile force is approximately 40 to $60 \%$ of peak isometric force. Force-sarcomere shortening velocity relations derived from afterloaded contractions starting from a constant sarcomere length, revealed that 40 to $60 \%$ of maximum force can be developed with sarcomere shortening velocities ranging from 1.50 to $2.50 \mu \mathrm{m} / \mathrm{s}$ $[26,29]$. In order to compare calculated values of fiber stress with values of fiber stress as found in these isolated contracting muscle studies, we assumed that average sarcomere length in the left ventricular wall with zero transmural pressure is equal to $1.95 \mu \mathrm{m}$ [11]. In our experiments, the left ventricular volume accompanying this zero transmural pressure $\left(\mathrm{V}_{0}\right)$ was found to be approximately $30 \%$ of left ventricular wall volume. Applying the values for $V_{\text {be }}$ and $V_{0}$ in Eq. (5), a sarcomere length at beginejection ranging from 2.00 to $2.25 \mu \mathrm{m}$ was found. Using these values, maximum shortening velocity was found to be in between 1.75 to $2.50 \mu \mathrm{m} / \mathrm{s}$. On the basis of these estimated sarcomere shortening velocities and the measurements as performed in the isolated cardiac muscle, fiber stress can be expected to range from 40 to $60 \mathrm{kPa}$. This agrees reasonably well with the mean magnitude of maximum calculated average fiber stress, $32.1 \mathrm{kPa}$ (range 16.3 to 50.8 $\mathrm{kPa}$ ), thus supporting the applicability of the model equations.

Errors related to the assumptions underlying Eqs. (1) to (5), are discussed in detail in the original article describing the model [1], and will only be discussed in brief. The geometry of the left ventricle influences the accuracy of the equation on average fiber stress. However, if the left ventricle resembles a prolate ellipsoid with a long to short axis ratio of two or more, which is realistic $[18,23]$ fiber stress is overes- 
Regional mechanics and global hemodynamics

timated by less than $3 \%$. Another source of error is related to the assumed transmural course of the myocardial fibers. It was assumed that the fibers do not cross from the subendocardium to the subepicardium. In the equatorial region this assumption might be realistic, but in the apical and basal regions muscle fibers in the subendocardium continue in the subepicardium [27]. However, the errors thus introduced may be moderate [1].

Pump work is described by pressure times change in volume or by force acting in a certain direction times shortening in the same direction. As shown in Fig. 8, global pump work as normalized to wall volume is not significantly different from estimated mean regional contractile work during the ejection phase. However, during the isovolumic contraction phase, considerable differences exist between these two variables for the control situation. This discrepancy is likely caused by shape changes occurring during the isovolumic contraction phase as discussed above. Mean subepicardial fiber strain was calculated from measured deformation of the anterior free wall of the left ventricle only. During the isovolumic contraction phase, the fibers below the anterior epicardium might not be a good representative of the fibers in the wall. Simultaneous measurements of anterior and posterior wall deformation showed considerable inhomogeneities in regional deformation during the isovolumic contraction phase, whereas these regions have similar overall contributions during the ejection phase [13]. Another explanation might be that during the isovolumic contraction phase, the work generated by the left ventricular wall is converted into elastic potential energy stored in the collagen tissue, which is set free during diastole.

\section{Conclusion}

Using the principle of conservation of energy, i.e., mechanical work generated by the myocardial fibers in the entire wall is equal to pumping work of the left ventricle, fiber stress and strain in the left ventricular wall can be estimated from left ventricular pressure and the ratio of left ventricular cavity volume to wall volume according to equations as proposed by Arts and co-investigators [1]. In the present study it is found that during normal as well as increased end-diastolic volume: 1) fiber strain during the ejection phase as derived from the proposed equation is not significantly different from measured values of subepicardial fiber strain in the anterior free wall of the left ventricle; 2) fiber stress as calculated from left ventricular pressure and volume corresponds qualitatively and quantitatively with results obtained in isolated cardiac muscle; 3 ) regional contractile work per unit of tissue volume, calculated as the integral from estimated fiber stress with respect to measured fiber strain, is not significantly different from global pump work as normalized to wall volume. These findings support the assumption of Arts and co-investigators that muscle fiber strain and stress in the left ventricular wal] are homogeneously distributed during the ejection phase. Therefore, average 
values of fiber stress and fiber strain may be estimated on the basis of measured left ventricular pressure and volume.

\section{Appendix A}

Calculation of left ventricular cavity volume using inductive coils

The left ventricular volume measurement is based on the determination of segment lengths using inductive coils [30]. In short, one coil generates a magnetic field which induces a voltage in the other coil. In the electronic system, the output signal $U$ is linear with the natural strain of the spanned segment with respect to a reference distance between the two coils $\left(\ln \left(d / d_{r e f}\right)\right)$ :

$$
\mathrm{U}=\mathrm{U}_{\mathrm{ref}}+\frac{3.9 \text { Volt }}{\ln 2} \ln \left(\frac{\mathrm{d}}{\mathrm{d}_{\mathrm{ref}}}\right)
$$

With the measuring device, six natural strains between four coils are determined simultaneously and continuously. The four coils were sutured to the epicardial surface of the left ventricle in a tetrahedral configuration (Fig. 9), so that the length of each of the six edges was more or less equal. Coil A, B, C, and D had the following positions on the left ventricular wall: the corner formed by the left anterior descending coronary artery and the left circumflex coronary artery, the basal posterior wall of the left ventricle, the anterior free wall close to the right

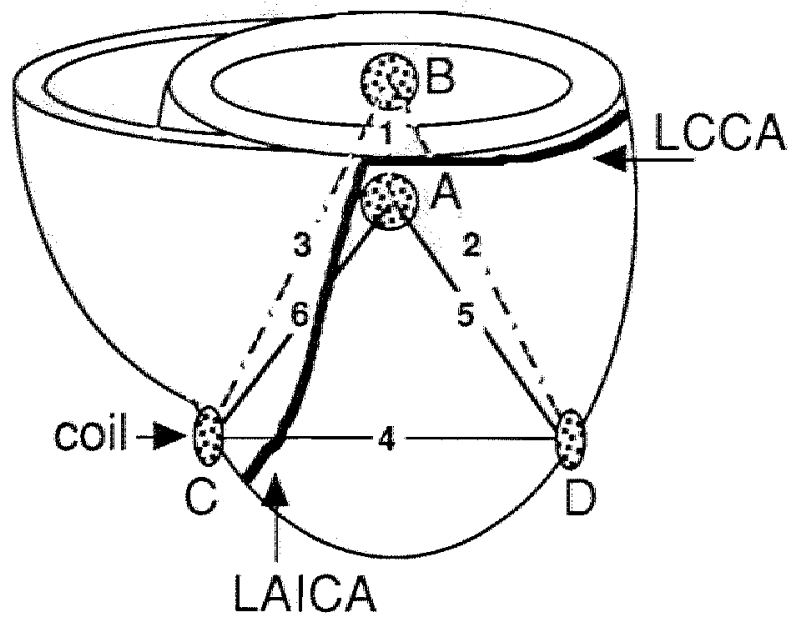

Fig. 9. Position of inductive coils on the left ventricular wall. LAICA refers to the left anterior interventricular coronary artery, and LCCA to the left circumflex coronary antery.

ventricular apex, and the apical lateral free wall, respectively. Segment A-B of the tetrahedron was approximately perpendicular to segment C-D.

It was assumed that the mean change in the induced voltage is linear with the volume change of the body enclosed by the coils. So, by use of Eq. (A1), for the average $\overline{\mathrm{U}}$ of the voltages related to the 6 segments, it holds:

$$
\bar{U}=\bar{U}_{\text {ref }}+\frac{3.9 \text { Volt }}{3 \ln 2} \ln \left(\frac{V_{l v}+V_{w}}{V_{l v, r e f}+V_{w}}\right)
$$

where $V_{l v}$ denotes left ventricular cavity volume and $V_{w}$ left ventricular wall volume. The factor 
3 in the denominator refers to volume being a length to the third power. Eq. (A2) can be rewritten as:

$$
\begin{aligned}
& \mathrm{V}_{\mathrm{lv}}= \\
& \left(\mathrm{V}_{\mathrm{lv}, \mathrm{ref}}+\mathrm{V}_{\mathrm{w}}\right) \exp \left(\frac{\left(\overline{\mathrm{U}}-\overline{\mathrm{U}}_{\text {ref }}\right) \ln 2}{1.3 \mathrm{Volt}_{\mathrm{ol}}}\right)-\mathrm{V}_{\mathrm{w}}
\end{aligned}
$$

$V_{\text {lv, ref was determined by two-dimensional }}$ echocardiography (Appendix B), whereas $V_{w}$ was calculated from the left ventricular weight, assuming a density of the myocardium of 1.05 g. $\mathrm{ml}^{-1}$.

\section{Appendix B}

Calculation of reference left ventricular cavity volume

A two-dimensional echocardiographic image of the minor axis projection of the left ventricle at the equator (Fig. 10A) was used to calculate the ratio of left ventricular cavity volume to wall volume at end-diastole. The inner radius $\left(r_{i}\right)$ was determined from the area within the endocardial wall $\left(A_{i}\right)$, which is the area occupied by the left ventricular cavity $\left(A_{l v}\right)$ and the papillary muscles $\left(A_{\text {pap }}\right)$ by:

$$
r_{i}=\sqrt{\frac{A_{l v}+A_{\text {pap }}}{\pi}}
$$
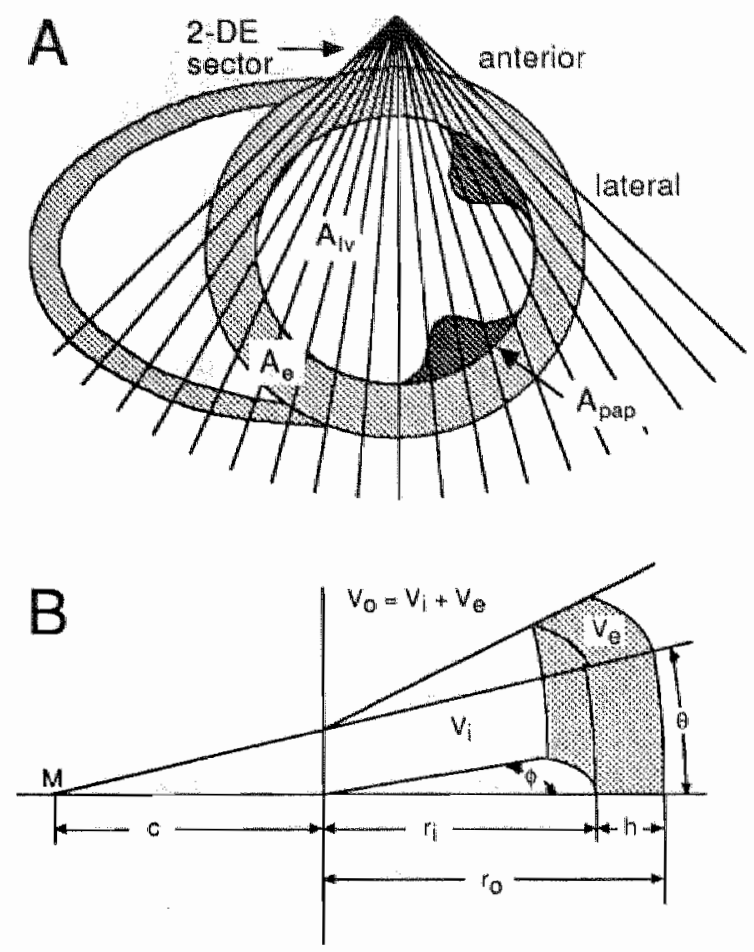

Fig. 10. Panel A: apical view of two-dimensional transverse projection at the equator of the left ventricle. $A_{\mid v}, A_{p a p}$, and $A_{\theta}$ refer to the area occupied by the left ventricular cavity, the papillary muscles, and the left ventricular wall minus $A_{p a p}$, respectively. Panel $B$ : wedge from the transverse projection at the equator of the left ventricular wall. $V_{i}$ and $V_{e}$ are the volumes of the inner and the external part of the wedge, respectively. $r$ and $r_{0}$ are the inner and outer circumferential radius, respectively. $c$ is the distance between the centerpoint of axial curvature and the axis of the left ventricle. $\phi$ and $\theta$ are the opening angle of the wedge in the circumferential and the axial directions, respectively. $\mathrm{h}$ is the wall thickness. $M$ is the common center point. 
The outer radius $\left(r_{0}\right)$ was calculated from $r_{1}$ and mean wall thickness $(h)$ of the posterior wall and the septum of the left ventricle by:

$$
r_{0}=r_{i}+h
$$

At the equator, the radii of curvature in the axial direction of the outer surface $\left(\rho_{Z, 0}\right)$ and the inner surface $\left(\rho_{z, i}\right)$ are assumed to have a common center M (Fig. 10B), For the distance $\mathrm{c}$ between $M$ and the longitudinal axis of the ventricle it holds:

$$
c=p_{z, 0}-r_{0}=p_{z, i}-r_{i}
$$

$V_{i}$ and $V_{e}$ are the volumes of the inner and the external part of the wedge, respectively. For the calculation of the volumes of the wedges $V_{i}$ and $V_{o}\left(=V_{i}+V_{e}\right)$, we define $\phi$ and $\theta$ to be the opening angle of the wedge in the circumferential direction, and the opening angle in the axial direction, respectively. For $\theta \ll 1$ it can be found:

$$
V_{i}=\frac{1}{2} \phi \theta r_{i}^{2}\left(c+\frac{2}{3} r_{i}\right)
$$

and

$$
\mathrm{V}_{\mathrm{o}}=\frac{1}{2} \phi \theta \mathrm{r}_{\mathrm{o}}^{2}\left(\mathrm{c}+\frac{2}{3} \mathrm{r}_{\mathrm{o}}\right)
$$

Dividing Eq. (B4.1) by Eq. (B4.2) results in the ratio of inner to outer wedge volume:

$$
\frac{V_{i}}{V_{o}}=a^{4} \frac{R+a}{R+1 / a}
$$

with

$$
a=\sqrt{\frac{r_{i}}{r_{o}}}=\sqrt[4]{\frac{A_{i}}{A_{o}}}
$$

and

$$
\mathrm{R}=\frac{3 \mathrm{c}}{2 \sqrt{\mathrm{r}_{\mathrm{i}} \mathrm{r}_{\mathrm{o}}}}
$$

When approximating left ventricular geometry by a truncated ellipsoid with a ratio of the semiminor axis to the semi-major axis of $1: 2$, it is found that $\mathrm{R}=4.5$.

For the volumes $V_{i}$ and $V_{o}$ it holds respectively:

$$
V_{i}=V_{1 v}+V_{\text {pap }}
$$

$$
V_{o}=V_{l v}+V_{p a p}+V_{e}=V_{l v}+V_{w}
$$

where $V_{l v}, V_{\text {pap }}$, and $V_{w}$ represent the volume of the cavity, the papillary muscle volume lo- 
cated within the endocardial ellipsoid, and total wall volume, respectively. So, if wall volume is known, $V_{\text {lv }}$ can be calculated by the following equation:

$$
\mathrm{V}_{\mathrm{lv}}=\left(\frac{1-\alpha}{1-\mathrm{k}}-1\right) \mathrm{V}_{\mathrm{w}}
$$

with

$$
\alpha=\frac{V_{\text {pap }}}{V_{w}}
$$

and

$$
k=\frac{V_{i}}{V_{o}}
$$

In our experiments, $\alpha$ was chosen to be 0.03 [25]

\section{References}

1. Arts $T$, Bovendeerd PHM, Prinzen FW, Reneman RS (1991) Relation between left ventricular cavity pressure and volume and systolic fiber stress and strain in the wall. Biophys I 59: 93-102

2. Arts T, Reneman RS (1980) Measurement of deformation of canine epicardium in vivo during cardiac cycle. Am J Physiol 239: H432-H437

3. Arts $T$, Veenstra PC, Reneman RS (1982) Epicardial deformation and left ventricular wall me chanics during ejection in the dog. Am J Physiol

\section{3: H379-H390}

4. Beyar $\mathrm{R}$, Sideman $\mathrm{S}(1986)$ The dynamic twisting of the left ventricle: a computer study. Ann Biomed Eng 14: 547-562

5. Bovendeerd PHM (1990) The mechanics of the normal and ischemic left ventricle during the cardiac cycle, PhD thesis, University of Limburg

6. Bovendeerd PHM, Arts T, Huyghe JM, van Campen DH, Reneman RS (1992) Dependence of local left ventricular wall mechanics on myocardial fiber orientation: a model study. J Biomech 25: 1129 . 1140

7. Douglas AS, Rodriguez EK, O'Dell W, Hunter WC (1991) Unique strain history during ejection in canine left ventricle. Am J Physiol 260: H1591. H1611

8. Falsetti HL, Mates RE, Grant C, Greene DG, Bunnell IL (1970) Left ventricular wall stress calculated from one plane cineangiography - An approach to force-velocity analysis in man. Circ Res 26: $71-83$

9. Feigl EO, Simon GA, Fry DL. (1967) Auxotonic and isometric cardiac force transducers. J Appl Physiol 23: 597-600

10. Fenton TR, Cherry JM, Klassen GA (1978) Transmural myocardial deformation in the canine left ventricular wall. Am J Physiol 235: H523H530

11. Grimm AF, Lin HL, Grimm BR (1980) Left wentricular free wall and intraventricular pressure sarcomere length distributions. Am J Physiol 239: H101-H.107

12. Huisman RM, Elzinga, Westerhof $N$, Sipkema $P$ (1980) Measurement of left ventricular wall stress. Cardiovasc Res 14: 142-153

13. Lew WYW, Le Winter MM (1986) Regional comparison of midwall segment and area shortening in the canine left ventricle. Circ Res 58: 678-691

14. LeWinter MM, Kent RS, Kroener JM, Carew TE, Covell JW (1975) Regional differences in myocardial performance in the left ventricle of the dog. 
Circ Res 37: 191-199

15. Medugorac I (1982) Characterization of intramuscuJar collagen in the mammalian left ventricle. Basic Res Cardiol 77: 589-598

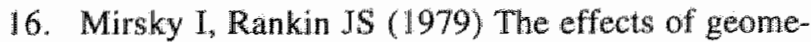
try, elasticity and external pressures on the diastolic pressure-volume and stiffness-stress relations; how important is the pericardium? Circ Res 44:601-611

17. Muijtjens AMM, Roos JMA, Prinzen TT, Arts T (1990) Noise reduction in estimating epicardial deformation from marker tracks. Am J Physiol 258: H599-H605

18. Olsen CO, Rankin JS, Arentzen CA, Ring WS, McHale PA, Anderson RW (1981) The deformational characteristics of the left ventricle in the conscious dog. Circ Res 49:843-855

19. Pollack GH, Krueger JW (1976) Sarcomere dynamics in intact cardiac muscle. Eur J Cardiol 4 (suppl): 53-65

20. Prinzen FW, Arts T, van der Vusse GJ, Reneman RS (1984) Fiber shortening in the inner layers of the left ventricular wall as assessed from epicardial deformation during normoxia and ischemia. $J$ Biomech 17: 801-811

21. Prinzen FW, Augustijn CH, Arts T, Allessie MA, Reneman RS (1990) Redistribution of myocardial fiber strain and blood flow by asynchronous electrical activation. Am J Physiol 259: H300-H308

22. Prinzen TT, Arts T, Prinzen FW, Reneman RS (1986) Mapping of epicardial deformation using a video processing technique. J Biomech 19:263-273

23. Rankin IS, McHale P, Arentzen CE, Ling D, Greenfield JC, Anderson RW (1976) The three-dimensional dynamic geometry of the left ventricle in the concious dog. Cire Res 39: 304-313

24. Rodriguez EK, Hunter WC, Royce MJ, Leppo MK, Douglas AS, Weisman HF (1992) A method to reconstruct myocardial sarcomere lngths and orientations at transmural sites in beating canine hearts. Am J Physiol 263: H293-H306

25. Streeter DD, Hanna WT (1973) Engineering mechanics for successive states in canine left ventricular myocardium: II fiber angle and sarcomere length. Circ Res 33: 656-664

26. ter Keurs HEDJ, Bucx JJJ, de Tombe PP, Backx P, Iwazumi $\mathrm{T}$ (1988) The effects of sarcomere length and $\mathrm{Ca}++$ on force and velocity of shortening in cardiac muscle. In: Sugi $\mathbb{H}$, Pollack $\mathrm{GH}$ (Eds) Molecular mechanism of muscle contraction. Plenum, New York, pp 581-593

27. Torrent Guasp F (1973) The cardiac muscle. Juan March Foundation, Barcelona

28. van der Vusse GJ, Arts T, Glatz JFC, Reneman RS (1990) Transmural differences in energy metabolism of the left ventricular myocardium: fact or fiction. J Moll Cell Cardiol 22: 23-37

29. van Heuningen R, Rijnsburger WH, ter Keurs HEDJ (1982) Sarcomere length control in striated muscle. Am J Physiol 242: H411-H420

30. van Renterghem RJ, Arts T, van Steenhoven AA, Reneman RS (1988) On-line measurement of aortic valve ring deformation during the cardiac cycle. Am J Physiol 254: H795-H800

31. Waldman LK, Fung YC, Covell JW (1985) Transmural myocardial deformation in the canine left ventricle. Normal in vivo three-dimensional finite strain. Circ Res 57: 152-163

32. Waldman LK, Nosan D, Covell JW (1988) Relation between transmural deformation and local myofiber direction in canine left ventricle. Circ Res 63: $550-562$

33. Yellin EL, Nicolic S, Frater RWM (1990) Left ventricular filling dynamics and diastolic function. Prog Cardiovasc Dis 32: 247-271

34. Zerhouni EA, Parish DM, Rogers WJ, Yang A, Shapiro EP (1988) Human heart: tagging with MR imaging - a method for noninvasive assessment of myocardial motion. Radiology 169:59.63 


\section{REGIONAL FIBER STRESS-FIBER STRAIN AREA AS ESTIMATE OF REGIONAL OXYGEN DEMAND IN THE CANINE HEART}

Tammo Delhaas, Theo Arts*, Frits W. Prinzen and Robert S. Reneman

Departments of Physiology ${ }^{1}$ and Biophysics ${ }^{2}$,

Cardiovascular Research Institute Maastricht,

University of Limburg, P.O.Box 616,

NL-6200 MD Maastricht, The Netherlands.

Accepted for publication in: J Physiol (Lond) 
Abstract. In the present study the relation between regional left ventricular contractile work, regional myocardial blood flow and oxygen uptake was assessed during asynchronous electrical activation. In analogy to the use of the pressure-volume area for the estimation of global oxygen demand, the fiber stress-fiber strain area, as assessed regionally, was used to estimate regionall oxygen demand. The more often used relation between the pressure-sarcomere length area and regional oxygen demand was also assessed. Experiments were performed in 6 anesthetized open-thorax dogs. Regional differences in mechanical work were generated by asynchronous electrical activation of the myocardial wall. The ventricles were paced from the right atrium, the left ventricular free wall, the left ventricular apex or the right ventricular outflow tract. Regional fiber strain was measured at the epicardial anterior left ventricular free wall with a two-dimensional video technique. Regional fiber stress was estimated from left ventricular pressure, the ratio of left ventricular cavity volume to wall volume, and regional deformation. Total mechanical power (TMP) was calculated from the fiber stress-fiber strain area (SSA) and the duration of the cardiac cycle $\left(t_{\text {cycle }}\right)$ by: TMP $=\mathrm{SSA} / t_{\text {cycle }}$. Regional myocardial blood flow was measured with radioactive microspheres. Regional oxygen uptake was estimated from regional myocardial blood flow values and arterio-venous differences in oxygen content. During asynchronous electrical activation, total mechanical power, pressure-sarcomere length area, myocardial blood flow and oxygen uptake were significantly lower in early than in late activated regions $(\mathrm{P}<0.05)$. Within the experiments, the correlation between the pressure-sarcomere length area and regional oxygen uptake was not significantly lower than the one between total mechanical power (TMP) and regional oxygen uptake $\left(\dot{V}_{\mathrm{O}_{2, \text { reg }}}\right)$. However, variability of this relation between the experiments was less for total mechanical power. Pooling all experimental data revealed: $\dot{\mathrm{V}}_{\mathrm{O}_{2} \text {,reg }}=\mathrm{k}_{1} \mathrm{TMP}+\mathrm{k}_{2}$, with $\mathrm{k}_{1}=4.94 \pm 0.31 \mathrm{~mol} / \mathrm{J}$ and $\mathrm{k}_{2}=24.2 \pm 1.9$ $\mathrm{mmol} /\left(\mathrm{m}^{3} \mathrm{~s}\right)$ (mean $\pm \mathrm{SE}$ ). This relation is in quantitative agreement with previously reported relations between the pressure-volume area and global oxygen demand. The results indicate that asynchronous electrical activation causes a redistribution of mechanical work and oxygen demand and that regional total mechanical power is a better and more general estimate of regional oxygen demand than the regional pressure-sarcomere length area.

\section{Introduction}

The relationship between global mechanical work and oxygen demand has been widely investigated in the left ventricle $[7,25,26,41]$. Suga and co-investigators proposed a method to estimate global oxygen demand from the pressure-volume area of the left ventricle [33-35]. The pressure-volume area is defined as the area bounded by the pressure-volume trajectory during systole and both the end-systolic and end-diastolic pressure-volume relationship 
curves. For a wide range of conditions, the pressure-volume area is closely related to myocardial oxygen consumption $[16,20,34,36]$.

Several methods to estimate regional contractile work in the left ventricle in control situation as well as during ischemia or asynchronous electrical activation have been proposed $[5,13$, $21,38,39]$. In one method, left ventricular pressure is plotted as a function of regionally measured segment length $[38,39]$. Another method [13,21] uses values of calculated regional stress and unidirectionally measured segmental shortening. In both methods, generation of mechanical work is indicated by the presence of a loop. However, in none of the studies mentioned, an attempt was made to relate the indices of regional work to regional oxygen demand.

In analogy to the pressure-volume area concept for the global left ventricle, regional oxygen demand may be determined from the regional fiber stress-fiber strain area. The pressure-volume area and the regional fiber stressfiber strain areas are related as follows: the sum of the regional fiber stress-fiber strain areas for the individual muscle fibers that constitute a ventricle is equal to the pressure-volume area of that ventricle. In experiments on isolated ferret papillary muscle, the force-length area - the analog of the pressure-volume area for a linear muscle - was found to be closely related to oxygen consumption [17]. These findings suggest that the regional fiber stress-fiber strain area can be used to estimate regional oxygen demand.

In the present study it was investigated in anesthetized open-thorax dogs whether the left ventricular pressure-sarcomere length area or the fiber stress-fiber strain area is the best predictor of regional oxygen demand. To address this question, the determination of global hemodynamics, and regional fiber stress and fiber strain is required. Regional fiber strain can be measured accurately in the subepicardial layers by determining planar deformation at the epicardial surface $[3,30]$. Direct measurement of regional fiber stress is practically impossible, because the insertion of transducers into the wall damages the tissue at the site of measurement $[12,19]$. Therefore, a modification of an earlier model of cardiac mechanics [2, 4] was used to estimate regional fiber stress during systole from experimentally measured left ventricular pressure, left ventricular cavity volume, and regionally measured fiber strain. Subepicardial fiber strain was assessed at the epicardial surface of the anterior left ventricular free wall, using a two-dimensional video technique [30]. Ventricular pacing from various sites was used as an intervention to obtain regional differences in mechanical performance $[5,10,23,29,43]$. Regional oxygen uptake was estimated from regional myocardial blood flow as determined by radioactively labeled microspheres, and measured arterio-coronary sinus differences in oxygen content.

\section{Methods}

Estimation of regional fiber stress. In the present study a modification of the model of Arts 
and co-investigators $[2,4]$ was used to estimate regional fiber stress. In the original model it was found that during ejection the dimensionless ratio of left ventricular pressure ( $\mathrm{p}_{\mathrm{IV}}$ ) and mean Cauchy fiber stress $\left(\sigma_{f}\right)$, averaged over the left ventricular wall, which is force per actual cross-sectional area of the muscle fiber bundle, can be approximated by the dimensionless ratio of left ventricular cavity $\left(V_{]_{V}}\right)$ to wall volume $\left(V_{w}\right)$ :

$$
\frac{\sigma_{\mathrm{f}}}{\mathrm{p}_{\mathrm{IV}}}=1+3 \frac{\mathrm{V}_{\mathrm{lv}}}{\mathrm{V}_{\mathrm{w}}}
$$

Furthermore, during ejection mean sarcomere length $\left(l_{\mathrm{s}, \text { avg }}\right)$, averaged over the left ventricular wall, depends solely on the instantaneous ratio of left ventricular cavity volume to left ventricular wall volume $[2,4]$ :

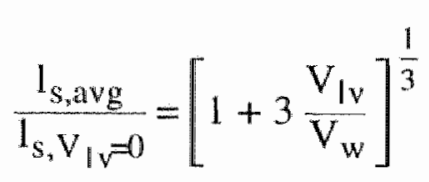

where $I_{S_{1}} V_{l v}=0$ represents sarcomere length at extrapolated zero left ventricular cavity volume. In the present study, the length of the cardiac muscle fiber was quantified in terms of estimated sarcomere length.

During asynchronous electrical activation, large differences in regional fiber shortening, and, hence, in regional cross-sectional area are found $[5,10,29]$. This results in regional dif- ferences in Cauchy fiber stress. To estimate regional Cauchy fiber stress in a non-uniformly contracting ventricle, the following additional assumptions were made:

- In the reference situation, myocardial fibers do not cross and follow pathways with zero divergence [8]. Then Cauchy fiber stress is homogeneous.

- During contraction, force along a given myocardial bundle is the same everywhere due to a free conductance of force along the fibers. Thus the force per original cross-sectional area, the so called first Piola-Kirchhoff stress $\tau_{f}$ is homogeneously distributed throughout the ventricular wall.

Due to tissue incompressibility, average sarcomere length is inversely proportional to the cross-sectional area of the fiber. Thus for $\tau_{f}$ it holds:

$$
\tau_{\mathrm{f}}=\sigma_{\mathrm{f}} \frac{1_{\mathrm{S}, \mathrm{V}_{\mathrm{lf}}=0}}{\mathrm{l}_{\mathrm{s}, \mathrm{avg}}}
$$

Applying Eqs. (1) and (2) to Eq. (3), for $\tau_{\mathrm{f}}$ in the left ventricle it is found:

$$
\tau_{\mathrm{f}}=\mathrm{p}_{\mathrm{Iv}}\left[1+3 \frac{\mathrm{V}_{\mathrm{lv}}}{\mathrm{V}_{\mathrm{w}}}\right]^{\frac{2}{3}}
$$

Correcting Eq. (4) with fiber strain as regionally measured with respect to the configuration at extrapolated zero cavity volume $\left(\mathrm{l}_{\mathrm{s}, \mathrm{reg}} /\right.$ 
$\left.l_{S}, V_{l v}=0\right)$, regional Cauchy fiber stress $\left(\sigma_{f, r e g}\right)$ may be expressed in experimentally measurable quantities:

$$
\sigma_{\text {f,reg }}=p_{l v}\left[1+3 \frac{v_{l v}}{V_{w}}\right]^{\frac{2}{3}} \frac{1_{s, r e g}}{l_{s, v_{l v}=0}}
$$

Estimation of regional sarcomere length. Calculation of fiber stress from fiber strain by use of the constitutive relation of myocardial tissue, requires estimation of regional sarcomere length. The following assumptions were used:

- Sarcomere length at zero left ventricular transmural pressure in the passive state $\left(1_{s, e q}\right)$ equals $1.95 \mu \mathrm{m}[15,32]$, while the corresponding left ventricular cavity volume is defined as $\mathrm{V}_{\mathrm{lv}, \mathrm{eq} \text {. }}$

- In the systolic phase, if left ventricular cavity volume equals $V_{1 v, e q}$, sarcomere length keeps $1_{\mathrm{s}, \mathrm{eq}}$.

- In the synchronously activated left ventricle, fiber shortening and, hence, sarcomere shortening is homogeneous during the ejection phase [9].

So, sarcomere length at mid-ejection of the control beat $\left(\mathrm{I}_{\mathrm{S}, \mathrm{ref}}\right)$, which is the reference state for the deformation measurements, can be calculated by:

$$
1_{\mathrm{s}, \text { ref }}=1_{\mathrm{s}, \mathrm{eq}}\left[\frac{1+3\left(\mathrm{~V}_{1 \mathrm{v}, \text { ref }} / \mathrm{V}_{\mathrm{w}}\right)}{1+3\left(\mathrm{~V}_{\mathrm{lv}, \mathrm{eq}} / \mathrm{V}_{\mathrm{w}}\right)}\right]^{\frac{1}{3}}
$$

Regional sarcomere length is calculated from regionally measured strain differences between the control and the actual state.

Estimation of regional contractile work and energy demand. The first index of regional contractile work used in this study was the pressure-sarcomere length area, which is the area bounded by the systolic limb of the pressuresarcomere length loop trajectory and the $x$-axis $[38,39]$.

The second index used was the fiber stressfiber strain area, a regional analog of the model presented by Suga and co-investigators [33-35]. In this model, the total amount of mechanical energy needed for the left ventricle to contract from end-diastolic to end-systolic volume is the sum of the external mechanical work $\left(E_{e}\right)$ and the so-called end-systolic potential work $\left(\mathrm{E}_{\mathrm{p}}\right)$. This combined area is equal to the pressure-volume area, which is the area bounded by the endsystolic and end-diastolic pressure-volume curves and the systolic limb of the pressurevolume loop trajectory (Fig. 1A). The intersection of the end-systolic pressure-volume curve and the $x$-axis is denoted by $V_{l v, d}$. Below this volume no active pressure can be developed. The relation between the pressure-volume area (PVA) and the global oxygen demand $\left(\dot{V}_{\mathrm{O}_{2}}\right)$ was described by a linear equation:

$$
\dot{\mathrm{V}}_{\mathrm{O}_{2}}=\mathrm{c}_{1} \mathrm{PVA}+\mathrm{c}_{2}
$$

where $c_{1}$ represents a conversion constant of 

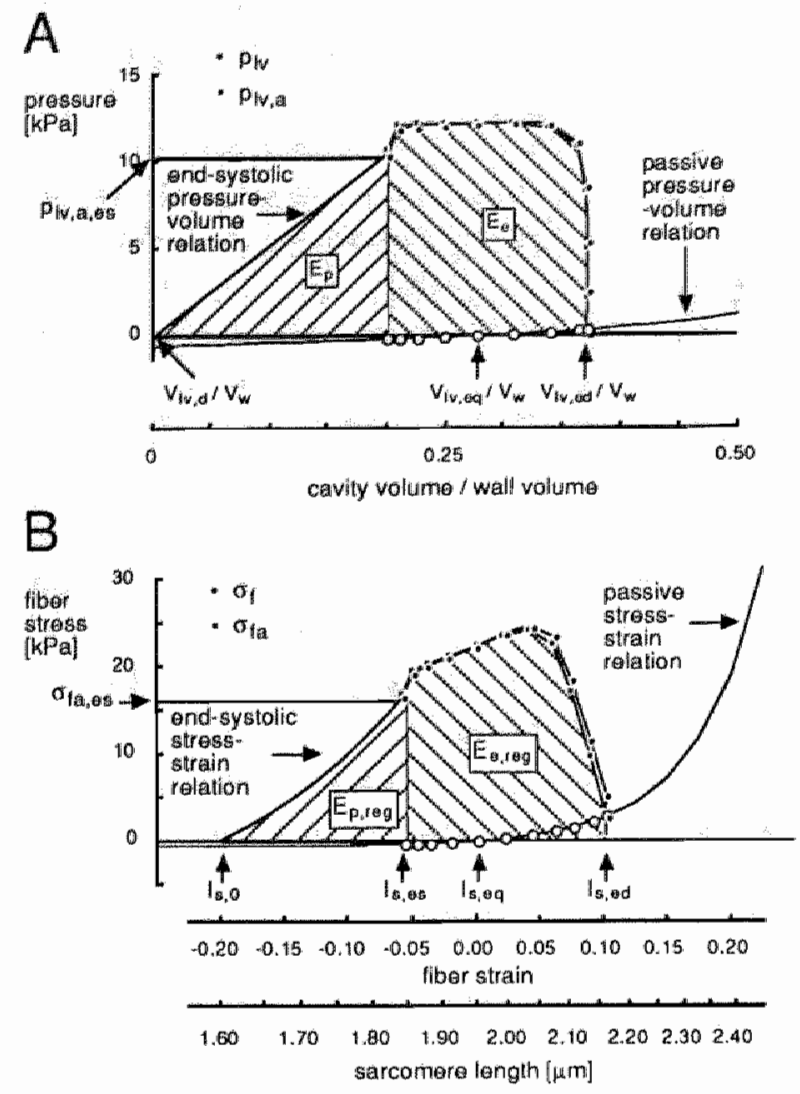

mechanical work to oxygen demand, and $c_{2}$ the oxygen required by the left ventricle for basal metabolism plus excitation-contraction coupling.

Analogously, regional oxygen demand in the left ventricular tissue is assumed to be proportional to the regional fiber stress-fiber strain area (Fig. 1B). The regional fiber stress-fiber strain area was calculated as follows:

- Using Eq. (5), regional Cauchy fiber stress
Fig. 1. Myocardial oxygen demand may be determined globally (panel A) as well as regionally (panel B) from the mechanical work performed. In panel $A$, left ventricular pressure is plotted as a function of left ventricular cavity volume normalized to wall volume. Myocardial oxygen demand correlates with the pressure-volume area (PVA). This PVA is the sum of the external mechanical work $E_{e}$ and the so-called potential mechanical work $E_{p}$, which is related to end-systolic pressure [33-35]. It holds: PIv,a,es is end-systolic active left ventricular pressure; $V_{\mathrm{IV}, \mathrm{d}}$ and $\mathrm{V}_{\mathrm{IV} \text {,eq }}$ are left ventricular cavity volume at zero end-systolic left ventricular pressure and at passive zero transmural pressure, respectively; $V_{w}$ is wall volume. Cavity volume is normalized to wall volume. In panel $B$, fiber stress is plotted as a function of fiber strain. On the horizontal axis, calculated sarcomere length is also indicated. Regional myocardial oxygen uptake has been correlated with the regional SSA $\left(S S A_{\text {reg }}\right.$ ), being the sum of the regional external mechanical work $\left(E_{\theta, \text { reg }}\right)$ and the regional potential mechanical work $\left(E_{p, r e g}\right)$. It holds: $\sigma_{f a, e s}$ is end-systolic active fiber stress; $I_{s, 0}, I_{s, e s}, I_{s, e q}$, and $I_{s, e d}$ represent sarcomere length at zero active fiber stress, at end-systole, at passive zero transmural pressure, and at end-diastole, respectively.

was calculated from left ventricular pressure, the ratio of left ventricular cavity volume to wall volume, and sarcomere length estimated according to the above-mentioned method.

- Neglecting the viscous behavior of passive myocardial fibers, the relation between passive fiber stress $\left(\sigma_{\mathrm{fp}}\right)$ and sarcomere length $\left(1_{\mathrm{s}}\right)$ is described by:

$$
\sigma_{\mathrm{fp}}=\sigma_{\mathrm{fpo}}\left(\exp \left[\mathrm{b}\left(1_{\mathrm{s}}-1_{\mathrm{s}, \mathrm{eq}}\right)\right]-1\right)
$$


in which $1_{\mathrm{S}, \mathrm{eq}}, \mathrm{b}$, and $\sigma_{\mathrm{fp} 0}$ are parameters. The parameter $b$ governs the exponential increase of $\sigma_{\mathrm{fp}}$ with increasing sarcomere length. Based on experiments on isolated cat papillary muscle the value of $b$ was assumed to be $8 \mu \mathrm{m}^{-1}[37,40]$. For each separate experiment, the value of $\sigma_{\mathrm{fp} 0}$ was calculated from end-diastolic left ventricular pressure and left ventricular cavity volume as measured in the control situation, applying Eqs. (1) and (2).

- The active component of regional fiber stress during systole $\left(\sigma_{\mathrm{fa}}\right)$ was obtained by subtracting passive fiber stress (Eq. (8)) from total fiber stress (Eq. (5)).

- Regional external work during systole $\left(\mathrm{E}_{\mathrm{e}, \mathrm{reg}}\right)$ was calculated from the area bounded by the systolic limb of the active fiber stress-fiber strain loop trajectory and the $x$-axis (Fig. 1B).

- The regional potential work term $E_{p, r e g}[33-$ 35 ] was estimated from the area bounded by the end-systolic fiber stress-fiber strain relation and the $x$-axis.

- Finally, the regional fiber stress-fiber strain area SSA was calculated as:

$$
\mathrm{SSA}=\mathrm{E}_{\mathrm{e}, \mathrm{reg}}+\mathrm{E}_{\mathrm{p}, \mathrm{reg}}
$$

Regional total mechanical power (TMP) was calculated from the regional fiber stress-fiber strain area (SSA) and the duration of the cardiac cycle $\left(t_{\text {cycle; }} s\right)$ by:

$$
\mathrm{TMP}=\frac{\mathrm{SSA}}{\mathrm{t}_{\text {cycle }}}
$$

Animal preparation and instrumentation. Six adult mongrel dogs of either sex, weighing 23 to $29 \mathrm{~kg}$, were premedicated by an intramuscular injection of Hypnorm $\left(1 \mathrm{ml} . \mathrm{kg}^{-1} ; 1 \mathrm{ml}\right.$ Hypnorm contains $10 \mathrm{mg}$ fluanisone and 0.2 $\mathrm{mg}$ fentanyl base). Anesthesia was induced by an intravenous injection of pentobarbital sodium $\left(10 \mathrm{mg} \cdot \mathrm{kg}^{-1}\right)$ and maintained after endotracheal intubation with nitrous oxide $\left(33 \% \mathrm{O}_{2}, 67 \%\right.$ $\mathrm{N}_{2} \mathrm{O}$ ) and a continuous infusion of pentobarbital sodium ( $\left.2 \mathrm{mg} \cdot \mathrm{kg}^{-1} \cdot \mathrm{h}^{-1}\right)$. Ventilation was kept constant with a positive pressure respirator (Pulmomat, Dräger). The animal was placed on its right side, and body temperature was kept between 37.5 and $38.5^{\circ} \mathrm{C}$ by means of a thermostatically regulated heating pad. A standard limb lead electrocardiogram (ECG) was used. Arterial blood samples were taken periodically to determine $\mathrm{PO}_{2}, \mathrm{PCO}_{2}, \mathrm{pH}$, oxygen saturation and hemoglobin concentration (ABL 3, Radiometer). Sodium bicarbonate solution $(4.2 \%)$ was administered intravenously to adjust the acid-base balance when necessary.

The chest was opened through the left fifth intercostall space. After removal of the fifth rib, the pericardium was opened, and the heart suspended in a pericardial cradle. Epicardial bipolar platinum pacing electrodes were sutured to the heart at the right atrium, left ventricular apex, left ventricular free wall, and right ventricular outflow tract (Fig. 2).

To obtain coronary venous blood, polyethylene catheters were inserted into the distal part of the left anterior interventricular vein 


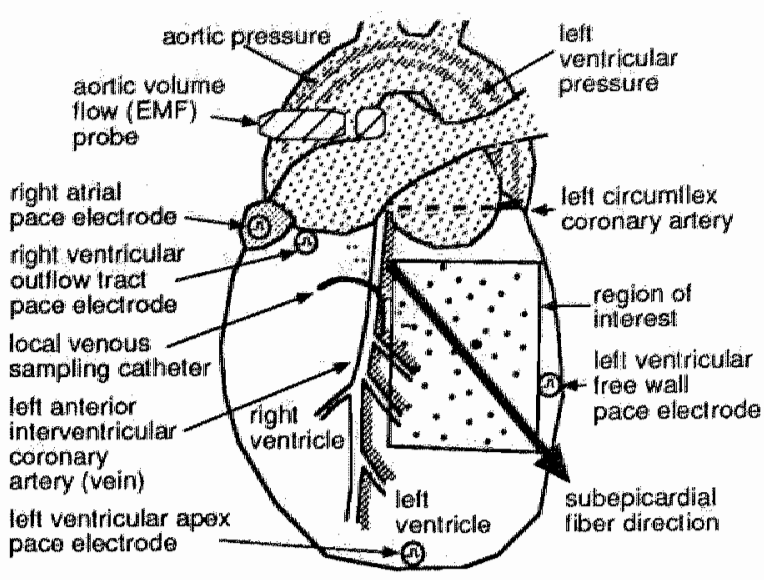

Fig. 2. Schematic representation of experimental setup. The dots within the area of interest are optical markers, attached to the epicardial surface. The sampling catheter in the coronary sinus is not depicted.

draining the medial-apical part of the region of interest (Fig. 2), and into the coronary sinus.

To assess regional myocardial blood flow (see below), a silastic catheter was placed in the left atrium for the injection of radioactively labeled microspheres. A polyethylene catheter was inserted into the right brachial artery to obtain blood for the arterial reference sample.

Left ventricular cavity and ascending aortic pressure were measured with catheter-tip micromanometers (Millar PC-470), inserted via the right brachial and the right femoral artery, respectively. To enable pressure calibration during the experiment, the fluid-filled lumina of the catheter-tip micromanometers were connected via three-way cocks to an external pres- sure transducer (Electromedics MS20). The third opening of the three-way cock was connected to a reference pressure level, which was the right atrial level for all pressure measurements [4]. Ascending aortic volume flow was measured with an electromagnetic flow meter (Skalar Transflow 601).

Four inductive coils were sutured to the epicardium of the left ventricle in a tetrahedral configuration, so that the length of each of the six edges was more or less the same. The 6 signals obtained from these coils were used for the determination of left ventricular cavity volume (see below).

ECG, pressure and ascending aortic volume flow signals, as well as the 6 signals from the inductive coils, were continuously visualized on an oscilloscope (Knott). These signals were also recorded on a paper recorder (Schwarzer) and a multichannel tape recorder (Ampex PR2200).

Experimental protocol. For all pacing sites, minimum current levels and pace rate at which activation was regular, were determined. Pacing was performed from 4 different sites: right atrium, left ventricular apex, left ventricular free wall, and right ventricular outflow tract. During ventricular pacing the right atrium was stimulated $30 \mathrm{~ms}$ before the ventricle. Fifteen minutes after switching to a particular pacing site, arterial, local venous, and coronary sinus blood samples were taken for blood gas analysis. Subsequently, microspheres were injected and a reference arterial sample was taken for the cal- 
culation of regional myocardial blood flow (not during left ventricular free wall pacing). Hemodynamic variables and epicardial deformation were recorded simultaneously. Within $1 \mathrm{~min}$ thereafter simultaneous recordings of hemodynamic variables and epicardial electrical activation were performed. The experiment was terminated by administration of an overdose of pentobarbital sodium. Within $5 \mathrm{~min}$ thereafter, the heart was excised, the atria were removed from the ventricles, and the ventricles were rinsed. To determine the cavity volume of the passive left ventricle at zero transmural pressure, the left ventricle was immersed in saline, keeping the base on top, just above the saline level. Subsequently, the content of the left ventricular cavity was withdrawn with a graded syringe. Thereafter the free wall of the right ventricle was dissected, and the left ventricle was weighed.

Determination of hemodynamic variables. After performing the experiment, the hemodynamic data as recorded on analog tape were sampled $(200 \mathrm{~Hz})$ and digitized using a 16-channel 12bit A/D card (DASH 16G2), connected to a MSDOS personal computer (Tulip AT Compact). Sampling and analysis were performed using a software package (ASYST 3.0, MacMillan Software Company) and software developed in our laboratory. In the cardiac cycle three events were determined (Fig. 3). The end of the diastolic phase was defined as the moment before ejection at which the rate of change of left ventricular pressure $\left(\mathrm{dp} \mathrm{l}_{\mathrm{v}} / \mathrm{dt}\right)$ exceeded $10 \mathrm{kPa} . \mathrm{s}^{-1}$

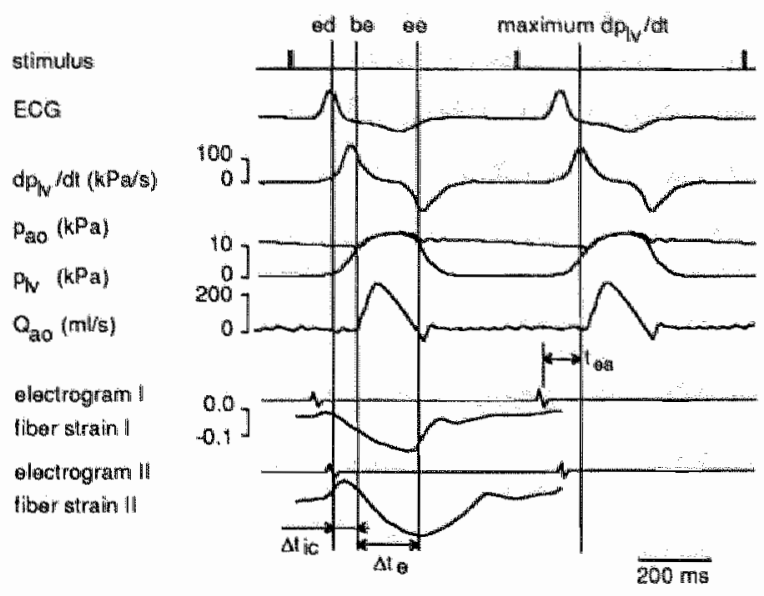

Fig. 3. Typical digital recordings of hemodynamic, electrophysiological and deformation data measured during pacing at the right ventricular outflow tract. Traces from top to bottom: stimulus artifact, electrocardiogram (ECG), first derivative of left ventricular pressure $(\mathrm{dp} / \mathrm{V} / \mathrm{dt}$ ), left ventricular pressure $\left(p_{\mid v}\right)$, instantaneous aortic volume flow, and fiber strain in early activated basal-medial region (fiber strain I) and in late activated apical-lateral region (fiber strain II). In the cardiac cycle three events are determined: end-diastole (ed), begin-ejection (be) and end-ejection (ee). $\Delta t_{i c}$ and $\Delta t_{\theta}$ indicate the duration of the isovolumic contraction phase and the ejection-phase, respectively.

[22]. The beginning of the ejection phase was determined by the moment at which left ventricular pressure exceeded end-diastolic aortic pressure. The duration of the ejection phase was determined from the aortic volume flow signal. From left ventricular pressure as a function of time, end-diastolic left ventricular pressure, maximum left ventricular pressure, and maxi- 
mum first derivative of left ventricular pressure were determined. Besides, the following hemodynamic variables were determined: heart rate, left ventricular cavity volume as a function of time (see below), maximum instantaneous ascending aortic volume flow, and ejected volume (time integral of ascending aortic volume flow).

Left ventricular cavity volume during systole was estimated as described in detail before [9]. In brief, the weight of the left ventricle and a two-dimensional echocardiographic image of the minor axis projection at the equator of the left ventricle were used to calculate left ventricular cavity volume at end-diastole in the control situation (right atrial pacing). Changes in enddiastolic volume as compared with this reference situation were determined using the 6 signals of the four inductive coils. The time course of left ventricular cavity volume during ejection was obtained by subtracting the instantaneous integral of ascending aortic volume flow from end-diastolic volume.

Precise synchronization of hemodynamic data with deformation or electrical data was performed as described previously [10].

\section{Mapping of left ventricular epicardial electrical} activation pattern. A 192-electrode brush $(44 \times 64 \mathrm{~mm})$ was used for simultaneous recording of epicardial surface electrograms at the left ventricular anterior free wall. The grid spacing between the electrodes was approximately $3.5 \mathrm{~mm}$. Left ventricular pressure and ECG were recorded with the same system simultaneously with the electrode signals. Off- line, in each electrogram, the moment with the steepest negative deflection was detected and labeled by a time mark, indicating the moment of regional activation of the tissue underneath the recording electrode $[1,18]$. Mean regional electrical activation time was calculated for the regions as used for the deformation assessment (see below) by determining the time interval between the moment of maximum $\mathrm{dp}_{1 \mathrm{v}} / \mathrm{dt}$ and the average moment of electrical activation within one region [10].

During the experiment reproducible positioning of the ellectrode brush was obtained by visual matching of landmarks on the electrode brush with anatomical landmarks and/or video markers on the epicardial surface. Spatial matching of electrophysiological and deformation maps was enabled by four white markers, attached to the upper surface of the multi-electrode brush.

Mapping of left ventricular epicardial deformation. Two-dimensional epicardial deformation was determined with a video technique as previously described in detail [30]. In brief, approximately 40 white markers were attached with tissue glue (Histoacryl) to the epicardial surface of the left ventricular anterior wall. The inter-marker spacing was approximately $6 \mathrm{~mm}$. The area covered with markers extended $3-4 \mathrm{~cm}$ in the circumferential and $4-5 \mathrm{~cm}$ in the base-toapex direction (Fig. 2). A video camera (Sony AVC $32500 \mathrm{CE}$ ) with a $200 \mathrm{~mm}$ tele-objective, positioned at a distance of $2.5 \mathrm{~m}$, and a mirror, mounted above the heart at an angle of $45^{\circ}$, 
were used to record the motion of the markers on a video recorder (Sony SL-C9ES, Betamax) at a speed of 50 frames per second. A videotriggered xenon flashlight illumination (Chadwick-Helmuth) was employed to prevent motion artifacts due to smearing of the images. The direction of the epicardial fibers, being parallel to the branches of the left anterior interventricular coronary artery, and the long axis of the left ventricle, as determined by visual inspection, was indicated by a directed ruler and recorded on video during the control situation (Fig. 2). To enable synchronization of hemodynamic data with deformation data, a frequency-modulated left ventricular pressure signal was recorded on an audio channel of the video recorder.

After the experiment 64 consecutive video frames $(50 \mathrm{~Hz})$ were digitized and stored in a 2 Mbyte digital video memory, which was coupled to a computer (PDP 11/73). Markers were detected, filtered using a singular value decomposition filtering technique [24], and used for the estimation of epicardial deformation in $4 \times 4$ mutually overlapping regions by means of a least-squares criterion [30]. Mid-ejection of the control situation (right atrial pacing) was used as the reference state for all deformation measurements within an experiment. Natural strain in the direction of the subepicardial fibers $\left(e_{f}\right)$ was calculated from epicardial deformation by:

$$
e_{\mathrm{f}}=\ln \frac{\mathrm{l}_{\mathrm{f}}}{\mathrm{l}_{\mathrm{f}, \mathrm{ref}}}
$$

in which $l_{f}$ and $l_{f, r e f}$ represent fiber length along the subepicardial fiber direction in the actual and the reference situation, respectively. To compare myocardial fiber length in different experiments quantitatively, sarcomere length was estimated as described above.

Determination of regional myocardial blood flow. Regional myocardial blood flow was determined with radioactively labeled microspheres ( $15.0 \pm 1.0 \mu \mathrm{m}$; NEN-TRAC, DuPont DeNemours), suspended in $10 \%$ dextran with $0.01 \%$ Tween 80 [28]. The labels used were: ${ }^{141} \mathrm{Ce},{ }^{113} \mathrm{Sn},{ }^{103} \mathrm{Ru}$, or ${ }^{95} \mathrm{Nb}$. At each determination, $3 \times 10^{6}$ microspheres were injected into the left atrium. An arterial reference sample was taken from the brachial artery at a rate of $20.7 \mathrm{ml} / \mathrm{min}$, using a Harvard withdrawal pump. Withdrawal of blood started $5 \mathrm{~s}$ before the injection of the microspheres, and was continued during at least 1 min.

After the experiment, the heart was fixated in $5 \%$ formaldehyde. Before dissection, nonmuscular structures, like fat and vessels at the epicardium, and chordae tendinae, were removed. The part of the left ventricular free wall with the optical markers was removed from the heart and dissected into 24-36 square transmural sections of approximately $7 \times 7 \mathrm{~mm}$. Each section was subdivided into a subepicardial and a subendocardial half, each of which was weighed. For the relation between regional mechanics, electrical activation and myocardial blood flow, only the subepicardial part was used. The radioactivity of the tissue and arterial blood samples was determined in a gamma 
Regional performance and oxygen demand

counter (Packard multichannel Analyzer). Regional subepicardial myocardial blood flow in milliliters per second per gram was calculated for the same 16 regions as used for the determination of regional subepicardial fiber strain. Regional myocardial oxygen uptake was estimated using regional myocardial blood flow values and differences in oxygen content between blood withdrawn from the right brachial artery and the coronary sinus.

Relation between regional mechanical load and oxygen uptake. For each experiment the relation between regional oxygen uptake per second and the regional pressure-sarcomere length area or total mechanical power was expressed by a linear regression.

Statistical analysis. The effects of ventricular pacing on the variables related to hemodynamics, mechanics, myocardial blood flow, and oxygen uptake were evaluated for statistical significance by applying the Wilcoxon matchedpairs signed-rank test. Values obtained during right atrial pacing in the same animal were used as reference. A difference with $\mathrm{P}<0.05$ was considered to be significant (two-tailed probability). Data are presented as mean $\pm \mathrm{SD}$, unless indicated otherwise.

\section{Results}

Influence of pacing site on hemodynamic performance

Compared with right atrial (RA) pacing, pacing at the left ventricular apex (LVA), the left ventricular free wall (LVFW), and the right ventricular outflow tract (RVOT) resulted in a significant deterioration of hemodynamic performance. Maximum left ventricular pressure decreased from $13.2 \pm 2.0$ to $11.2 \pm 1.6,11.6 \pm$ 1.5 , and $10.7 \pm 2.2 \mathrm{kPa}$ during LVA, LVFW, and RVOT pacing, respectively. Maximum $\mathrm{dpIv} / \mathrm{dt}$ decreased from $188 \pm 32$ (RA) to $144 \pm$ 15 (LVFW), $161 \pm 35$ (LVA), and $128 \pm 26$ $\mathrm{kPa}_{\mathrm{s}}{ }^{-1}$ (RVOT). Maximum instantaneous aortic volume flow decreased from $209 \pm 55$ (RA) to $173 \pm 37$ (LVFW), $176 \pm 40$ (LVA), and $180 \pm$ $60 \mathrm{ml} . \mathrm{s}^{-1}$ (RVOT). Stroke volume decreased from $22.8 \pm 4.5$ (RA) to $18.9 \pm 3.2$ (LVFW), $19.8 \pm 3.4$ (LVA), and $19.3 \pm 5.4 \mathrm{ml}$ (RVOT). Heart rate, the duration of the isovolumic contraction phase and the ejection phase, and the end-diastolic left ventricular pressure were not significantly different between the various pacing modes.

\section{Influence of pacing site on electrical activation}

During right atrial pacing, electrical activation time as referred to the moment of maximum $\mathrm{dp} / \mathrm{v} / \mathrm{dt}$, was $-50 \pm 3 \mathrm{~ms}$ at the anterior left ventricular free wall. Mean values of regional electrical activation ranged between -80 and $-40 \mathrm{~ms}$ 
during pacing from the three ventricular sites. Since the moment of maximum $\mathrm{dp}_{\mathrm{lv}} / \mathrm{dt}$ is used as time reference, electrical activation time is less negative in late than in early activated regions. The direction of the depolarization wave in the region of interest was highly dependent on the site of pacing. Stimulation at the right ventricular outflow tract caused a basal-medial to apical-lateral directed wave. When the heart was stimulated at the left ventricular apex, the depolarization wave was oppositely directed. During stimulation at the left ventricular free wall the depolarization wave traveled more or less perpendicular to the two former directions.

Subepicardial fiber strain and regional work during asynchronous electrical activation.

In Fig. 4A, maps are shown of regional subepicardial fiber strain as a function of time as obtained during right atrial pacing in experiment

Fig. 4. Maps of measured subepicardial fiber $\operatorname{strain}\left(\ln \left[1 /\left.\right|_{\text {ref }}\right]\right)$ as a function of time (panel A), of calculated regional fiber stress as a function of time (panel B), and of calculated regional fiber stress as a function of measured fiber strain (panel C) as determined in 16 regions of the left ventricular anterior free wall in experiment 3 during right atrial pacing. The top row of signals refers to regions near the base. The left column refers to regions near the left anterior interventricular coronary artery. ed, be and ee refer to end-diastole, begin-ejection and endejection, respectively. The course of the loops in panel $C$ is counter-clockwise, as indicated by the arrow in the right-upper plot.
3. For all regions, the pattern of fiber strain was quite similar. In Fig, $4 \mathrm{~B}$, calculated regional fiber stress is depicted as a function of time for the systolic phase of the same beat. Fiber stress increased during the isovolumic phase, reached a maximum level $40 \mathrm{~ms}$ after the beginning of
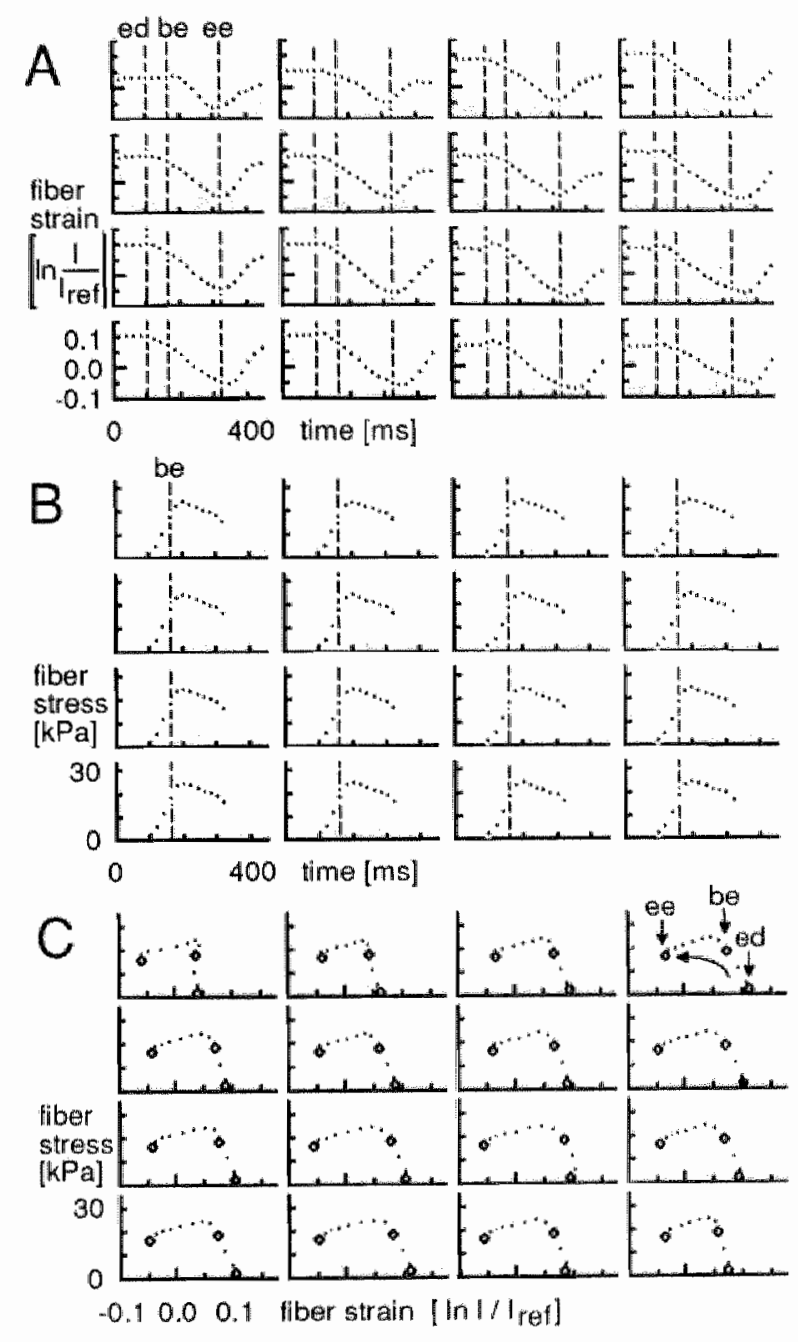
the ejection phase and declined steadily during the rest of the ejection phase. In Fig. $4 \mathrm{C}$, regional fiber stress is plotted as a function of fiber strain, using the data of Fig. $4 \mathrm{~A}$ and B. The course of the loops is counter-clockwise, indicating generation of mechanical work.

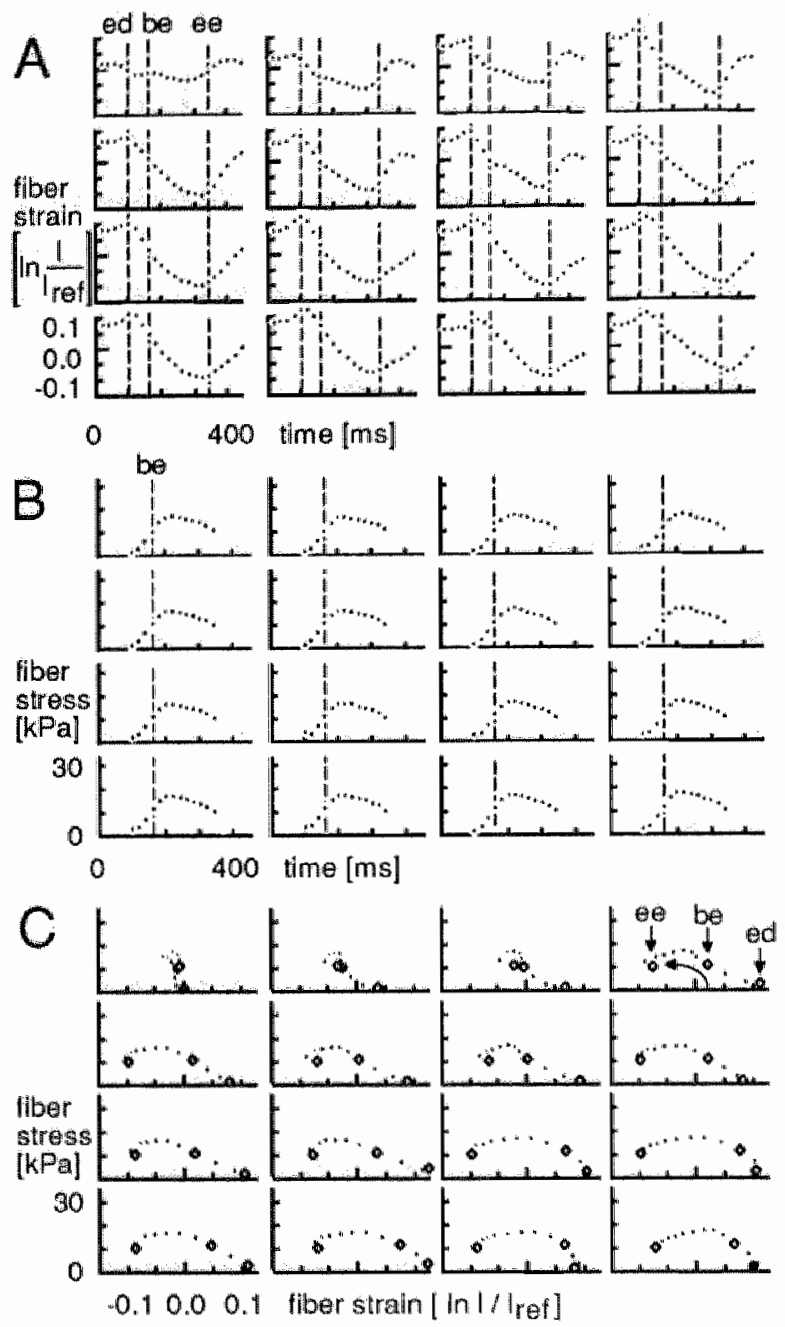

Although during the isovolumic contraction phase global pump work was zero, regional external work during this phase appeared to be significantly different from zero, as indicated by the area under that part of the curve.

The setup of Fig. 5 is similar to Fig. 4, but data are now obtained during right ventricular outflow tract pacing in the same experiment. The pattern of fiber strain was highly dependent on the moment of electrical activation. In the early activated regions (upper region) fibers shorten markedly during the isovolumic contraction phase. During the ejection phase fiber strain in those regions was smaller than in the late activated regions. As compared with right atrial pacing, maximum fiber stress was markedly diminished and approximately the same in all regions. In Fig. 5C, early activated regions, as shown in the upper region, generate less external mechanical work than late activated regions.

Fig. 5. The setup is similar to Fig. 4, but data are now obtained during right ventricular outflow tract pacing in the same experiment. Panel A: fibers shorten markedly during the isovolumic contraction phase in early activated regions (upper region). During the ejection phase fiber strain in those regions was smaller than in late activated regions. Panel B: As compared with right atrial pacing, maximum fiber stress was markedly diminished and approximately the same in all regions. C: early activated regions (upper region) generate less external mechanical work than late activated regions. 
Regional performance and oxygen demand

\begin{tabular}{|c|c|c|c|c|c|c|c|}
\hline & $\begin{array}{c}\text { fiber strain } \\
{\left[\ln |/|_{\text {rel }}\right]}\end{array}$ & {$\left[\begin{array}{l}\mathrm{s}, \mathrm{be} \\
{[\mu \mathrm{m}]}\end{array}\right]$} & $\begin{array}{c}\text { fiber stress } \\
{[\mathrm{kPa}]}\end{array}$ & $\begin{array}{c}\text { PSL } \\
{\left[\mathrm{kWatt} / \mathrm{m}^{2}\right]}\end{array}$ & $\begin{array}{c}\text { TMP } \\
{\left[\mathrm{kWat} / \mathrm{m}^{3}\right]}\end{array}$ & $\begin{array}{l}\text { blood flow } \\
{[\mu / \mathrm{g} . \mathrm{s}]}\end{array}$ & $\begin{array}{l}\text { oxygen uptake } \\
\text { [ mMol/miss }\end{array}$ \\
\hline & $103-103-103-102$ & 2062.062062006 & $26.626 .5 \quad 26.5226 .4$ & $138 \times 39 \times 40 \times 39$ & $53 \cdot 59 / 2060$ & 11.6121124425 & 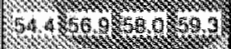 \\
\hline & $104 / 102-103=103$ & $2.07 / 2.05206 \% 2.06$ & $26.6 \quad 26.4 \quad 26.5 \quad 26.5$ & $39 / 39 / 39 / 39$ & $59459<0.60$ & 11011.41201116 & $51,152955.863 .3$ \\
\hline & $098<100<110,100$ & $206207 \quad 008.07$ & 26.726 .726 .726 .5 & $38 / 4,4,2439$ & $59161<62060$ & 1131200117011.4 & 52055.7538 .530 \\
\hline & $.092-102=100-085$ & 2.072072 .052 .04 & 26.826 .726 .426 .4 & $3.6 \times 39 \times 3.934$ & $57 \times 6060.5$ & 12.6192136122 & 158.566 .66511562 \\
\hline & $17+119-103 \cdot 080$ & 062042.03 & 022.1 & & & $11010.6 \quad 10, \$ 9.4$ & $5 \times 50$ \\
\hline & $103: X_{\beta}-063-038$ & $2.04 \mathrm{~d}(2,02,2.00$ & 21.821 .922 .122 .1 & $38 / 2=26$ & $57 \times 1=45 \quad 37$ & 104.1520940 .1 & $49.5 / 77,4.1,42.8$ \\
\hline & $086.054>829.002$ & 000 & $\begin{array}{llll}21.6 & 21.7 & 22.0 & 22.3\end{array}$ & & $52 / 4 /<5$ & 9999 & 46.6 \\
\hline & $049-017.01 \backslash 027$ & $\begin{array}{llll}1.96 & 1.94 & 1.93\end{array} \mathrm{~g}^{94}$ & $\begin{array}{llll}21.8 & 22.0 & 22.4 & 22.7\end{array}$ & $\begin{array}{llll}1.8 & 0.8 & -0.1\end{array}$ & $3.8<28,19 \times 11$ & 10499.9629 .1 & $47.845 .744,5425$ \\
\hline & $03 \int_{041,060087}$ & $2 \lambda \times 1.991 .992 .02$ & $21.8 \quad 21.6 \quad 21.4 \quad 29.4$ & 29 & $3.8 \% 4.5$ & 9383 & $45 . D_{45.4}^{4} 43,543,0$ \\
\hline & $072-08<-092-111$ & $2.022)(2052.09$ & 21.721 .521 .722 .0 & $2 \% 32$ & 4.751 .6 .6 .1 & 900909 & 44. \\
\hline & $1041178 \times 2143$ & $2.04210 \times 142,14$ & $21.622 .1 \quad 22.3: 22.4$ & $3.7 \times 5 \times 4.5$ & $5,8,0,2>0,9$ & $101 / 102$ & $49.248,9 \mathrm{~V} / 3 / 45.9$ \\
\hline & $119 \% 144.160 \times 6$ & $2.102 .14<16=17$ & $\begin{array}{llll}22.1 & 22.3 & 22.4 & 22.5\end{array}$ & 97.4 .4640 & $61,69,72>3$ & $12,110,11 \times 121$ & $50,0.2,750 \times 450$ \\
\hline & .042 .025 .010 .005 & 20020.0520022 .02 & $\begin{array}{llll}23.0 & 22.9 & 22.9 & 22.9\end{array}$ & $\begin{array}{cccc}1.3 & 0.8 & 0.0 & -0.5\end{array}$ & $3.12 .8,2.0 \quad 1.4$ & & \\
\hline & $.052 .026 \cdot .003 .026$ & $2.07 \times 042.042 .00$ & $\begin{array}{llll}22.7 & 22.7 & 23.0 & 22.9\end{array}$ & 1.80 .8 & $3.6 \% 27 \quad 1.9$ & not & not \\
\hline & 063.034. & $2062.0322 \times 1.98$ & $\begin{array}{lllll}22.6 & 22.4 & 22.4 & 22.2\end{array}$ & & 4028325 & determined & determined \\
\hline & $066-045-035,005$ & 2.032 .0011 .981 .96 & $22.0 \quad 21.8 \quad 21.6 \quad 21.6$ & 2.61 .8 & $45>37>35$ & & \\
\hline
\end{tabular}

Fig. 6. Mean (sub)epicardial maps as averaged over the 6 experiments when stimulating at the right atrium (RA), left ventricular apex (LVA), right ventricular outflow tract (RVOT), or left ventricular free wall (LVFW). Depicted are: fiber strain during the ejection phase; sarcomere length at the beginning of the ejection phase $\left(\mathrm{I}_{\mathrm{s}, \mathrm{be}}\right)$ estimated using Eq. 6 and fiber strain measurement; fiber stress calculated using Eq. (5); pressuresarcomere length area (PSL); total mechanical power (TMP) per unit of tissue volume; regional blood flow; regional oxygen uptake. Gradients are indicated by arrows. The boundaries between different degrees of shading indicate intervals of 0.05 in fiber strain, $0.05 \mu \mathrm{m}$ in sarcomere length, $1.0 \mathrm{kWatt} / \mathrm{m}^{2}$ in PSL, 1.0 $\mathrm{kWatt} / \mathrm{m}^{3}$ in TMP, $5 \mathrm{ml} / \mathrm{g} . \mathrm{s}$ in blood flow, and $5 \mathrm{mMol} / \mathrm{m}^{3} . \mathrm{s}$ in oxygen uptake.

Influence of pacing site on fiber strain, regional mechanical performance, myocardial blood flow and oxygen uptake; comparison of six experiments

The patterns of fiber strain, fiber stress, and the fiber stress-fiber strain loops as shown in the experiment presented in Figs. 4 and 5 were found in all 6 experiments. Maps of mean regional fiber strain during the ejection phase, estimated sarcomere length at the beginning of the ejection phase, maximum active fiber stress, 
pressure-sarcomere length area, total mechanical power, subepicardial blood flow, and oxygen uptake are shown in Fig. 6 for right atrial, left ventricular apex, right ventricular outflow tract, and left ventricular free wall pacing. As indicated by the shading pattern, during right atrial pacing some regional differences were present in the variables presented. However, using two- dimensional analysis, in none of the variables presented, a gradient could be found. During pacing from ventricular sites, however, mean values of mechanical variables and oxygen uptake were markedly decreased in the early activated regions, except for estimated maximum fiber stress. The gradients, depicted in Fig. 6, pointed toward the same direction as the depo

Table 1. Values of several chemical variables in arterial (A), local venous (LV), and coronary sinus (CS) blood samples.

\begin{tabular}{|c|c|c|c|c|c|}
\hline & & \multicolumn{4}{|c|}{ pacing site } \\
\hline & & RA & LVFW & LVA & RVOT \\
\hline \multirow[t]{3}{*}{$\mathrm{pH}$} & A & $7.39 \pm 0.04$ & $7.37 \pm 0.04$ & $7.41 \pm 0.03$ & $7.42 \pm 0.06$ \\
\hline & LV & $7.36 \pm 0.05$ & $7.34 \pm 0.04$ & $7.35 \pm 0.03$ & $7.39 \pm 0.05$ \\
\hline & $\mathrm{CS}$ & $7.35 \pm 0.05$ & $7.34 \pm 0.04$ & $7.34 \pm 0.04$ & $7.38 \pm 0.04$ \\
\hline \multirow{3}{*}{$\mathrm{PCO}_{2}$} & $A$ & $5.0 \pm 0.7$ & $4.9 \pm 0.4$ & $5.2 \pm 0.8$ & $4.7 \pm 0.7$ \\
\hline & LV & $5.4 \pm 1.5$ & $6.1 \pm 0.5$ & $6.2 \pm 0.7$ & $5.7 \pm 0.9$ \\
\hline & $\mathrm{CS}$ & $6.3 \pm 0.7$ & $6.1 \pm 0.5$ & $6.2 \pm 0.6$ & $6.0 \pm 0.8$ \\
\hline $\mathrm{Hb}$ & A & $7.3 \pm 1.1$ & $6.9 \pm 1.1$ & $6.9 \pm 1.3$ & $7.1 \pm 1.2$ \\
\hline \multirow[t]{3}{*}{$\mathrm{S}_{\mathrm{O}_{2}}$} & $A$ & \pm 0 & $99 \pm 0$ & \pm 0 & $99 \pm 0$ \\
\hline & LV & \pm 7 & $29 \pm 3$ & \pm 3 & $32 \pm 6$ \\
\hline & $\mathrm{CS}$ & \pm 7 & $31 \pm 2$ & $31 \pm 3$ & $31 \pm 6$ \\
\hline \multirow[t]{3}{*}{$\mathrm{O}_{2} \mathrm{ct}$} & $\mathrm{A}$ & $7.48 \pm 1.06$ & $7.10 \pm 1.10$ & $7.09 \pm 1.30$ & $7.27 \pm 1.21$ \\
\hline & L.V & $2.40 \pm 0.72$ & $2.09 \pm 0.54$ & $2.29 \pm 0.57$ & $2.45 \pm 0.83$ \\
\hline & $\mathrm{Cs}$ & $2.80 \pm 0.65$ & $2.19 \pm 0.44$ & $2.27 \pm 0.63$ & $2.34 \pm 0.76$ \\
\hline \multirow[t]{2}{*}{$\Delta \mathrm{O}_{2} \mathrm{ct}$} & $A-L V$ & $5.08 \pm 0.60$ & $5.02 \pm 0.60$ & $4.80 \pm 0.73$ & $4.81 \pm 0.54$ \\
\hline & $\mathrm{A}-\mathrm{CS}$ & $4.68 \pm 0.88$ & $4.91 \pm 0.76$ & $4.83 \pm 0.76$ & $4.93 \pm 0.74$ \\
\hline \multirow[t]{2}{*}{$\mathrm{O}_{2}$ extraction $(\%)$} & $\mathrm{LV}$ & \pm 7 & \pm 4 & \pm 3 & \pm 7 \\
\hline & $\mathrm{CS}$ & \pm 8 & \pm 3 & \pm 4 & \pm 7 \\
\hline
\end{tabular}

Valtues are mean $\pm S D$. Abbreviations: RA, right atrium; LVFW, left ventricular free wall; $L V A$, left ventricular apex; $\mathbb{R V O T}$, right ventricular outflow tract; $\mathrm{Hb}$, hemoglobin; $\mathrm{SO}_{2}$, oxygen saturation; $\mathrm{O}_{2} \mathrm{ct}$, oxygen content; $\Delta \mathrm{O}_{2} \mathrm{ct}$, difference in oxygen content. 
larization wave. On the average, fiber lengthening during the ejection phase was observed in the early activated areas while the hearts were paced at the left ventricular free wall or the left ventricular apex. Therefore, regional external work was negative in these regions. In each experiment the non-uniformities due to the asynchronous electrical activation were generally larger than as indicated by the mean values for each region, because the position of the region with the lowest and highest values varied for each experiment.

In Table 1, values of $\mathrm{pH}, \mathrm{pCO}_{2}, \mathrm{Hb}$, oxygen saturation, oxygen content, arterio-venous difference in oxygen content, and of oxygen extraction are shown for the different pacing modes using arterial, local venous and coronary sinus blood samples. None of the variables presented was significantly affected by ventricular pacing. Moreover, no significant differences could be detected between these biochemical variables as measured in local venous blood and in coronary sinus blood.

Relation between regional mechanical indices and oxygen uptake

$95 \%$ confidence intervals of the relation between regional oxygen uptake and the regional pressure-sarcomere length area or total mechanical power obtained during pacing at the right atrium, the left ventricular apex, and the right ventricular outflow tract in 6 experiments are plotted in Fig. 7A and B, respectively. Because of the variation in hemodynamic conditions in
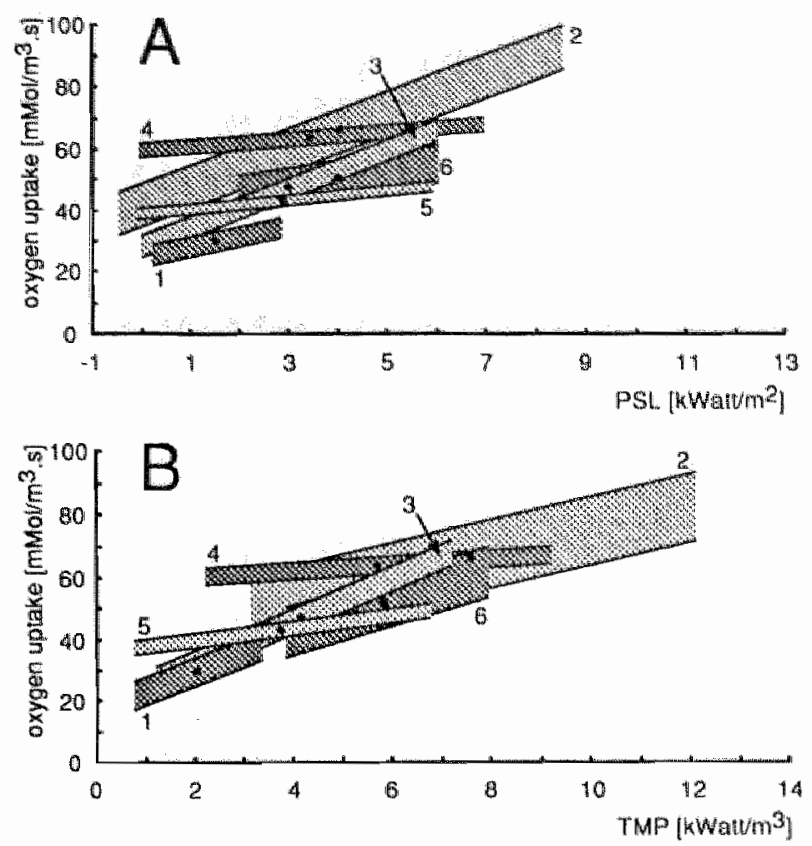

Fig. 7. 95\% confidence intervals of correlation between oxygen uptake and pressure-sarcomere length area (panel $A$ ) or total mechanical power (panel B), as measured in all 6 experiments during right atrial, left ventricular apex, and right ventricular outflow tract pacing. Numbers refer to the experiments as mentioned in Table 2. The solid circles indicate the centers of the estimated relations.

the different experiments, data were obtained during a variety of loading conditions, heart rates and contractile conditions. Besides, different patterns of electrical activation were investigated. The pressure-sarcomere length area ranged from -0.4 to $8.7 \mathrm{~kW} / \mathrm{m}^{2}$, total mechanical power from 0.5 to $12.5 \mathrm{~kW} / \mathrm{m}^{3}$, and regional oxygen uptake from 10 to

120 
Regional performance and oxygen demand

Table 2. Coefficients (SE) of estimated linear relation between regional oxygen demand and total mechanical power (TMP) or pressure-sarcomere length area (PSL).

\begin{tabular}{|c|c|c|c|c|c|c|c|c|}
\hline \multirow{2}{*}{$\frac{\exp .}{1}$} & \multicolumn{2}{|c|}{$\begin{array}{l}\text { slope TMP } \\
(\mathrm{mol} / \mathrm{J})\end{array}$} & \multirow{2}{*}{$\begin{array}{l}\text { interceptTMP } \\
\left({\mathrm{mmol} /\left(\mathrm{m}^{3} . \mathrm{s}\right)}\right. \\
15.78(5.55)\end{array}$} & \multirow{2}{*}{$\begin{array}{r}{ }^{\text {TTMP }} \\
0.37\end{array}$} & \multicolumn{2}{|c|}{$\begin{array}{l}\text { slopepSL } \\
(\mathrm{mol} / \mathrm{J} . \mathrm{m})\end{array}$} & \multirow{2}{*}{$\begin{array}{l}\text { interceptPSL } \\
\left({\mathrm{mmol} /\left(\mathrm{m}^{3} \mathrm{~s}\right)}^{24.83(3.37)}\right.\end{array}$} & \multirow{2}{*}{$\begin{array}{r}\text { TPSL } \\
0.25\end{array}$} \\
\hline & 6.71 & $(2.51)$ & & & 3.42 & (1.96) & & \\
\hline 2 & 4.69 & (1.34) & $25.96(12.13)$ & 0.46 & 6.00 & $(1.51$ & $41.92(7.16)$ & 0.50 \\
\hline 3 & 7.05 & $(0.85)$ & $17.47(3.76)$ & 0.77 & 6.33 & $(1.09)$ & $28.37(3.51)$ & 0.65 \\
\hline 4 & 1.38 & $(0.65)$ & 55.54 (4.14) & 0.30 & 1.22 & $(0.54)$ & $59.77(2.19)$ & 0.31 \\
\hline 5 & 2.43 & $(0.66)$ & $33.68(2.80)$ & 0.48 & 1.56 & $(0.50)$ & $38.94(1.70)$ & 0.42 \\
\hline 6 & 5.65 & (1.41) & $13.61 \quad(9.26)$ & 0.51 & 2.48 & $(1.52)$ & $40.58(6.24)$ & 0.23 \\
\hline pooled & 4.94 & $(0.31)$ & $24.24(1.85)$ & 0.68 & 5.53 & $(0.52)$ & $32.78(1.90)$ & 0.53 \\
\hline
\end{tabular}

$\mathrm{mmol} / \mathrm{m}^{3}$.s. The correlation coefficients of the relations between the pressure-sarcomere length area and regional oxygen uptake within the individual experiments did not significantly differ from the ones between total mechanical power and regional oxygen uptake. Because of the differences in offset of the centers of the relations between the pressure-sarcomere length area and regional oxygen uptake, the linear relation obtained from the pooled data holds only for the relation between total mechanical power (TMP) and regional oxygen uptake $\left(\dot{\mathrm{V}}_{\mathrm{O}_{2, \text { reg }}}\right)$, revealing the following linear regression:

$$
\dot{\mathrm{V}}_{\mathrm{O}_{2, \mathrm{reg}}}=\mathrm{k}_{1} \mathrm{TMP}+\mathrm{k}_{2}
$$

with

$$
\mathrm{k}_{\Downarrow}=4.94 \pm 0.3 \llbracket \mathrm{mol} / \mathrm{J}
$$

and

$$
\mathrm{k}_{2}=24.2 \pm 1.9 \mathrm{mmol} /\left(\mathrm{m}^{3} . \mathrm{s}\right)
$$

The regression coefficient was 0.68 . Table 2 shows the coefficients of the linear regression lines of the relation between measured regional oxygen uptake and total mechanical power as estimated for the individual experiments, and for the pooled data. Within the experiments correlations were less than for the pooled data. Table 2 also shows the coefficients of the linear regression lines of the relation between measured regional oxygen uptake and the pressuresarcomere length area.

\section{Discussion}

In the present study a new method is proposed and applied to estimate regional fiber stress in the left ventricular wall. The second and main goal was to find a proper index of regional oxygen demand in the subepicardial layers of the anterior free wall of the left ventricle. To obtain 
regional differences in mechanical performance, the hearts were paced from the right atrium and various ventricular sites. In early activated regions, both regional oxygen uptake and regional mechanical work were significantly less than in late activated regions. The pressure-sarcomere length area and total mechanical power, an index obtained from the time curve of estimated fiber stress and fiber strain in analogy to the pressure-volume area of Suga and co-investigators [33-35], were related to regional oxygen consumption as estimated from regional subepicardial blood flow and arterio-coronary sinus differences in oxygen content. In the individual experiment the correlation between the pressuresarcomere length area and regional oxygen uptake was not significantly different from the one between total mechanical power and regional oxygen uptake. However, pooling of the linear relations between the pressure-sarcomere length area and regional oxygen uptake does not reveal a reliable relation because of the differences in offset of the center of the individual relations. The results suggest that regional total mechanical power is a better and more general estimate of regional oxygen demand than the pressuresarcomere length area.

Calculation of regional stress has not been commonly applied. Most calculation methods use local radii of curvature, wall thickness, regional material properties, and ventricular pressure. In the present study, a method has been proposed to estimate regional fiber stress during systole from calculated average fiber stress and measured regional fiber strain. In estimating regional fiber stress it was assumed that the distribution of force acting in the fiber direction, defined as Cauchy fiber stress times cross-sectional area of the myocardial fiber bundle, is homogeneously distributed due to a free conductance of force along the fiber bundle. This assumption is especially important in case of ventricular pacing. Then electrical activation is asynchronous, causing fiber strain to become non-uniform. Despite spatial differences in fiber strain during ventricular pacing (Fig. 6), no significant spatial gradient could be calculated for regional maximum fiber stress. This can be explained as follows. The inhomogeneous fiber shortening during asynchronous electrical activation caused differences in sarcomere length at the moment that average fiber stress according to Eq. (1) is maximal. These differences in sarcomere length did not have a gradient in spatial distribution. Estimated sarcomere length at this moment ranged from $1.82 \mu \mathrm{m}$ to $2.20 \mu \mathrm{m}$ (median $2.01 \mu \mathrm{m}$ ), while regional differences in length within a cardiac cycle analyzed ranged from $0.05 \mu \mathrm{m}$ to $0.20 \mu \mathrm{m}$ (median $0.08 \mu \mathrm{m}$ ). According to Eq. (5) differences in maximum Cauchy fiber stress ranged from 2 to $10 \%$ (median 5\%).

The stress in the myocardial fibers is calculated as the sum of axial and circumferential stress minus twice the radial stress $[2,4]$. If the fibers are embedded in soft incompressible material, this stress is exactly the same as the stress in the fibers. If the embedding material is stiffer, thus simulating shear force interaction between the fibers, the stress as calculated is 
still an accurate predictor of the stress related to generation of regional mechanical work by the tissue $[2,4]$, which is just the parameter we are interested in. When using the equations for segmental calculation of left ventricular wall stress as presented by Regen et al. [31], fiber stress was found to be twice as low. However, in this approach fiber stress is defined as the average of meridional and hoop stress, whereas in our method it is defined as the stress in the fibers which is the sum of axial and circumferential minus twice the radial stress. Because radial stress is almost zero in the subepicardial layers, Regen's values and ours are essentially the same.

Since direct experimental measurement of fiber stress is practically impossible, often mathematical models of the mechanics of the left ventricle are used to estimate fiber stress. When using experimentally determined mechanical properties of myocardial material, in such a model, the distribution of fiber stress appeared to be quite uniform, even if activation of the left ventricle was asynchronous [6]. The distribution of fiber strain during the ejection phase, however, was found to vary significantly with changes in activation time.

Regional contractile work has been estimated by calculating the area within the loop described by plotting left ventricular pressure as a function of regionally measured sarcomere or segment length $[5,21,38,39]$. Although the presence of a loop indicates generation of mechanical work, the quantitative value is limited. After all, left ventricular pressure is not a proper representative of myocardial fiber stress due to unknown and variable geometric factors. Furthermore, measured segment length is proportional to the more or less arbitrary length in the reference state. As a result, within one experiment the method may be used to obtain an indication of changes in regional work during the experiment, but comparison between different hearts is impossible. Hence, in two animals with equal stroke volume and time course of left ventricular pressure, but with different left ventricular wall and cavity volume, the same oxygen consumption will be calculated using the pressure length area, although the animal with the lowest left ventricular cavity to wall volume ratio is expected to have a lower fiber stress, and, consequently, a lower oxygen consumption.

In calculating the pressure-volume area, the left ventricular cavity volume below which no active pressure can be developed $\left(\mathrm{V}_{\mathrm{Iv}, \mathrm{d}}\right)$, may be set to zero without introducing large errors $[34,35]$. Using the values of measured left ventricular cavity volume at passive zero transmural pressure in Eq. (2), estimated sarcomere length at zero left ventricular cavity volume was found to be $1.59 \pm 0.04 \mu \mathrm{m}$ (Table 3). This is not significantly different from $1.60 \mu \mathrm{m}$, which is the sarcomere length at which active fiber stress is assumed to be zero [27].

The areas of the fiber stress-fiber strain loops in Fig. 5C consistently show an increase in size from early to late activated regions. So, late activated areas are likely to have a higher oxygen demand, which is supported by the 
Regional performance and oxygen demand

Table 3. Expermentaly derved values of let ventricular cavy woume at zero transmurat pressure (Veq), of

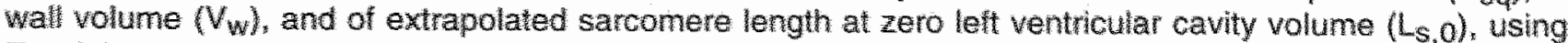
Eq. (2).

\begin{tabular}{|c|c|c|c|c|}
\hline experiment & $V_{\mathrm{ag}}(\mathrm{m})$ & $\mathrm{V}_{\mathrm{w}}(\mathrm{m})$ & $\mathrm{V}_{\mathrm{eq}} / \mathrm{V}_{w}$ & $L_{\mathrm{s}, 0}(\mathrm{~mm})$ \\
\hline 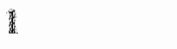 & 2 & 109.5 & 0.38 & 1.51 \\
\hline 2 & 38 & 135.2 & 0.28 & 1.59 \\
\hline 3 & 34 & 1229 & 0.28 & 1.59 \\
\hline 4 & 47 & 58.1 & 0.30 & 1.58 \\
\hline 5 & 34 & 147.6 & 0.23 & 1.64 \\
\hline 6 & 31 & 整8. & 0.26 & 4.61 \\
\hline mean $\pm S D$ & & & $0.29 \pm 0.05$ & $1.59 \pm 0.04$ \\
\hline
\end{tabular}

finding that the distributions of regional total mechanical power, blood llow, and oxygen uptake show a similar pattern. The present data indicate that the low myocardial blood flow and oxygen uptake values in early activated regions are determined by the lower demands in these regions. First of all, fiber stress is not higher in early than in late activated regions (Fig. 6). So, a larger compression of the microcirculation in early activated regions is not likely to be the cause of the lower blood flow. Moreover, the present study deats with blood flow in the subepicardial layers of the left ventricular free wall, which is known to be hardly affected by cardiac contraction. If early activation had induced underperfusion, one would expect increased oxygen extraction and increased $\mathrm{PCO}_{2}$ in the locally sampled venous blood in case of left ventricular apex pacing. However, this was not the case (Table 1 ). This finding is in accordance with the finding that altered myocardial oxygen demand generally induces a change in coronary blood flow rather than in oxygen ex traction $[7,11]$. However, despite simultaneous withdrawal of blood from the local vein and the coronary sinus, it cannot be excluded that through the local venous catheter, blood is also sampled from adjacent vascular beds via venous collaterals. If mixing with blood from adjacent areas occurs, changes due to asynchronous electrical activation will be underestimated. More detailed lateral and transmural mapping of oxygen uptake, for example using the microspectrometry technique developed by Weiss and co-investigators [42], is required to ultimately investigate the influence of asynchronous electrical activation on oxygen uptake.

The lower mechanical power in the early activated regions may be explained as follows. In early activated regions, the initial contraction is almost isotonic. The resulting smaller sarcomere length at the beginning of the ejection phase may be responsible for the absence of increased fiber stress during the ejection phase, 
although the sarcomeres contract isometrically (Figs. 5 and 6). Due to isometric contraction during ejection in early activated regions, external power is lower in early than in late activated regions. Because maximum fiber stress and sarcomere length at the end of the ejection phase are approximately the same in early and in late activated regions (Fig. 6), also potential power is approximately the same for all regions. Therefore, total mechanical power, being the sum of external and potential power, is lower in early than in late activated regions (Fig. 6).

Despite a fairly good overall relation between total mechanical power and regional oxygen uptake $(r=0.68)$, as shown in Table 2 and Fig. 7B, within the experiments the correlation was not always so high. One of the most important causes for this phenomenon is that the range in regional total mechanical power and oxygen uptake within an experiment was rather small. An alternative explanation for the varying reliability of the relation between oxygen uptake and total mechanical power is the difference in site of determination of oxygen uptake and deformation. Oxygen uptake was calculated from myocardial blood flow, as regionally measured in the subepicardial half of the left ventricular wall, and the arterio-coronary sinus difference in oxygen content. The regional fiber stressfiber strain area was determined at the epicardial surface. Since no differences were found between the biochemical variables measured in the blood samples from the local coronary vein and the coronary sinus (Table 1), the blood sample from the coronary sinus was regarded to be representative of the whole heart, even during asynchronous electrical activation. Since oxygen consumption was estimated from regionally measured blood flow and arterio-coronary sinus differences in oxygen content, regional oxygen uptake is mainly a function of the microsphere distribution. However, from experiment to experiment, and, within each experiment, from pacing mode to pacing mode, random differences in arterio-venous differences in oxygen content were detected. Therefore, both components of oxygen uptake, blood flow and oxygen extraction, are taken into account as far as the relation with the regional indices of contractile work is concerned.

Table 4. Comparison of total mechanical power (TMP)-regional oxygen demand relation with pressurevolume area (PVA)-global oxygen demand relation as presented in literature.

\begin{tabular}{llllll}
\hline study & procedure & (non)ejecting & species & $\begin{array}{l}\text { slope } \\
(\mathrm{mol} / \mathrm{J})\end{array}$ & $\begin{array}{l}\text { intercept } \\
\left(\mathrm{mmol} /\left(\mathrm{m}^{3} . \mathrm{s}\right)\right)\end{array}$ \\
\hline this study & SSA & ejecting & $\operatorname{dog}$ & 4.65 & 25.7 \\
Suga 79 & PVA & ejecting & $\operatorname{dog}$ & 4.16 & 18.3 \\
Suga 83 & PVA & ejecting & dog & 4.62 & 22.9 \\
Khalafbeigui 79 & PVA & nonejecting & dog & 4.64 & 13.0 \\
Goto 88 & PVA & nonejecting & rabbit & 5.76 & 26.9 \\
\hline
\end{tabular}


The relation between regional total mechanical power and regional myocardial oxygen uptake, obtained by pooling all data, is in quantitative agreement with the relations as described between the pressure-volume area and global cardiac oxygen demand (Table 4) $[14,20,33$, 36]. In those studies, energy units of the pressure-volume area and oxygen uptake were $\mathrm{mmHg} \cdot \mathrm{ml}$ and $\mathrm{ml} \mathrm{O}_{2}$, respectively. These units were converted into the units as used in this study, assuming that the values of oxygen uptake were given in $\mathrm{ml}$ at $273 \mathrm{~K}$ and at 1 atmosphere. The similarity of the relations provides evidence that regional total mechanical power can be used to estimate regional oxygen demand.

\section{Conclusions}

Regional fiber stress in the subepicardial half of the left ventricular wall during synchronous as well as asynchronous electrical activation, can be calculated from left ventricular pressure, left ventricular cavity and wall volume, and regional subepicardial fiber strain. Regional fiber stress thus calculated during asynchronous electrical activation is quite uniformly distributed, despite large differences in regional fiber strain. During asynchronous electrical activation, regional contractile work, myocardial blood flow, and oxygen uptake were significantly lower in early than in late activated regions. Using values of regionally measured fiber strain and calculated fiber stress, regional oxygen demand can be estimated from the fiber stress-fiber strain area in analogy to the estimation of global left ventricular oxygen demand on the basis of left ventricular pressure and volume according to Suga and co-investigators [33-35]. Division of the fiber stress-fiber strain area by the duration of the cardiac cycle reveals regional total mechanical power (TMP). When determining regional oxygen uptake $\left(\dot{\mathrm{V}}_{\mathrm{O}_{2, \mathrm{reg}}}\right)$ as the product of regional myocardial blood flow and arterio-coronary sinus difference in oxygen content, it is found that $\dot{\mathrm{V}}_{\mathrm{O}_{2, \mathrm{reg}}}=\mathrm{k}_{1} \mathrm{TMP}+\mathrm{k}_{2}$, with $\mathrm{k}_{1}=4.94 \pm$ $0.31 \mathrm{~mol} / \mathrm{J}$ and $\mathrm{k}_{2}=24.2 \pm 1.9 \mathrm{mmol} / \mathrm{m}^{3}$.s. This relation between regional total mechanical power and myocardial oxygen demand is in quantitative agreement with previously reported relations between global oxygen demand and measured pressure-volume area. The results indicate that asynchronous electrical activation causes a redistribution of mechanical work and oxygen demand and that regional total mechanical power is a better and more general estimate of regional oxygen demand than the pressuresarcomere length area.

\section{References}

1. Allessie MA, Hoeks APG, Schmitz GML; Reneman RS (1986) On-line mapping system for the visualization of the electrical activation of the heart. Int J Cardiac Imag 2: 59-63

2. Arts T, Bovendeerd PHM, Prinzen FW, Reneman RS (1991) Relation between left ventricular cavity pressure and volume and systolic fiber stress and strain in the wall. Biophys J 59: 93-102

3. Arts T, Reneman RS (1980) Measurement of deformation of canine epicardium in vivo during car 
diac cycle. Am I Physiol 239: H432-H437

4. Arts T, Veenstra PC, Reneman RS (1982) Epicardial deformation and left ventricular wall mechanics during ejection in the dog. Am J Physiol 243: H379-H390

5. Badke FR, Boinay P, Covell JW (1980) Effect of ventricular pacing on regionall left ventricular performance in the dog. Am I Physiol 238: H858$1 \mathrm{H} 867$

6. Bovendeerd PHM (1990) The mechanics of the normal and ischemic left ventricle during the cardiac cycle, PhD thesis, University of Limburg

7. Braunwald $\mathrm{E}$ (1971) Control of myocardiall oxygen consumption. Am J Cardiol 27: 416-432

8. Chadwick RS (1982) Mechanics of the left ventricle. Biophys J 39: 279-288

9. Delhaas T, Arts T, Bovendeerd PHM, Prinzen FW, Reneman RS (1993) Subepicardial fiber stress and strain as related to left ventricular pressure and volume. Am J Physiol 264: H1548-H1559

10. Delhaas $T$, Arts T, Prinzen FW, Reneman RS (1993) Relation between regional electrical activation time and subepicardial fiber strain in the canine left ventricle. Pflügers Arch (Eur J Physiol) 423: $78-87$

11. Feigl EO (1983) Coronary Physiology. Physiological Reviews 63: 1-205

12. Feigl EO, Simon GA, Fry DL (1967) Auxotonic and isometric cardiac force transducers. J Appl Physiol 23: 597-600

13. Gallagher KP, Osakada G, Matsuzaki M, Kemper WS, Ross jr J (1982) Myocardial blood flow and function with critical coronary stenosis in exercising dogs. Am J Physiol 243: H698-H707

14. Goto Y, Slinker BK, LeWinter MM (1988) Similar normalized Emax and $\mathrm{O} 2$ consumption-pressurevolume area relation in rabbit and $\operatorname{dog}$. Am J Physiol 255: H366-H374

15. Grimm $\mathrm{AF}^{F}$, Lin HL, Grimm BR (1980) Left ventricular free wall and intraventricular pressure sarcomere length distributions. Am J Physiol 239:

\section{H101-H107}

16. Hata $\mathbb{K}$, Goto $Y$, Suga $H$ (1991) External mechancall work during relaxation period does not affect myocardial oxygen consumption. Am J Physiol 261: H1778-H1784

17. Hisano $R$, Cooper $G(1987)$ Correlation of forcelength area with oxygen consumption in ferret papillary muscle. Circ Res 61: 318-328

18. Hoeks APG, Schmitz GML, Allessie MA, Jas H, Hollen SJ, Reneman RS (1988) Multichannel storage and display system to record the electrical activity of the heart. Med \& Biol Eng \& Comput 26: 434-438

19. Huisman RM, Elzinga, Westerhof N, Sipkema $P$ (1980) Measurement of left ventricular wall stress. Cardiovase Res 14: $142-153$

20. Khalafbeigui F, Suga H, Sagawa K (1979) Left ventricular systolic pressure-volume area correlates with oxygen consumption. Am J Physiol 237: H566-H569

21. Lew WYW (1987) Influence of ischemic zone size on nonischemic area function in the canine left ventricle. Am J Physiol 252: H990-H997

22. LeWinter MM, Kent RS, Kroener JM, Carew TE, Covell JW (1975) Regional differences in myocardial performance in the left ventricle of the dog. Cire Res 37: 191-199

23. Lister JW, Klotz DH, Jomain SL, Stuckey JH, Hoffman B (1964) Effect of pacemaker site on cardiac output and ventricular activation in dogs with complete heart block. Am J Cardiol 14: 494-503

24. Muijtjens AMM, Roos JMA, Prinzen TT, Arts T (1990) Noise reduction in estimating epicardial deformation from marker tracks. Am J Physiol 258: H599-H605

25. Panerai RB (1980) A model of cardiac muscle mechanics and energetics. J Biomech 13:929-940

26. Parmley WW, Tyberg JV (1976) Determinants of myocardial oxygen demand. Prog Cardiol. 5: 19-36

27. Pollack GH, Krueger JW (1976) Sarcomere dynamics in intact cardiac muscle. Eur J Cardiol 4 
(suppl): 53-65

28. Primzen FW, Arts T, van der Vusse GJ, Coumans WA, Reneman RS (1986) Gradients in fiber shortening and metabolism across ischemic left ventricular wall. Am J Physiol 250: H255-H264

29. Prinzen FW, Augustijn $\mathrm{CH}$, Arts T, Allessie MA, Reneman RS (1990) Redistribution of myocardial fiber strain and blood flow by asynchronous electrical activation. Am J Physiol 259: H300-H308

30. Prinzen TT, Arts T, Prinzen FW, Reneman RS (1986) Mapping of epicardial deformation using a video processing technique. J Biomech 19: 263-273

31. Regen DM, Anversa P. Capasso JM (1993) Segmental calculation of left ventricular wall stresses. Am J Physiol 264: H1411-H1421

32. Spotnitz HM, Sonnenblick EH, Spiro D (1966) Relation of ultrastructure to function of the intact heart. Sarcomere structure relative to pressure-volume curves of intact left ventricles of dog and cat. Circ Res 18: 49-66

33. Suga H (1979) Total mechanical energy of a ventricle model and cardiac oxygen consumption. Am J Physiol 236: H498-H505

34. Suga H, Hayashi T, Shirahata M (1981) Ventricular systolic pressure volume area as predictor of cardiac oxygen consumption. Am J Physiol 240: $\mathrm{H} 39-\mathrm{H} 44$

35. Suga $H$, Hayashi $T$, Shirahata $M$, Suehiro $S$, Hisano R (1981) Regression of cardiac oxygen consumption on ventricular pressure volume area in dog. Am J Physiol 240: H320-H325
36. Suga $H$, Hisano R, Hirata S, Mryashi T, Yamada O, Ninomiya I (1983) Heart rare-independent energetics and systolic pressure-volume area in dog heart. Am J Physiol 244: H206-H214

37. ter Keurs HEDJ, Rijnsburger WH, van Heuningen R, Nagelsmit MJ (1980) Tension development and sarcomere length in rat cardiac trabeculae; evidence of length-dependent activation. Cire Res 46: 703714

38. Theroux P, Franklin D, Ross JJ, Kemper WS (1974) Regional myocardial function during acute coronary artery occlusion and its modification by pharmacologic agents in the dog. Circ Res 35: 896908

39. Tyberg JV, Forrester JS, Wyatt HL, Goldner SJ, Parmley WW, Swan HJC (1974) An analysis of segmental dysfunction utilizing the pressure-length loop. Circulation 49: 748-754

40. van Heuningen R, Rijnsburger WH, ter Keurs HEDJ (1982) Sarcomere length control in striated muscle. Am J Physio! 242: H4 I I-H420

41. Weber KT (1979) Seminar on myocardial oxygen utilization. Introduction: physiologic and clinical conelates. Am J Cardiol 44: 719-721

42. Weiss HR, Neubauer JA, Lipp JA, Sinha AK (1978) Quantitative determination of regional oxygen consumption in the dog heart. Circ Res 42 : 394-401

43. Wiggers CI (1925) The muscular reactions of the mammalian ventricles to artificial surface stimuli. Am J Physiol 73: 346-378 



\section{REGIONAL BLOOD FLOW AND CONTRACTILE WORK IN THE CANINE LEFT VENTRICULAR SUBEPICARDIUM DURING CORONARY ARTERY OCCLUSION}

Tammo Delhaas, Theo Arts*, Frits W. Prinzen and Robert S. Reneman

Departments of Physiology and Biophysics*, Cardiovascular Research Institute Maastricht, University of Limburg, P.O.Box 616, NL-6200 MD Maastricht, The Netherlands.

Submitted 
Abstract. Occlusion of the left anterior interventricular coronary artery (LAICA) causes ischemia, which is known to disturb mechanical performance. In contrast to regional deformation, the distribution of active $\left(\sigma_{\mathrm{fa}}\right)$ and passive fiber stress $\left(\sigma_{\mathrm{fp}}\right)$ is hardly known. Because direct measurement of regional $\sigma_{\mathrm{f}}$ is practically impossible, a model of cardiac mechanics will be introduced to estimate regional $\sigma_{\mathrm{fa}}$ and $\sigma_{\mathrm{fp}}$ during systole from experimentally measured left ventricular (LV) pressure, LV cavity and wall volume, and regionally measured fiber strain $\left(e_{f}\right)$. In this study, the effect of LV dilation, caused by normoxic or ischemic hypervolemia, on regional subepicardial mechanics will be quantified. Furthermore, four indices of regional performance, i.e. ef, pressure-sarcomere length area (PSL), external (EMP) or total mechanical power (TMP), were compared on their predictive value of regional oxygen uptake $\dot{\mathrm{V}}_{2}$ during control and ischemia. In 5 anesthetized open-thorax dogs subepicardial blood flow ( $\dot{\mathrm{Q}}_{\mathrm{epi}}$ ), $\dot{\mathrm{V}}_{\mathrm{O}_{2}}$, and $\mathrm{e}_{\mathrm{f}}$ were measured in 16 regions of the $\mathrm{LV}$ anterior wall during normoxia, and normoxic and ischemic hypervolemia. Ischemia was induced by LAICA oc-

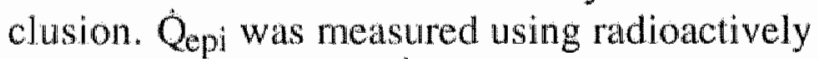
labeled microspheres. $\dot{V}_{\mathrm{O}_{2}}$ was calculated from Qepi and arterio-venous differences in oxygen content. ef was measured using optical markers attached to the epicardial surface and recorded on video. EMP and TMP were estimated from the time curve of $\sigma_{f a}$ and $e_{f}$ in analogy to the pressure-volume area of Suga and co-investigators. During the normoxic control and hyper- volemic situation, $\dot{Q}_{e p i}, \dot{V}_{\mathrm{O}_{2}}, e_{\mathrm{f}}, \sigma_{\mathrm{fa}}, \mathrm{PSL}$, EMP and TMP were uniformly distributed. Values of estimated $\sigma_{\mathrm{fa}}$ and $\sigma_{\mathrm{fp}}$ were within the physiological range. During LAICA occlusion, considerable development of $\sigma_{\mathrm{fa}}$ was found within the ischemic region. In the central ischemic area $\dot{\mathrm{Q}}_{\mathrm{epi}}, \dot{\mathrm{V}}_{\mathrm{O}_{2}}$, e $\mathrm{e}_{\mathrm{f}}, \sigma_{\mathrm{fa}}, \mathrm{PSL}, \mathrm{EMP}$, and TMP were reduced by maximally $80 \%$. Within an individual experiment significant, not mutually different correlations between the four indices of regional performance and $\dot{\mathrm{V}}_{\mathrm{O}_{2}}$ were found. However, from the pooled data, it appeared that EMP and TMP were the best predictors of regional oxygen consumption. The intercept of the relation between TMP and $\dot{\mathrm{V}}_{\mathrm{O}_{2}}$, however, was negative, and its slope was steeper than the slopes of the reported relations between PVA and $\dot{\mathrm{V}}_{2}$. Using our model, fiber stress can be reliably calculated. TMP, derived from calculated $\sigma_{f a}$ and measured $e_{f}$, can be used to predict $\dot{\mathrm{V}}_{\mathrm{O}_{2}}$, although the negative intercept and the high values for the slope of the relation between TMP and $\dot{\mathrm{V}}_{2}$, indicate that more knowledge about (passive) material properties is required.

\section{Introduction}

Myocardial ischemia, caused by coronary artery occlusion, affects the mechanical function of the myocardium. After occlusion of a coronary artery, in the ischemic area systolic fiber shortening stops within seconds, while paradoxical systolic lengthening may be observed within a few minutes $[23,37]$. In contrast to regional de- 
formation, the distribution of active and passive fiber stress is hardly known. Since ischemia causes dilation of the ventricle $[9,14]$, an increase of fiber stress is to be expected $[1,3]$. Direct measurement of regional fiber stress is practically impossible, because the insertion of transducers into the wall damages the tissue at the site of measurement $[5,13]$. Therefore, a modification of an earlier model of cardiac mechanics $[1,2]$ was used to estimate regional fiber stress during systole from experimentally measured left ventricular pressure, left ventrictilar cavity and wall volume, and regionally measured fiber strain. In this study, the effect of left ventricular dilation, caused by normoxic hypervolemia or ischemia, on the regional subepicardial mechanics of the left ventricle will be quantified.

For the normoxic left ventricle, fiber shortening or mechanical work on the one hand, and myocardial blood flow or oxygen uptake on the other, were shown to be mutually related [24]. For the ischemic left ventricle regional myocardial blood flow and oxygen uptake increase with regionally developed power. The lowest values of blood flow and mechanical function occurred in the ischemic area and the highest values in the normoxic area $[7,8,43,45]$. However, in none of the studies mentioned regional external work, as estimated from fiber stress and fiber strain, is related to regional oxygen demand. In this study, regional blood flow and oxygen uptake were related to regional external mechanical power and regional total mechanical power. The latter index was ob- tained from the time curve of estimated fiber stress and fiber strain in analogy to the pressure-volume area of Suga and co-investigators [30-32]. For comparison, the hitherto used indices of mechanical function, regional fiber strain during the ejection phase and regional pressure sarcomere length area, were related to regional oxygen uptake as well. Experiments were performed in anesthetized open-thorax dogs, while the right atrium was paced. Measurements were made during a normoxic control, a normoxic hypervolemic as well as an ischemic hypervolemic period. Ischemia was induced by occlusion of the distal part of the left anterior interventricular coronary artery (LAICA).

\section{Methods}

Calculation of regional fiber stress. In the present study a modification of the model of Arts et al. $[1,2]$ was used to estimate regional values for fiber stress. In brief, the left ventricle was assumed to be thick-walled and rotationally symmetric. The wall consist of anisotropic material, e.g. muscle fibers embedded in soft incompressible material. The distribution of force acting in the fiber direction, defined as Cauchy fiber stress $\left(\sigma_{f}\right)$ times cross-sectional area of the muscle fibers, is homogeneous. Regional wall volume was assumed to be constant throughout the cardiac cycle. On the basis of these assumptions it was derived that during the ejection phase the first Piola-Kirchhoff stress $\left(\tau_{f}\right)$ acting in the fiber direction can be derived from left 
ventricular pressure $\left(\mathrm{p}_{\mathrm{V}}\right)$ and the dimensionless ratio of left ventricular cavity $\left(\mathrm{V}_{\mathrm{lv}}\right)$ to wall volume $\left(V_{w}\right)$ as follows:

$$
\tau_{\mathrm{f}}=\mathrm{p}_{\mathrm{IV}}\left[1+3 \mathrm{v}_{\mathrm{lv}} / \mathrm{v}_{\mathrm{w}}\right]^{\frac{2}{3}}
$$

Cross-sectional area of the fibers at extrapolated. zero left ventricular cavity volume was taken as reference. To derive regional values of Cauchy fiber stress associated with the actual size of the cross-sectional area of the muscle fibers, Eq. (1) was corrected using regional values of fiber shortening as compared to the reference situation. So, for regional Cauchy fiber stress $\sigma_{\text {f,reg }}$ it is found:

$$
\sigma_{\mathrm{f}, \mathrm{reg}}=\mathrm{p}_{\mathrm{Iv}}\left[1+3 \mathrm{v}_{\mathrm{lv}} / \mathrm{v}_{\mathrm{w}}\right]^{\frac{2}{3}} \frac{\mathrm{l}_{\mathrm{s}, \mathrm{reg}}}{\mathrm{l}_{\mathrm{s}, \mathrm{V}_{\mathrm{IV}}=0}}
$$

in which $\mathrm{l}_{\mathrm{S} \text {,reg }}$ and $\mathrm{l}_{\mathrm{S}, \mathrm{V}} \mathrm{V}=0$ represent regional sarcomere length in the actual situation and at zero left ventricular cavity volume, respectively.

Neglecting the viscous behavior of passive myocardial fibers, the relation between regional passive fiber stress $\left(\sigma_{\mathrm{fp}, \mathrm{reg}}\right)$ and regional sarcomere length $\left(\mathrm{l}_{\mathrm{s}, \mathrm{reg}}\right)$ can be described by:

$$
\sigma_{\text {fp,reg }}=\sigma_{\text {fpo }}\left(\exp \left[\mathbf{b}\left(1_{\mathrm{s}, \mathrm{reg}}-\mathbf{a}\right)\right]-1\right)
$$

in which $a, b$, and $\sigma_{\mathrm{fp} 0}$ are parameters. The parameter a represents the sarcomere length under zero load $\left(\sigma_{\mathrm{fp}, \mathrm{reg}}=0\right)$, and was initially set at $1.95 \mu \mathrm{m}$, which is the sarcomere length at zero left ventricular transmural pressure in the passive state $[12,29]$. If regional passive fiber stress at end-diastole appeared to be higher than calculated total stress, a was corrected regionally, so that passive and total fiber stress were equal. The parameter $b$ governs the exponential increase of $\sigma_{\mathrm{fp}}$ with increasing sarcomere length. Based on experiments on isolated cat papillary muscle the value of $b$ was assumed to be $8 \mu \mathrm{m}^{-1}[38,42]$. For each separate experiment, the value of $\sigma_{\mathrm{fp} 0}$ was calculated from end-diastolic left ventricular pressure and left ventricular cavity volume as measured in the control situation.

The active component of regional fiber stress during systole $\left(\sigma_{\mathrm{fa}, \mathrm{reg}}\right)$ was obtained by subtracting regional passive fiber stress $\left(\sigma_{\mathrm{fp}, \mathrm{reg}}\right.$; Eq. (3)) from total fiber stress $\left(\sigma_{\mathrm{f}, \mathrm{reg}}\right.$; Eq. (2)).

Estimation of regional sarcomere length. During ejection average sarcomere length $\left(l_{\mathrm{s}}\right.$,avg $)$ depends solely on the instantaneous ratio of left ventricular cavity volume to left ventricular wall volume $[1,2]$ :

$$
\frac{1_{s, a v g}}{1_{s, V_{1 v}=0}}=\left[L+3 \frac{V_{l v}}{V_{w}}\right]^{\frac{1}{3}}
$$

where $1_{s, V_{I v}=0}$ represents sarcomere length at extrapolated zero left ventricular cavity volume.

In the present study, sarcomere length was 
used to quantify the length of the cardiac muscle fiber. The following assumptions were made:

- Sarcomere length at zero left ventricular transmural pressure in the passive state $\left(\mathrm{I}_{\mathrm{s}, \text { eq }}\right)$ equals $1.95 \mu \mathrm{m}[12,29]$, while the corresponding left ventricular cavity volume is defined as $\mathrm{V}_{\mathrm{lv} \text {,eq. }}$.

- In the systolic phase, sarcomere length keeps $l_{s, e q}$, if left ventricular cavity volume equals $\mathrm{V}_{\text {lv,eq. }}$

- In the synchronously activated left ventricle, fiber shortening and, hence, sarcomere shortening is homogeneous during the ejection phase [3].

So, sarcomere length at mid-ejection of the control beat $\left(1_{s, r e f}\right)$, which is the reference state for the deformation measurements, can be calculated by:

$$
\mathrm{I}_{\mathrm{s}, \mathrm{ref}}=\mathrm{l}_{\mathrm{s}, \mathrm{eq}}\left[\frac{1+3\left(\mathrm{~V}_{\mathrm{lv}, \mathrm{ref}} / \mathrm{V}_{\mathrm{w}}\right)}{1+3\left(\mathrm{~V}_{\mathrm{lv}, \mathrm{eq}} / \mathrm{V}_{\mathrm{w}}\right)}\right]^{\frac{1}{3}}
$$

Regional sarcomere length is calculated from regionally measured strain differences between the control and the actual state.

Estimation of regional contractile work and energy demand. In the present study several indices of regional mechanical function were correlated with regional oxygen uptake: a) fiber strain during the ejection phase $\left(e_{f}\right)$; b) the pressure-sarcomere length area (PSL), which is the area bounded by the systolic limb of the pressure-sarcomere length loop trajectory and the $x$-axis $[39,41]$; c) regional external mechanical power (EMP) estimated from regional external mechanical work $\left(E_{e}\right)$, i.e. the area enclosed by the fiber stress-fiber strain loop, divided by the duration of the cardiac cycle $\left.\left(t_{\text {cycle }}\right) ; d\right)$ the fiber stress-fiber strain area, a regional analog of the model presented by Suga and co-investigators [30-32]. In this model, the total amount of mechanical energy needed for the left ventricle to contract from end-diastolic to end-systolic volume is the sum of $\mathrm{E}_{\mathrm{e}}$ and the socalled end-systolic potential work $\left(E_{p}\right)$. This combined area is equal to the pressure-volume area (PVA), which is the area bounded by the end-systolic (active) and end-diastolic (passive) pressure-volume curves and the systolic limb of the pressure-volume loop trajectory (Fig. 1A). The intersection of the end-systolic pressurevolume curve and the $x$-axis is denoted by $\mathrm{V}_{\mathrm{lv}, \mathrm{d}}$. Below this volume no active pressure can be developed [30-32]. The relation of PVA to the oxygen demand $\left(\dot{V}_{\mathrm{O}_{2}}\right)$ was described by a linear equation. Analogously, regional oxygen demand in the left ventricular tissue is assumed to be proportional to the regional fiber stressfiber strain area (SSA) (Fig. 1B). The regional SSA was calculated from the area bounded by the end-systolic and passive fiber stress-fiber strain relations, and the systolic limb of the fiber stress-fiber strain loop trajectory (Fig. 1B). Regional total mechanical power (TMP) was calculated as SSA divided by $t_{\text {cycle. }}$.

Whereas the end-systolic pressure-volume relation is represented by a straight line, the end-systolic fiber stress-fiber strain relation is 


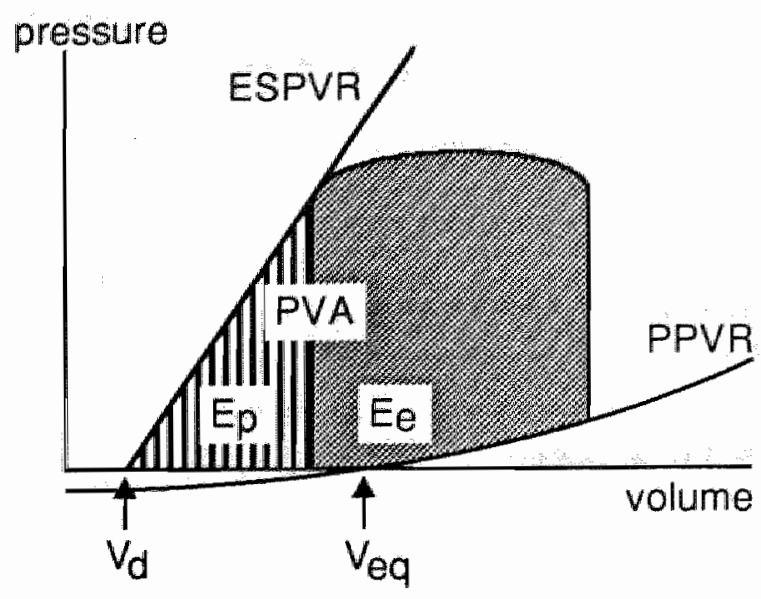

fiber stress

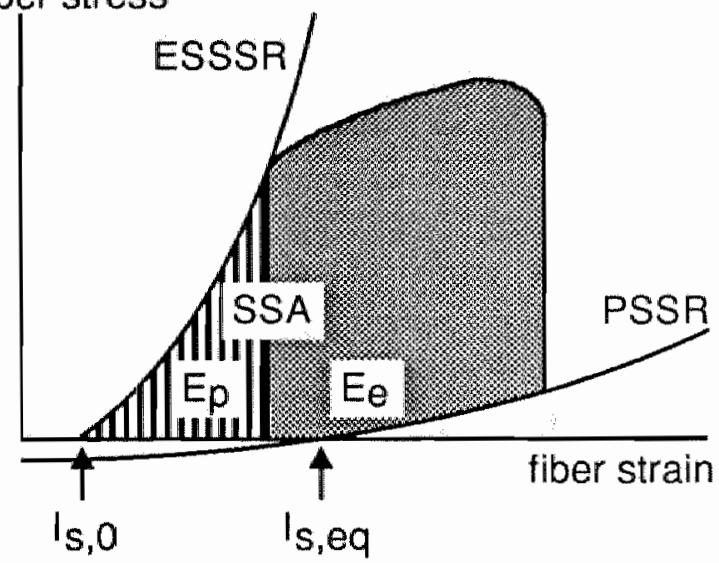

curvilinear. This difference in shape is explained by the fact that left ventricular cavity pressure is linearly related to fiber stress, while left ventricular cavity volume is proportional to fiber strain to the third power.

Animal preparation and instrumentation. All experiments were performed in accordance with the "Guiding principles in the care and use of
Fig. 1. Graphic representation of pressure-volume area (PVA; panel $A$ ) and fiber stress-fiber strain area (SSA; panel B). Both PVA and SSA have two components, external $\left(E_{e}\right)$ and potential work $\left(E_{p}\right)$. $E_{e}$ is area within pressure-volume (PV) or fiber stress-fiber strain (SS) trajectory of one contraction. $E_{p}$ is defined as area surrounded by end-systolic PV (ESPVR) or SS relation (ESSSR), passive PV (PPVR) or SS relation (PSSR), and isovolumic relaxation segment of PV or SS trajectory. ESPVR is represented by a straight line, while ESSSR is curvilinear. This difference in shape is explained by the fact that left ventricular pressure is linearly related to fiber stress, while left ventricular cavity volume is proportional to fiber strain to the third power. $V_{d}$ and $V_{e q}$ are left ventricular cavity volume at zero end-systolic left ventricular pressure and at passive zero transmural pressure, respectively. $I_{s, 0}$ and $\mathrm{I}_{\mathrm{s}, \mathrm{eq}}$ represent sarcomere length at zero active fiber stress and at passive zero transmural pressure, respectively.

animals" as approved by the council of the American Physiological Society and under the regulations of the Animal Care Committee of the University of Limburg.

Five adult mongrel dogs of either sex, ranging in weight from 23 to $29 \mathrm{~kg}$ were premedicated with an intramuscular injection of Hypnorm ( $1 \mathrm{ml} . \mathrm{kg}^{-1} ; 1 \mathrm{ml}$ Hypnorm contains $10 \mathrm{mg}$ fluanisone and $0.2 \mathrm{mg}$ fentanyl base). 


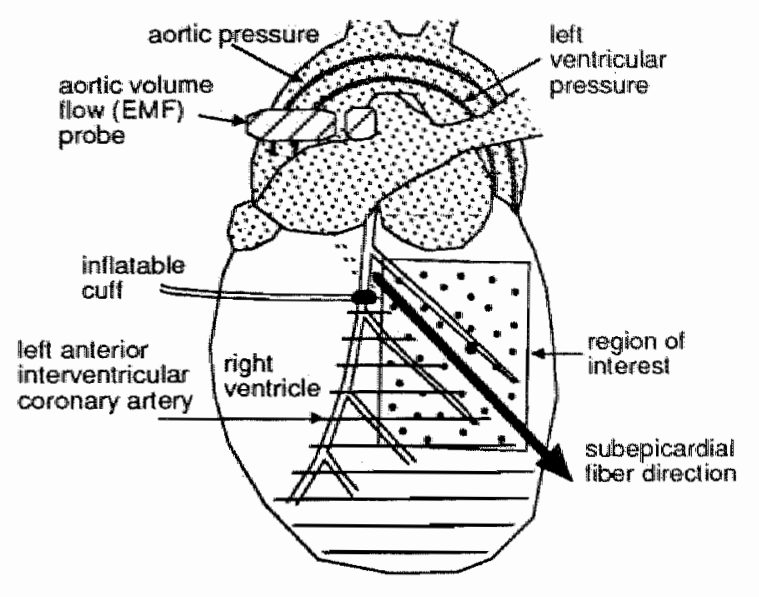

Fig. 2. Schematic representation of experimental setup. Dots within the area of interest are optical markers attached to the epicardial surface. Shaded area indicates ischemic region, resulting from the occlusion of the distal part of the left anterior interventricular coronary artery.

Anesthesia was induced with an intravenous injection of pentobarbital sodium $\left(10 \mathrm{mg} \cdot \mathrm{kg}^{-1}\right)$ and maintained after endotracheal intubation with nitrous oxide $\left(33 \% \mathrm{O}_{2}, 67 \% \mathrm{~N}_{2} \mathrm{O}\right)$ and a continuous infusion of pentobarbital sodium ( 2 mg. $\left.\mathrm{kg}^{-1} \cdot \mathrm{h}^{-1}\right)$. Ventilation was kept constant with a positive pressure respirator (Pulmomat, Dräger). The animal was placed on its right side, and body temperature was kept between 37.5 and $38.5^{\circ} \mathrm{C}$ by means of a thermostatically regulated heating pad. A standard limb lead electrocardiogram (ECG) was used. Arterial biood samples were taken periodically to determine $\mathrm{pO}_{2}, \mathrm{pCO}_{2}, \mathrm{pH}$, oxygen saturation and hemoglobin concentration ( $\mathrm{ABL}$ 3, Radio- meter). Sodium bicarbonate solution $(4.2 \%)$ was administered intravenously to adjust the acid-base balance when necessary.

The chest was opened through the left fifth intercostal space. After removal of the fifth rib, the pericardium was opened and the heart was suspended in a pericardial cradle. Epicardial bipolar platinum pacing electrodes were sutured to the heart at the right atrium (Fig. 2).

The LAICA was dissected free distal to the first diagonal side branch over a distance of about $1.5 \mathrm{~cm}$ and an inflatable cuff with a width of approximately $0.6 \mathrm{~cm}$ was placed around it.

A polyethylene catheter was inserted into the left anterior interventricular vein to obtain venous blood from the area expected to become ischemic. A polyethylene catheter was inserted into the coronary sinus. Blood samples obtained through this catheter were considered to be representative of the remaining non-ischemic part of the left ventricle.

To assess regional myocardial blood flow, a silastic catheter was placed in the left atrium for the injection of radioactively labeled microspheres [23]. A polyethylene catheter was inserted into the right brachial artery to obtain blood for the arterial reference sample.

Left ventricular cavity and ascending aortic pressure were measured with catheter-tip micromanometers (Millar PC-470), inserted via the right brachial and the right femoral artery, respectively. To enable pressure calibration during the experiment, the fluid-filled lumina of the catheter-tip micromanometers were connected via three-way cocks to an external pres- 
sure transducer (Electromedics MS20). The third opening of the three-way cock was connected to a reference pressure level, which was the right atrial level for all pressure measurements [2]. Ascending aortic volume flow was measured with an electromagnetic flow meter (Skalar Transflow 601).

Four inductive coils were sutured to the epicardium of the left ventricle in a tetrahedral configuration, so that the length of each of the six edges was more or less equal. The 6 signalls obtained from these coills were used for the determination of left ventricular cavity volume (see below) [3].

ECG, pressure and ascending aortic volume flow signals, as well as the 6 signals from the inductive coils, were continuously visualized on an oscilloscope (Knott). These signals were also recorded on a paper recorder (Schwarzer) and a multichannel tape recorder (Ampex PR2200).

Experimental protocol. Measurements were performed during a normoxic control situation, and after $15 \mathrm{~min}$ of normoxic hypervolemia and ischemic hypervolemia. Ischemia was induced by occlusion of the distal part of the LAICA. Hypervolemia was induced by rapid intravenous infusion of a polygeline infusion liquid (Haemaccel ${ }^{\circledR}$, Behringwerke $\mathrm{AG}$ ). When enddiastolic pressure reached the level of $1.8 \mathrm{kPa}$ and was stable for more than $2 \mathrm{~min}$, the infusion rate was decreased to a maintenance level for $15 \mathrm{~min}$. Subsequently, the distal part of the LAICA was occluded.
In all experimental conditions measurements were performed as follows. Arterial, local venous, and coronary sinus blood samples were taken for blood gas analysis after a stabilization period of $15 \mathrm{~min}$. Subsequently, microspheres were injected and a reference arterial sample was taken for the calculation of regional. myocardial blood flow. Hemodynamic variables and epicardial deformation were recorded simultaneously. During normoxic hypervolemia no microspheres were injected.

The experiment was terminated by administration of an overdose of pentobarbital sodium. Within 5 min thereafter, the heart was excised, the ventricles were removed from the atria, and were rinsed. To determine the volume of the left ventricular cavity at zero transmural pressure, the left ventricle was immersed in saline, keeping the base on top just above the saline level. Subsequently, the content of the left ventricular cavity was withdrawn with a graded syringe. Thereafter the free wall of the right ventricle was dissected and the weight of the left ventricle was determined.

Determination of hemodynamic variables. After the experiments, the hemodynamic data, as recorded on analog tape, were sampled (200 $\mathrm{Hz}$ ) and digitized using a 16-channel 12-bit A/D card (DASH 16G2), connected to a MS-DOS personal computer (Tulip AT Compact). Sampling and analysis were performed using a software package (ASYST 3.0, MacMillan Software Company) and software developed in our laboratory. In the cardiac cycle three events 
were determined. The end of the diastolic phase was defined as the moment before ejection at which the rate of change of left ventricular pressure $\left(\mathrm{dp} / \mathrm{v} / \mathrm{dt}\right.$ ) exceeded $10 \mathrm{kPa}^{-1}$ [18]. The beginning of the ejection phase was determined by the moment at which left ventricular pressure exceeded end-diastolic aortic pressure. The duration of the ejection phase was determined from the aortic volume flow signal. From left ventricular pressure as a function of time, enddiastolic left ventricular pressure, maximum left ventricular pressure, and maximum first derivative of left ventricular pressure were determined. Besides, the following hemodynamic variables were determined: heart rate, left ventricular cavity volume as a function of time (see below), maximum instantaneous ascending aortic volume flow, and ejected volume (time integral of ascending aortic volume flow).

Left ventricular cavity volume during systole was estimated as described in detail before [3]. In brief, a two-dimensional echocardiographic image of the minor axis projection at the equator of the left ventricle was used to calculate left ventricular cavity volume at end-diastole in the control situation. Changes in end-diastolic volume as compared with this reference situation were determined using the 6 signals of the four inductive coils. The time course of left ventricular cavity volume during ejection was obtained by subtracting the instantaneous integral of ascending aortic volume flow from enddiastolic volume.

Synchronization of hemodynamic data with deformation data was performed as described previously [4].

Mapping of left ventricular epicardial deformation. Two-dimensional epicardial deformation was determined with a video technique as previously described in detail [26]. In brief, approximately 40 white markers were attached with tissue glue (Histoacryl) to the epicardial surface of the left ventricular anterior wall at mutual distances of approximately $6 \mathrm{~mm}$. The area covered with markers extended $3-4 \mathrm{~cm}$ in the circumferential and $4-5 \mathrm{~cm}$ in the base-toapex direction (Fig. 2). A video camera (Sony AVC $32500 \mathrm{CE}$ ) with a $200 \mathrm{~mm}$ tele-objective, positioned at an optical distance of $2.5 \mathrm{~m}$ was used to record the motion of the markers on a video recorder (Sony SL-C9ES, Betamax) at a speed of 50 frames per second. For convenience, the optical axis was deflected by a mirror, mounted above the heart at an angle of $45^{\circ}$. Video-triggered xenon flashlight illumination (Chadwick-Helmuth) was employed to prevent motion artifacts due to smearing of the images. The direction of the epicardial fibers and the long axis of the left ventricle, as determined by visual inspection, was indicated by a directed ruler and recorded on video (Fig. 2). To enable synchronization with hemodynamic data, a frequency-modulated left ventricular pressure signal was recorded on an audio channel of the video recorder.

After the experiment, 64 consecutive video frames $(50 \mathrm{~Hz}$ ) were digitized and stored in a 2 
Mbyte digital video memory, which was coupled to a computer (PDP 11/73). Markers were detected, filtered by use of a singular value decomposition technique [19], and used for the estimation of epicardial deformation in $4 \times 4$ mutually overlapping regions by means of a least-squares criterion [26]. Mid-ejection of the control situation was used as the reference state for all deformation measurements within an experiment. Natural strain in the direction of the subepicardial fibers $\left(e_{f}\right)$ was calculated from epicardial deformation by:

$$
e_{\mathrm{f}}=\ln \frac{\mathrm{l}_{\mathrm{f}}}{\mathrm{l}_{\mathrm{f}, \mathrm{ref}}}
$$

in which $\mathrm{l}_{\mathrm{f}}$ and $\mathrm{l}_{\mathrm{f} \text {,ref }}$ represent fiber length along the subepicardial fiber direction in the actual and the reference situation, respectively. To compare myocardial fiber length in different experiments quantitatively, sarcomere length was estimated.

\section{Determination of regional myocardial blood} flow. Regional myocardial blood flow was determined with radioactively labeled microspheres $(15.0 \pm 1.0 \mu \mathrm{m}$; NEN-TRAC, DuPont DeNemours), suspended in $10 \%$ dextran with $0.01 \%$ Tween 80 [23]. The labels used were: ${ }^{14} \mathrm{Ce},{ }^{113} \mathrm{Sn},{ }^{103} \mathrm{Ru}$, or ${ }^{95} \mathrm{Nb}$. At each determination, $3 \times 10^{6}$ microspheres were injected into the left atrium. An arterial reference sample was taken from the brachial artery at a rate of $20.7 \mathrm{ml} / \mathrm{min}$, using a Harvard withdrawal pump. Withdrawal of blood started $5 \mathrm{~s}$ before the injection of the microspheres, and was continued during at least $1 \mathrm{~min}$.

After the experiment, the heart was fixated in $5 \%$ formaldehyde. Before dissection, nonmuscular structures, like fat and vessels at the epicardium, and chordae tendinae, were removed. The part of the left ventricular free wall with the optical markers was removed from the heart and dissected into 24-36 square transmural sections with an epicardial surface of $\sim 7 \times 7$ $\mathrm{mm}$. Each section was subdivided into a subepicardial and a subendocardial half, each of which was weighed. For the relation between regional mechanics, electrical activation and blood flow, only the subepicardial part was used. The radioactivity of the tissue and arterial blood samples was determined in a gamma counter (Packard multichannel Analyzer). Regional subepicardial myocardial blood flow in milliliters per second per gram was calculated for the same 16 regions as used for the determination of regional subepicardial fiber strain. Regional myocardial oxygen uptake was callculated from regional blood flow and arterio-venous differences in oxygen content.

Statistical analysis. The Sign test $(n=5)$ was used to evaluate the effect of hypervolemia and coronary artery occlusion. The effect of hypervolemia on the variables related to hemodynamics, mechanics, blood flow, and oxygen uptake were evaluated for statistical significance, using the values obtained during control in the same animal as a reference. The effect of coronary 
Regional performance during coronary artery occlusion

artery occlusion was evaluated using the values obtained during control as well as normoxic hypervolemia in the same animal as a reference. $A$ value of $\mathrm{P}<0.05$ was considered to be a significant difference. Data are presented as mean values $\pm S D$.

\section{Results}

Influence of hypervolemia and occlusion on hemodynamic performance

Hemodynamic data are summarized in Table 1. No significant change in heart rate was observed during normoxic hypervolemia or during occlusion of the distal part of the LAICA compared with the control condition. As may be expected, normoxic hypervolemia induced by fluid infusion resulted in an increase of end-diastolic pressure. During normoxic hypervolemia maximum left ventricular pressure, maximum $\mathrm{dp}_{\mathrm{Iv}} / \mathrm{dt}$, maximum instantaneous aortic volume flow, stroke volume, and left ventricular cavity volume at end-diastole were significantly higher as compared with the control situation. Occlusion caused a significant decrease in maximum left ventricular pressure, maximum $\mathrm{dp}_{\mathrm{lv}} / \mathrm{dt}$, maximum instantaneous aortic volume flow, and left ventricular stroke volume, as compared with the normoxic hypervolemic situation.

Influence of hypervolemia and occlusion on subepicardial fiber strain and regional work

In Fig. 3, subepicardial fiber strain as a func- tion of time is depicted for a lateral-basal and a medial-apical region of experiment 1 during control, nomoxic hypervolemia and LAICA occlusion, respectively. For each region, fiber length at mid-ejection of the control situation was used as reference length $\left(e_{f}=0\right)$. For the control and the normoxic hypervolemic situations, the pattern of fiber strain in both regions was almost similar. Shortening of the fibers began during the isovolumic contraction phase, and was more pronounced during the ejection phase. Hypervolemia caused dilation of the left ventricle, which was, during normoxia, reflected by a similar increase in fiber length at end-diastole and the beginning of the ejection phase for both regions. After occlusion of the distal part of the LAICA, the homogeneous pattern of fiber strain, as found during normal perfusion, was markedly disturbed. In the normoxic area (top), fibers lengthened during the isovolumic contraction phase, and continued to shorten during the isovolumic relaxation phase. Fiber strain during the ejection phase was decreased compared with the normoxic hypervolemic situation. In the ischemic area (bottom), the fibers were stretched during the isovolumic contraction phase, and impaired to shorten during the ejection phase. In both the normoxic and the ischemic area, fiber length at the beginning of the ejection phase was slightly increased as compared to the normoxic hypervolemic situation due to a higher left ventricular cavity volume. In the ischemic area, this increase was more pronounced due to a greater extent of fiber stretching during the isovolumic contraction phase. 
Table 1. Hemodynamic variables during control $(\mathrm{C})$, hypervolemia $(\mathrm{H})$, and left anterior interventricular coronary artery occlusion $(\mathrm{O})$.

\begin{tabular}{|c|c|c|c|c|c|c|c|c|}
\hline \multirow{2}{*}{ Variable } & & \multicolumn{5}{|c|}{ Experiment } & \multirow[b]{2}{*}{ Mean } & \multirow[b]{2}{*}{$\mathrm{SD}$} \\
\hline & & 1 & 2 & 3 & 4 & 5 & & \\
\hline \multirow[t]{3}{*}{$f_{h}\left(\right.$ beritmin $\left.{ }^{-1}\right)$} & $\mathrm{C}$ & 99 & 85 & 90 & 92 & 66 & 86 & 11 \\
\hline & $\mathbb{H}$ & 110 & 85 & 90 & 68 & 82 & 87 & 14 \\
\hline & 0 & 120 & 100 & 85 & 85 & 71 & 92 & 17 \\
\hline \multirow[t]{3}{*}{ Plv,ed (kPa) } & C & 1.2 & 1.0 & 1.2 & 1.1 & 1.3 & 1.2 & 0.2 \\
\hline & $H$ & 2.1 & 1.4 & 2.0 & 1.8 & 2.0 & 1.9 & 0.2 \\
\hline & $\mathrm{O}$ & 2.3 & 1.4 & 2.0 & 2.0 & 1.8 & 1.9 & 0.3 \\
\hline \multirow[t]{3}{*}{$\mathrm{ply}_{\mathrm{i}, \max }(\mathrm{kPa})$} & $\mathrm{C}$ & 14.7 & 12.3 & 15.6 & 12.8 & 14.3 & 13.9 & 1. 2 \\
\hline & $\mathrm{H}$ & 16.6 & 14.5 & 21.4 & 14.0 & 17.0 & 16.7 & 2.6 \\
\hline & $\mathrm{O}$ & 13.3 & 9.0 & 14.5 & 11.6 & 11.9 & 12.1 & 1.8 \\
\hline \multirow[t]{3}{*}{$\mathrm{dplv} / \mathrm{dt}_{\max }\left(\mathrm{kPa} . \mathrm{s}^{-1}\right)$} & $\mathrm{C}$ & 240 & 168 & 183 & 183 & 212 & 197 & 26 \\
\hline & $H$ & 267 & 169 & $23 \|$ & 163 & 207 & 207 & 39 \\
\hline & 0 & 213 & 116 & 192 & 147 & 151 & 164 & 35 \\
\hline \multirow[t]{3}{*}{$Q_{a o, \max }\left(\mathrm{ml} \cdot \mathrm{s}^{-1}\right)$} & $\mathrm{C}$ & 298 & 198 & 234 & 182 & 224 & 227 & 40 \\
\hline & $\mathrm{H}$ & 330 & 207 & 286 & 217 & 226 & 253 & 47 \\
\hline & 0 & 243 & 147 & 234 & 186 & 196 & 201 & 35 \\
\hline \multirow[t]{3}{*}{$\mathrm{V}_{\mathrm{e}}(\mathrm{ml})$} & $\mathrm{C}$ & 29.0 & 21.0 & 23.6 & 20.4 & 27.0 & 24.2 & 3.3 \\
\hline & $\mathrm{H}$ & 34.9 & 25.9 & 36.2 & 37.9 & 37.4 & 34.5 & 4.4 \\
\hline & $\mathrm{O}$ & 26.3 & 18.1 & 31.3 & 26.4 & 29.7 & 26.4 & 4.6 \\
\hline \multirow[t]{3}{*}{$\mathrm{V}_{\text {IV,be }}(\mathrm{ml})$} & $\mathrm{C}$ & 66.2 & 45.6 & 55.3 & 39.0 & 54.2 & 52.1 & 9.2 \\
\hline & $\mathrm{H}$ & 71.6 & 59.5 & 95.4 & 85.4 & 79.6 & 78.3 & 12.2 \\
\hline & 0 & 92.6 & 67.1 & 99.8 & 95.5 & 79.8 & 86.8 & 12.1 \\
\hline $\mathrm{v}_{w}(\mathrm{ml})$ & & 135 & 123 & 158 & 148 & 118 & 132 & 17 \\
\hline Dog weight (kg) & & 37 & 27 & 27 & 29 & 23 & 28 & 4 \\
\hline
\end{tabular}

Abbreviations: $f_{h}$, heart rate; $p_{1 v}$,ed, end-diastolic left ventricular (LV) pressure; Plv, max, maximum LV pressure; dplv/dtmax. maximum first derivative of $\mathrm{LV}$ pressure; Qao,max, maximum instantaneous aortic volume flow; $\mathrm{V}_{\mathrm{e}}$, ejected volume; $V_{I V_{n} b e}$ LV cavity wolume at the beginning of the ejection phase; $V_{w, ~}$ LV wall volume. 
Regional performance during coronary artery occlusion

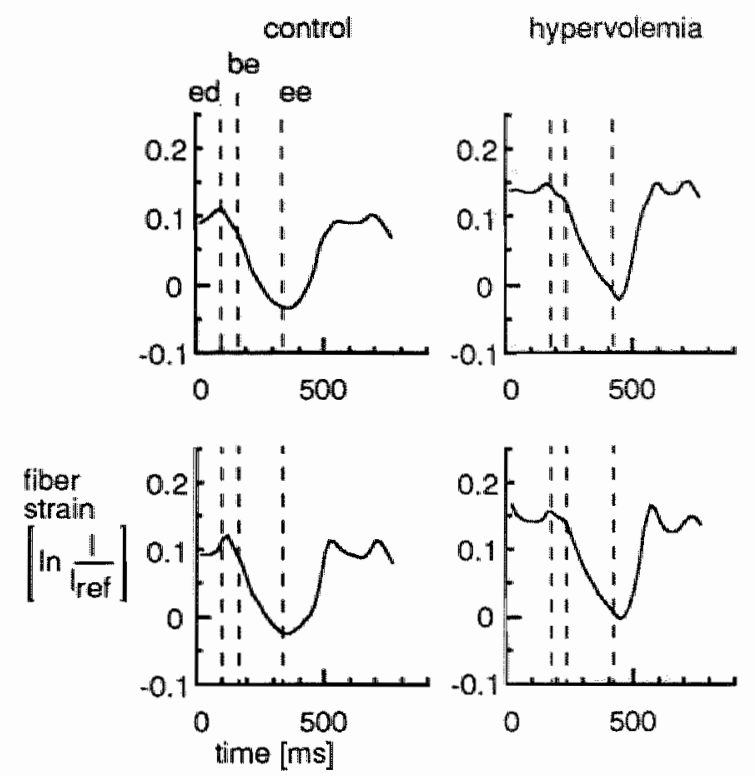

ocelusion
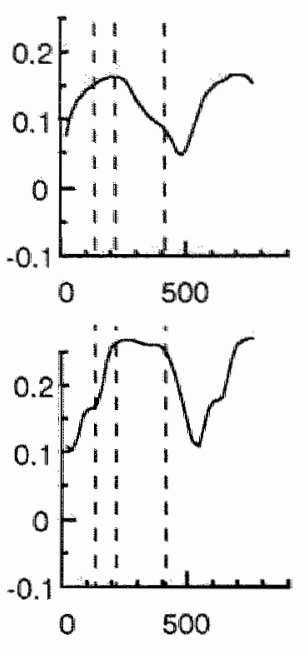

basallateral

apicalmedial
Fig. 3. Subepicardial fiber strain as a function of time for a basal-lateral (top row) and a apical-medial region (bottom row) of experiment 1 during control (left column), normoxic hypervolemia (mid column), and occlusion of the left anterior interventricular coronary artery (right column). Fiber length at midejection of the control situation is used as reference length. ed, be and ee refer to end-diastole, and begin and end-ejection, respectively.
Maps of mean regional fiber strain during the ejection phase, sarcomere length at end-diastole and at the beginning of the ejection phase are shown in Fig. 4. In the control and the normoxic hypervolemic situation, the regional variation in the depicted variables was less than $\pm 10 \%$, indicating a homogeneous behavior of the left ventricular anterior free wall. Compared to the control situation, fiber strain during the ejection phase was not significantly affected during normoxic hypervolemia. After $15 \mathrm{~min}$ utes of occlusion of the distal part of the LAICA, fiber strain during the ejection phase was lowered in all regions with values ranging from -0.01 in the ischemic area, to -0.08 in the normoxic area. In the control situation mean regional sarcomere length was calculated to be between 2.13 and $2.18 \mu \mathrm{m}$ at end-diastole and

\begin{tabular}{|c|c|c|c|}
\hline & control & hypervolemia & occlusion \\
\hline & $-.10-.10-10-.11$ & $-10-.12-.12 \quad-13$ & $-08,07,09,08$ \\
\hline & $\begin{array}{llll}-.10 & -.10 & -.10 & -.11\end{array}$ & $\begin{array}{llll}-.11 & -.11 & -.11 & -.12\end{array}$ & $-05-05=05,06$ \\
\hline & $\begin{array}{llll}-.10 & -.11 & -.12 & -.11\end{array}$ & $-.11-.12-.13-.12$ & $-.02-.03 \cdot .03-05$ \\
\hline & $-.10-.11-.11-.09$ & $-.11-.12-.12-.09$ & $-.01-.01 \quad-01-.02$ \\
\hline & 2.142 .152 .182 .17 & 2.282 .322 .312 .31 & $2.302 .32<332,33$ \\
\hline & 2.162 .162 .172 .17 & 2.332 .322 .312 .32 & 2.342 .352 .33233 \\
\hline & 2.182 .172 .172 .17 & 2.352 .352 .332 .33 & 2.382 .422 .362 .35 \\
\hline & 2.162 .162 .142 .13 & 2.332 .312 .282 .31 & 2.392 .372 .33234 \\
\hline & 2.092 .092 .102 .10 & 2.272 .292 .282 .29 & 2332.352 .34234 \\
\hline & 2.112 .092 .102 .11 & 2312.292 .292 .29 & 2392372352,34 \\
\hline & 2.112 .122 .122 .12 & 2.322 .332 .322 .30 & 2.452 .492 .422 .39 \\
\hline & 2.112 .122 .092 .09 & 2.302 .302 .272 .27 & 2.482 .472 .40239 \\
\hline
\end{tabular}

Fig. 4. Mean maps of regional fiber strain during the ejection phase (ef), sarcomere length at beginejection $\left(\|_{s, b e}\right)$ and at zero passive fiber stress $\left(I_{s, e q}\right)$ during control, normoxic hypervolemia, and occlusion of the left anterior interventricular coronary artery (LAICA). The ischemic area due to LAICA occlusion is located bottom left. 
between 2.09 and $2.12 \mu \mathrm{m}$ at the beginning of the ejection phase. Dilation of the left ventricle, caused by hypervolemia, was reflected by a significant increase in fiber length for the whole area under investigation. Mean regional sarcomere length ranged from 2.28 to $2.35 \mu \mathrm{m}$ at end-diastole and from 2.27 to $2.33 \mu \mathrm{m}$ at the beginning of the ejection phase. During LAICA occlusion, mean estimated regional sarcomere length showed a gradient. Sarcomere length at end-diastole ranged from 2.30 in the normoxic area to $2.39 \mu \mathrm{m}$ in the ischemic area. At the beginning of the ejection phase, these values were 2.33 and $2.49 \mu \mathrm{m}$, respectively. In all regions, the values were higher than during normoxic hypervolemia, reflecting more pronounced dilation under these circumstances. These values also demonstrate that there is a considerable fiber lengthening in the ischemic area during the isovolumic contraction phase.

In Fig. 5, calculated total, active and passive regional fiber stress is plotted as a function of time for the systolic phases of the same beats as in Fig. 3. During the control as well as the normoxic hypervolemic situation, calculated total fiber stress rose during the isovolumic contraction phase, reached a maximum soon after the beginning of the ejection phase, and declined steadily during the rest of the ejection phase in both regions. The total fiber stress born by the muscle fibers was far above the passive stress levels. Therefore, total and active fiber stress were almost equal. During coronary artery occlusion, however, the patterns and the level of calculated total, active and passive fiber stresses were different for the normoxic and the

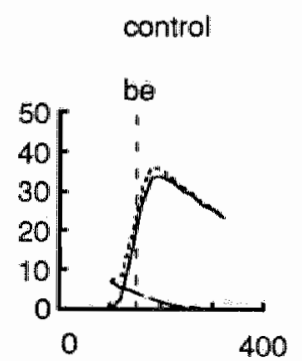

hypervolemia
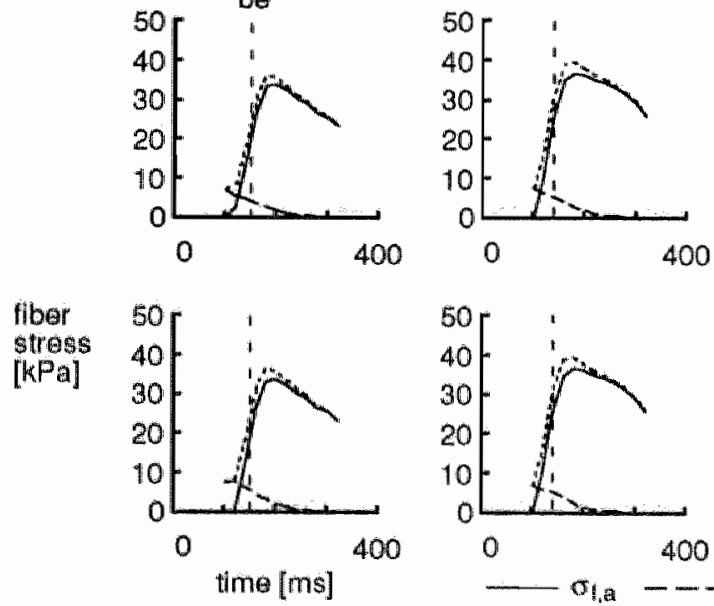

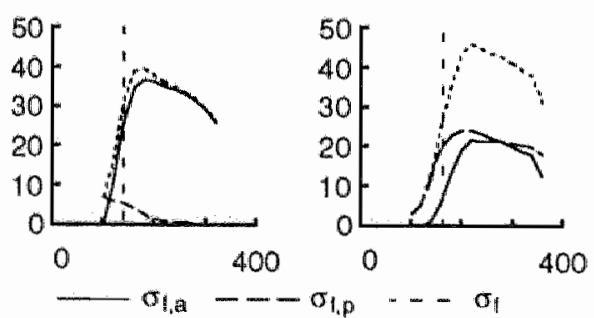

Fig. 5. Calculated total, active and passive regional fiber stress plotted as a function of time for the systolic phases of the same beats as in Fig. 3. 
Regional performance during coronary artery occlusion

ischemic area. Although total fiber stress was hardly changed in the normoxic area, in the ischemic area total fiber stress exceeded the one as calculated during normoxic hypervolemia. In both regions, active fiber stress was lower than during the control and the normoxic hypervolemic situation. Maximum active fiber stress was lower in the ischemic than in the normoxic area. In the normoxic area, passive fiber stress remained low as compared to total fiber stress, although it was higher than during control and normoxic hypervolemia. In the ischemic area, however, passive fiber stress was high, because of fiber lengthening during the isovolumic contraction phase, and the absence of fiber shortening during the ejection phase.

Maps of mean regional maximum active and passive fiber stress are shown in Fig. 6. During control, maximum passive fiber stress ranged from 2 to $5 \mathrm{kPa}$, and was 10 to $18 \%$ of maximum active fiber stress $(28 \mathrm{kPa})$. In none of the experiments, regional end-diastolic passive fiber stress exceeded total regional fiber stress. Therefore, the regional parameter value a (see Eq. (3)) was kept unchanged for all regions $(1.95 \mu \mathrm{m})$. During normoxic hypervolemia, the regional parameter value a had to be corrected maximally to $1.97 \mu \mathrm{m}$. Maximum active (36-37 $\mathrm{kPa}$ ) and passive fiber stress $(7-9 \mathrm{kPa})$ were significantly higher than during the control situation. This was due to a higher left ventricular pressure as well as a higher ratio of left ventricular cavity volume to wall volume (Table 1). After 15 minutes of occlusion of the distal part of the LAICA, maximum passive as well as ac

\begin{tabular}{|c|c|c|c|c|c|c|c|}
\hline \multirow{5}{*}{$\frac{\frac{\varepsilon}{\sigma}}{0}$} & \multicolumn{3}{|c|}{ contral } & \multicolumn{4}{|c|}{ hypervolemia occlusion } \\
\hline & 2828 & 28 & & 3737 & 37 & 37 & 272727 \\
\hline & 2828 & 28 & & 3637 & 37 & & 242526 \\
\hline & $2828-v-v-v-1$ & 28 & 28 & 3636 & 37 & 37 & 2324242 \\
\hline & 2828 & 28 & 28 & 3636 & 37 & 37 & $23 \quad 22 \quad 23 \quad 24$ \\
\hline & $3 \quad 3$ & 3 & 3 & 7 & 7 & 8 & $8 \% 96$ \\
\hline & & 3 & 3 & 7 & 7 & 7 & $11 \quad 10 \quad 9$ \\
\hline & & 4 & 3 & & 8 & 8 & $13 \quad 13 \quad 1111$ \\
\hline & 4 & 3 & 2 & 7 & 7 & 8 & $14 \quad 13 \quad 12 \quad 12$ \\
\hline
\end{tabular}

Fig. 6. Mean maps of regional maximum active $\left(\sigma_{\mathrm{fa}}\right)$ and passive fiber stress $\left(\sigma_{\mathrm{tp}}\right)$ during control, normoxic hypervolemia, and occlusion of the left anterior interventricular coronary artery (LAICA). The ischemic area due to LAICA occlusion is 10cated bottom left.

tive fiber stress showed a gradient, although oppositely directed. The parameter value a had to be corrected regionally. Values ranged from $1.95 \mathrm{in}$ the normoxic area, to $2.06 \mu \mathrm{m}$ in the ischemic area. Maximum active fiber stress ranged from $27 \mathrm{kPa}$ in the normoxic (top right), to $22 \mathrm{kPa}$ in the ischemic area (bottom left). Mean maximum passive fiber stress was lowest in the normoxic area $(8 \mathrm{kPa})$, and highest in the ischemic area (14 $\mathrm{kPa})$.

In Fig. 7, calculated active regional fiber stress is plotted as a function of fiber strain for the systolic phases of the same beats as in Figs. 3 and 5 . On the horizontal axis, calculated sarcomere length is also indicated. During the isovolumic contraction phase in the control as well as the normoxic hypervolemic situation, fiber stress increased, while fiber strain slightly 

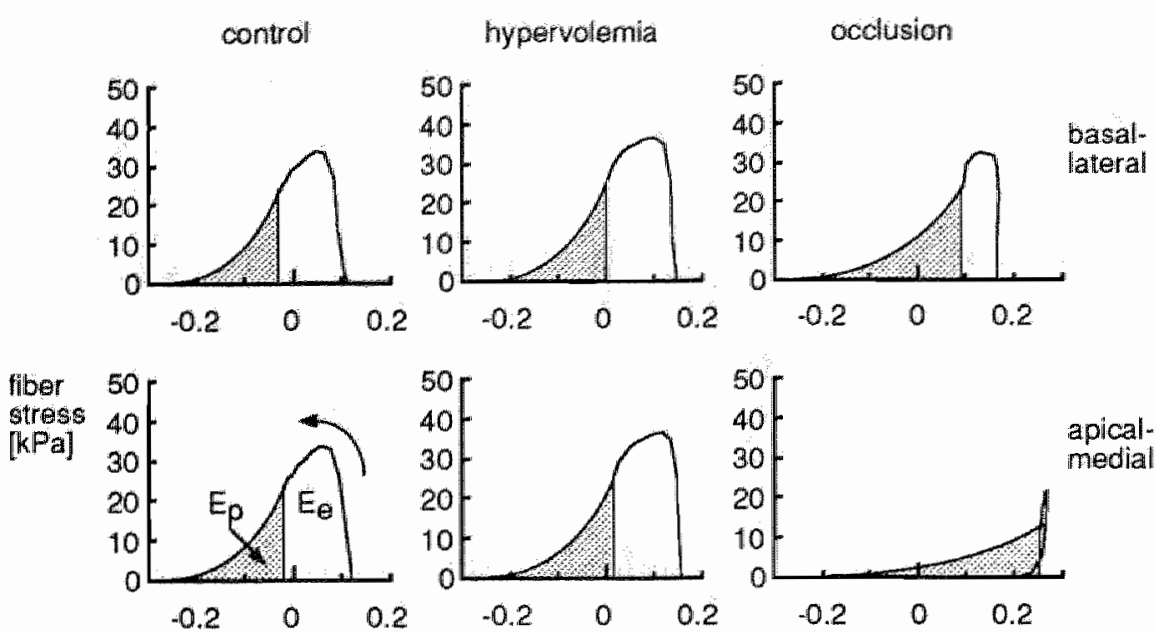

fiber strallin [ Iri //iref]
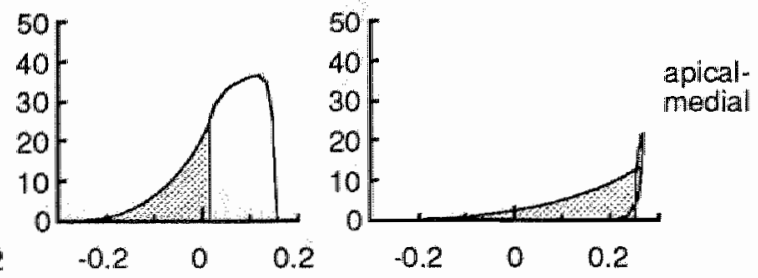

Fig. 7. Calculated active regional fiber stress plotted as a function of fiber strain for the systolic phases of the same beats as in Figs. 3 and 5 . On the horizontal axis, calculated sarcomere length is also indicated. The course of the loops is counter-clockwise, as indicated by the arrow in the right-upper plot. $E_{a}$ and $E_{p}$ refer to external and potential work, respectively. decreased. During the ejection phase, fiber stress decreased approximately linearly with fiber strain. In calculating regional external work, a fall to zero active fiber stress during the isovolumic relaxation phase was assumed. For the control as well as the normoxic hypervolemic situation, regional external work and potential work were equal for the basal-lateral and the apical-medial region. During normoxic hypervolemia, the fiber stress-fiber strain area (SSA), which is the sum of external and potential work, was higher for both areas, as compared to the control situation. During coronary artery occlusion the fiber stress-fiber strain curve was different for the normoxic and the ischemic area as compared to the control and the normoxic hypervolemic situation. In the nor- moxic area, regional external work was decreased due to less fiber shortening during the ejection phase. Fiber stress remained almost at the same level during the ejection phase. In the ischemic area the loops closed. Throughout systole, the shape of the active fiber stress-fiber strain relation was concave.

Maps of mean regional pressure-sarcomere length area (PSL), external (EMP) and total mechanical power (TMP) are shown in Fig. 8. For the normoxic control and hypervolemic situation, PSL, EMP, and TMP were homogeneously distributed. During LAICA occlusion, PSL, EMP, and TMP showed a gradient from the normoxic to the ischemic area. In the normoxic area, values of PSL, EMP, and TMP were lower than during the control and the nor- 
Regional performance during coronary artery occlusion

\begin{tabular}{|c|c|c|c|c|c|c|c|c|c|}
\hline & \multicolumn{4}{|c|}{ control } & \multicolumn{5}{|c|}{ hypervolemia occlusion } \\
\hline & 4 & 4 & 4 & 4 & 5 & 5 & 5 & 6 & 2.222232 \\
\hline & 4 & 4 & 4 & 4 & 5 & 5 & 5 & 5 & 1.5171 .619 \\
\hline & 4 & 4 & 4 & 4 & 5 & 6 & 6 & 5 & 0.61 .01 .01 .5 \\
\hline & 4 & 4 & 4 & 4 & 5 & 6 & 5 & 5 & 0.50 .30 .50 .6 \\
\hline & 4 & 4 & 4 & 4 & 6 & 6 & 6 & 7 & 3.13 .013 .131 \\
\hline & 4 & 4 & 4 & 4 & 6 & 6 & 6 & 6 & 1.82 .22 .125 \\
\hline & 4 & 5 & 5 & 4 & 5 & 6 & 6 & 6 & $0.81,1121.9$ \\
\hline W & 4 & 4 & 4 & 4 & 6 & 6 & 6 & 5 & $0.6 \quad 0.3 \quad 0.5 \quad 0.8$ \\
\hline & 6 & 7 & 7 & 7 & 11 & 11 & 11 & 11 & $17,67,7 / 7.87 .7$ \\
\hline & 7 & 7 & 7 & 7 & 11 & 11 & 11 & 11 & $6.3: 6.87 .071$ \\
\hline & 7 & 7 & 7 & 7 & 11 & 11 & 12 & 11 & 4.66 .26 .06 .6 \\
\hline & 7 & 7 & 7 & 6 & 11 & 11 & 11 & 11 & 4.74 .55 .05 .6 \\
\hline
\end{tabular}

Fig. 8. Mean maps of regional pressure-sarcomere length area (PSL), external (EMP) and total mechanical power (TMP) during control, normoxic hypervolemia, and occlusion of the left anterior interventricular coronary artery (LAICA). The ischemic area due to LAICA occlusion is located bottom left.

moxic hypervolemic situation. In the ischemic area, values of PSL and EMP were almost zero, whereas TMP was only $\sim 40 \%$ lower than in the normoxic area, indicating little change in potential work.

Values of several chemical variables in arterial, local venous, and coronary sinus blood samples are shown in Table 2. Due to hemodilution, caused by the volume loading with intravenous infusion of a polygeline infusion liquid, arterial hemoglobin concentration decreased from $7.4 \pm 1.1$ during control, to $5.6 \pm 0.8$

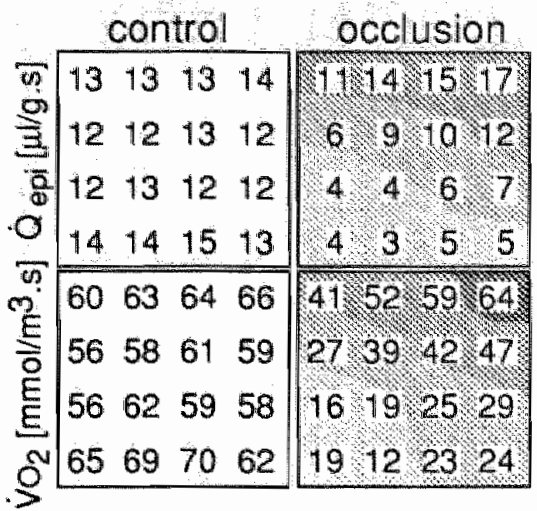

Fig. 9. Mean maps of regional subepicardial blood flow $\left(\mathrm{Q}_{\mathrm{epi}}\right)$ oxygen uptake $\left(\mathrm{V}_{\mathrm{O}_{2}}\right)$ during control and occlusion of the left anterior interventricular coronary artery (LAICA). The ischemic area due to LAICA occlusion is located bottom left.

mmol.1 $1^{-1}$ during normoxic hypervolemia. Consequently, arterial oxygen content decreased as well, but the oxygen extraction fraction was unchanged. Occlusion of the LAICA caused ischemia, as indicated by the significant decrease in $\mathrm{pH}$ in the coronary effluent of the ischemic area (Table 2). The oxygen extraction fraction in the ischemic area increased significantly compared with the control as well as the normoxic hypervolemic situation ( $81 \%$ versus 67 and $65 \%$, respectively). In the normoxic areas, oxy gen extraction fraction remained unchanged.

Maps of mean regional subepicardial blood flow and oxygen uptake are shown in Fig. 9. In the control situation, both estimates were homogeneously distributed. During LAICA occlusion, subepicardial blood flow ranged from 
Regional performance during coronary artery occlusion

Table 2. Values of several chemical variables in arterial (A), local venous (LV), and coronary sinus (CS) blood samples.

\begin{tabular}{|c|c|c|c|c|}
\hline \multirow[b]{2}{*}{ Variable } & \multicolumn{4}{|c|}{ sutuation } \\
\hline & & control & hypervolemia & occlusion \\
\hline \multirow{3}{*}{$\mathrm{pH}$} & A & $7.41 \pm 0.01$ & $7.37 \pm 0.04$ & $7.40 \pm 0.04$ \\
\hline & $\mathrm{LV}$ & $7.38 \pm 0.01$ & $7.34 \pm 0.04$ & $7.23 \pm 0.04 *$ \\
\hline & $\mathrm{CS}$ & $7.37 \pm 0.01$ & $7.33 \pm 0.04$ & $7.35 \pm 0.05$ \\
\hline \multirow[t]{3}{*}{$\mathrm{PCO}_{2}(\mathrm{kPa})$} & A & $5.0 \pm 0.7$ & $4.9 \pm 0.5$ & $4.5 \pm 0.5$ \\
\hline & LV & $6.0 \pm 0.8$ & $6.0 \pm 0.7$ & $7.7 \pm 0.9 *$ \\
\hline & $\mathrm{CS}$ & $6.1 \pm 0.7$ & $6.1 \pm 0.4$ & $5.8 \pm 0.4$ \\
\hline $\mathrm{Hb}(\mathrm{mM})$ & $A$ & $7.4 \pm 1.1$ & $5.6 \pm 0.8$ & $5.4 \pm 1.0^{*} *$ \\
\hline \multirow[t]{3}{*}{$\mathrm{SO}_{2}$} & $A$ & $99 \pm 0$ & \pm 0 & $99 \pm 0$ \\
\hline & $\mathrm{LV}$ & $33 \pm 7$ & 35 & $18 \pm 5 *$ \\
\hline & $\mathrm{CS}$ & $35 \pm 6$ & $33 \pm 4$ & $32 \pm 4$ \\
\hline \multirow[t]{3}{*}{$\mathrm{O}_{2} \mathrm{ct}(\mathrm{mM})$} & A & $7.64 \pm 1.10$ & $5.83 \pm 0.79 *$ & $5.58 \pm 1.03 *$ \\
\hline & $\mathrm{LV}$ & $2.56 \pm 0.69$ & $2.08 \pm 0.64 *$ & $0.98 \pm 0.27 *$ \\
\hline & A & $7.64 \pm 1.10$ & $5.83 \pm 0.79 *$ & $5.58 \pm 1.03 *$ \\
\hline \multirow[t]{2}{*}{$\Delta \mathrm{O}_{2} \mathrm{ct}(\mathrm{mM})$} & A-LV & $5.08 \pm 0.66$ & $3.75 \pm 0.56 *$ & $4.24 \pm 0.75 *$ \\
\hline & A-CS & $4.97 \pm 0.66$ & $3.85 \pm 0.46 *$ & $3.69 \pm 0.53 *$ \\
\hline \multirow[t]{2}{*}{ O2 extraction (\%) } & LV & \pm 7 & $65 \pm 8$ & $\pm 5^{*}$ \\
\hline & $\mathrm{CS}$ & $65 \pm 6$ & $66 \pm 4$ & \pm 5 \\
\hline
\end{tabular}

Values are means $\pm \mathrm{SD}$. Abbreviations: $\mathrm{Hb}$, hemoglobin; $\mathrm{SO}_{2}$, oxygen saturation, $\mathrm{O}_{2} \mathrm{ct}$, oxygen content; $\Delta \mathrm{O}_{2} \mathrm{ct}$, difference in oxygen content. ${ }^{*} \mathrm{P}<0.05$ as compared with control (Sign test).

$17 \mu \mathrm{l} / \mathrm{g} . \mathrm{s}$ in the normoxic area to $3 \mu \mathrm{l} / \mathrm{g} . \mathrm{s}$ in the ischemic area. Oxygen uptake ranged from $64 \mathrm{mmol} / \mathrm{m}^{3}$.s in the normoxic area to 12 $\mathrm{mmol} / \mathrm{m}^{3}$.s in the ischemic area.

Relation between regional mechanics and oxygen uptake

In Table 3 the slope and offset as well as the correlation coefficients are given from the estimated linear relations between regional oxygen uptake and fiber strain, external mechanical power, total mechanical power, and the pressure sarcomere length area as estimated in 16 regions during control and LAICA occlusion. Although in the individual experiments no significant differences were found between the different estimates of metabolic need, for the pooled 
Regional performance during coronary artery ocelusion

Table 3. Coefficients (SE) of estimated linear relation between regional oxygen demand and fiber strain during the ejection phase (eff), regional external mechanical power (EMP), regional total mechanical power (TMP), and pressure sarcomere length area (PSL).

\begin{tabular}{|c|c|c|c|c|c|c|c|}
\hline exp. & $\begin{array}{l}\text { slope }_{\mathrm{er}} \\
\left(\mathrm{mmol} / \mathrm{m}^{3}{ }_{\mathrm{s}} \mathrm{s}\right)\end{array}$ & $\begin{array}{l}\text { intercepter } \\
\left(\mathrm{mmol} / \mathrm{m}^{3} \cdot \mathrm{s}\right)\end{array}$ & $\mathbb{r}_{\mathrm{e}_{\mathrm{f}}}$ & $\exp$ & $\begin{array}{l}\text { slopetMP } \\
\text { (minol/s) }\end{array}$ & $\begin{array}{l}\text { interceptTMP } \\
\left(\mathrm{mmol} / \mathrm{m}^{3} \mathrm{~s}\right)\end{array}$ & TTMP \\
\hline 1 & $-980(135)$ & $5.3(6.3)$ & 0.89 & 1 & $10.0(1.5)$ & $-9.8(8.8)$ & 0.87 \\
\hline 2 & $-706(125)$ & $0.4(3.3)$ & 0.83 & 2 & $13.1(2.9)$ & $-6.5(5.1)$ & 0.77 \\
\hline 3 & $-472(131)$ & $20.1(9.3)$ & 0.69 & 3 & $8.9(2.2)$ & $-6.1(14.8)$ & 0.73 \\
\hline 4 & $-250(58)$ & $16.2(3.4)$ & 0.76 & 4 & $6.7(1.4)$ & $0.9(5.9)$ & 0.79 \\
\hline 5 & $-608(68)$ & $2.6(3.9)$ & 0.92 & 5 & $16.7(1.8)$ & $-9.2(4.8)$ & 0.93 \\
\hline poolled & $-412(44)$ & $17.5(3.7)$ & 0.60 & pooled & $9.7(0.4)$ & $-3.6(2.5)$ & 0.88 \\
\hline exp. & $\begin{array}{l}\text { slopeEMP } \\
(\mathrm{mmol} / \mathrm{J})\end{array}$ & $\begin{array}{l}\text { interceptEMP } \\
\left(\mathrm{mmol} / \mathrm{m}^{3} \cdot \mathrm{s}\right)\end{array}$ & IEMP & exp. & $\begin{array}{l}\text { slopepsL } \\
\text { (mmol/J.m) }\end{array}$ & $\begin{array}{l}\text { interceptpSL } \\
\left(\mathrm{mmol} / \mathrm{m}^{3} \mathrm{~s}\right)\end{array}$ & rPSIL \\
\hline 1 & $15.1(1.8)$ & $12.9(4.8)$ & 0.91 & 1 & $25.2(4.3)$ & $3.1(7.9)$ & 0.85 \\
\hline 2 & $23.3(4.8)$ & $2.8(3.5)$ & 0.79 & 2 & $26.6(4.9)$ & $0.5(3.4)$ & 0.82 \\
\hline 3 & $8.8(2.2)$ & $22.8(7.9)$ & 0.72 & 3 & $14.2(4.0)$ & $18.6(9.9)$ & 0.69 \\
\hline 4 & $7.3(1.5)$ & $15.7(3.3)$ & 0.79 & 4 & $10.7(3.1)$ & $18.4(3.7)$ & 0.68 \\
\hline 5 & $22.7(2.3)$ & $6.8(3.2)$ & 0.93 & 5 & $19.2(2.2)$ & $4.2(3.8)$ & 0.92 \\
\hline pooled & $13.8(0.3)$ & $10.2(3.0)$ & 0.93 & pooled & $12.7(0.7)$ & $12.3(2.4)$ & 0.81 \\
\hline
\end{tabular}

data it was found that external and total mechanical power were best related to oxygen consumption.

\section{Discussion}

This study reports on the influence of myocardial ischemia on simultaneously measured epicardial deformation, regional work, blood flow and oxygen uptake. Moreover, this study is the first that quantitatively evaluates regional work from (calculated) fiber stress - (measured) fiber strain loops during ischemia. Measurements were performed during control, and a normoxic as well as an ischemic hypervolemic period. In both normoxic situations, control and hypervolemia, fiber strain during the ejection phase, sarcomere length at end-diastole and at the beginning of the ejection phase, maximum active and passive fiber stress, pressure-sarcomere length area, external and total mechanical power, blood llow as well as oxygen uptake are homogeneously distributed over the left ventricular anterior free wall. During the normoxic control and hypervolemic situations, estimated regional sarcomere length and fiber stress as 
calculated according to our model were found to be within the physiological range $[3,22,38$, 42]. During coronary artery occlusion all measured or estimated regional variables showed a gradient. For fiber strain during the ejection phase, active fiber stress, pressure-sarcomere length area, external and total mechanical power, and blood flow and oxygen uptake, the gradient pointed toward the normoxic area. For sarcomere length at end-diastole and at the beginning of the ejection phase, passive fiber stress, and the oxygen extraction fraction, the gradient pointed toward the ischemic area. Considerable active fiber stress development was found within the ischemic region. Within an individual experiment significant, the correlations between oxygen uptake and the four indices of regional performance, used to predict oxygen uptake, were not found to be mutually different. However, from the pooled data, it appeared that indices with the physical dimension of work per unit of volume, i.e. external mechanical power and total mechanical power, were the best predictors of regional oxygen consumption.

\section{Deformation and fiber stress calculation}

Because one reference was used for all deformation measurements within an experiment, i.e. mid-ejection in the control situation (see methods), it could be shown that during LAICA occlusion the ischemic region dilated more than the normoxic region. In the ischemic regions, estimated sarcomere length at the beginning of the ejection phase was found to range from 2.40 to $2.49 \mu \mathrm{m}$. In rat papillary or trabecular muscle experiments, maximum sarcomere length was found to be slightly less $(2.40 \mu \mathrm{m} ;[22,38$, 42]). The increase in sarcomere length in ischemic areas might be due to structural rearrangements or changes in material properties [6, $9,28,40,44]$. These include disruption of the extracellular matrix cell shape changes, changes in boundary conditions imposed by healthy adjacent tissue, and loss of tissue turgor.

The measured isovolumic lengthening and decreased shortening of the muscle fibers in the ischemic area is in accordance with findings as reported in literature $[9,10,35,37,40]$. Since myocardial fibers may shorten passively due to an overall decrease in left ventricular cavity volume during systole, it is impossible to distinguish whether the fiber shortening during the ejection phase, as measured in the ischemic areas, is active or passive. The generally observed increased shortening of remote normoxic zones, especially during the isovolumic contraction phase $[16,17,20,40]$, was not found in the present study. This may be explained as follows. First, because of the relatively high level of end-diastolic left ventricular pressure and volume, sarcomeres length in the ischemic area was close to its maximum $[22,38,42]$. The serially connected normoxic fibers were therefore unable to shorten additionally. Second, the normoxic area under investigation might have been closer to the ischemic area than in the studies referred to.

To obtain information about the accuracy of 
our fiber stress calculation, the calculated fiber stress in the left ventricular wall was compared with fiber stress as measured in isolated contracting muscle. In rat papillary muscle preparations, during isometric contraction active peak tension as a function of sarcomere length was found to be $100 \mathrm{kPa}$ at a sarcomere length of approximately $2.1 \mu \mathrm{m}[22,38,42]$. Under normal conditions, contractile work is maximal if contractile force is approximately 40 to $60 \%$ of peak isometric force. Force-sarcomere shortening velocity relations derived from afterloaded contractions starting from a constant sarcomere length, revealed that 40 to $60 \%$ of maximum force can be developed with sarcomere shortening velocities ranging from 1.50 to $2.50 \mu \mathrm{m} / \mathrm{s}$. In our experiments, maximum shortening velocity was found to be in between 1.75 to 2.50 $\mu \mathrm{m} / \mathrm{s}$ in the normoxic control and hypervolemic situation [3]. Therefore, fiber stress can be expected to range from 40 to $60 \mathrm{kPa}$. This agrees reasonably well with the range of calculated maximum active fiber stress ( 16.3 to $50.8 \mathrm{kPa}$ ), thus supporting the applicability of the model equations.

For all regions, an exponential passive fiber stress-fiber strain relationship as described by Eq. (3) was assumed. The only correction allowed was an adaptation in the regional parameter value a to values higher than the standard value of $1.95 \mu \mathrm{m}$ to prevent passive fiber stress to be higher than total fiber stress according to Eq. (2). In the ischemic area, a had to be corrected to values of 2.00 to $2.06 \mu \mathrm{m}$. This estimated rightward shift of the passive fiber stress- fiber strain relation in the ischemic area is in accordance with the rightward shift of the passive left ventricular pressure-volume relationship during ischemia $[6,40]$. The parameter value $b$ in Eq. (3), governing the exponential increase of passive fiber stress with increasing sarcomere length, was not corrected regionally. Because the length of a sarcomere is limited, it is to be expected that; when the passive fiber stress-fiber strain relation is shifted to the right, the steepness of the slope at higher sarcomere lengths, and, hence, the parameter value $b$, have to be increased. Because the value of $b$ was not corrected, passive fiber stress might be underestimated. Because active fiber stress was calculated as the difference between total fiber stress according to Eq. (2) and estimated passive fiber stress according to Eq. (3), underestimation of passive fiber stress results in overestimation of active fiber stress.

\section{Calculation of external and total mechanical power}

The ability to quantify regional myocardial performance is essential to study myocardial responses to ischemia. A regional performance index with proper dimensions of energy or energy per unit of volume, as derived from wall tension-regional area loops $[10,35]$ or from fiber stress-fiber strain loops [3] should be preferred above the index as derived from left ventricular pressure-segment length loops $[39,41]$. Within one experiment the latter method may be used to obtain an indication of changes in re- 
gional work during the experiment, but comparison between hearts with different degrees of filling is not allowed (Table 3). Although values of calculated circumferential regional stress and deformation are used to estimate regional myocardial contractile work [16], myocardial deformation was quantified by measuring segmental shortening unidirectionally, which may not reflect overall performance of the fibers in the region. In contrast, when using our measurement technique for two-dimensional fiber strain and our model for the calculation of regional total, active and passive fiber stress, it is possible to obtain a physically correct estimate of regional contractile work, in both normoxic and ischemic areas at the epicardium of the left ventricular anterior free wall, which can be used to predict oxygen uptake.

Absolute values of external and totall mechanical power, however, may have been subject to imperfection of the model used. During LAICA occlusion, regional external and total mechanical work might be overestimated due to overestimation of active fiber stress, as discussed in detail above. Moreover, regional total mechanical work is overestimated too, if regional potential work is overestimated. This occurs if estimated end-systolic active fiber stress values are too high or if the $x$-intercept of the active fiber stress-fiber strain relation $\left(1_{s, 0}\right)$, which was assumed to be at a sarcomere length of $1.60 \mu \mathrm{m}$, is shifted to greater sarcomere lengths. Glower et al. [9] examined the left ventricular end-systolic pressure-segment length relationship, the slope of which is given by
$E_{\max }$ [27]. They observed a paradoxical increase in $E_{\max }$ during a fall in inotropic state as induced by regional ischemia. This increase may result from ischemia-induced creep, due to structural rearrangements or changes in material properties, shifting the $x$-intercept of the endsystolic pressure-length relation to the right. A rightward shift without a change in $E_{\max }$ during regional ischemia has been reported for the relation between left ventricular end-systolic pressure and volume in the physiological end-systolic pressure range [36]. Converting these findings to a more local level, we might conclude that sarcomere length at zero active fiber stress $\left(1_{\mathrm{s}, 0}\right)$ should be larger than $1.60 \mu \mathrm{m}$. Therefore, regional potential work is likely to be overestimated in our study. It is to be concluded that more knowledge about passive material properties is required for correct estimation of the workload of the ischemic region.

Relation between regional estimates of mechanical performance and oxygen uptake during ischemia

When the efficiency of conversion of chemical to mechanical energy is defined as the slope of the regression line of regional total mechanical power to oxygen uptake [30-32, 34], a steeper slope implies an increase in efficiency. The slope of the pooled linear relation between total mechanical power and oxygen uptake (9.7 $\mathrm{mol} / \mathrm{J}$ ) was steeper than the slope of the relation between the pressure-volume area and global oxygen uptake as reported in literature, being 
$4.2[30], 4.6[15,33]$, and $5.8 \mathrm{~mol} / \mathrm{s}[11]$. Moreover, the pooled linear relation between total mechanical power and oxygen uptake showed a negative $y$-axis intercept. The more pronounced steepness of the slope and the negative intercept can be explained by possible measurement errors. First, regional TMP might be overestimated, as discussed in detail before. Second, regional oxygen uptake in the subepicardial layers, calculated from blood flow and arterio-venous differences in oxygen content, might be underestimated during LAICA occlusion due to the following reasons. First, subepicardial blood flow measured by means of radioactively labeled microspheres may be underestimated because microspheres tend to be trapped more in the subendocardial than in the subepicardial layers due to streaming of the beats [21]. Second, regional oxygen uptake in the ischemic area was calculated using the difference in oxygen content between arterial blood and blood samples drawn from a small coronary vein accompanying the LAICA. Despite simultaneously withdrawal of blood from the local vein and the coronary sinus, it cannot be excluded that in sampling blood through the local venous catheter, blood is also collected from adjacent vascular beds of normoxic areas via venous collaterals. Since in the normoxic areas oxygen extraction is less than in the ischemic areas, admixture of venous blood from outside the ischemic region results in underestimation of the regional oxygen uptake. However, since in our experiments the oxygen extraction fractions were $65 \pm 5 \%$ and $81 \pm 5 \%$ for blood drawn from the coronary sinus and the local vein draining the ischemic area, respectively, errors are expected to be minor. Yet it should be emphasized that it is not clear whether the local venous blood samples reflect average transmural venous blood, or that mainly blood is obtained from the subepicardial layers. Therefore, it still remains possible that more detailed lateral and transmural mapping of oxygen extraction [46] would reveal different values of oxygen uptake.

The difference in slope might also be interpreted as a mismatch between oxygen demand and supply in the ischemic area. This mismatch might be partially counteracted by the contribution of anaerobic metabolism. In experiments with stenosis of the distal part of the LAICA, while coronary perfusion pressure behind the stenosis was kept constant at $3.3 \mathrm{kPa}$, inorganic phosphate content and lactate release into the ischemic area were assessed $[23,25]$. From these data it could be estimated that the majority of anaerobic energy production occurs during the first $10 \mathrm{~min}$ of ischemia. However, the maximum amount of metabolic energy provided by anaerobic metabolism is only $10 \%$ of normoxic energy production, which is too little to explain completely the deep slope and the negative intercept of the pooled linear relation between total mechanical power and oxygen uptake. 


\section{References}

1. Arts $T$, Bovendeerd PHM, Prinzen FW, Reneman RS (1991) Relation berween left ventricular cavily pressure and yolume and systolic fiber stress and strain in the wall. Biophys J 59: 93-102

2. Arts $T$. Veenstra PC, Reneman RS (1982) Epicardial deformation and left ventricular wall mechanics during ejection in the dog. Am J Physiol 243: $1379-H 390$

3. Delhass $T$, Arts T, Bovendeerd PHM, Prinzen FW, Reneman RS (1993) Subepicardial fiber stress and strinin as related to left ventricular pressure and volume. Ain J Physiol 264: H1548-H1559

4. Delhaas T, Arts T, Prinzen FW, Reneman RS (1993) Relation between regional electrical activation time and subepicardial fiber strain in the canine left wentricle. Pflügers Arch (Eur J Physiol) 423: 78-87

5. Feigl EO, Simon GA, Fry DL (1967) Auxotonic and isometric cardiac force transducers. J Appl Physiol 23: 597-600

6. Forrester JS, Diamond G, Parmley WW, Swann HJC (1972) Early increases in left ventricular compliance after myocardial infarction. J Clin Invest 51: 598-603

7. Gallagher KP, Osakada G, Hess OM, Koziol IA, Keper WS, Ross Jr. J (1982) Subepicardial segmental function during coronary stenosis and the role of myocardial fiber orientation. Circ Res 50: 352-359

8. Gallagher $\mathbb{K P}$. Stirling MC, Choy M, Szpunar CA, Gerren RA, Botham MJ, Lemmer JH (1985) Dissociation between epicardial and transmural function during acute myocardial ischemia. Circulation 71: 1279.1291

9. Glower DD, Spratt JA, Kabas JS, Davis IW, Rankin JS (11988) Quantification of regional myocardial dysfunction after acute ischemic injury. Am J Physiol 255: H85-H93

10. Goto $Y$, Igarashi $Y$, Yastumura $Y$, Nozawa $T$,
Futaka $S$, Hiramori $K$, Suga $H$ (1988) Integrated regional work equals total left ventricular work in regionally ischemic canine heart. Am J Physiol 254: H894-H904

11 1. Goto Y, Slinker BK, LeWinter MM (1988) Similar normalized Emax and $\mathrm{O} 2$ consumption-pressurevolume area relation in rabbit and dog. Am J Physiol 255: H366-H374

112. Grimm AF, Lin HL, Grimm BR (1980) Left ventricular free wall and intraventricular pressure sarcomere length distributions. Am J Physiol 239: H101-H107

13. Huisman RM, Elzinga, Westerhof $N$, Sipkema P (1980) Measurement of left ventricular wall stress. Cardiovasc Res 14: 142-153

14. Kass DA, Marino P, Maughan WL, Sagawa K (1989) Determinants of end-systolic pressure-volume relations during acute regional ischemia in situ. Circulation 80: 1783-1794

15. Khalafbeigui F, Suga H, Sagawa K (1979) Left ventricular systolic pressure-volume area correlates with oxygen consumption. Am J Physiol 237: H566-H569

16. Lew WYW (1987) Influence of ischemic zone size on nonischemic area function in the canine left ventricle. Am J Physiol 252: H990-H997

17. Lew WYW (1991) Functional consequencies of regional heterogeneity in the left ventricle. In: Glass L, Hunter P, McCullogh A.D (Eds) Theory of heart: biomechanics, biophysics, and nonlinear dynamics of cardiac function. Springer, New York Berlin Heidelberg, pp 209-237

18. LeWinter MM, Kent RS, Kroener JM, Carew TE, Covell JW (1975) Regional differences in myocardial performance in the left ventricle of the dog. Circ Res 37: 191-199

19. Muijtjens AMM, Roos JMA, Prinzen TT, Arts T (1990) Noise reduction in estimating epicardial deformation from marker tracks. Am J Physiol 258: H599-H605

20. Noma S, Askenase AD, Weintraub WS, Klein LW, 
Agarwal JB, Helfant RH (1988) Augmentation of contraction in remote nonischemic zone during acute ischemia. Am J Physiol 255: H301-H310

21. Phibbs $\mathbb{R H}$, Dong L (1970) Nonuniform distribution of microspheres in blood flowing through a medium-size artery. Canad J Physiol Pharmacol 48: 415-421

22. Pollack GH, Krueger JW (1976) Sarcomere dynamics in intact cardiac muscle. Eur J Cardiol 4 (suppl): 53-65

23. Prinzen FW, Arts T, van der Vusse GI, Coumans WA, Reneman RS (1986) Gradients in fuber shortening and metabolism across ischemic left ventricular wall. Am J Physiol 250: H255-H264

24. Prinzen FW, Augustijn CH, Arts T, Allessie MA, Reneman RS (1990) Redistribution of: myocardial fiber strain and blood flow by asynchronous electrical activation. Am J Physiol 259: H300-H308

25. Prinzen FW, van der Vusse GJ, Arts T, Roemen THM, Coumans WA, Reneman RS (1984) Accumulation of non-esterified fatty acids in ischemic canine myocardium. Am J Physiol 247 : H264-H272

26. Prinzen TT, Arts $T$, Prinzen FW, Reneman RS (1986) Mapping of epicardial deformation using a video processing technique. J Biomech 19: 263-273

27. Sagawa K (1978) The ventricular pressure-volume diagram revisited. Circ Res 43: 677-687

28. Smalling RW, Ekas RD, Richards Felli P, Binion L, Desmond J (1986) Reciprocal functional interaction of adjacent myocardial segments during regional ischemia: an interventricular loading phenomenon affecting apparent regional contractile function in the intact heart. J Am Coll Cardiol 7: 1335-1346

29. Spotnitz HM, Sonnenblick EH, Spiro D (1966) Relation of ultrastructure to function of the intact heart. Sarcomere structure relative to pressure-volume curves of intact left ventricles of dog and cat. Circ Res 18: 49-66

30. Suga $H$ (1979) Total mechanical energy of a ventri- cle model and cardiac oxygen consumption. Am J Physiol 236: H498-1505

31. Suga H, Hayashi $T$, Shirahata M (1981) Ventricular systolic pressure volume area as predictor of cardiac oxygen consunption. Am I Physiol 240: H39-H44

32. Suga $H$, Hayashi $T$, Shirahata $M$, Suehiro $S$, Hisano R (1981) Regression of cardiac oxygen consumption on ventricular pressure volume area in dog. Am II Physiol 240: H320-H325

33. Suga $H$, Hisano $\mathbb{R}$, Hirata $S$, Hayashi $T$, Yamada $O$, Ninomiya I (1983) Heart rate-independent energetics and systolic pressure-volume area in dog heart. Am J Physiol 244: $\mathbb{H 2 0 6}-\mathrm{H} 214$

34. Suga $H$, Yasumura $Y$, Nozawa $T$, Futaki $S$, Igarashi Y, Goto Y (1987) Prospective prediction of 02 consumption from pressure-volume area in dog hearts. Am J Physiol 252: H1258-H1264

35. Sugawara $M_{*}$ Tamiya $K$, Nakano $K$ (1985) Regional work of the left ventricle: wall tension area relation. Heart and Vessels 1: $133-144$

36. Sunagawa $K$, Burkhoff $D$, Sagawa $K$, Maughan WL (1983) Left ventricular interaction with arterial load studies in isolated canine ventricle. Am J Physiol 245: H773-H780

37. Tennant R, Wiggers CJ (1935) The effect of coronary occlusion on myocardial contraction. Am J Physiol 112: 351-361

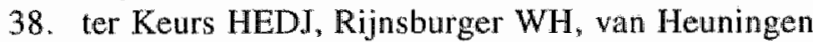
R, Nagelsmit MJ (1980) Tension development and sarcomere length in rat cardiac trabeculae; evidence of length-dependent activation. Circ Res 46:703. 714

39. Theroux P, Franklin D, Ross JJ, Kemper WS (1974) Regional myocardial function during acute coronary artery occlusion and its modification by pharmacologic agents in the dog. Circ Res 35: 896908

40. Theroux P, Ross JI, Franklin D, Covell JW, Bloor CM, Sasayama S (1977) Regional myocardial function and dimensions early and late after myocardial 
infarction in the unanaesthetized dog. Circ Res 40 : $158-165$

41. Tyberg IV, Forrester JS, Wyat HL, Goldner $S J$, Parmley WW, Swan HJC (1974) An analysils of segmental dysfunction utilizing the pressure-length loop. Circulation 49: 748-754

42. van Heuningen $\mathrm{R}$, Rijnsburger $\mathrm{WH}_{\text {, ter }}$ Keurs HEDJ (1982) Sarcomere length control in striated muscle. Am J Physiol 242: $\mathrm{H} 411-\mathrm{H} 420$

43. Vatner SF (1980) Correlation between acute reductions in myocardial blood flow and function in conscious dogs. Circ Res 47: 201-207

44. Villareal FJ, Lew WYW, Waldman LK, Covell JW
(1991) Transmural myocardial deformation in the ischemic canine left ventricle. Circ Res 68: 368 381

45. Weintraub WS, Hattori S, Agarwal JB, Bodenheimer MM, Banka VS, Helfant RH (1981) The relationship between myocardial blood flow and contraction by myocardial layer in the canine left ventricle during ischemia. Circ Res $48: 430-438$

46. Weiss HR, Neubauer JA, Lipp JA, Sinha AK (1978) Quantitative determination of regional oxygen consumption in the dog heart. Circ Res 42 : 394-401 


\section{CONTRACTILE FAILURE OF REGIONALLY ISCHEMIC MYOCARDIUM: ROLE OF DELAYED ELECTRICAL ACTIVATION IS MINOR}

Tammo Delhaas; Theo Arts*, Frits W. Prinzen and Robert S. Reneman

Departments of Physiology and Biophysics*, Cardiovascular Research Institute Maastricht, University of Limburg, P.O.Box 616, NL-6200 MD Maastricht, The Netherlands.

Submitted 
Abstract. Asynchronous electrical activation of the left ventricle, significantly affects regional mechanical performance. Regional fiber strain and external work during the ejection phase are found to be lower in early-activated than in lateactivated regions. The asynchronous contractions of the various regions impede overall hemodynamic performance. The present study was designed to investigate to what extent electrical asynchrony may be held responsible for the regional and global mechanical deterioration as found in the ischemic left ventricle. Regional electrical activation time $\left(t_{e a}\right)$ and fiber strain during the ejection phase $\left(\mathrm{e}_{\mathrm{f}}\right)$ were measured in the epicardial layers of the left ventricular anterior wall during normoxia, and after $15 \mathrm{~min}$ of total occlusion $(n=5)$ or $30,60,120$ and 180 min of partial occlusion of the left anterior interventricular coronary artery $(n=11)$. Myocardial blood flow (MBF), $\mathrm{pH}$, blood gases, and arterio-venous differences in lactate and inorganic phosphate content were determined to assess the presence of ischemia. During normoxia, $e_{f}$ and $t_{\text {ea }}$ were homogeneously distributed over the epicardial layers of the left ventricular anterior wall. During total occlusion, in the ischemic area, subepicardial MBF decreased from $0.86 \pm$ 0.36 to $0.18 \pm 0.09 \mathrm{ml} \cdot \mathrm{g}^{-1} \cdot \mathrm{min}^{-1}$ (mean $\pm \mathrm{SD}$ ), and $\mathrm{e}_{\text {from }}-0.11 \pm 0.02$ to $-0.01 \pm 0.01$. The delay in $t_{e a}$ between the normoxic basal-lateral and the ischemic apical-medial area increased significantly, although limited, from $1.9 \pm 8.0$ to $7.5 \pm 8.0 \mathrm{~ms}$. During partial occlusion, in the normoxic area subepicardial MBF increased from $0.64 \pm 0.24$ to $0.70 \pm 0.23 \mathrm{ml} \cdot \mathrm{g}^{-1} \cdot \mathrm{min}^{-1}$ and $e_{f}$ changed from $-0.09 \pm 0.03$ to $-0.07 \pm$ 0.01 In the ischemic area, subepicardial MBF decreased from $0.62 \pm 0.17$ to $0.49 \pm 0.18$ $\mathrm{ml} \cdot \mathrm{g}^{-1} \cdot \mathrm{min}^{-1}$ and $\mathrm{e}_{\mathrm{f}}$ from $-0.08 \pm 0.01$ to -0.03 \pm 0.01 . No significant change in the difference in $t_{e a}$ between the normoxic and the ischemic area could be detected. We conclude that the mechanical dysfunction during regional ischemia results predominantly from the reduction in MBF rather than from inhomogeneities in electrical activation.

\section{Introduction}

Myocardial ischemia due to (partial) coronary artery occlusion affects both mechanical and electrical function of the myocardium. After occlusion of a coronary artery, systolic fiber shortening in the ischemic area is reduced within seconds. Within minutes, the ischemic fibers show paradoxical lengthening during early systole, followed by some residual shortening [21, 29] after decline of left ventricular pressure. Ischemia also affects the electrophysiological properties of the cardiac cells $[6,10$, $11,18,26]$. A reduction is found in resting membrane potential, and in upstroke velocity and amplitude of the action potential [11]. These changes influence considerably the conduction of the depolarization wave in the ischemic region. In canine [3] as well as feline hearts [18], occlusion of the left anterior interventricular coronary artery (LAICA) caused delays in the activation of the ischemic myocardium up to 70 $\mathrm{ms}$ after the onset of ventricular activation. 
Studies on the interaction between electrical asynchrony and mechanical function revealed that at the medial free wall of the left ventricle electrical asynchronies significantly affect regional mechanical performance $[5,22]$ causing impediment of overall hemodynamic performance. Regional fiber shortening and external work during the ejection phase were found to be lower in early-activated than in late-activated regions.

The present study was designed to investigate to what extent electrical asynchrony is responsible for the regional and global deterioration of contractile performance as found in the ischemic left ventricle [23]. Electrical activation time and deformation were measured at the epicardium of the left ventricular free wall in openthorax dogs. The study consisted of two series. In series $1(\mathrm{n}=5)$, measurements were made during control and after $15 \mathrm{~min}$ of total occlusion of the distal part of the LAICA. In series 2 $(\mathrm{n}=11)$, measurements were made during control and after 30,60,120, and 180 min of partial occlusion of the distal part of the LAICA by an inflatable cuff, keeping mean coronary perfusion pressure distal to the stenosis at $4.0 \mathrm{kPa}$.

\section{Methods}

Animal preparation and instrumentation. Mongrel dogs of either sex, ranging in weight from 22 to $34 \mathrm{~kg}$, were premedicated with an intramuscular injection of Hypnorm (1 ml. $\mathrm{kg}^{-1}$; $1 \mathrm{ml}$ Hypnorm contains $10 \mathrm{mg}$ fluanisone and $0.2 \mathrm{mg}$ fentanyl base). Anesthesia was induced with an intravenous injection of pentobarbital sodium (10 mg.kg-1) and was maintained with nitrous oxide $\left(33 \% \mathrm{O}_{2}, 67 \% \mathrm{~N}_{2} \mathrm{O}\right)$ and a continuous infusion of pentobarbital sodium (2 $\mathrm{mg} \cdot \mathrm{kg}^{-1} \cdot \mathrm{h}^{-1}$ ) after endotracheal intubation. Ventilation was kept constant with a positive pressure respirator (Pulmomat, Dräger). The animal was placed on its right side, and body temperature was kept between 37.5 and $38.5^{\circ} \mathrm{C}$ by means of a thermostatically regulated heating pad. A standard limb lead electrocardiogram (ECG) was recorded. Arterial blood samples were taken periodically to determine $\mathrm{PO}_{2}, \mathrm{PCO}_{2}$, $\mathrm{pH}$, oxygen saturation and hemoglobin concentration (ABL 3, Radiometer). Sodium bicarbonate solution $(4.2 \%)$ was administered intravenously to adjust the acid-base balance when necessary.

The chest was opened through the left fifth intercostal space. After removal of the fifth rib, the pericardium was opened, and the heart was suspended in a pericardial cradle.

The LAICA was dissected free distal to the first diagonal side branch over a distance of about $1.5 \mathrm{~cm}$ and an inflatable cuff with a width of approximately $0.6 \mathrm{~cm}$ was placed around it (Fig. 1). A polyethylene catheter was inserted into a preferentially apical small side branch of the LAICA for the measurement of blood pressure distal to the stenosis (see below).

Polyethylene catheters were inserted into the left anterior interventricular vein and into the coronary sinus to obtain venous blood samples.

To assess regional myocardial blood flow, a silastic catheter was placed in the left atrium 


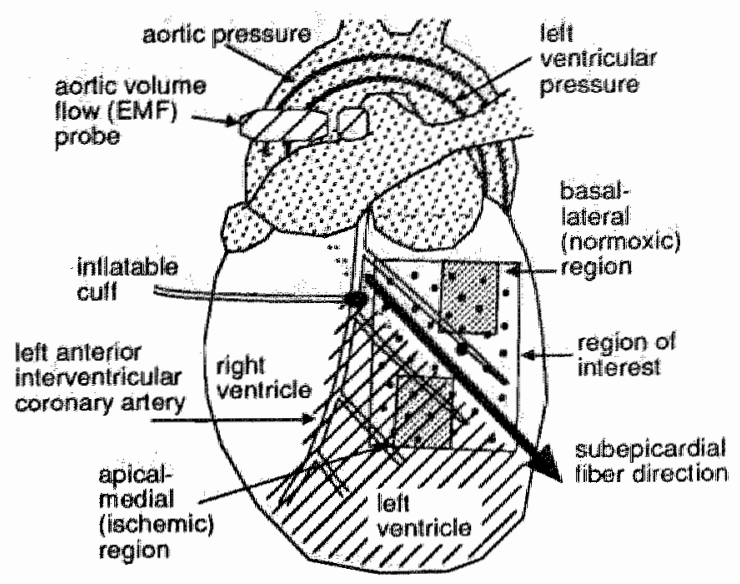

Fig. 1. Schematic representation of experimental setup. Dots within the area of interest are optical markers, attached to the epicardial surface. Shaded area indicates ischemic area, resulting from the (partial) occlusion of the distal part of the LAICA. The shaded rectangles indicate the regions for analysis of electrical activation and fiber strain in Fig. 4.

for the injection of radioactively labeled microspheres [21]. A polyethylene catheter was inserted into the right brachial artery to obtain blood for the arterial reference sample.

Left ventricular cavity and ascending aortic pressure were measured with catheter-tip micromanometers (Millar PC-470), inserted via the right brachial and the right femoral artery, respectively. To enable pressure calibration during the experiment, the fluid-filled lumina of the catheter-tip micromanometers were connected to an external pressure transducer (Electromedics MS20) via three-way cocks. The third opening of the three-way cock was connected to a reference pressure level, which was set at the right atrial level and used for all pressure measurements [2]. Ascending aortic volume flow was measured with an electromagnetic flow meter (Skalar Transflow 601).

ECG, pressure and ascending aortic volume flow signals were continuously displayed on an oscilloscope (Knott). These signals were also recorded on a paper recorder (Schwarzer), and sampled $(200 \mathrm{~Hz})$ and digitized using a 16channel 12-bit A/D card (DASH 16G2), connected to a MS-DOS personal computer (Tulip AT Compact). Sampling and analysis were performed using a software package (ASYST 3.0, MacMillan Software Company) and software developed in our laboratory.

Determination of hemodynamic variables. In the cardiac cycle three events were determined. The end of the diastolic phase was defined as the moment before ejection at which the rate of change of left ventricular pressure $\left(\mathrm{dp}_{\mathrm{lv}} / \mathrm{dt}\right) \mathrm{ex}$ ceeded $10 \mathrm{kPa}^{-1} \mathrm{~s}^{-1}$ [14]. The beginning of the ejection phase was determined by the moment at which left ventricular pressure exceeded end-diastolic aortic pressure. The duration of the ejection phase was determined from the aortic volume flow signal. From left ventricular pressure as a function of time, end-diastolic left ventricular pressure, maximum left ventricular pressure, and the maximum and minimum first derivative of left ventricular pressure were determined. Besides, the following hemodynamic variables were assessed: heart rate, maximum instantaneous ascending aortic volume flow, 
and ejected volume (time integral of ascending aortic volume flow).

Mapping of left ventricular epicardial electrical activation pattern. A 192-electrode brush $(44 \times 64 \mathrm{~mm})$ was used for simultaneous recording of epicardial surface electrograms at the left ventricular anterior free wall. The grid spacing between the electrodes was approximately $3.5 \mathrm{~mm}$. Left ventricular pressure and ECG were recorded with the same system simultaneously with the electrode signals. Offline, in each electrogram, the moment with the steepest negative deflection was detected and labeled by a time mark, indicating the moment of regional activation of the tissue underneath the recording electrode $[1,9]$. Mean electrical activation time was calculated for the regions as used for the deformation assessment (see below) by determining the time interval between the moment of maximum $\mathrm{dp}_{\mathrm{lv}} / \mathrm{dt}$ and the average moment of electrical activation within one region [5].

Mapping of left ventricular epicardial fiber strain. Natural strain in the direction of the subepicardial fibers $\left(e_{f}\right)$ was calculated from epicardial deformation by:

$$
e_{f}=\ln \frac{1_{f}}{d_{f, b e}}
$$

where $l_{f}$ and $l_{f, b e}$ represent epicardial segment length along the subepicardial fiber direction in the actual situation and at the beginning of the ejection phase, respectively.

Two-dimensional epicardial deformation was determined with a video technique as previously described in detail [24]. In brief, approximately 40 white markers were attached with tissue glue (Histoacryl) to the epicardial surface of the left ventricular anterior wall at mutual distances of approximately $6 \mathrm{~mm}$. The area covered with markers extended $3-4 \mathrm{~cm}$ in the circumferential and $4-5 \mathrm{~cm}$ in the base-toapex direction (Fig. 1). A video camera (Sony AVC $32500 \mathrm{CE}$ ) with a $200 \mathrm{~mm}$ tele-objective, positioned at an optical distance of $2.5 \mathrm{~m}$ was used to record the motion of the markers on a video recorder (Sony SL-C9ES, Betamax) at a speed of 50 frames per second. For convenience, the optical axis was deflected by a mirror mounted above the heart at an angle of $45^{\circ}$. Video-triggered xenon flashlight illumination (Chadwick-Helmuth) was employed to prevent motion artifacts due to smearing of the images. The direction of the epicardial fibers and the long axis of the left ventricle as determined by visual inspection was indicated by a directed ruler and recorded on video (Fig. 1). To enable synchronization with hemodynamic data, a frequency-modulated left ventricular pressure signal was recorded on an audio channel of the video recorder.

After the experiment, 64 consecutive video frames were digitized and stored in a $2 \mathrm{MB}$ digital video memory which was coupled to a computer (Laser AT). Marker positions were detected, filtered by a singular value decomposi- 
tion technique [15], and used for the estimation of epicardial deformation in $4 \times 4$ mutually overlapping regions by means of a least-squares criterion [24].

Biochemical analysis. Lactate and inorganic phosphate in serum as well as $\mathrm{pH}$ and oxygen extraction in whole blood were determined as published previously [32]. Differences between arterial samples, and samples obtained from the coronary sinus or the left anterior interventricular vein were regarded to be representative of the normoxic basal-lateral and the ischemic apical-medial part of the anterior free wall of the left ventricle, respectively.

\section{Determination of regional myocardial blood} flow. Regional myocardial blood flow was determined with radioactively labeled microspheres $(15.0 \pm 1.0 \mu \mathrm{m}$; NEN-TRAC, DuPont DeNemours), suspended in $10 \%$ dextran with $0.01 \%$ Tween 80 [21]. The labels used were: ${ }^{141} \mathrm{Ce},{ }^{113} \mathrm{Sn},{ }^{103} \mathrm{Ru}$, or ${ }^{95} \mathrm{Nb}$. At each determination, $3 \times 10^{6}$ microspheres were injected into the left atrium. An arterial reference sample was taken from the brachial artery at a rate of $20.7 \mathrm{ml} / \mathrm{min}$, using a Harvard withdrawal pump. Withdrawal of blood started $5 \mathrm{~s}$ before the injection of the microspheres, and was continued during at least $1 \mathrm{~min}$.

After the experiment, the heart was fixated in $5 \%$ formaldehyde. Before dissection, nonmuscular structures, like fat and vessels at the epicardium and chordae tendinae, were removed. Two transmural sections with an epi- cardial surface of $\sim 7 \times 7 \mathrm{~mm}$ were dissected from the left ventricular anterior free wall: a basal-lateral normoxic, and an apical-medial ischemic section. Each section was subdivided into a subepicardial and a subendocardial half, each of which was weighed. The radioactivity of the tissue and arterial blood samples was determined in a gamma counter (Packard multichannel Analyzer). Regional myocardial blood flow in milliliters per gram per minute was calculated.

Experimental protocol. In series $1(\mathrm{n}=5)$, hemodynamics, regional fiber strain, electrical activation time, and myocardial blood flow were assessed during control and after $15 \mathrm{~min}$ of total occlusion of the distal part of the LAICA.

In series $2(n=11)$, measurements were performed during control, and after 30, 60, 120, and 180 min of moderate ischemia, as induced by careful inflation of the occluder cuff around the LAICA, as described in detail before [20]. Mean coronary pressure distal to the stenosis was kept constant at $4.0 \mathrm{kPa}$ throughout the experimental period, using a servo-motor pump with an autoregulating feedback system controlled by mean coronary artery pressure distal to the stenosis.

Measurements were performed as follows. Arterial, local venous, and coronary sinus blood samples were taken for chemical and blood gas analysis. Subsequently, microspheres were injected and a reference arterial sample was taken for the calculation of regional myocardial blood flow. Hemodynamic variables and epicardial 
deformation were recorded simultaneously. Within $1 \mathrm{~min}$ thereafter simultaneous recordings of hemodynamic variables and epicardial electrical activation were performed. Regional myocardial blood flow was only determined at control, and after 60 and 180 min of ischemia. Measurement of regional fiber strain was limited to 4 experiments.

Precise synchronization of hemodynamic data with deformation or electrical data was achieved by applying a correlation-interpolation technique to the left ventricular pressure signals obtained from the different recording devices [4]. During the experiment reproducible positioning of the electrode brush was obtained by visual matching of landmarks on the electrode brush with anatomical landmarks and/or video markers on the epicardial surface. Spatial matching of electrophysiological and deformation maps was enabled by four white markers, attached to the upper surface of the multi-electrode brush.

The experiment was terminated by administration of an overdose of pentobarbital sodium. Within 5 min thereafter, the heart was excised, the atria were removed from the ventricles, and the ventricles were rinsed.

Statistical analysis. The effect of total and partial occlusion of the distal part of the LAICA on hemodynamics, electrical activation time, deformation, biochemics, and regional blood flow was evaluated for statistical significance by comparing the data at the various intervals with the control values in the same animal. The Sign test and the Wilcoxon matched-pairs signedrank test were used in series $\mathbb{}(\mathrm{n}=5)$ and series $2(n=11)$, respectively. A value of $P<0.05$ was considered to be a significant difference. The data are presented as mean $\pm S D$.

\section{Results}

\section{Series 1: Normoxia}

During normoxia, regional deformation and electrical activation were homogeneously distributed over the epicardium of the left ventricular anterior free wall (Fig. 2). No difference in myocardial blood flow, neither between the subepicardium and the subendocardium, nor between the normoxic area and the area expected to become ischemic could be detected (Table 1).

\section{Series 1: Ischemia}

Total occlusion of the distal part of the LAICA caused ischemia as indicated by the decrease in $\mathrm{pH}$ in the coronary effluent of the ischemic area (Table 2). The oxygen extraction fraction in the ischemic area increased from $67 \%$ to $81 \%$. In the normoxic areas, the oxygen extraction fraction remained unchanged.

Hemodynamic performance decreased after total occlusion of the distal part of the ILAICA. As compared with the control values, end-diastolic and maximum left ventricular pressure, mean post-stenotic coronary perfusion pressure, maximum aortic volume flow, and maximum 


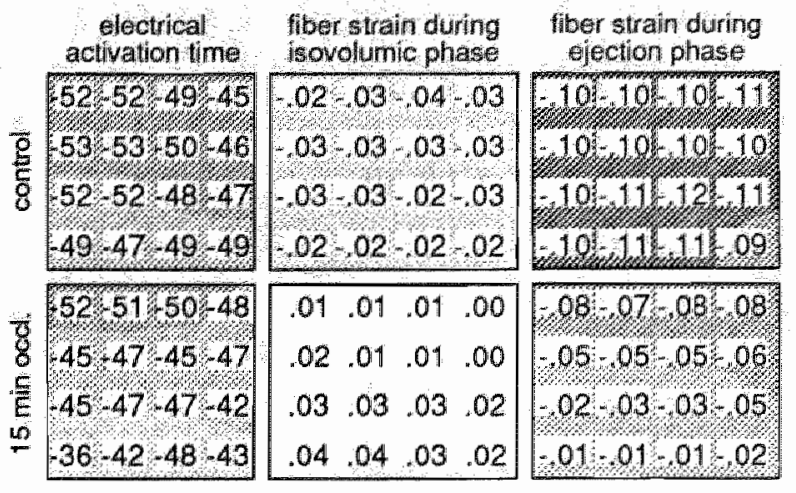

Fig. 2. Maps of regional electrical activation time and regional subepicardial fiber strain during the isovolumic contraction phase and the ejection phase, during control (top row) and after 15 min of total occlusion of the LAICA (bottom row). The time $t_{e a}$ is referred to the moment of maximum $\mathrm{dplv} / \mathrm{dt}$. Note that tea values in late-activated regions are less negative than in early-activated regions. The detailed maps obtained with the 192-electrode brush were reduced to a $4 \times 4$ matrix. The boundaries between different degrees of shading indicate time intervals of $5 \mathrm{~ms}$. In the maps depicting fiber strain, these boundaries mark intervals in strain of 0.05 .

Table 1. Regional myocardial blood flow ( $\mathrm{ml}^{-1} \cdot \mathrm{m}^{-1} \mathrm{mi}^{-1}$ ) in the outer (epi) and inner (endlo) layers of the left ventricular wall, as well as their ratio (endo/epi) during control and after (partial) occlusion of the left anterior interventricular coronary artery.

\begin{tabular}{|c|c|c|c|c|c|}
\hline & \multicolumn{2}{|l|}{ series 1} & \multicolumn{3}{|l|}{ series 2} \\
\hline & $\begin{array}{l}\text { control } \\
(n=5)\end{array}$ & $\begin{array}{l}15 \text { min } \\
\text { occlusion } \\
(\mathrm{n}=5)\end{array}$ & $\begin{array}{l}\text { control } \\
(n=11)\end{array}$ & $\begin{array}{l}60 \text { min partial } \\
\text { occlusion } \\
(n=7)\end{array}$ & $\begin{array}{l}180 \text { min partial } \\
\text { occlusion } \\
(\mathrm{n}=11)\end{array}$ \\
\hline \multicolumn{6}{|l|}{ normoxic region } \\
\hline epi & $0.80 \pm 0.32$ & $0.92 \pm 0.25 *$ & $0.64 \pm 0.24$ & $0.73 \pm 0.26 *$ & $0.70 \pm 0.23$ \\
\hline endo & $0.91 \pm 0.39$ & $0.72 \pm 0.24$ & $0.68 \pm 0.21$ & $0.71 \pm 0.23$ & $0.71 \pm 0.24$ \\
\hline endo/epi ratio & $1.13 \pm 0.16$ & $0.81 \pm 0.28$ & $1.10 \pm 0.22$ & $1.00 \pm 0.29 *$ & $1.02 \pm 0.14$ \\
\hline \multicolumn{6}{|l|}{ ischemic region } \\
\hline epi & $0.86 \pm 0.36$ & $0.18 \pm 0.09$ & $0.62 \pm 0.17$ & $0.58 \pm 0.13$ & $0.49 \pm 0.18^{*}$ \\
\hline endo & $0.78 \pm 0.24$ & $0.04 \pm 0.02$ & $0.65 \pm 0.19$ & $0.35 \pm 0.15 *$ & $0.31 \pm 0.16$ \\
\hline endolepi ratio & $0,96 \pm 0.14$ & $0.25 \pm 0.12$ & $1.07 \pm 0.23$ & $0.60 \pm 0.22$ & $0.63 \pm 0.24^{\text {水 }}$ \\
\hline
\end{tabular}

Values are mean $\pm \mathrm{SD}$. Statistically significantly different from results obtained during control within same series ( $\mathrm{P}$ $<0.05$ ) by Sign test and Wilcoxon signed rank test for series 1 and 2 , respectively.

and minimum $\mathrm{dp}$ Iv $/ \mathrm{dt}$ were reduced (Table 3 ).

Total occlusion of the distal part of the LAICA also reduced subepicardial and suben- docardial myocardial blood flow in the apicalmedial regions of the area under investigation from $0.86 \pm 0.36$ to $0.17 \pm 0.11$ and from 0.78 
Table 2. Values of several chemical variables in arterial (A), local venous (LV), and coronary sinus (CS) blood samples for series 1 (total occlusion of the left anterior interventricular coronary artery (LAICA); $n=5$ ) and series 2 (partial occlusion of the LAICA; $n=11$, except for the determination of (differences in) lactate and inorganic phosphate content $(n=7)$ ).

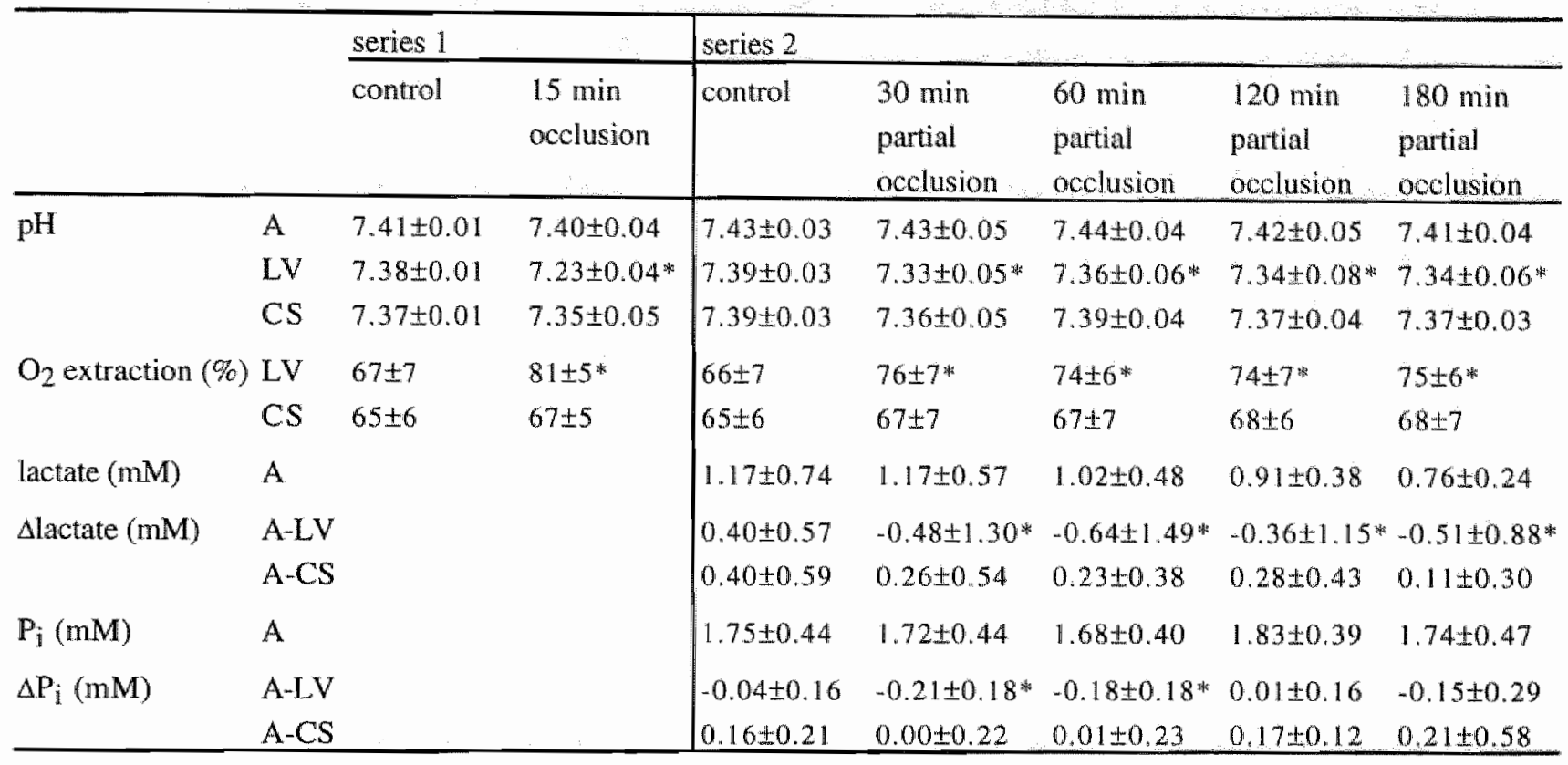

Values are means $\pm \mathrm{SD}$. Abbreviations: $; \mathrm{P}_{\mathrm{i},}$ anorganic phosphate; $\Delta \mathrm{P}_{\mathrm{i}}$, difference in anorganic phosphate. ${ }^{*}$ Statistically significantly different from control $(\mathrm{P}<0.05)$ by Sign test and Wilcoxon signed rank test for series 1 and 2 , respectively.

\pm 0.24 to $0.04 \pm 0.02 \mathrm{ml} \cdot \mathrm{g}^{-1} \cdot \mathrm{min}^{-1}$, respectively. The ratio of subendocardial to subepicardial blood flow (endo/epi ratio) decreased from $0.96 \pm 0.14$ to $0.25 \pm 0.12$ (Table 1). Electrical activation times and fiber strain during the ejection phase changed concomitantly (Fig. 2). The delay in electrical activation time between the normoxic basal-lateral and the ischemic apical-medial area increased from $1.9 \pm$ 8.0 to $7.5 \pm 8.0 \mathrm{~ms}$. In the ischemic apical-me- dial region, fiber strain during the isovolumic contraction phase changed from $-0.02 \pm 0.01$ to $+0.04 \pm 0.03$, and during the ejection phase from $-0.11 \pm 0.02$ to $-0.01 \pm 0.01$.

\section{Series 2: Normaxia}

The findings on the distribution of myocardial blood flow (Table 1) and regional fiber strain (Fig. 3) were similar to those in series 1. 


\begin{tabular}{|c|c|c|c|}
\hline & $\begin{array}{c}\text { electrical } \\
\text { activation time }\end{array}$ & $\begin{array}{l}\text { fiber strain during } \\
\text { isovolumic phase }\end{array}$ & $\begin{array}{l}\text { tiber strain during } \\
\text { ejection phase }\end{array}$ \\
\hline & $53<52<52<52$ & $-.02, .02-02-01$ & $010,09,09 \% 09$ \\
\hline & $52<52,52<54$ & $-02-.01-.02-01$ & $.09-09,09>10$ \\
\hline & $50-50,51<53$ & $-01-.01-01-01$ & $.08,08,09=10$ \\
\hline & $4747 \times 4749$ & $00,01,01,01$ & $.080 .08,09 \div .08$ \\
\hline & $53,52<51<53$ & $-01 \div .01 \div .02-01$ & $07,06,06,06$ \\
\hline & $52-53-53<55$ & $-.02-02-01-01$ & $.04,08<07,08$ \\
\hline & $49-50=50-54$ & $.01 \quad .00-.01-01$ & $-04-05 \quad 07 / 07$ \\
\hline & $-47-46 \quad 46 \quad 48$ & $.02 .02-.01-01$ & $-03,03,04,05$ \\
\hline & $54-54 / 52<53$ & $.01-.01-.02-.01$ & $088-07=067.07$ \\
\hline & $53<54<53-54$ & $.00 \% .01 .00 \quad .00$ & $=06,06,07,06$ \\
\hline & $-49-49-50-53$ & $.01 .00 \quad .00 \quad .00$ & $05-06-07,08$ \\
\hline & $-45-45 \quad 45-48$ & .03 .01 .01 .01 & $.03 .04 .05 \quad 05$ \\
\hline & $-53-52,50-50$ & $.00-01-01-.02$ & $06-06-06-06$ \\
\hline & $52<53<52<53$ & $.00-01-01,00$ & $.05-.06-06-06$ \\
\hline & $49-50-49-52$ & $.01 .00 .00 \quad .00$ & $-04.05,06=07$ \\
\hline & $-46 \quad 45 \quad 45-48$ & $.02 .02 \quad .02 .01$ & $-.03,03-04, .04$ \\
\hline & $56-55 \quad 53-55$ & $.01-.02-.02-.02$ & $.07,07,07 \% 07$ \\
\hline & $55,56,55-57$ & $-.01-.01-.01-.01$ & $.06-07-07 \% .07$ \\
\hline & $52-53<52-56$ & $.01 .00 \quad .00-.01$ & $.03-04-06=07$ \\
\hline & $-49-48 \quad-49-51$ & .02 .01 .00 .00 & $.02-03-05-05$ \\
\hline
\end{tabular}

Fig. 3. Maps of regional electrical activation time (tea; $n=11$ ) and regional subepicardial fiber strain during the isovolumic contraction phase $(n=4)$ and the ejection phase $(n=4)$, as averaged over the experiments with 3 hour partial occlusion of the LAICA. The successive rows show the results obtained during control, and after $30,60,120$, and 180 min of partial occlusion of the LAICA.

However, electrical activation maps showed a gentle gradient. On the average, the basal-lateral area was activated slightly ( $5 \mathrm{~ms}$ ) before the apical-medial area.

\section{Series 2: Ischemia}

\section{Hemodynamics}

Post-stenotic coronary artery pressure was kept constant at $4.0 \mathrm{kPa}$, with less than $0.5 \mathrm{kPa}$ intra-individual variation throughout the experimental period and less than $1.0 \mathrm{kPa}$ variation between animals (Table 3). Ejected volume, maximum rate of aortic volume flow, and maximum and minimum first derivative of left ventricular pressure were decreased after impairment of coronary flow. Maximum left ventricular pressure was decreased after 180 minutes of partial occlusion.

\section{Blood gases and biochemical variables}

Keeping mean post-stenotic pressure at $\sim 4.0$ $\mathrm{kPa}$, the related impairment of coronary inflow caused ischemia as indicated by the decrease in $\mathrm{pH}$, and the release of lactate and inorganic phosphate into the coronary effluent of the ischemic area. Oxygen extraction was increased in the ischemic area (Table 2).

\section{Regional myocardial blood flow}

Partial occlusion of the distal part of the LAICA induced a redistribution of myocardial blood flow. Subepicardiall blood flow in the non-ischemic area was increased after 60 and $180 \mathrm{~min}$ of ischemia, whereas subendocardial blood flow did not change (Table 1). As a consequence, the ratio of subendocardial to subepi- 
Deformation and electrical activation during ischemia

Table 3. Hemodynamic variables during control as well as (partial) occlusion of the left anterior interventricular coronary artery ( $n=5$ and $n=11$ for series 1 and 2 , respectively).

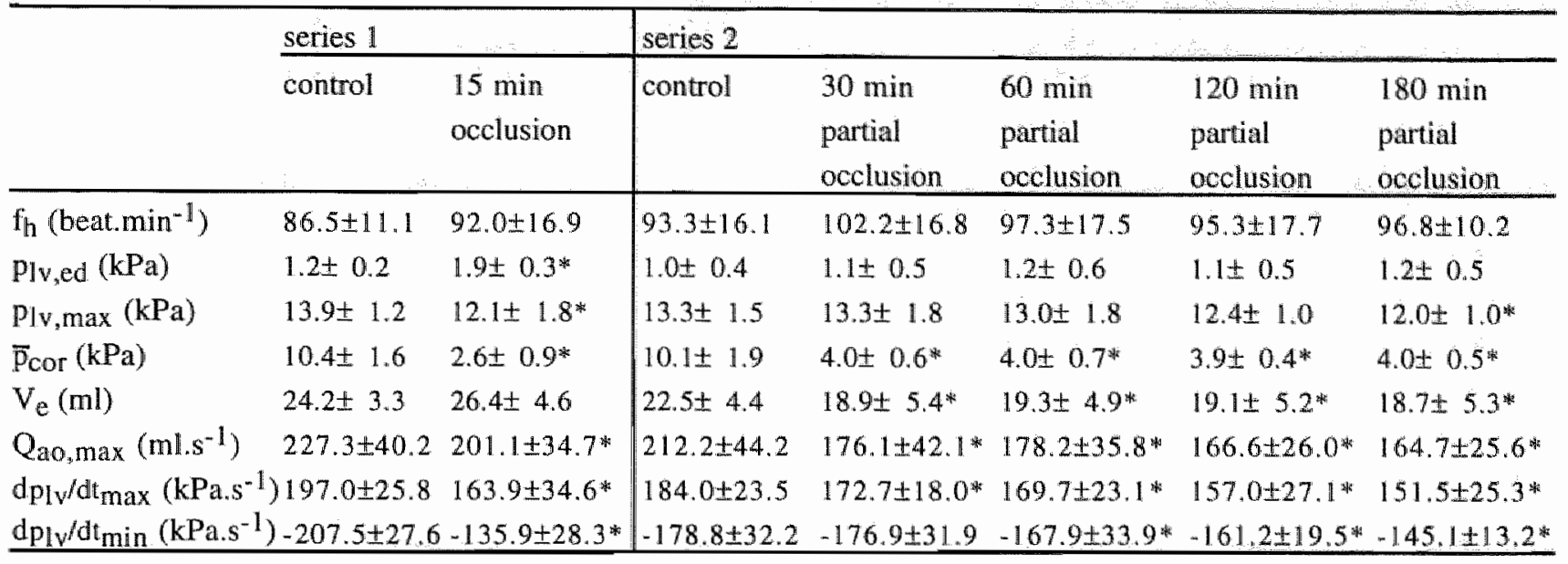

Values are mean $\pm S D$. Abbreviations: $f_{h}$, heart rate; $\mathrm{plv}$,ed, left ventricular pressure at end diastole; $\mathrm{plv}$, $\max$, maximum left ventricular pressure; $\overline{\mathrm{p}}_{\mathrm{cor}}$, mean post-stenotic coronary artery pressure; $\mathrm{V}_{\mathrm{e}}$, ejected volume; $\mathrm{Qao}, \mathrm{max}$, maximum aortic volume flow; $\mathrm{dp}_{\mathrm{lv}} / \mathrm{d}_{\mathrm{max}}$ and $\mathrm{dplv} / \mathrm{d} \mathrm{t}_{\mathrm{min}}$, maximum and miminum first derivative of left ventricular pressure, respectively. "Statistically significantly different from results obtained during control $(\mathrm{P}<0.05)$ by Sign test and Wilcoxon signed rank test for series 1 and 2 , respectively.

cardial blood flow (endo/epi ratio) decreased from 1.10 to 1.00 and 1.02 after 60 and 180 min of ischemia, respectively. In the ischemic area, subepicardial blood flow was decreased at $180 \mathrm{~min}$ of ischemia, whereas subendocardial blood flow was decreased both at 60 and at 180 min of ischemia. The endo/epi ratio decreased from 1.07 to 0.60 and 0.63 after 60 and 180 min of partial occlusion, respectively.

\section{Regional electrical activation}

Partial acclusion of the LAICA caused only minor changes in electrical activation of the area under investigation. Mean epicardial electrical activation times, as averaged over the experiments $(n=11)$, are presented in Fig. 3. During normoxia and ischemia, the basal regions of the area under investigation were activated first, followed by the apical-lateral region and the apical-medial region in that order. The delay in electrical activation time between the normoxic basal-lateral and the ischemic apical-medial ischemic area did not change during the course of the experiment, being $5.1 \pm 4.8,5.0 \pm 3.8,7.2$ $\pm 4.8,4.6 \pm 4.9$, and $5.2 \pm 5.8 \mathrm{~ms}$ during control and at $30,60,120$, and $180 \mathrm{~min}$ of ischemia, respectively (Fig. 4). 

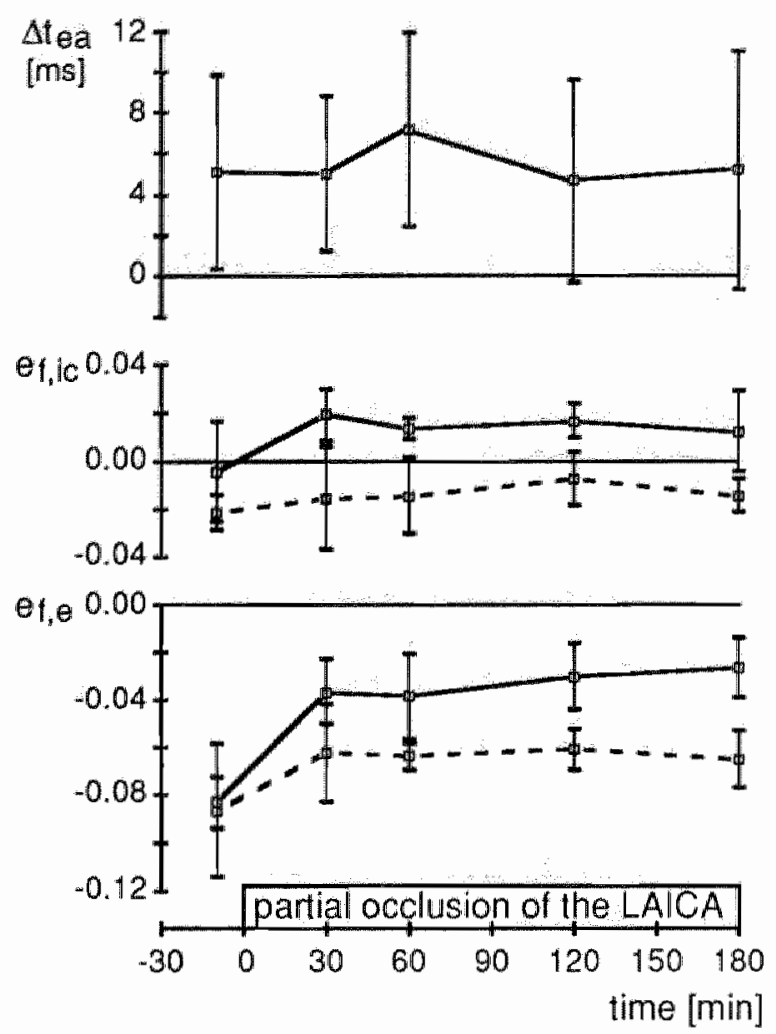

Fig. 4. Plots of the delay in electrical activation time in the ischemic apical-lateral area with respect to the normoxic basal-medial $\left(\Delta t_{e a} ; n=11\right)$, and fiber strain during the isovolumic phase $\left(e_{f}, i c, n=4\right)$ and the ejection phase $\left(e_{1}, e_{i} n=4\right)$. In the middle and bottom plots, the dashed and the solid line refer to the normoxic and ischemic area, respectively.

\section{Regional fiber strain}

After partial occlusion of the LAICA, the degree of fiber strain was inhomogeneously distributed. In the basal regions the subepicardial fibers shortened slightly during the isovolumic contraction phase (Fig. 3). During the ejection phase, fiber shortening was slightly decreased. In the ischemic apical-medial area, fibers lengthened during the isovolumic contraction phase, and during the ejection phase fiber shortened less than in the non-ischemic area. As a result, during both phases of the cardiac cycle, a spatial gradient in the degree of fiber shortening could be noticed during partial occlusion of the LAICA.

\section{Discussion}

The findings in the present study indicate that the mechanical dysfunction observed in the ischemic subepicardial layers during acute total and partial occlusion of a coronary artery results from reduced blood flow rather than from disturbances in electrical activation. Following total coronary artery occlusion, the decrease in fiber shortening in the ischemic area is pronounced, while the delay in electrical activation, although significant, is limited. It is unlikely that an average delay of $\sim 7.5 \mathrm{~ms}$ will cause large inhomogeneities in fiber shortening $[5,22]$. Besides, because this delay is positive, fiber strain would be enhanced by approximately -0.025 , rather than reduced in late activated regions $[5,22]$. During partial occlusion of a coronary artery, no disturbances in electrical activation are found, while the ischemic fibers are lengthening paradoxically during early $\cdot$ systole, followed by some residual shortening after decline of left ventricular pressure. Although measurement of regional fiber strain during prolonged partial 
coronary artery occlusion was limited to $4 \mathrm{ex}$ periments, the results obtained are in agreement with previous measurements on ischemia $[7,8$, $16,21,28,29,34]$.

In the normoxic left ventricle with epicardial ventricular pacing, electrical activation time was related to the amount of fiber strain during the ejection phase [5]. It could be argued whether this relation holds for the ischemic heart as well. With epicardial ventricular pacing, the epicardium of the investigated area at the left ventricular anterior free wall is activated by muscle conduction, and the subepicardial muscle fibers are activated earlier than the endocardial ones below the investigated area. During ischemia with sinus rhythm or atrial pacing, however, endocardial muscle fibers below the investigated area are activated before the subepicardial ones. Therefore, the contraction of the subepicardial fibers might be influenced by the subendocardial fibers.

It cannot be excluded that the activation of the deeper layers in the ischemic part of the area under investigation is relatively unaffected [26]. Slowing down of conduction may be absent in subendocardial Purkinje layers despite a significant decrease in coronary blood flow. Resting membrane potential may not decrease too precipitously due to the diffusion of oxygen from the cavitary blood into the subendocardium [35]. The delay in electrical activation of the ischemic myocardium, if any, is due to impairment of transmural conduction and will increase from the endocardium to the epicardium.
Therefore, epicardial electrical activation measurements as performed in this study should have detect delay in electrical activation, if present.

Total and partial occlusion of the LAICA had different effects on epicardial electrical activation. Only during total coronary artery occlusion, electrical activation was delayed in the ischemic area as compared to the normoxic area. This can be explained by the different degree of reduction in epicardial blood flow in the two series (Table 1). It has been reported that conduction is disturbed only in areas with blood flows between 0.05 and $0.30 \mathrm{ml}^{-1} \cdot \mathrm{min}^{-1}$, and that conduction does not change as long as blood flow exceeds $25 \%$ of control [27]. The observation that epicardial electrical activation was not affected by partial occlusion of the LAICA is supported by experiments on canine hearts in which the main circumflex coronary artery was partially occluded [25]. In these experiments, a decrease in coronary blood flow of $50 \%$ did not change epicardial conduction time from the normoxic to the ischemic area.

The difference between the delay in electrical activation of $\sim 7.5 \mathrm{~ms}$ as found during total occlusion of the LAICA, and the reported delay of up to $70 \mathrm{~ms}$ in similar experiments on canine [3] and feline hearts [18], might be explained as follows. In our experiments, the delay was defined as the difference in electrical activation time between the normoxic basal-lateral and the ischemic apical-medial region of the area under investigation, whereas in the other studies the 
delay was defined as the difference in activation time between the first and last activated part of the left ventricular wall.

In pig hearts, made regionally ischemic by total coronary artery occlusion, the delay in electrical activation of the ischemic subepicardium is reported to diminishes after 10-30 min due to the reappearance of transmembrane potentials in previously unresponsive cells [11]. Therefore, it could be argued that our deformation measurements should have been performed earlier after partial occlusion of the LAICA to detect any influence of delayed electrical activation. However, the delay in electrical activation of the ischemic apical-lateral area with respect to the normoxic basal-lateral one did not change after 5,10 , and 20 min of partial occlusion of the LAICA $(6.6 \pm 5.8,6.5 \pm 4.5$, and $3.4 \pm 3,4$ $\mathrm{ms}$, respectively), as compared to the control situation $(5.1 \pm 4.8 \mathrm{~ms})$.

The generally observed increased shortening of remote normoxic zones, especially during the isovolumic contraction phase $[12,13,31]$, was not found in the present study. This may be explained as follows. First, because of the relatively high level of end-diastolic left ventricular pressure and volume, the length of the sarcomeres in the ischemic area might have been close to their maximum $[19,30,33]$. If so, the serially connected normoxic fibers were unable to shorten additionally. Second, the normoxic area under investigation might have been closer to the ischemic area than in the studies referred to.

During partial occlusion of the LAICA, part of the myocardium became ischemic, as indicated by the release of lactate [36] and inorganic phosphate, due to breakdown of energy-rich phosphates [17], from the ischemic area. The time course of arterio-local venous differences in lactate and inorganic phosphate content is in accordance with that observed in previous studies [23, 32], which reported a maximum release of both substances within $15 \mathrm{~min}$ after induction of partial occlusion of the LAICA. In these studies, the LAICA was partially occluded for $120 \mathrm{~min}$, while mean post-stenotic pressure was kept constant at approximately $3.0 \mathrm{kPa}$. The release of lactate remained increased during the total course of the experiment, whereas the release of inorganic phosphate was not increased anymore after $60 \mathrm{~min}$ of partial occlusion. The higher mean post-stenotic pressure as used in our study resulted in a less severe degree of ischemia, as indicated by the less pronounced release of both lactate and inorganic phosphates.

\section{References}

1. Allessie MA, Hoeks APG, Schmitz GML, Reneman RS (1986) On-line mapping system for the visualization of the electrical activation of the heart. Int J Cardiac Imag 2: 59-63

2. Arts T, Veenstra PC, Reneman RS (1982) Epicardial deformation and left ventricular wall mechanics during ejection in the dog. Am I Physiol 243: H379-H390

3. Boineau JP, Cox JL (1973) Slow ventricular activation in acute myocardial infarction. A source of re-entrant premature ventricular contractions. 
Circulation 43: 702-713

4. de Jong PGM, Arts $T$, Hoeks APG, Reneman $R$ (1990) Determination of tissue motion velocity by correlation interpolation of pulsed ultrasonic echo signals. Ultrasonic Imaging 12: 84-98

5. Delhaas T, Arts T, Prinzen FW, Reneman RS (1993) Relation between regional electrical activation time and subepicardial fiber strain in the canine left ventricle. Pflügers Arch (Eur J Physiol) 423: 78-87

6. Elharrar V, Foster PR, Jirak TL, Gaum WE, Zipes DP (1977) Alterations in canine myocardial excitability during ischemia. Circ Res 40: 98-105

7. Glower DD, Spratt JA, Kabas JS, Davis JW, Rankin JS (1988) Quantification of regional myocardial dysfunction after acute ischemic injury. Am I Physiol 255: H85-H93

8. Goto $Y$, Igarashi $Y$, Yasumura $Y$, Nozawa T, Futaka S, Hiramori K, Suga H (1988) Integrated regional work equals total left ventricular work in regionally ischemic canine heart. Am J Physiol 254: H894-H9O4

9. Hoeks APG, Schmitz GML, Allessie MA, Jas H, Hollen SJ, Reneman RS (1988) Multichannel storage and display system to record the electrical activity of the heart. Med \& Biol Eng \& Comput 26: 434-438

10. Janse MJ, Wit AL (1989) Electrophysiological mechanisms of ventricular arrhythmias resulting from myocardial ischemia and infarction. Physiological Reviews 69: 1049-1169

11. Kléber AG, Janse MJ, Van Capelle IJL, Durner D (1978) Mechanisms and time course of ST and TQ segment changes during acute regional ischemia in the pig heart determined by extracellular and intracellular recordings. Circ Res 42: 603-613

12. Lew WYW (1987) Influence of ischemic zone size on nonischemic area function in the canine left ven. tricle. Am J Physiol 252: H990-H997

13. Lew WYW (1991) Functional consequencies of regional heterogeneity in the left ventricle. In:
Glass L, Funter P, MoCullogh A.D (Eds) Theory of heart: biomechanics, biophysics, and nonlinear dynamics of cardiac function. Springer, New York Berlin Heidelberg, pp 209-237

14. LeWinter MM, Kent RS, Kroener IM, Carew TE, Covell JW (1975) Regional differences in myocardial performance in the left ventricle of the dog. Circ Res 37: 191-199

15. Muijtjens AMM, Roos JMA, Prinzen TT, Arts T (1990) Noise reduction in estimating epicardial deformation from marker tracks. An J Physiol 258: H599-H605

16. Nakamura $\mathrm{Y}$, Hayashi J, Mori H, Ogawa S, Ohsuzu F, Takahashi M, Hattori S, Horikawa M (1980) The changes in pattern of myocardial shortening by reduction of regional coronary blood flow. Jap Heart J 21: 225-234

17. Opie LH, Thomas M, Owen P, Shulman G (1972) Increased coronary venous inorganic phosphate concentrations during experimental myocardial ischemia. Am I Cardiol 30: 503-513

18. Pogwidz SM, Corr PB (1987) Electrophysiologic mechanisms underlying arrhythmias due to reperfusion of ischemic myocardium. Circulation 76: 404426

19. Pollack GH, Krueger JW (1976) Sarcomere dynamics in intact cardiac muscle. Eur $J$ Cardiol 4 (suppl): 53-65

20. Prinzen FW, Alewijnse $R$, van der Vusse GJ, Kruger RTI, van der Nagel T, Reneman RS (1987) Coronary artery stenosis controlled by distal perfusion pressure: description of the servo-system and time-dependent changes in regional myocardial blood flow. Basic Res Cardiol 82: 375-387

21. Prinzen FW, Arts T, van der Vusse GJ, Coumans WA, Reneman RS (1986) Gradients in fiber shortening and metabolism across ischemic left ventricular wall. Am J Physiol 250: H255-H264

22. Prinzen FW, Augustijn CH, Arts T, Allessie MA, Reneman RS (1990) Redistribution of myocardial fiber strain and blood flow by asynchronous electri- 
cal activation. Am I Physiol 259: H300-H308

23. Prinzen FW, van der Vusse GJ, Arts $\mathrm{T}$, Roemen THM, Coumans WA, Reneman RS (1984) Accumulation of non-esterified fatty acids in ischemic canine myocardium. Am J Physiol 247 : $\mathrm{H} 264-\mathrm{H} 272$

24. Prinzen TT, Arts T, Prinzen FW, Reneman RS (1986) Mapping of epicardial deformation using a video processing technique. If Biomech 19: 263-273

25. Ramanathan KB, Bodenheimer MM, Banka VS, Helfant RH (1977) Electrophysiologic effects of partial coronary occlusion and reperfusion. Am J Cardiol 40: 50-54

26. Ruffy $R$, Lovelace DE, Mueller TM, Knoebel SB, Zipes DP (1979) Relationship between changes in left ventricular bipolar electrograms and regional myocardial blood flow during acute coronary artery occlusion in dogs. Circ Res 45: 764-770

27. Russell DC, Riemersma RA, Lawrie JS, Oliver MF (1982) Patterns of flow and conduction during early ventricular arrhythmias following coronary arterial occlusion in the dog. Cardiovasc Res 16 : 613-623

28. Sugawara M, Tamiya $K$. Nakano $K$ (1985) Regional work of the left ventricle: wall tension area relation. Heart and Vessels 1: 133-144

29. Tennant R, Wiggers CJ (1935) The effect of coronary occlusion on myocardial contraction. Am J Physiol 112: 351-361

30. ter Keurs HEDJ, Rijnsburger WH, van Heuningen R, Nagelsmit MJ (1980) Tension development and sarcomere length in rat cardiac trabeculae; evidence of length-dependent activation. Circ Res 46: 703714

31. Theroux P, Ross JJ, Franklin D, Covell JW, Bloor CM, Sasayama S (1977) Regionall myocardial function and dimensions early and late after myocardial infarction in the unanaesthetized dog. Circ Res 40 : 158-165

32. wan der Vusse GJ, Roemen THM, Prinzen FW, Coumans WA, Reneman RS (1982) Uptake and tissue content of fatty acids in dog myocardium under normoxic and ischemic conditions. Circ Res 50: 538-546

33. van Heuningen $\mathrm{R}$, Rijnsburger WH, ter Keurs HEDJ (1982) Sarcomere length control in striated muscle. Am J Physiol 242: H411-H420

34. Wiegner A, Allen GJ, Bing OHL (1978) Weak and strong myocardium in series: implications for segmental dysfunction. Am J Physiol 235: H776H783

35. Wilensky RL, Tranum-Jensen J, Coronel R, Wilde AAM, Fiolet JWT, Janse MJ (1986) The subendocardial border zone during acute ischemia of the rabbit heart: an electrophysiologic, metabolic, and morphologic correlative study. Circulation 74 : 1137-1146

36. Williamson JR (1966) Glycolytic control mechanisms. II. Kinetics of intermediate changes during the aerobic- anoxic transition in perfused rat heart. $\mathrm{J}$ Biol Chem 241: 5026-5036 


\section{ASYMMETRICAL CHANGES IN VENTRICULAR WALL MASS BY ASYNCHRONOUS ELECTRICAL ACTIVATION OF THE HEART}

Frits W. Prinzen, Tammo Delhaas, Theo Arts*, and Robert S. Reneman

Departments of Physiology and Biophysics*,

Cardiovascular Research Institute Maastricht, University of Limburg, P.O.Box 616,

NL-6200 MD Maastricht, The Netherlands.

To be published in: Sideman S, Beyar R (Eds) Interactive Phenomena in the Cardiac System. Plenum, New York 
Abstract. Ventricular pacing causes asynchronous electrical activation of the ventricular wall, because impulse conduction occurs via muscle fibers rather than via the Purkinje system. Chronic (up to 3 months) ventricular pacing caused a $-30 \%$ decrease of wall mass in early activated regions but did not change wall mass in late activated regions. These are the first data indicating that chronic asynchronous activation induces asymmetrical structural adaptations. This asymmetry is likely to be evoked by regional differences in contractile work, as demonstrated in previous experiments from our laboratory. The nature of the structural adaptation as well as its clinical implications deserve more detailed investigation.

\section{Introduction}

Ventricular pacing, impulse conduction disorders and ventricular extrasystolic beats are associated with abnormal, slow electrical activation, since the conduction of the electrical wave front occurs initially via myocardial muscle cells rather than via the Purkinje system. This causes asynchrony of contraction in the various regions of the ventricular wall $[7,12]$ and a decrease in global ventricular pump function [9]. The pattern of regional fiber strain is severely affected $[1,13]$. In relatively early activated regions, fibers shorten considerably already during the isovolumic contraction phase, thereby stretching later activated fibers. Fibers strain during the ejection phase is small for early activated fibers (less than -.05) as compared to this strain dur- ing sinus rhythm (approximately -0.10 ), whereas fiber strain was more pronounced in the late activated fibers (to more than -.15; Fig. 1). These changes in the amount of fiber strain during the ejection phase are likely to be explained by local differences in sarcomere length at the time of electrical activation of the fibers [4]. Furthermore, during ventricular pacing the distribution of regional myocardial blood flow was similar to the distribution of fiber strain during the ejection phase (Fig. 1; [13]).

The differences in fiber strain are likely to be associated with differences in workload, while regional blood flow is adjusted through metabolic regulation to meet the altered oxygen demand [13]. This hypothesis is supported by recent findings from our laboratory, showing that regional contractile work, defined as the time integral of the fiber stress-fiber strain diagram, was approximately $30 \%$ lower in early activated regions than during atrial pacing. In contrast, in the late activated region contractile work was approximately $15 \%$ larger than during synchronous activation [3].

Mass and composition of cardiac muscle are known to adapt in response to altered external conditions. Sustained elevated ventricular cavity pressure causes an increase in wall thickness without major changes in cavity volume (concentric hypertrophy). In contrast, volume overload induces an increase of both ventricular wall mass and cavity volume (eccentric hypertrophy). Besides these adaptations of the whole heart to altered global loading conditions, also regional adaptations have been demonstrated, as 


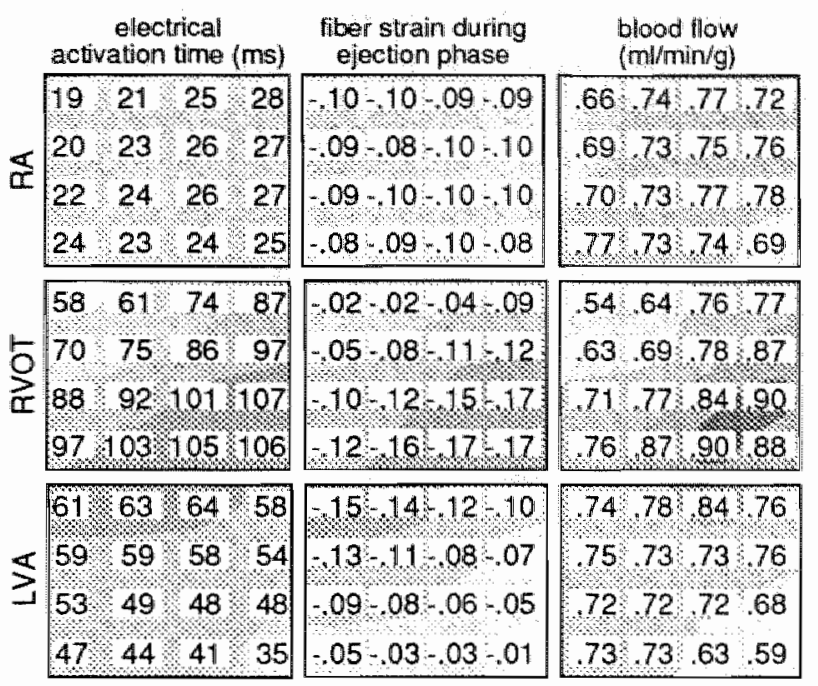

Fig. 1. Mean maps of epicardial electrical activation time, fiber strain and blood flow. The rectangles represent a part of the anterior wall of the left ventricle, with the basal part at the top and the left anterior descending coronary artery at the left side. This part was divided in 16 regions using a $4 \times 4$ matrix. For the construction of the mean maps, the data from 8-10 experiments were used, in which all three variables were determined in the same regions. Different degrees of shading were drawn to facilitate interpretation of the maps. Modified after [13].

a result of regionally abnormal loading. The best known example is ventricular remodeling after myocardial infarction. The entire ventricular wall is stretched and wall stress is increased. In the infarcted zone this may lead to infarct extension. In the surviving part hypertrophy occurs to compensate for the larger regional pump work. The structural adaptation in non-infarcted myocardium can be characterized as regional eccentric hypertrophy [11].

The goal of the present study was to investigate to what extent the regional differences in contractile work, induced by ventricular pacing, result in changes in the geometry of the left ventricular wall. To this purpose serial 2 -dimensional echocardiographical measurements of regional ventricular wall mass were made in a group of dogs at various time intervals during chronic ventricular pacing.

\section{Methods}

Implantation Procedure. Four mongrel dogs were used for this study. The pacemaker and pacing electrodes were implanted during a sterile surgical procedure. A Medtronic 4057 unipolar endocardial screw-in lead was introduced into the atrial cavity through the wall of the right atrial appendix and screwed into the endocardial surface of the right atriall wall. The ventricular lead was a Medtronic 6917A-35T sutureless lead. This lead was attached to the epicardium of the free wall of the left ventricle, $1 \mathrm{~cm}$ below the base, using its screw-in device. A pacemaker (Medtronic Synergist H7027) was implanted subcutaneously over the left lower thoracic region and the leads were guided subcutaneously towards the pacemaker pocket. After fixation of the leads into the pacemaker and checking proper electrical contact between pacemaker and lead, the pacemaker was introduced into its subcutaneous pocket and the skin over the pocket was closed. The animals were 
allowed to recover from anesthesia and from the surgical procedure, while the pacemaker was not in function yet.

Ventricular pacing was started approximately two weeks after implantation. Pacing was performed in the DDD-mode (dual chamber, dual sensing, dual pacing, with a maximal rate of $175 \mathrm{beats} / \mathrm{min}$ ), so that the heart was paced at its natural rhythm. The A-V stimulation interval was $25 \mathrm{~ms}$ to assure that the whole ventricle was activated from the ectopic focus rather than through conduction via the $\mathrm{A}-\mathrm{V}$ node.

Measurement of Ventricular Wall Mass. Ultrasound images of the left ventricle were made by two-dimensional echocardiography using a Hewlett Packard Ultrasound System (77020A) with a $3.5 \mathrm{MHz}$ transducer (21206A). The images were recorded on video tape. One week before and 1,2 and 3 months after onset of pacing measurements were made while the conscious animals were standing in the upright position. Cross-sectional images were made, taking care that the top of the papillary muscles and the pacing lead were visible and that the ventricular cross-section was as circular as possible.

Measurements were made on video prints (10.15 cm using a video printer) of end-diastolic images. Of each image, endocardial and epicardial contours were drawn on overhead sheets. Subsequently, the left ventricular crosssection of the pre-pacing image was divided into 6 regions, using the following anatomical landmarks: the anterior and posterior papillary mus- cles and the anterior attachment of the right ventricular wall to the left ventricular wall (see Fig. 2). The three anatomical landmarks in the images obtained at various time intervals during ventricular pacing were localized, by optimal superposition of templates of the endocardial (papillary muscles) and epicardial contour (RVLV attachment) of the pre-pacing image. Thereafter, also the ventricular cross section of the images of paced beats was divided into 6 regions. Usually, in the echocardiographical images section 6 was incomplete. In all animals the pacing lead was located in wall section 2. Consequently, sections 1 and 3 were adjacent to the pacing electrode and section 5 , located in the ventricular septum, was the most remote region.

The area of the wall sections (in case of regions 1, 2 and 3: including papillary muscle) as well as the area of the ventricular cavity was determined by planimetry. The sector angles of the various wall sections were determined as well. Regionall wall mass was quantified by the ratio of the wall area and the sector angle of a particular wall section, and expressed as a percentage of the pre-pacing wall mass. Using these measurements an indication is obtained about the size of the ventricular cavity, and of the length and mass of the various wall sections. Using relatively large wall sections inaccuracies in determining the endocardial and epicardial boundary at a particular point were averaged out. Measurements on video frames from end-diastole of subsequent cardiac cycles indicated a variation of $\pm 5 \%( \pm \mathrm{SD})$ in wall mass and $\pm 5^{\circ}$ in sector angle. 


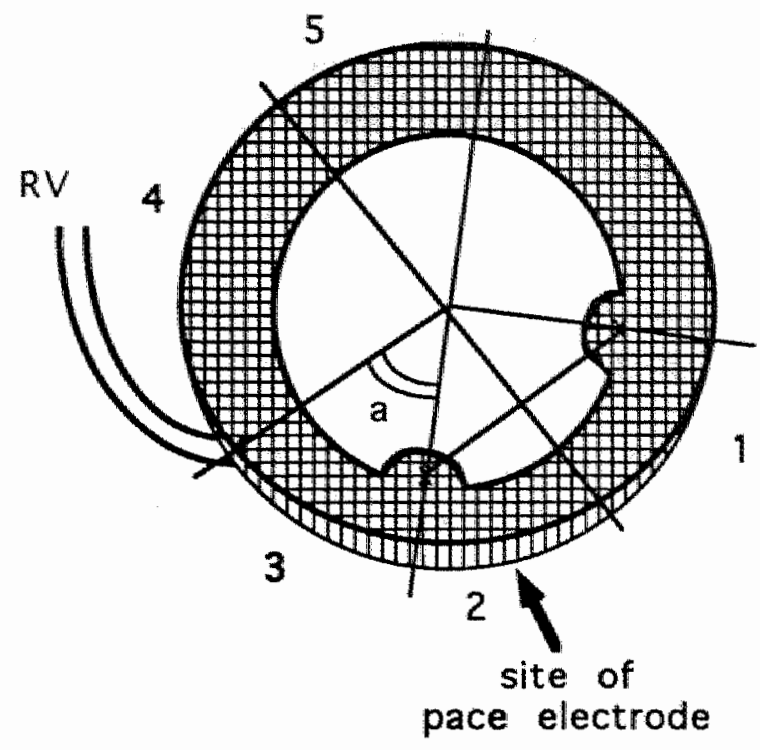

Fig. 2. Division of a ventricular cross section on a two-dimensional echocardiographical image into 6 regions using three anatomical landmarks (crosses): the papillary muscles and the attachment of the right ventricle to the left ventricle at the anterior wail. The center of the cavity was positioned midway the line perpendicular to the line connecting the two papillary muscles. The sector angle of regions 1,2 and 5 was equal.

\section{Results}

In 3 animals sensing and stimulation thresholds increased slightly. In these cases pacing was continued at higher amplitude or with longer duration of the stimulus. However, in one animal sensing and stimulation thresholds increased to such an extent within 2 weeks after onset of pacing, that ventricular pacing failed. Therefore, it was decided to program the pacemaker to its lowest, subliminal, values. This anmal served as a sham animal.

Fig. 3 depicts the time course of the changes in wall mass in regions 2 and 5 . Although the individual patterns of the 3 paced dogs varied to some extent, the results indicate that wall mass at the left ventricular wall close to the pacing lead (section 2) gradually decreased during the 3 months of pacing, whereas it remained approximately constant in the late activated septal region (section 5).

After 3 months of ventricular pacing wall mass of section 2 decreased to 60,61 and $83 \%$

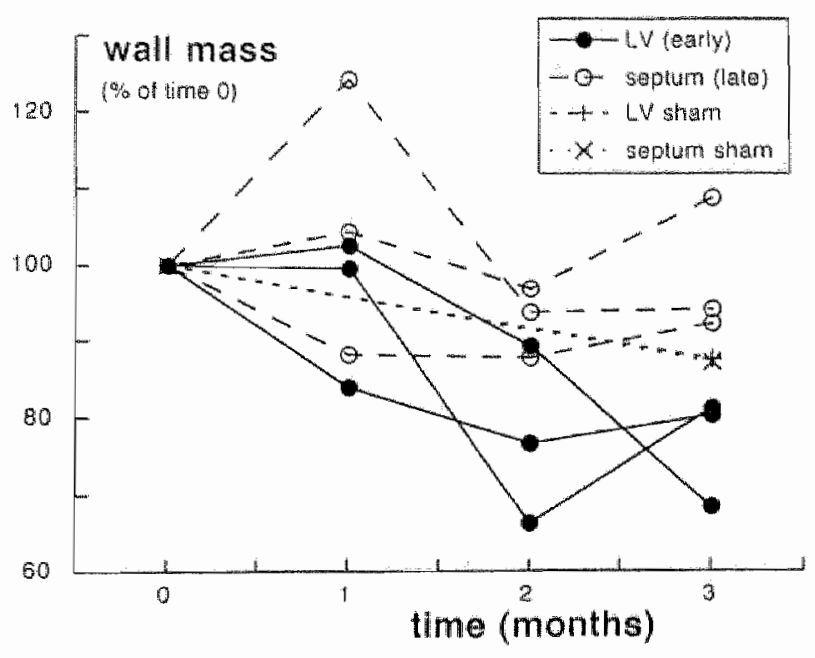

Fig. 3. Time course of the change in local wall mass during chronic ventricular pacing. The values of the three paced dogs (circles) and the one sham dog $(+$ and $x)$ are presented as $\%$ of the mass at time 0 . Closed circles denote the early activated region 2 on the free wall of the left ventricle, open circles denote the late activated region 5 in the ventricular septum (see fig 2). 
of the initial values in the three animals. Wall mass in section 5 was 96,99 and $106 \%$ of its initial value. Also, no consistent change was observed in ventricular cavity area and in the angles of the 5 wall sections studied. In the sham animal the mass in regions 2 and 5 decreased to the same extent $(11 \%)$.

\section{Discussion}

The data in the present study indicate that chronic ventricular pacing can induce a reduction in left ventricular wall mass in early activated regions. This reduction occurred in regions where, in acute experiments, fiber strain, contractile work and blood flow were found to be reduced compared with atrial pacing $[3,13]$. Therefore, it seems likely, that the reduction in contractile work, induced by early electrical activation, results in the relative atrophy.

In the same studies, we also observed an increase in fiber strain [13] and contractile work [3] in late activated regions. Nevertheless, no consistent increase in wall mass was found in the late activated septum in the chronic pacing study. This may be due to the fact that the increase in contractile work in late activated regions was smaller than its decrease in early activated regions. Consequently, it can be expected, that the stimulus for hypertrophy in late activated regions was smaller than the stimulus for atrophy in early activated regions. It is possible that such a hypertrophy can be demonstrated using either a larger number of observations or prolonged ventricular pacing. The latter possibility is supported by the observation, that in the early activated regions the reduction in wall mass had not yet reached a stable level after 3 months (Fig. 3).

The relation between sequence of electrical activation, fiber strain and blood flow, depicted in Fig. 1, was established in the epicardial layers of the left ventricular wall. Because of technical limitations to perform direct measurements of fiber strain in the deeper layers of the wall, we were not yet able to demonstrate the same relationship in the deeper layers. However, we hypothesized, that the inhomogeneity in contractile work as a function of the sequence of electrical activation would not be limited to the epicardial layers, since the differences in contractile work during ventricular pacing are most likely due to differences in the fiber (sarcomere) length at the beginning of the ejection phase, one of the basic myocardial material properties. Because the changes in wall mass during chronic pacing are too large to be located in a single layer, and because during volume-overload hypertrophy the distribution of tissue growth is homogeneous across the wall [10], the altered wall mass in early activated regions supports the idea, that the dependency of regional contractile work on the sequence of electrical activation also holds for deeper layers.

The present findings are interesting from a basic scientific point of view, but may also have implications for some cardiac abnormalities. Ventricular pacing appears to be a means to induce different levels of workload within the same heart, which may be useful in studying 
cardiac adaptive processes. This may, however, also imply, that ventricular pacing, and presumably also idiopathically originated impulse propagation can give rise to asymmetrical hypertrophy. No conclusive evidence for this hypothesis was found in literature so far.

Abnormal wall motion patterns are well known in patients with for example ventricular pacing, left bundle branch block and WolfeParkinson-White syndrome $[2,6]$, but information on absolute wall thickness was lacking. In a recent retrospective study in patients with left bundle branch block [14], using M-mode echocardiography, wall thickness was found to be significantly less in the early activated septum than in the late activated posterior wall. These data support the idea from the present study, that asynchronous electrical activation may cause asymmetrical hypertrophy.

Consequence of the impact of asynchronous activation on the geometry of the ventricular wall may be the search for optimal positioning of ventricular pace electrodes. In case of patients with $\mathrm{A}-\mathrm{V}$ block or sick-sinus syndrome this optimization should lead to the least asynchronous activation. In case of septal hypertrophy in patients with hypertrophic obstructive cardiomyopathy, positioning of the lead in the septal wall may be feasible, since this may lead to reduction of the regional hypertrophy. Interestingly, recent trials with pacing in the right ventricular apex in these patients showed significant reduction in ventriculo-aortic pressure gradients and subjective improvements [5, 8]. However, no reduction in hypertrophy oc- curred within 4 years [8]. It seems worthwhile to investigate, whether septal pacing rather than right ventricular apex pacing could further improve the results of the pacemaker therapy in these patients.

\section{Conclusions}

Prolonged ( 3 months) ventricular pacing reduced wall mass in early activated regions by approximately $30 \%$ and did not induce significant changes in wall mass in late activated regions. This indicates that asynchronous activation causes asymmetrical structural adaptations in the ventricular wall. These findings may have important implications for the use of pacemakers and the treatment of patients with abnormal impulse propagation.

\section{References}

1. Badke FR, Boinay P, Covell JW (1980) Effect of ventricular pacing on regional left ventricular performance in the dog. Am J Physiol 238: H858H867

2. Boucher CA, Pohost GM, Okada RD, Levine FH, Strauss W, Harthorne JW (1983) Effect of ventricular pacing on left ventricular function assessed by radionuclide angiography. Am Heart J 106: 1105 1111

3. Delhaas $T$, Arts $T$, Prinzen FW, Reneman RS (1992) Regional contractile work and electrical activation in the canine left ventricle during. coronary artery occlusion (abstract). Pflugers Arch (Eur J Physiol) 420 (suppl 1): R II0

4. Delhaas T, Arts T, Prinzen FW, Reneman RS (1993) Relation between regional electrical activa- 
ton time and subepicardial fiber strain in the canine left ventricle. Pflugers Areh (Eur I Physiol) 423 ; $78-87$

5. Fanazapir L, Cannon RO, Tripodi D, Panza JA (1992) Impact of dual-chamber permanent pacing in patients with obstructive cardiomyopathy with symptoms refractory to verapamil and beta-adrenergic blocker therapy. Cireulation 85: 2149-2161

6. Frais MA, Botvinick EH, Shosa DW, O'Connel WI, Scheinman MM, Hatner RS, Morady F (1982) Phase image characterization of ventricular contraction in left and right bundle branch block. Am J Cardiol 50: 95-105

7. Hotta $\$$ (1967) The seculuence of mechanical activation of the ventricle. Ipn Circ J 31: 1568 - 1572

8. Jeanrenaud X, Goy JJ, Kappemberger L (1992) Effects of dual-chamber pacing in hypertrophyc obstructive cardiomyopathy. Lancet 339: 1318-1323

9. Lister JW, Klotz DH, Jomain $\mathrm{SL}$, Stuckey $\mathrm{JH}_{\text {, }}$ Hoffman B (1964) Effect of pacemaker site on cardiac output and ventricular activation in dogs with complete heart block. Am J Cardiol 14: 494-503
10. Omens $J H_{,}$Covell JW (1991) Transmural distribufion of myocardial tissue growth induced by volume overload hypertrophy in the dog. Circulation 84: 1235-1245

11. Pfeffer MA, Braunwald E (1990) Ventricular remodelling after myocardial infarction. Experimental observations and clinical implications. Circulation 81: 1161-1172

12. Prinzen $\mathrm{FW}$, Augustijn $\mathrm{CH}$, Allessie MA, Arts $\mathrm{T}$, Delhaas T, Reneman RS (1992) The time sequence of electrical and mechanical activation during spontaneous beating and ectopic stimulation. Eur Heart J 13:535-543

13. Prinzen FW, Augustijn CH, Arts T, Allessie MA, Reneman RS (1990) Redistribution of myocardial fiber strain and blood flow by asynchronous electrical activation. Am J Physiol 259: H300-H308

14. Prinzen FW, Cheriex EC, Arts T, Delhaas T, Reneman RS (1992) Changes in left ventricular diastolic wall thickness induced by chronic asynchronous electrical activation (abstract). J Moll Cell Cardiol 24 (suppl V): S50 


\section{GENERAL DISCUSSION}


Regional subepicardial mechanics of the left ventricular anterior free wall and its relation with global hemodynamics, and regional electrical activation and perfusion was investigated under normoxic (chapter 2, 3, 4, and 7) and ischemic circumstances (chapter 5 and 6). Experiments were performed in the anesthetized open-thorax dog (chapter 2 through 6 ) or in the chronically ventricular paced awake closed-thorax dog (chapter 7). Differences in global loading conditions were induced by volume loading (chapter 2, 3, and 5). Ventricular pacing from various sites was used as an intervention to obtain regional differences in electrical activation time and in mechanical performance (chapter 2 , 4, and 7). Regional ischemia was induced by partial or total occlusion of the distal part of the left anterior interventricular coronary artery (LAICA; chapter 5 and 6). Generally, the following variables were measured:

- Left ventricular, aortic and coronary artery pressure.

- Left ventricular cavity and wall volume.

- Subepicardial fiber strain, using a video technique [28].

- Moment of epicardial electrical activation, using a 192-electrode brush $[1,15]$.

- Myocardial blood flow, using radioactively labeled microspheres.

- Arterial, local venous and coronary sinus blood gases.

The major objective of the study described in chapter 2 was to determine the relation between the moment of regional epicardial electrical activation and the degree of regional subepi- cardial fiber strain. To this purpose, electrical activation and fiber strain were measured regionally at the epicardium of the left ventricular anterior free wall when the heart was paced from the right atrium (synchronous activation), the left ventricular free wall, the left ventricular apex or the right ventricular outflow tract (asynchronous activation). Activation time has been defined as the time interval between a time reference and the moment of regional electrical activation. Our results indicate that the choice of the time reference is important. When using electrophysiological events to define the moment of electrical activation, the correlation between the electrical activation time and the amount of fiber strain during the ejection phase was not as good as when using the moment of maximum rate of change of left ventricular pressure $\left(\mathrm{dp}_{\mathrm{lv}} / \mathrm{dt}\right)$. Using the latter hemodynamically based time reference, linear regression analysis revealed that, if electrical activation occurred between 40 and $80 \mathrm{~ms}$ before maximum dplv $/ \mathrm{dt}$, fiber strain was estimated with an accuracy of \pm 0.026 ( $\pm \mathrm{SE}$ ), when compared with the measured values. The mean slope of the linear equation between subepicardial fiber strain during the ejection phase and regional activation time as found by linear regression was $-3.46 \pm$ $0.73 \mathrm{~s}^{-1}$, while the offset was $-0.28 \pm 0.05$. The slope of the linear equation appeared to depend on end-diastolic pressure being $-3.96 \pm$ $0.53 \mathrm{~s}^{-1}$ and $-2.86 \pm 0.41 \mathrm{~s}^{-1}$ for normal (1.1 $\mathrm{kPa})$ and elevated end-diastolic pressure (1.8 $\mathrm{kPa}$ ), respectively. The decrease of the slope after elevation of end-diastolic pressure indi- 
cates that inhomogeneities in fiber strain are less pronounced when myocardial contractile force is increased.

In the normal left ventricle, regional differences in mechanical load of the myocardial fibers are likely to be small, as indicated by several physiological experiments [42]. The transmural distributions of blood flow, oxygen consumption, enzyme activities and concentrations of substrates are generally found to be quite homogeneous ( $\pm 10 \%$ ), indicating that energy requirements are evenly distributed across the left ventricular wall. This supports the idea of a homogeneous distribution of mechanical load. Because fiber strain during the ejection phase was found to be homogeneously distributed laterally [26] and transmurally across the left ventricular wall $[10,25,45,48]$, fiber stress is likely to be homogeneously distributed too.

Since measurement of fiber stress in vivo is difficult and probably not reliable because the local myocardial structure is easily damaged due to the insertion of the measuring device $[9,16]$, a variety of mathematical models of cardiac mechanics, based on the laws of continuum mechanics, were designed to estimate fiber stress $[2,3,5,6,8,17,20]$. In a model by Arts and co-investigators [2], the assumption of a homogeneous distribution of fiber stress and fiber strain during systole throughout the left ventricular wall was used to estimate average values of these regional quantities from global quantities such as left ventricular pressure, cavity volume, and wall volume. In the model study, these relations have been reported to be practi- cally independent of ventricular shape, preload and afterload [2]. In chapter 3 the proposed relations were evaluated experimentally. It was found that during normal as well as increased end-diastolic volume, fiber strain during the ejection phase as derived from the proposed equation was not significantly different from measured values of subepicardial fiber strain in the anterior free wall of the left ventricle. Since the two estimations of fiber strain are independent of each other, and because the principle of conservation of energy was the major assumption to derive the equation on fiber strain from the equation on fiber stress, the similarity between calculated and measured fiber strain is interpreted as an indication of the applicability of the equations for both fiber strain and fiber stress. Fiber stress, as calculated from left ventricular pressure and volume, corresponded qualitatively and quantitatively with the results obtained in isolated cardiac muscle $[23,37,43]$. These findings support the assumption of Arts and co-investigators [2] that muscle fiber strain and stress in the left ventricular wall are homogeneously distributed during the ejection phase. Therefore, average values of fiber stress and fiber strain may be estimated on the basis of measured left ventricular pressure and volume.

The ability to quantify regional myocardial performance is essential to predict regional oxygen demand. In Chapter 4 it was investigated which of the following regional indices is the best predictor of regional oxygen demand: left ventricular pressure-sarcomere length area (PSL) or total mechanical power (TMP), an in- 
dex obtained from the time curve of estimated fiber stress and fiber strain in analogy to the pressure-volume area (PVA) of Suga and co-investigators [31-33]. A regional performance index with proper dimensions of energy or energy per unit of volume, as derived from wall tension-regional area loops $[13,35]$ or from fiber stress-fiber strain loops (chapter 3) should be preferred above the index as derived from left ventricular pressure-segment length loops [39, 41]. Within one experiment the latter method may be used to obtain an indication of changes in regional work during the experiment, but comparison between hearts with different degrees of filling is not allowed. The basic question to be answered in chapter 4 required regional determination of both fiber strain and fiber stress. By use of a modification of the model of cardiac mechanics $[2,3]$ assessed in chapter 3 , regional fiber stress during systole was estimated from experimentally measured left ventricular pressure, left ventricular cavity volume, and regionally measured fiber strain. Ventricular pacing from various sites was used as an intervention to obtain regional differences in mechanical performance $[4,19,26,47]$.

Regional fiber stress, calculated according to the proposed model, is quite uniformly distributed during asynchronous electrical activation, despite large differences in regional fiber strain. During asynchronous electrical activation, regional contractile work, blood flow, and oxygen uptake were significantly lower in early than in late activated regions. The correlation coefficients of the relations between the left ventricular pressure-sarcomere length area and regional oxygen uptake within the individual experiments did not significantly differ from the ones between total mechanical power and regional oxygen uptake. Because of the differences in offset of the centers of the relations between the left ventricular pressure-sarcomere length area and regional oxygen uptake, the linear relation obtained from the pooled data holds only for the relation between total mechanical power (TMP) and regional oxygen uptake $\left(\mathrm{V}_{\mathrm{O}_{2, \text { reg }}}\right)$. It is found that $\dot{\mathrm{V}}_{\mathrm{O}_{2}}=\mathrm{k}_{1} \mathrm{TMP}$ $+\mathrm{k}_{2}$, whith $\mathrm{k}_{1}=4.94 \pm 0.31 \mathrm{~mol} / \mathrm{J}$ and $\mathrm{k}_{2}=$ $24.2 \pm 1.9 \mathrm{mmol} /\left(\mathrm{m}^{3} \mathrm{~s}\right)$. This relation between total mechanical power and regional oxygen uptake is in quantitative agreement with previously reported relations between global oxygen demand and measured pressure-volume area $[14,18,31,34]$. The results indicate that asynchronous electrical activation causes a redistribution of mechanical work and oxygen demand and that total mechanical power is a better and more general estimate of regional oxygen demand than the left ventricular pressuresarcomere length area.

In chapter 5 the effect of left ventricular dilation, caused by normoxic or ischemic hypervolemia, on the regional subepicardial mechanics of the left ventricle was quantified. In addition, regional oxygen uptake was related to external and total mechanical power (EMP and TMP, respectively). For comparison, the hitherto used indices of mechanical function, regional fiber strain during the ejection phase and the left ventricular pressure-sarcomere length 
area (PSL) were related to regional oxygen uptake as well.

During the normoxic control and hypervolemic situations, estimated regional sarcomere length and fiber stress as calculated according to our model were found to be within the physiological range $[7,23,38,43]$. During coronary artery occlusion all measured or estimated regional variables showed a gradient. For fiber strain during the ejection phase, active fiber stress, pressure-sarcomere length area, external and total mechanical power, and blood flow and oxygen uptake, the gradient pointed toward the normoxic area. For sarcomere length at end-diastole and at the beginning of the ejection phase, passive fiber stress, and the oxygen extraction fraction, the gradient pointed toward the ischemic area. Considerable active fiber stress development was found within the ischemic region. Within an individual experiment significant, not mutually different correlations between oxygen uptake and the four indices of regional performance, used to predict oxygen uptake, were found. From the pooled data, however, it appeared that indices with the physical dimension of work per unit of volume, i.e. EMP and TMP, were the best predictors of regional oxygen uptake. However, the slope of the pooled linear relation between total mechanical power and oxygen uptake $(9.7 \mathrm{~mol} / \mathrm{J})$ was steeper than the slope of the relation as found in chapter 4 $(4.7 \mathrm{~mol} / \mathrm{J})$ and the one between the pressurevolume area and global oxygen uptake as reported in literature, being $4.2[31], 4.6[18$, 34], and $5.8 \mathrm{~mol} / \mathrm{J}$ [14]. Moreover, the linear relation found had a negative intercept. The more pronounced steepness and the negative intercept can be explained by possible errors made in the estimation of regional workload or regional oxygen uptake. During LAICA occlusion, total mechanical work might be overestimated due to overestimation of active fiber stress or regional potential work. Both are likely to be overestimated due to uncertainties regarding the estimation of passive fiber stress. It could be shown that the ischemic region dilated more than the normoxic region. In the ischemic regions, estimated sarcomere length at the beginning of the ejection phase was found to range from 2.40 to $2.49 \mu \mathrm{m}$. In rat papillary or trabecular muscle experiments, maximum sarcomere length was found to be slightly less $(2.40 \mu \mathrm{m} ;[23,38,43])$. The increase in sarcomere length in ischemic areas might be due to structural rearrangements or changes in material properties $[11,12,30,40,44]$. It is to be concluded that more knowledge about passive material properties is required for correct estimation of workload of the ischemic region. Regional oxygen uptake in the subepicardial layers, as calculated from myocardial blood flow and arterio-venous differences in oxygen content, might be underestimated during LAICA occlusion as a consequence of a) underestimation of blood flow in the subepicardial layers due to a streaming effect of the microspheres [22], and b) underestimation of oxygen extraction in the ischemic area due to admixture of blood from the normoxic area. 
The studies on the interaction between electrical asynchrony and mechanical function as described in chapter 2 and 4 revealed that electrical asynchronies significantly affect regional mechanical performance. Regional fiber strain and external work during the ejection phase were found to be lower in early-activated than in late-activated regions. The asynchronous contractions of the various regions impeded overall hemodynamic performance. The study presented in chapter 6 was designed to investigate to what extent electrical asynchrony may be held responsible for the regional and global mechanical deterioration as found in the ischemic left ventricle [27].

The findings indicate that the mechanical dysfunction observed in the ischemic subepicardial layers during acute total and partial occlusion (up to 3 hours) of the distal part of the LAICA results from reduced blood flow rather than from disturbances in electrical activation. Following total LAICA occlusion, fiber strain in the ischemic area decreased from $-0.11 \pm 0.02$ to $-0.01 \pm 0.01$. The delay in electrical activation between the normoxic basal-lateral and the ischemic apical-medial area increased significantly, although limited, from $1.9 \pm 8.0$ to 7.5 $\pm 8.0 \mathrm{~ms}$. It is unlikely that an average delay of $\sim 7.5 \mathrm{~ms}$ will cause significant inhomogeneities in fiber strain (chapter 2). Besides, if the observed delay plays a role, fiber strain would be enhanced by approximately -0.025 , rather than reduced in late activated regions (chapter 2). During partial LAICA occlusion, no disturbances in electrical activation were found, while fiber strain decreased in the ischemic area. Although measurement of regional deformation was limited to 4 experiments, the results obtained are in agreement with previous measurements during ischemia $[12,13,21,24,35,36$, 46]. The ischemic fibers showed paradoxical systolic lengthening during early systole, followed by some residual shortening

As described in chapter 2 and 4, asynchronous electrical activation induces differences in regional fiber strain during the ejection phase, regional mechanical work, and myocardial blood flow and oxygen uptake. Mass and composition of cardiac muscle are known to adapt in response to altered external conditions. In the study described in chapter 7 it was investigated to what extent regional differences in contractile work, induced by chronic ( 3 months) ventricular pacing, result in changes in the geometry of the left ventricular wall. The dog obtained DDD-pacing (dual camber, dual sensing, dual pacing) with the atrial sense electrode attached to the right atrium and the ventricular pace electrode sutured to the epicardium of the left ventricular lateral free wall $1 \mathrm{~cm}$ below the base. Two-dimensional echocardiography was used to assess left ventricular regional dimensions at various time intervals during three months.

The results indicate that chronic ventricular pacing induced a $\sim 30 \%$ reduction in left ventricular wall mass in early activated regions. Therefore, it seems likely, that the reduction in contractile work, induced by early electrical activation (chapter 4), results in structural changes. It 
implies that ventricular pacing, and presumably also idiopathically originating impulse propagation [29] can give rise to asymmetrical geometry of the left ventricle. No conclusive evidence for this hypothesis was found in literature so far.

In summary the following conclusions can be drawn from the investigations presented in this thesis:

- The difference in time between the moment of the maximum first derivative of left ventricular pressure and the moment of regional electrical activation determines the amount of regional fiber strain during the ejection phase.

- Average values of fiber stress and fiber strain may be estimated on the basis of measured left ventricular pressure and volume.

- Regional fiber stress, calculated from measured left ventricular pressure and volume and regional fiber strain, is quite uniformly distributed during asynchronous electrical activation, despite large differences in regional fiber strain.

- Total mechanical power, a regional analog of the pressure-volume area of Suga and co-investigators, can be used to predict regional oxygen uptake during asynchronous electrical activation.

- The negative intercept and the high values for the slope of the relation between total mechanical power and regional oxygen uptake during LAICA occlusion indicate that more knowledge about the (passive) material properties of the left ventricular wall is required.

- Mechanical dysfunction observed in the is- chemic subepicardial layers during acute total and partial occlusion (up to 3 hours) of the distal part of the LAICA results from reduced blood flow rather than from disturbances in electrical activation.

- Ventricular pacing, and presumably also idiopathically originating impulse propagation can give rise to asymmetrical geometry of the left ventricle.

\section{References}

1. Allessie MA, Hoeks APG, Schmitz GML, Reneman RS (1986) On-line mapping system for the visualization of the electrical activation of the heart. Int J Cardiac Imag 2: 59.63

2. Arts T, Bovendeerd PHM, Prinzen FW, Reneman RS (1991) Relation between left ventricular cavity pressure and volume and systolic fiber stress and strain in the wall. Biophys J 59: 93-102

3. Arts T, Veenstra PC, Reneman RS (1982) Epicardial deformation and left ventricular wall mechanics during ejection in the dog. Am J Physiol 243: H379-H390

4. Badke FR, Boinay P, Covell JW (1980) Effect of ventricular pacing on regional left ventricular performance in the dog. Am J Physiol 238: H858H867

5. Beyar $\mathbb{R}$, Sideman S (1986) The dynamic twisting of the left ventricle: a computer study. Ann Biomed Eng 14: 547-562

6. Bovendeerd PHM, Arts "T, Huyghe JM, van Campen DH, Reneman RS (1992) Dependence of local left ventricular wall mechanics on myocardial fiber orientation: a model study. J Biomech 25: $1129-1140$

7. Delhaas T, Arts T, Bovendeerd PHM, Prinzen FW, Reneman RS (1993) Subepicardial fiber stress and strain as related to left ventricular pressure and wollo 
ume. An J Physiol 264: H1 548-H1559

8. Fallsetti HL, Mates $\mathbb{R E}_{\text {; }}$ Grant $C$, Greene $D G$, Bunnell IL (1970) Left ventricular wall stress calculated from one plane cineangiography - An approach to force-velocity analysis in man. Circ Res 26: $71-83$

9. Feigl EO, Simon GA, Fry DL (1967) Auxotonic and isometric cardiac force transducers. J Appl Physiol 23: 597-600

10. Fenton TR, Cherry JM, Klassen GA (1978) Transmural myocardial deformation in the canine left ventricular wall. Am J Physiol 235: H523-H530

11. Forrester JS, Diamond G, Parmley WW, Swann HJC (1972) Early increases in left ventricular compliance after myocardial infarction. $J$ Clin Invest 51: 598-603

12. Glower DD, Spratt JA, Kabas JS, Davis JW, Rankin JS (1988) Quantification of regional myocardial dysfunction after acute ischemic injury. Am J Physiol 255: $185-\mathrm{H} 93$

13. Goto $Y$, Igarashi $Y$, Yasumura $Y$, Nozawa $T$, Futaka $S$, Hiramori K, Suga $H$ (1988) Integrated regional work equals total left ventricular work in regionally ischemic canine heart. Am J Physiol 254: H894-H904

14. Goto Y, Slinker BK, LeWinter MM (1988) Similar normalized Emax and $\mathrm{O} 2$ consumption-pressurevolume area relation in rabbit and $\mathrm{dog}$. Am J Physiol 255: H366-H374

15. Hoeks APG, Schmitz GML, Allessie MA, Jas $H$, Hollen SI, Reneman RS (1988) Multichannel storage and display system to record the electrical activity of the heart. Med \& Biol Eng \& Comput 26: $434-438$

16. Huisman RM, Elzinga Westerhof $N$, Sipkema $P$ (1980) Measurement of left ventricular wall stress. Cardiovasc Res 14: 142-153

17. Huyghe JM, Arts T, van Campen DH, Reneman RS (1992) Porous medium finite element model of the beating left ventricle. Am J Physiol 262: H1256-H1267
18. Khalafbeigui $F$, Suga $H$, Sagawa $K$ (1979) Left ventricular systolic pressure-volume area correlates with oxygen consumption. Am I Physiol 237: H566- H 569

19. Lister JW, Klotz DH, Jomain SL, Stuckey JH, Hoffman B (1964) Effect of pacemaker site on cardiac output and ventricular activation in dogs with complete heart block. Am J Cardiol 14: 494-503

20. Mirsky I, Rankin JS (1979) The effects of geometry, elasticity and external pressures on the diastolic pressure-volume and stiffness-stress relations; how important is the pericardium? Circ Res 44: 601-611

21. Nakamura $\mathrm{Y}$, Hayashi J, Mori $\mathrm{H}$, Ogawa $\mathrm{S}$, Ohsuzu F, Takahashi M, Hattori S, Horikawa M (1980) The changes in pattern of myocardial shortening by reduction of regional coronary blood flow. Jap Heart J 21 : 225-234

22. Phibbs $R H$, Dong $L$ (1970) Nonuniform distribution of microspheres in blood flowing through a medium-size artery. Canad J Physiol Pharmacol 48: 415-421

23. Pollack GH, Krueger JW (1976) Sarcomere dynamics in intact cardiac muscle. Eur I Cardiol 4 (suppl): 53-65

24. Prinzen FW, Arts T, van der Vusse GJ, Coumans WA, Reneman RS (1986) Gradients in fiber shortening and metabolism across ischemic left ventricular wall. Am J Physiol 250: H255-H264

25. Prinzen FW, Arts T, van der Vusse GJ, Reneman RS (1984) Fiber shortening in the inner layers of the left ventricular wall as assessed from epicardial deformation during normoxia and ischemia. J Biomech 17: 801-811

26. Prinzen FW, Augustijn CH, Arts T, Allessie MA, Reneman RS (1990) Redistribution of myocardial fiber strain and blood flow by asynchronous electrical activation. Am J Physiol 259: H300-H308

27. Prinzen FW, van der Vusse GJ, Arts T, Roemen THM, Coumans WA, Reneman RS (1984) Accumulation of non-esterified fatty acids in ischemic canine myocardium. Am J Physiol 247: 


\section{$\mathrm{H} 264-\mathrm{H} 272$}

28. Prinzen TT, Arts T, Prinzen FW, Reneman RS (1986) Mapping of epicardial deformation using a video processing technique. $J$ Biomech $19: 263-273$

29. Reneman RS, Prinzen FW, Cheriex EC, Arts T: Delhaas $T$ (1993) Asymmetrical changes in left ventricular diastolic wall thickness induced by chronic asynchronous electrical activation in man and dogs (abstract). FASEB J 7 (4): A752

30. Smalling RW, Ekas RD, Richards Felli $\mathbb{P}$, Binion L, Desmond J (1986) Reciprocal functional interaction of adjacent myocardial segments during regional ischemia: an interventricular loading phenomenon affecting apparent regional contractile function in the intact heart. J Am Coll Cardiol 7: $1335-1346$

31. Suga H (1979) Total mechanical energy of a ventricle model and cardiac oxygen consumption. Am J Physiol 236: H498-H505

32. Suga H, Hayashi T, Shirahata M (1981) Ventricular systolic pressure volume area as predictor of cardiac oxygen consumption. Am J Physiol 240: H39-H44

33. Suga H, Hayashi T, Shirahata M, Suehiro S, Hisano R (1981) Regression of cardiac oxygen consumption on ventricular pressure volume area in dog. Am J Physiol 240: H320-H325

34. Suga H, Hisano R, Hirata S, Hayashi T, Yamada O, Ninomiya I (1983) Heart rate-independent energetics and systolic pressure-volume area in dog heart. Am J Physiol 244: H206-H214

35. Sugawara $M$, Tamiya $K$, Nakano $K$ (1985) Regional work of the left ventricle: wall tension area relation. Heart and Vessels 1: 133-144

36. Tennant R, Wiggers CJ (1935) The effect of coronary occlusion on myocardial contraction. Am J Physiol 112: 35 \-361

37. ter Keurs HEDJ, Bucx JJJ, de Tombe PP, Backx P, Iwazumi T (1988) The effects of sarcomere length and $\mathrm{Ca}++$ on force and velocity of shortening in cardiac muscle. In: Sugi H, Pollack GH (Eds)
Molecular mechanism of muscle contraction. Plenum, New York, pp $581-593$

38. ter Keurs HEDI, Rijnsburger $W_{4}$, van Heuningen $R$, Nagelsmit MJ (1980) Tension development and sarcomere length in rat cardiac trabeculae; evidence of length-dependent activation. Circ Res 46: 703 714

39. Theroux P, Franklin D, Ross JJ, Kemper WS (1974) Regional myocardial function during acute coronary artery occlusion and its modification by pharmacologic agents in the dog. Circ Res $35: 896-$ 908

40. Theroux P, Ross JJ, Franklin D, Covell JW, Bloor CM, Sasayama S (1977) Regionall myocardial func/ tion and dimensions early and late after myocardial infarction in the unanaesthetized dog. Circ Res 40 : $158-165$

41. Tyberg JV, Forrester JS, Wyatt HL, Goldner SJ, Parmley WW, Swan HJC (1974) An analysis of segmental dysfunction utilizing the pressure-length loop. Circulation 49: 748-754

42. van der Vusse GI, Arts T, Glatz JFC, Reneman RS (1990) Transmural differences in energy metabolism of the left ventricular myocardium: fact or fiction. J Mol Cell Cardiol 22: 23-37

43. van Heuningen R, Rijnsburger WH, ter Keurs HEDJ (1982) Sarcomere length control in striated muscle. Am J Physiol 242: H411-H420

44. Villareal FJ, Lew WYW, Waldman LK, Covell JW (1991) Transmural myocardial deformation in the ischemic canine left ventricle. Circ Res 68: 368381

45. Waldman LK, Nosan D, Covell JW (1988) Relation between transmural deformation and local myofiber direction in canine left ventricle. Circ Res 63: $550-562$

46. Wiegner A, Allen GJ, Bing OHL ( 1978 ) Weak and strong myocardium in series: implications for segmental dysfunction. Am J Physiol 235: H776$\mathrm{H} 783$

47. Wiggers CI (1925) The muscular reactions of the 
mammalian ventricles to artificial surface stimuli. Am J Physiol 73: 346-378

48. Zerhouni EA, Parish DM, Rogers WJ, Yang A,
Shapiro EP (1988) Human heart: tagging with MR imaging - a method for nonivvasive assessment of myocardial motion. Radiology 169: 59-63 
SAMENVATTING 
De bloedvoorzlening van de weefsels in ons lichaam, noodzakelijk voor het aanvoeren van voedingsstoffen en zuurstof en het afvoeren van afvalstoffen en koolzuur, wordt in stand gehouden door het hart. Het hart bestaat uit een linker en een rechter pomp. Beide pompen zijn opgebouwd uit twee holten, de boezem (atrium) en de kamer (ventrikel). In het rechter atrium wordt het zuurstofarme en koolzuurrijke bloed verzameld dat vanuit het lichaam via de aders naar het hart toestroomt. Vanuit het rechter atrium wordt de rechter ventrikel gevuld, die vervolgens het bloed door de longen pompt. In de longcirculatie wordt koolzuur afgestaan en wordt zuurstof opgenomen. Het zuurstofrijke bloed dat de longen verlaat wordt opgevangen in het linker atrium. Van hieruit wordt de linker ventrikel gevuld, die tenslotte het bloed weer naar alle andere organen van het lichaam pompt.

De contractie van de hartspiervezels levert de mechanische energie die nodig is voor veranderingen in volume en druk in de boezems, de ventrikels en het vaatsysteem. Voor het leveren van deze energie door de hartspiervezels zijn voedingsstoffen en zuurstof onontbeerlijk. In een hartcyclus kunnen vier fasen onderscheiden worden. Tijdens de diastolische vullingsfase bevindt het hart zich in rust en wordt de linker ventrikel gevuld vanuit het linker atrium. Aan het eind van deze fase bereikt een depolarisatiegolf vanuit het atrium de cellen in de binnenwand van de ventrikel in de buurt van de apex. Van hieruit verspreidt deze golf zich in ongeveer $40 \mathrm{~ms}$ over de ventrikelwand. Nadat de spiercellen in de wand door de depolarisatie- golf geactiveerd zijn, trekken deze samen en bouwen een mechanische spanning op. De druk in de ventrikelholte neemt hierdoor toe en de klep tussen atrium en ventrikel, de mitraalklep, sluit. Daar de aortaklep ook nog gesloten is en de spanning in de spiercellen toeneemt, blijft het volume van de ventrikelholte constant en stijgt de druk snel. Deze fase wordt de isovolumische contractiefase genoemd. Zodra de ventrikeldruk hoger wordt dan de aortadruk, gaat de aortaklep open en wordt bloed uitgepompt in de aorta. Tegen het eind van deze ejectiefase sluit de aortaklep ten gevolge van een drukveld, ontstaan door een afname van de stroomsnelheid in de aorta. De spiervezels relaxeren, de ventrikeldruk daalt, en omdat zowel de mitraal-als de aortaklep gesloten zijn, blijft het volume weer constant. Dit is de isovolumische relaxatiefase. Zodra de ventrikeldruk lager is dan de atriumdruk, opent zich de mitraalklep, en herbegint de diastolische vullingsfase.

In het onderzoek beschreven in dit proefschrift stonden de spiervezelverkorting en spanning in de oppervlakkige lagen van de voorwand van de linker ventrikel centraal. De relatie met hemodynamica en regional activatietijd en zuurstofopname werd onderzocht tijdens normoxie en ischemie. Tijdens normoxie werd asynchrone electrische activatie van de linker ventrikel verkregen d.m.v. epicardiaal pacen. Voor het onderzoek beschreven in hoofdstuk 2 $\mathrm{t} / \mathrm{m} 6$ werden volledig verdoofde honden met open borstkas gebruikt. Voor de studie beschreven in hoofdstuk 7 werd gebruik gemaakt van wakkere honden met gesloten borstkas. 
Het blijkt dat de electrische activatie van de spiervezels in de linker ventrikelwand onder normale omstandigheden vrijwel synchroon verloopt, resulterend in een homogene verdeling van verkorting en zuurstofverbruik van de spiervezels. Epicardiaal stimuleren met behulp van een pacemaker veroorzaakt asynchrone electrische activatie. Het moment en de mate van. regionale spiervezelverkorting tijdens de ejectiefase bleek het best gerelateerd te kunnen worden aan het tijdsverschil tussen het moment van maximale stijgsnelheid van de linker ventrikeldruk en het moment van regionale electrische activatie (hoofdstuk 2).

Kennis over de grootte van spiervezelverkorting en spanning zijn noodzakelijk om regionale arbeid te kunnen kwantificeren. Spiervezelverkorting kan met bestaande technieken goed gemeten worden. Omdat de meting van spiervezelspanning in de intacte hartspier onbetrouwbaar is, zijn diverse modellen ontwikkeld. In hoofdstuk 3 wordt een van die modellen, ontwikkeld binnen ons laboratorium, op zijn betrouwbaarheid getaxeerd. In dit model wordt uitgegaan van een homogene distributie van spiervezelverkorting en spanning in de linker ventrikelwand gedurende de systolische fase. Linker ventrikeldruk, holtevolume en wandvolume zijn de invoervariabelen. De berekende gemiddelde spiervezelverkorting verschilt niet van de gemeten spiervezelverkorting. Daar het principe van behoud van energie de belangrijkste aanname is om de vergelijking voor spiervezelverkorting af te kunnen leiden van de vergelijking voor spiervezelspanning, wordt geconclu- deerd dat het model bruikbaar is voor de berekening van zowel spiervezelverkorting als spanning. Bovendien komt de berekende spiervezelspanning redelijk overeen met de spanning gemeten in geisoleerde hartspiervezels.

Epicardiaal pacen (hoofdstuk 4) en afsluiten van de voorste afdalende tak van de linker kransslagader (hoofdstuk 5) werden toegepast om verschillen in regionale arbeid te krijgen. Arbeid werd gekwantificeerd met behulp van gemeten spiervezelverkorting en spiervezelspanning, berekend met behulp van een modificatie van het model zoals geëvalueerd in hoofdstuk 3 . Deze modificatie is nodig om ook wanneer de spiervezelverkorting inhomogeen is, de spiervezelspanning te kunnen berekenen. Tijdens normoxie kan een redelijke schatting van de zuurstofbehoefte gernaakt worden met behulp van regionale arbeid. Om deze schatting ook tijdens ischemie te kunnen maken is echter meer kennis van de (passieve) materiaaleigenschappen van de hartspier noodzakelijk.

Kortdurende totale of langdurige (3 uur) gedeeltelijke afsluiting van een kransslagader veroorzaakt een verminderde spiervezelverkorting in het ischemische gedeelte. Gelijktijdig optredende veranderingen in de electrische activatie hebben hierop geen invloed (hoofdstuk 6).

Hoofdstuk 7, tenslotte, bevat een preliminaire studie naar de effecten van langdurig epicardiaal pacen op de linker ventrikelwanddikte. Het blijkt dat de reductie in spiervezelverkorting en zuurstofverbruik in relatief vroeg geactiveerde gebieden een afname van de wanddikte ter plaatse tot gevolg heeft. 
